\title{
Antecedents and Consequences of Service Quality in a Higher Education Context
}

\author{
Parves Sultan \\ M.Sc. in Development Economics (RAPU, Japan) \\ BBS (Honours) \& MBA in Marketing (UR, Bangladesh)
}

School of Management and Marketing Central Queensland University, Australia

Thesis submitted in fulfilment of the requirements of the Degree of Doctor of Philosophy

Date: 10 January 2011 


\section{Declaration}

This work has not previously been submitted for a degree or diploma in any university.

To the best of my knowledge and belief, the thesis contains no material previously published or written by another author except where due reference is made in the thesis itself.

Pacuessullarer

Parves Sultan 


\section{Acknowledgement}

This thesis would not have been completed without the contributions of a number of people. First, I acknowledge the contribution of my son as I have taken out much of his father's time. The time when he was supposed to play with his parents and friends, he gave it to me, and played and slept by himself in my research room. I am grateful to him.

Second, I am particularly indebted to my principal supervisor, Dr. Ho Yin Wong, for his valued and expert advice in preparing this thesis. I was blessed to get such a supervisor who came down to my research room to discuss research issues and advise me as my research progressed.

Third, my special thanks to Dr. Roshnee Ramsaran-Fowdar, my associate supervisor, for her kind assistance and support throughout this journey. I am also thankful to Ms. Kylie Radel, the ADRI, the Deans of the School of Management and Marketing, the academic and administrative staff, the research office, my research colleagues, the information and technology division (ITD) and the library of the CQUniversity.

Finally, I would like to extend my deepest appreciation to my family, especially my wife and parents for their emotional support and encouragement throughout my study in Australia. I am grateful to all of them. 


\section{Publications from thesis related research}

\section{$\underline{\text { Referred Journal Articles }}$}

1. Sultan, P. and Wong, H.Y. (2010) "Service Quality in Higher Education: A Review and Research Agenda", International Journal of Quality and Service Sciences, Vol. 2, No. 2, pp. 259-272.

2. Sultan, P. and Wong, H.Y. (2011) "Service Quality in a Higher Education Context: Antecedents and Dimensions", International Review of Business Research Papers, Vol. 7, No. 2, pp. 11-20.

\section{$\underline{\text { Referred Conference Papers }}$}

1. Sultan, P., Wong, H.Y. (2010) "Perspectives of service quality in a higher education context: A qualitative research approach", $24^{\text {th }}$ Annual Australian and New Zealand Academy of Management Conference (ANZAM), held on 8-10 December 2010 at the Adelaide Convention Centre, Australia.

2. Sultan, P., Wong, H.Y. (2010) "Service Quality in a Higher Education Context: Antecedents and Dimensions", $4^{\text {th }}$ Asian Business Research Conference (ABRC 2010), held on 23-24 December 2010 at the BIAM Foundation, 63 Eskaton, Dhaka, Bangladesh.

3. Sultan, P., Wong, H.Y. and Gabriel, D. (2008) "Antecedents of service quality and brand performance: a conceptual model", $9^{\text {th }}$ International Business Research Conference, held on 24-26 Nov. 2008 at Melbourne, Australia. 


\section{Table of Contents}

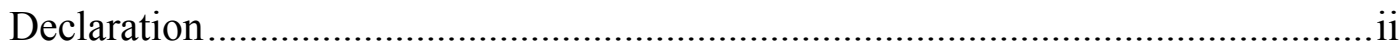

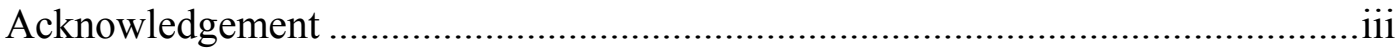

Publications from thesis related research............................................................. iv

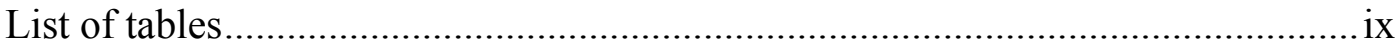

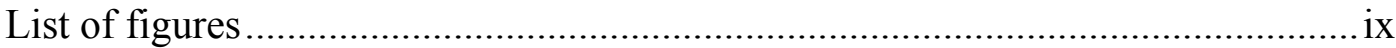

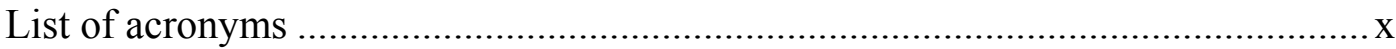

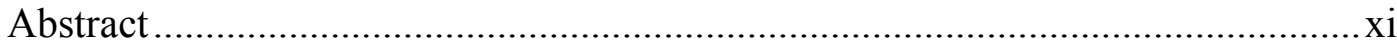

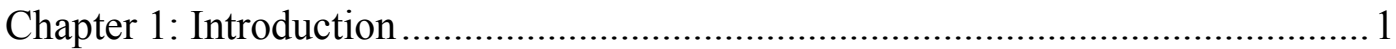

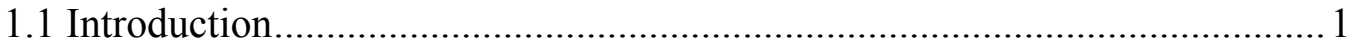

1.2 A discourse of a marketing approach to higher education............................2

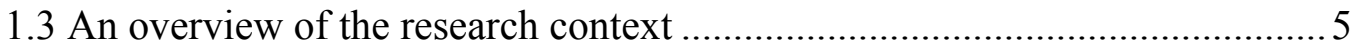

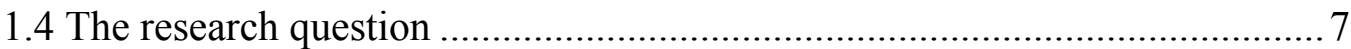

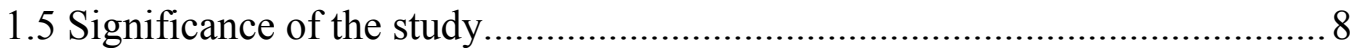

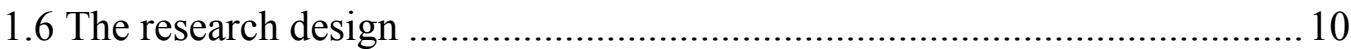

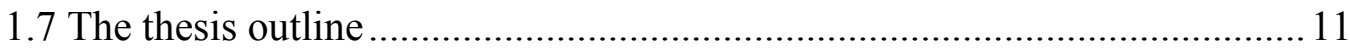

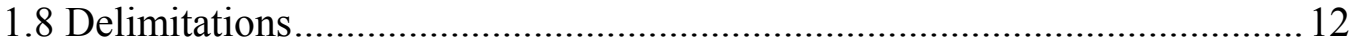

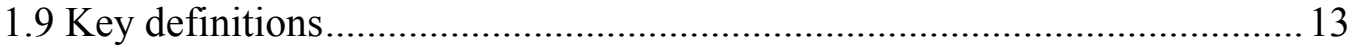

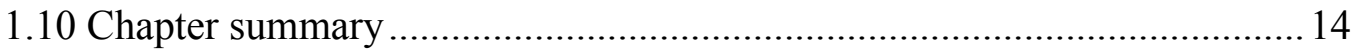

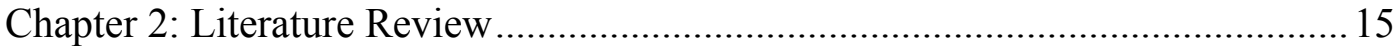

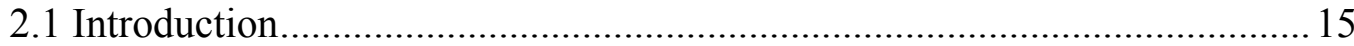

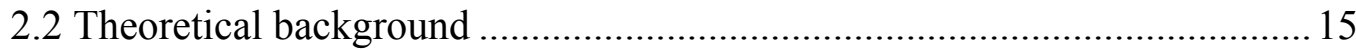

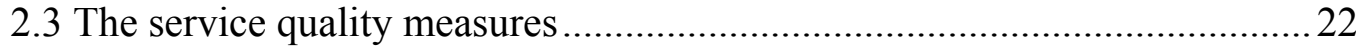

2.3.1 The dimensional approach of service quality ....................................24

2.3.2 The antecedent perspective of service quality .....................................25

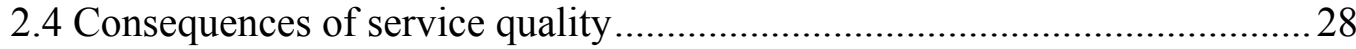

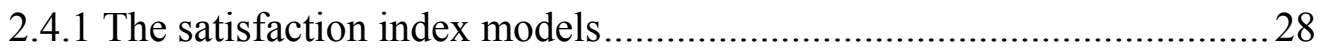

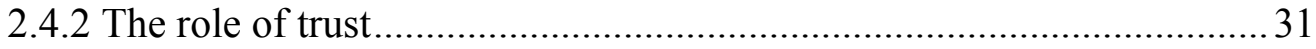

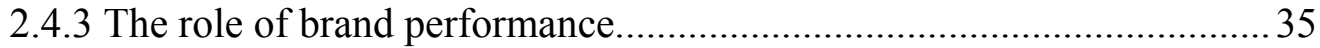

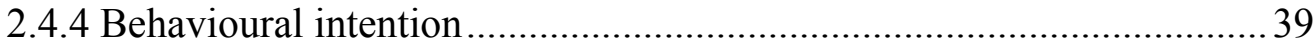

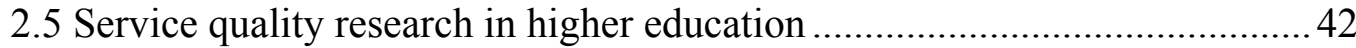

2.5.1 Service quality measures in higher education.................................... 43

2.5.2 Integrated models in higher education ..............................................46 
2.6 The research gap 50

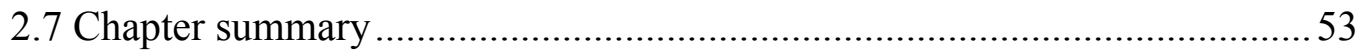

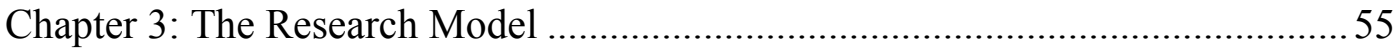

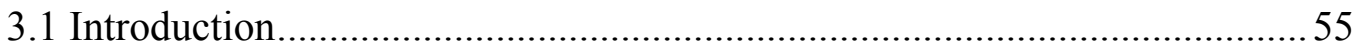

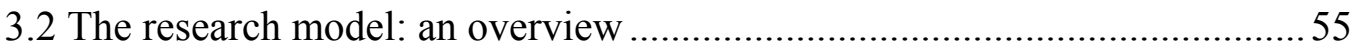

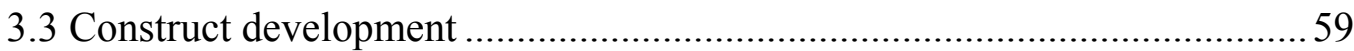

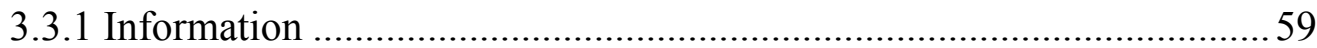

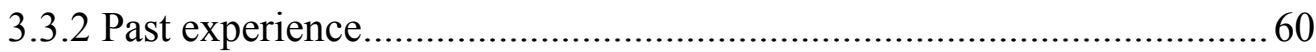

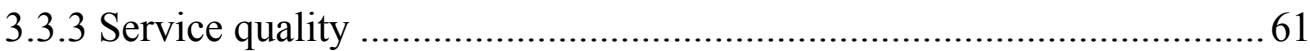

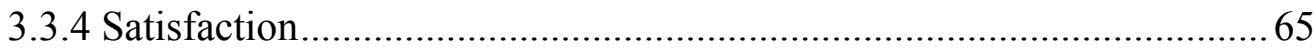

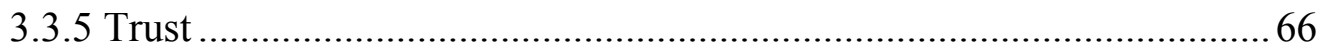

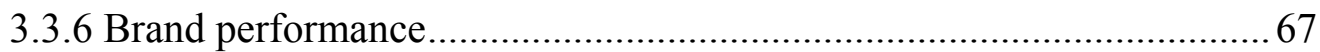

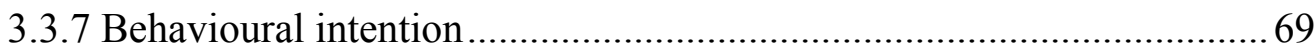

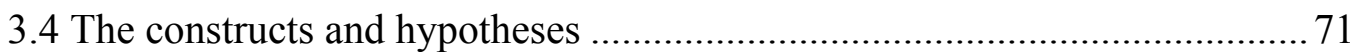

3.4.1 The relationship between information and service quality ................... 71

3.4.2 The relationship between past experience and service quality ............. 72

3.4.3 Service quality and its consequences ................................................. 75

3.4.4 The relationship between service quality and satisfaction.................... 76

3.4.5 The relationship between service quality and trust.............................. 78

3.4.6 The relationship between satisfaction and trust .................................... 79

3.4.7 The relationship between satisfaction and brand performance..............81 81

3.4.8 The relationship between trust and brand performance ....................... 82

3.4.9 The relationship between brand performance and behavioural intention 83

3.4.10 The relationship between satisfaction and behavioural intention ........8 84

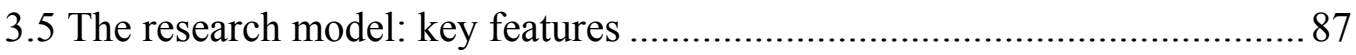

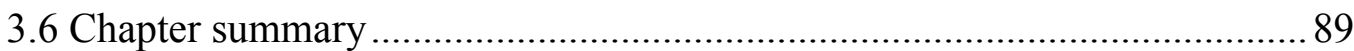

Chapter 4: The Research Method ..................................................................... 90

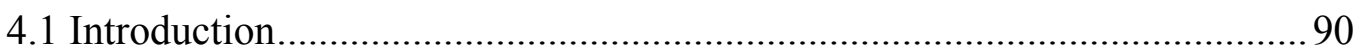

4.2 The paradigmatic approach to research design ......................................... 90

4.3 Qualitative research method ..................................................................... 93

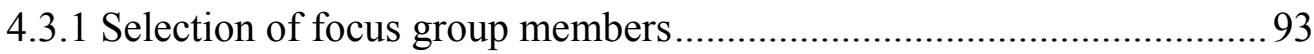

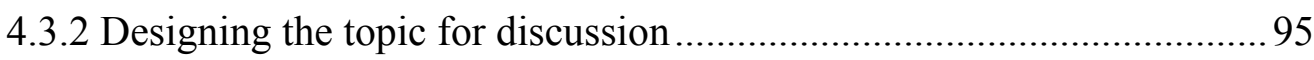

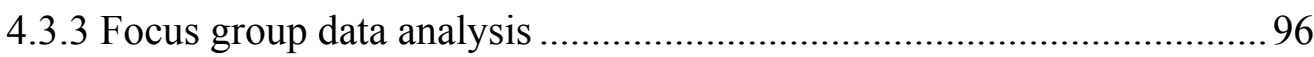

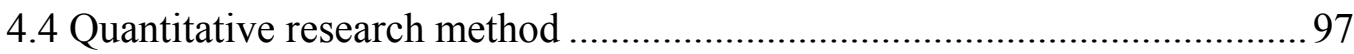




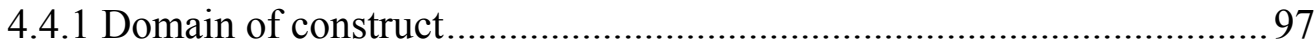

4.4.2 Item generation and questionnaire design........................................ 98

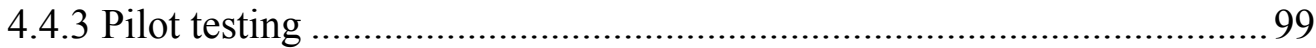

4.4.4 Scale purification and finalising the questionnaire ............................. 99

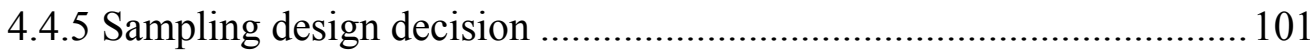

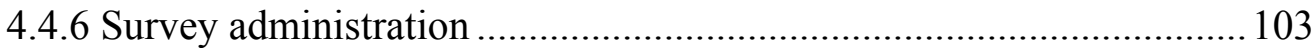

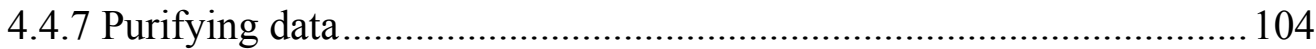

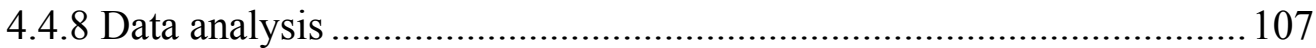

4.4.9 Measurement model analysis ........................................................... 112

4.4.10 Analysis of structural model estimation ........................................... 115

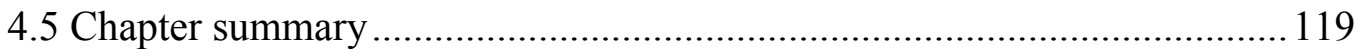

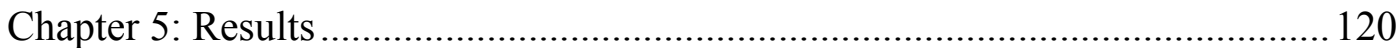

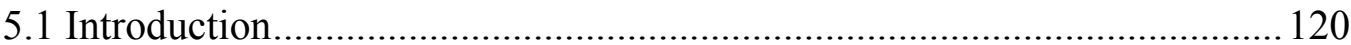

5.2 Data cleaning, demographics and descriptive statistics........................... 120

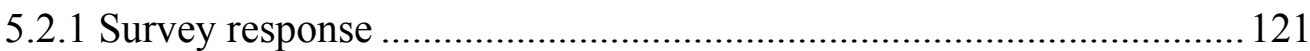

5.2.2 Assessment of normality and outliers ............................................. 121

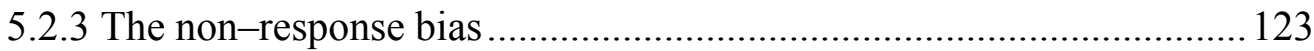

5.2.4 Demographics of the respondents ..................................................... 123

5.2.5 An overview of the descriptive statistics ......................................... 128

5.3 Exploratory factor analysis and reliability test ........................................ 129

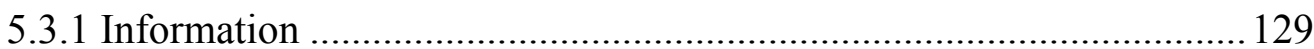

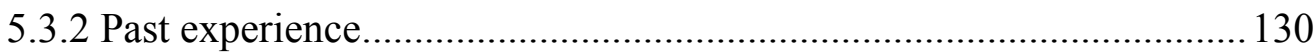

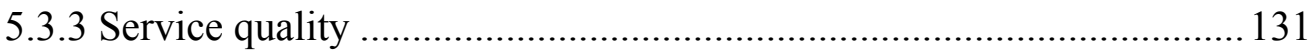

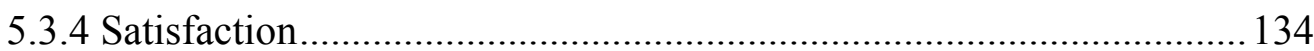

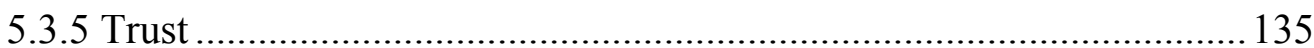

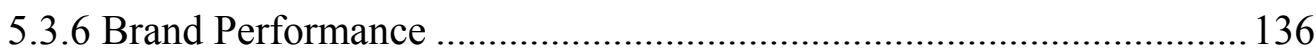

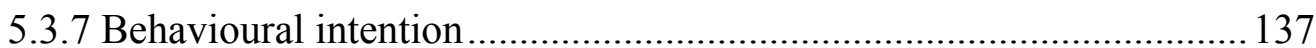

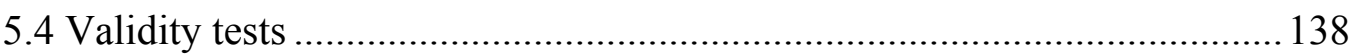

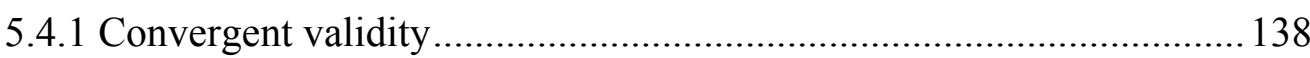

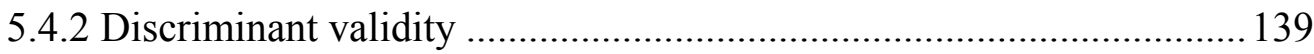

5.4.3 Nomological and predictive validity.............................................. 141

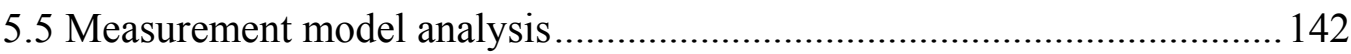

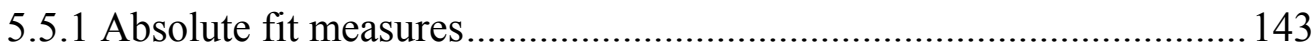

5.5.2 Incremental fit measures ................................................................. 145 
5.5.3 Parsimonious fit measures

5.6 The structural model analysis

5.7 Hypotheses testing results

5.8 Chapter summary

Chapter 6: Discussion 154

6.1 Introduction 154

6.2 Summary of the chapters 154

6.3 Summary of the research findings 156

6.4 Contributions to knowledge, research method and practice 157

6.4.1 Theoretical contributions 158

6.4.2 Methodological contribution 163

6.4.3 Practical contribution 165

6.5 Limitations of the study 168

6.6 Future research 170

6.7 Concluding comments 170

References 174

Appendices 192

Appendix A: The survey questionnaire 192

Appendix B: Non-response bias (independent sample t-test) 199

Appendix C: Descriptive statistics 200

Appendix D: Item parcelling method used for analysing measurement model 202 Appendix E: Demographics of the focus group participants 203 


\section{List of tables}

Table 1: Service quality dimensions in higher education 44

Table 2: Latent variable—information $\quad 58$

Table 3: Latent variable — past experience 59

Table 4: Latent variable — service quality 62

Table 5: Latent variable - satisfaction $\quad 64$

Table 6: Latent variable - trust 66

Table 7: Latent variable—brand performance $\quad 68$

Table 8: Latent variable—-behavioural intention $\quad 69$

Table 9: Summary of items in terms of inductive and deductive approaches $\quad 100$

Table 10: Current length of study 125

Table 11 Information: exploratory factor analysis and reliability test results $\quad 128$

Table 12 Past experience: exploratory factor analysis and reliability test results 129

Table 13 Service quality: exploratory factor analysis and reliability test results 131

Table 14 Satisfaction: exploratory factor analysis and reliability test results 132

Table 15 Trust: exploratory factor analysis and reliability test results 133

Table 16 Brand performance: exploratory factor analysis and reliability test results 134

Table 17 Behavioural intention: exploratory factor analysis and reliability test results 135

Table 18: Discriminant validity test using AVE and squared correlation method 138

Table 19: Predictive validity of the latent constructs 139

Table 20: The results of measurement model and accepted norms of fit measures 142

Table 21: Fit measures of the structural model 145

$\begin{array}{ll}\text { Table 22: Results for hypotheses } & 147\end{array}$

\section{List of figures}

Figure 1: The research gaps $\quad 51$

Figure 2: The conceptual model $\quad 57$

Figure 3: The overall research model $\quad 85$

Figure 4: The triangulation approach to research design 91

$\begin{array}{ll}\text { Figure 5: The process of construct validation } & 107\end{array}$

Figure 6: Number of responses in terms of age distribution $\quad 123$

Figure 7: Number of responses in terms of CQUniversity campuses 125

Figure 8: The measurement model 141

Figure 9: The structural model 146 


\section{List of acronyms}

ACSI=American Customer Satisfaction Index

ACSQ $=$ Academic Service Quality

$\mathrm{ADSQ}=$ Administrative Service Quality

AMOS $=$ Analysis of Moment Structures

$\mathrm{BI}=$ Behavioural Intention

$\mathrm{BP}=$ Brand Performance

$\mathrm{CEM}=$ Continuous Effect Model

$\mathrm{CFA}=$ Confirmatory Factor Analysis

CQUniversity $=$ Central Queensland University, Australia

DFAT $=$ Department of Foreign Affairs and Trade

ECSI=European Customer Satisfaction Index

$\mathrm{EDP}=$ Expectancy Disconfirmation Paradigm

$\mathrm{EFA}=$ Confirmatory Factor Analysis

FSQ $=$ Facilities Service Quality

$\mathrm{GDP}=$ Gross Domestic Product

$\mathrm{GNP}=$ Gross National Product

$\mathrm{GOF}=$ Goodness - of - Fit

HEdPERF=Higher Education Performance Only

In=Information

$\mathrm{IP}=$ Importance-Performance analysis

$\mathrm{NCSB}=$ Norwegian Customer Satisfaction Barometer

$\mathrm{OECD}=$ Organisation for Economic Cooperation and Development

$\mathrm{PE}=$ Past Experience

$\mathrm{P}-\mathrm{E}=$ Perception-Expectation

PHEd=Performance-based Higher Education

$\mathrm{R}=$ Respondent

$\mathrm{S}=$ Satisfaction

$\mathrm{SCSB}=$ Swedish Customer Satisfaction Barometer

SEM=Structural Equation Modelling

SERVPERF=Service Performance

SERVQUAL=Service Quality

SIM=Satisfaction Index Model

SPSS $=$ Statistical Package for Social Science

$\mathrm{SQ}=$ Service Quality

$\mathrm{T}=$ Trust

$\mathrm{UK}=$ the United Kingdom

UniBrand=University as a Brand

$\mathrm{USA}=$ the United States of America 


\begin{abstract}
This research aims to develop an integrated service quality model in a higher education context. The focus of this research is to study the antecedents, dimensions and consequences of service quality in the context of Central Queensland University (CQUniversity), Australia. The conceptual domain for this study is based on the European Customer Satisfaction Index (ECSI) model and the perception-only measure of service quality. The study used methodological triangulation approach where both qualitative and quantitative research methods were employed.
\end{abstract}

The theoretical model was derived from the literature review and the focus group discussions. The study received necessary ethical clearance (Project Number: H08/12-082) for collecting data from the student population of the CQUniversity. The three focus group discussions with nineteen students were conducted at the CQUniversity, Rockhampton. The focus group findings show that the critical antecedents to perceived service quality are information and past experience. Students perceive service quality as a set of attributes and they evaluate it cognitively. Satisfaction, trust, brand performance and behavioural intention are found to have relationships with service quality as consequences. The focus group discussions revealed that all of the interrelationships among various themes are positive. These findings have led to the development of nine hypotheses.

The theoretical model was then tested using quantitative research method. The multiattribute perception-only research instruments were developed from the literature review and focus group data. The initial questionnaire with 75 items was pre-tested with 106 respondents in September 2009. After a thorough statistical analysis and expert validation processes, the final questionnaire with 65 items was developed for the purpose of online click-only survey. The online click-only survey included all the student population of the CQUniversity with more than six months of studying experience. The data cleaning processes and tests of normality produced 528 cases that were subsequently entered to assess validity, reliability, model fit and hypotheses testing. All of the results are proved satisfactory including the results of the hypotheses testing. 
This study aims to expand knowledge of service quality in higher education on four levels. First, this study develops three new constructs including information, past experience and brand performance; and develops other constructs including service quality, satisfaction, trust and behavioural intention in a higher education context. Second, the study examines the relationships between a number of constructs including information-service quality, past experience-service quality, service quality-trust, trust-brand performance, satisfaction-brand performance and brand performance-behavioural intention. Third, it develops a comprehensive model that includes antecedents, dimensions and consequences of service quality in a higher education context. Fourth, it substantially improves and adapts the ECSI model in a higher education services marketing context.

There are also managerial implications arising from this study. Higher education managers should pay particular attention to develop a concrete information structure for potential students through promise and content of the message. Managers should also develop and maintain good relationships with present and previous students, local and regional school authorities, and other stakeholders. They should continuously upgrade the performance of the service attributes in order to improve service performance and satisfaction, and build students' trust in them. While brand plays a pivotal role in a globalised market place and to the student-customer, the managers should continuously improve students' trust and their satisfaction. These in turn assist in student retention and increased enrolment of new students, and build the reputation of the University. 


\section{Chapter 1: Introduction}

\subsection{Introduction}

The role of services in the world economy has increased significantly in the last decade, particularly in the developed nations (Ueltschy, Laroche, Eggert, \& Bindl, 2007). In the economically developed world, services have replaced goods as the building blocks of employment and gross national product (Bowen \& Hallowell, 2002). The shifting of the economy from goods to services in industrialised countries is considered one of the most important long-term trends in the business world today (Jiang \& Rosenbloom, 2005). For example, the service sector is one of the fastest growing sectors in the USA today, accounting for over 75 per cent of the increase in the GNP in the last decade (Ueltschy et al., 2007). In Australia, education, along with tourism, occupy the top positions in terms of services export performance. For example, services exports were worth A $\$ 48$ billion, with education exports worth A $\$ 12.6$ billion in 2007. The education exports increased to $23.4 \%$ totalling A $\$ 15.5$ billion in 2008 (DFAT, 2008).

Australian higher education institutions are one of the most popular destinations for international students (Bradley, Noonan, Nugent, \& Scales, 2008). Australian universities have made important developments towards the goal of internationalising quality higher education in 1980s. A number of measures were undertaken during that period. The important measures were the review of major disciplines to determine standards and to improve quality and efficiency, upgrading Colleges of Advanced Education and Institutes of Technology into universities, the opening of local market to fee-paying overseas students, and the requirement for institutions to search for alternative sources of funding (The Australian Higher Education Quality Assurance Framework, 2000; Marginson, 1997). These changes resulted Australian universities to become one of the first countries to restructure and to facilitate wider participation in higher education in the 1980s and afterwards. However, the recent Bradley report published in December 2008 states that there is a clear sign that the quality of the educational experience is declining. This report states that the provision of higher 
education in regional areas needs serious attention to increase participation. One of the significant recommendations of this study focuses on course experience as perceived by the students (Bradley et al., 2008). While Bradley et al.'s (2008) study emphasises students' perceptions of course experience, studies in the current literature focuses on students' perceptions of overall service quality in the higher education sector. One such study states that "discovering student perceptions of quality may be a quest for any centre, university or university system....Questions of interest include: what are the framework, appropriate strategy, and methodology for approaching this purpose?” (Gallifa \& Batalle, 2010, p. 157). In addition, several other studies also stress the need to develop a comprehensive model of service quality in the context of higher education (Sultan \& Wong, 2010a, 2010b). This thesis examines students' perception of service quality, and attempts to develop and examine an integrated model incorporating antecedents, dimensions and consequences of service quality in the context of CQUniversity. CQUniversity has four international campuses at Brisbane, Gold Coast, Melbourne and Sydney, and six regional campuses at Bundaberg, Emerald, Gladstone, Mackay, Noosa and Rockhampton. The main campus is located at Rockhampton.

This chapter is organised as follows. A discourse of a marketing approach to higher education is discussed in section 1.2. Section 1.3 discusses an overview of the research context. In this section the critical perspectives of service quality research are discussed briefly. The research question is discussed in section 1.4. Section 1.5 discusses the significance of this study. Next, a general overview of the research design is provided in section 1.6. Section 1.7 briefly discusses the outlines of this thesis. Sections 1.8 and 1.9 discuss delimitations and key definitions, respectively. Finally, section 1.10 discusses chapter summary.

\subsection{A discourse of a marketing approach to higher education}

A marketing approach, examining students' perceptions of service quality in the context of higher education, will contribute to improve service functions, attract and retain students. The metaphor about consumers in marketing is that 'the customer is 
king'. However, its analogy that 'the student is king' in higher education services marketing may not be true. It is often argued that students are the partners in the learning process and therefore, the supplier-customer relationship is not as clear cut as that of some other service relationships (Yorke, 1999). This is a critical issue especially when students' responses are taken into account to evaluate course-lecture performance. For example, the Higher Education Funding Council in England introduced a National Student Survey on behalf of the UK Government. This survey was aimed at final year students and their views on a number of aspects of teaching, assessment and support provided by their universities and courses. Thus, students are, inter alia, customers of the Higher Education Institution at which they are enrolled (Douglas, McClelland, \& Davies, 2008).

Students are becoming extremely critical and analytical when choosing their educational institutions (Binsardi \& Ekwulugo, 2003). Likewise, universities are aggressively promoting their offers and brands in order to attract students. One study stated that "it's time for educational institutions to face two facts: they are in a competitive battle for students, and students are customers" (Sines \& Duckworth, 1994, p. 2). Rojas-Me'ndez et al. (2009, p. 23) stated that "a student is also a consumer-despite the peculiarity of this designation due to the nature of education. $\mathrm{He} / \mathrm{she}$ consumes educational services just like any other and, thus, can be studied as a consumer of educational services".

Although students choose their university and course, and pay for their educational expenses, they are not simply customers. The reason for this is that the goal of education is not to delight the students but to equip them to be effective societycitizens (Franz, 1998). Students are often considered as the finished products of educational enterprises. The product analogy is also inappropriate in that a student become a skilled human resource with personal and social values, and ethics, and selfesteem. They participate in the learning process. Thus, students are co-workers (Franz (1998) of knowledge development in a higher education environment and human resources for our society. 
Higher education is a pure service and is characterised by a greater amount of interpersonal contact, complexity, divergence, and customisation than most other service businesses (Winsted \& Patterson, 1998; Franz, 1998). As higher education provision is a service and students are expected to fund their educational expenses, it would seem appropriate that universities make a shift from being product-led by relying on the product to sell, towards a more customer-led approach (Angell et al., 2008) using customised educational plans (Franz, 1998). The customer-centric approach of service quality in educational literature has gained momentum as the increasing cost of education has created a new generation of students with greater customer awareness than ever before (Stodnick \& Rogers, 2008).

Higher education is a high involvement decision. This requires students an effort to search for evidence of quality, value and cost comparisons. Studies state that students look for evidence of quality of services when making an uncertain and high risk decision of choosing a university (Angell, Heffernan, \& Megicks, 2008; Donaldson \& McNicholas, 2004). This emphasises the importance of service quality in the higher education domain. Ignorance of the competitive nature of attracting students along with the importance of measuring the service quality will ultimately be unfavourable to the institution (Angell et al., 2008).

A number of recent studies empirically examine the service quality models in the context of higher education taking students as sample units (Abdullah, 2005, 2006a, 2006b, 2006c; Angell et al., 2008; Sultan \& Wong, 2010a). Most often improving quality within the higher education context is mentioned as an internal goal without any explicit references to what is meant by service quality in higher education. Discussing better quality without defining what it is, how it is perceived by customers (e.g. students) (Grönroos, 1988), what are the antecedents and consequences of quality improvements, and how it can be improved and enhanced has of little value. Thus, the service quality literature provides a profound understanding about the justification that the customer-centric approach or the marketing approach in the higher education domain may provide important outcomes, and that service quality research in higher education can provide important insights. The following section is a brief discussion of the service quality literature. 


\subsection{An overview of the research context}

Evaluation of service is a credence quality. Quality by definition rests solely with consumers. Studies in service quality mainly focus on consumers' evaluation of service attributes. Service quality is more difficult for consumers to evaluate than product quality (Hong \& Goo, 2004). The quality of a product can be measured by observing feature, colour, shape, package, functions, country of origin, and even by comparing prices. These factors are difficult to define for services (Chowdhury \& Sultan, 2005; Sultan \& Tarafder, 2007) due to its unique features including perishability, intangibility, inseparability and heterogeneity (Lovelock, 1981; Parasuraman, Zeithaml, \& Berry, 1985; Zeithaml, 1981).

The current studies develop a number of frameworks and measures of service quality. For example, one of the dominant and pioneering studies develops importanceperformance (IP) framework to measure service quality (Martilla \& James, 1977). Grönroos develops a conceptual model consisting of technical and functional quality (Grönroos, 1978, 1982). The service quality (SERVQUAL) measure is one of the important milestones in service quality research. This approach is conceptualised on Expectancy-Disconfirmation Paradigm (EDP). The SERVQUAL is a five dimensional twenty-two item instrument to measure service quality. These dimensions are Reliability, Assurance, Tangibles, Empathy and Responsiveness (Parasuraman et al., 1985; 1988). In contrast, the service performance (SERVPERF) measure considers the performance-only items and excludes any consideration of expectation items of the SERVQUAL measure (Cronin \& Taylor, 1992, 1994). The subsequent developments in service quality literature either follow the SERVQUAL measure or the SERVPERF measure. Literature with regard to Satisfaction Index Model (SIM) has also been developed parallel to service quality research. In these models, perceived quality is one of the major determinants to value and satisfaction that has been conceptualised on performance-only items.

The service quality research has been extended in the higher education domain, as well. On the one hand, the literature attempted to measure functional performances of 
educational services either following the SERVQUAL measure, the SERVPERF measure or the IP framework. On the other hand, studies (see, for example, Brown \& Mazzarol, 2009; Chitty \& Soutar, 2004; Martensen, Grønholdt, Eskildsen, \& Kristensen, 2000) have empirically examined the European Customer Satisfaction Index (ECSI) model in the higher education domain. These studies do not find statistically significant relationships among some of the latent variables of the ECSI model in the context of higher education. One of the reasons for this is that the ECSI model and its instruments are developed for the commercial service sectors.

The global trends within the field of higher education brought new competitors (Cubillo, Sanchez, \& Cervino, 2006; Ivy, 2001) involved in an increasing and intense effort to attract new students (Cubillo et al., 2006; Nicholls, Harris, Morgan, Clarke, \& Sims, 1995; Soutar \& Turner, 2002) and retention of the existing students. Educational institutes attempt to maintain their competitive advantage by developing distinct image (Ivy, 2001; Välimaa, 2004), positioning (Cubillo et al., 2006), and maintaining and improving quality of services. The review of the current literature in the context of service quality in higher education reveals that the ECSI model might not be an appropriate approach to measure students' satisfaction and its subsequent effects, and that there is a need to further explore and develop an integrated model focusing on service quality, its antecedents and consequences in the context of higher education. 


\subsection{The research question}

Given the above discussion of the research context, there seems to be an imminent need and opportunity to understand service quality in terms of higher education, its driving forces and its outcomes as perceived by the students. Therefore, the research question to be addressed in this study is:

What are the antecedents and consequences of service quality in a higher education context?

The specific objectives of this study are as follows:

- What are the antecedents of service quality in a higher education context?

- What is perceived service quality in terms of a higher education institution?

- What are the impacts of antecedents of service quality on perceived service quality in a higher education context?

- What are the consequences of perceived service quality in a higher education context?

- How does perceived service quality affect these consequences in a higher education context? 


\subsection{Significance of the study}

The national student survey is important in the decision making process for students in selecting which university they will attend (Asthana \& Biggs, 2007). The importance of a national student survey is emphasised as one of the important recommendations in the Bradley Review of Australian Higher Education published in December, 2008. "Australia is falling behind other countries in performance and investment in higher education" (Bradley et al., 2008, p. xi). As poor retention rates have adverse funding consequences for institutions (Douglas et al., 2008; Rowley, 2003), the recruitment and retention of students have been moved to the top of most universities' agendas due to the necessity to increase the student population in line with the Federal Government targets (Sultan \& Wong, 2010b).

"Provision of higher education in regional areas needs serious attention to increase participation" (Bradley et al., 2008, p. xiv). The Bradley report also stress on the importance of studying the course experience as perceived by the students. The present study examines students' perception of service quality attributes in terms of the performance of the CQUniversity, Australia.

A thorough review of the current studies on service quality uncovers that the studies do not cover some of the important aspects of service quality including antecedents, dimensions and consequences in the context of higher education. It has also been evident in the current literature that there is an inadequate understanding about dimensionalities and antecedents of service quality (Dabholkar, Shepherd, \& Thorpe, 2000; Gounaris, Stathakopoulos, \& Athanassopoulos, 2003). Thus, there is a need for the development of a clear, rigorous, comprehensive and empirically based understanding of the antecedents, dimensions and consequences of service quality in the context of higher education.

There are several limitations in the current studies, which attempt to develop an integrated model in the context of higher education (see, for example, Alves \& Raposo, 2007; Brown \& Mazzarol, 2009; Helgesen \& Nesset, 2007; Rojas-Me'ndez, Vasquez-Parraga, Kara, \& Cerda-Urrutia, 2009). These limitations are explained in 
section 2.5.2. The present study attempts to address these limitations and broaden the existing knowledge by employing both qualitative and quantitative research methods, and finds a number of new measures and their indicators. Thus, this study is significant from both theoretical and empirical perspectives.

The studies demonstrate that higher education leads to economic growth (Asteriou \& Agiomirgianakis, 2001; De Meulemeester \& Rochat, 1995). It is revealed that Australia spent only 1.6 percent of the GDP on tertiary education in 2006, compared to the USA's, the UK's, and Canada's expenditure of 2.9 percent, 1.3 percent and 2.7 percent, respectively (OECD, 2009). Thus, the recent speech of the then Deputy Prime Minister of Australia Ms. Julia Gillard (5 March 2010) highlights that education and training along with health care service sectors will be in the top of high demand sectors in next five years in the Australian economy (Gillard, 2010). This implies that the higher education sector is one of the high agenda items for the current government. It is worth mentioning that Australian higher education sector is the fourth largest export sector, after iron, ore and coal, and tourism. In this context, ensuring service quality in higher education is an extremely important issue for universities and their management processes. This is because students' recruitment, satisfaction and retention are closely linked with service quality. While maximising students' satisfaction should be the aim of a university (Douglas et al., 2008), ignoring students' perception of service quality attributes may weaken the management processes and outcomes of a university. The present study is centred upon students' perspective of service quality in a higher education context, and provides evidences and understanding of how service quality is formed, its aspects/dimensions and its long-term attitudinal and behavioural outcomes guiding managerial decisions.

In summary, this dissertation is contributing in terms of advancing the existing theoretical and methodological frameworks, and providing tools to improve service quality and its related issues to higher education marketing managers. The main theoretical contribution is the enrichment of the existing knowledge on service quality in higher education; especially in terms of the antecedents and consequences of service quality. The main methodological contribution is the use of both qualitative and quantitative research methods. In addition, the data collection follows online 
click-only survey from student population of the CQUniversity. There are a number of critical managerial implications of this study in the context of CQUniversity, Australia. These include: a better understanding of how perceived service quality is formed, what consists of service quality, and what are the long-term effects of students' assessments of better perceived service quality in a higher education context.

\subsection{The research design}

To answer the research question stated in section 1.4, this study adopted a four-step procedure. These are briefly described below.

First, reviewing relevant literature is the fundamental step to find research gap and to conceptualise the research. Therefore, this study reviews the current literature in the field of service quality, satisfaction index models, trust, branding and brand performance, loyalty and behavioural intention. Conceptualisation of the constructs and its indicators for the development of a theoretical model in the context of higher education services marketing are primarily derived from literature review and focus group findings.

Second, a conceptual model with regard to the antecedents and consequences of service quality is developed in this stage. As a point of departure, the ECSI model and the SERVPERF measure played vital roles to develop the new conceptual model.

Third, the research conducted three focus group discussions with nineteen undergraduate, postgraduate and doctoral students at the Rockhampton campus in order to generate relevant themes and its indicators. Finally, based on the focus group findings the conceptual model was refined.

Fourth, an online click-only survey was conducted throughout CQUniversity's campuses of Australia. A cross-section of 1042 responses was obtained. After elimination of incomplete and outlier cases, 528 responses entered for the final analyses. Data gathered from the survey was analysed with Statistical Package for Social Science (SPSS) and Analysis of Moment Structures (AMOS). This study used 
quantitative research method for a number of reasons. First, this method tests the hypotheses in a rigorous manner. Second, the quantitative research method is used to validate the conceptual model. Finally, it helps establishing the generalizability of the theory.

\subsection{The thesis outline}

The presentation of this thesis follows the suggestions of Perry (1998). It has six main chapters. The chapters are introduced as follows.

Chapter 1 (Introduction): This chapter starts with an overview of the contribution of the service sector and its rapid growth. Then it narrows down its focus on the higher education service and CQUniversity Australia. This chapter briefly discusses the recent discussions and justifications of applying and examining Marketing models in the context of higher education and taking students as samples. This chapter also discusses a brief overview of the research context, the research questions and objectives of the research, significance of the study, the brief research design, delimitations, definitions and chapter summary.

Chapter 2 (Literature Review): The review of literature mainly covers research on service quality, research on satisfaction index models, research on the application of these models in the higher education domain, and some contemporary research on consumer trust, satisfaction, branding and loyalty.

Chapter 3 (Research Model): This chapter discusses the development of a research model following literature review and focus group findings. Definitions of all the constructs along with their hypothesised relationships are explained in this chapter. It also covers the development of scales for each of the constructs.

Chapter 4 (Research Method): This chapter discusses the qualitative and quantitative research methods employed in this study. The qualitative research method includes the selection of the samples for focus groups, procedures for focus group discussions and method of analysis. The quantitative research method includes selection of 
samples, survey administration and collection procedures, details of data analyses including descriptive statistics, tests of normality, reliability tests, exploratory factor analyses (EFA) and validity tests using EFA and confirmatory factor analyses (CFA). Then it discusses the logic behind the use of Structural Equation Modeling (SEM) in this study and the method of evaluating the measurement model. The absolute and incremental fit measures to evaluate the full theoretical model are discussed prior to model testing.

Chapter 5 (Findings): First, this chapter presents the findings of data cleaning in terms of outliers and normality tests, and non-response bias. This chapter, then, discusses respondents' demographics and brief descriptive statistics in order to better understand the data set. Next, this chapter discusses the results of EFA and CFA. The results of reliability tests and validity tests are reported, as well. The analysis and findings of measurement model and structural model in terms of various fit measures are also reported in this chapter. Finally, this chapter reports the findings of hypotheses testing.

Chapter 6 (Conclusion): This chapter discusses the research findings compared with the current literature. It also discusses theoretical, practical and methodological contributions. Finally, limitations and future research directions are also discussed in this section.

\subsection{Delimitations}

The data collection of this study is confined to the CQUniversity and its international and regional campuses all over Australia due to time and cost constraints. Another important aspect of limiting the scope of this study to the CQUniversity is relevant to getting ethical clearance. Ethical clearance is a key certification for this type of study prior to survey administration. The ethical clearance of the CQUniversity indicates that this study is confined to the CQUniversity students. 


\subsection{Key definitions}

The following are the key definitions for the purpose of this study.

Information (IN): Information is defined as explicit and implicit messages that students received directly and indirectly (via media) from the CQUniversity prior to enrolment.

Past Experience (PE): Past experience refers to students' previous educational experience before enrolling at the CQUniversity, previous experience of service encounter and subsequent treatment provided by the CQUniversity. This definition is adapted from the current literature (Devlin, Gwynne, \& Ennew, 2002; Zeithaml, Berry, \& Parasuraman, 1993).

Service Quality (SQ): Service quality is defined as the performance evaluation of the service attributes of the CQUniversity from students' perspectives during service encounter (Cronin \& Taylor, 1992, 1994). Service quality assessment is students' judgments of service attributes (Johnson \& Winchell, 1988). It is a cognitive process, meaning that service quality assessment is a psychological result of perception, learning, reasoning and understanding of the service attributes. This definition is adapted from the

Academic Service Quality (ACSQ): Academic service quality refers to those service attributes that are relevant to teaching quality and ability, course development and teacher-student relationships. These are critical service attributes for providing the core benefits/values to the students during their enrolment.

Administrative Service Quality (ADSQ): Administrative service quality refers to those service attributes that are relevant to skills and abilities of the administrative and supporting staff, and their relationships with students. These are critical service attributes for providing the support services to smooth running the programs/courses. 
Facilities Service Quality (FSQ): Facilities service quality refers to those service attributes that are required to create a good higher education environment.

Satisfaction (S): Satisfaction is defined as a psychological state of happiness of the students as a result of performance evaluation of the service attributes (Cronin \& Taylor, 1992, 1994).

Trust (T): Trust is a belief (Anderson \& Weitz, 1989) and confidence that the service performance and subsequent satisfaction will be identical in future. It is enduring.

Brand Performance $(B P)$ : Brand performance refers to the performance of the CQUniversity as a brand (UniBrand) in terms of students' perception with regard to their association, understanding and evaluation of the UniBrand in the market.

Behavioural Intention (BI): Behavioural intention is defined as the students' readiness to behave (Zeithaml et al., 1996).

\subsection{Chapter summary}

This chapter provides a broad overview of the structure and direction of the thesis. This research aims to develop a comprehensive model of perceived service quality and its antecedents and consequences in the context of a higher education services marketing. This chapter addresses the research background, the research question, research objectives, significance of the study, brief research methods, chapter outlines, delimitations and key definitions. The next chapter will discuss satisfaction and service quality literature. 


\section{Chapter 2: Literature Review}

\subsection{Introduction}

This chapter reviews current satisfaction and service quality literature with the aim of providing a foundation for answering the research question stated in chapter one. The structure of this chapter is as follows. First, section 2.2 discusses an overview of theoretical backgrounds to satisfaction and service quality. Second, section 2.3 discusses the critical measures of service quality scales evolved in the literature. The critiques of service quality literature will be addressed in this section. Third, section 2.4 discusses consequences of service quality. In this section, a review of satisfaction index models and other relevant studies along with the critiques of those models are discussed. Fourth, section 2.5 discusses service quality studies in the context of higher education. Fifth, section 2.6 addresses the research gap based on the review of literature. Finally, section 2.7 summarises the chapter.

\subsection{Theoretical background}

The key objective of this section is to review the fundamental satisfaction and service quality theories. Discussions of the fundamental research streams are important because these provide the foundations for this research. This also provides new insights and that subsequently can be used in conceptualisation of the research and hypotheses development. In the following paragraphs, the fundamental satisfaction theories are discussed.

The dissonance or assimilation theory posits that any discrepancy between expectation and performance will be minimised or assimilated by the consumers adjusting their perception of the product to be more consistent (or less dissonant), with expectation (Festinger, 1957). This theory states that consumers are always ready to adjust either expectations or perceptions in line with their expectation (to bring satisfaction). Therefore, there is no dissatisfaction. A number of studies argue that adjusting perception of performance and expectation can lead to a positive 
relationship between expectation and satisfaction (Anderson, 1973; Olson \& Dover, 1979). While expectation and satisfaction might have a positive relationship, the critical issue is that dissatisfaction, a major outcome of consumers' evaluation process, is absent in this theory. However, the contrast theory holds a reverse perspective. This theory assumes that the consumer will magnify the differences between the product received and the product expected (Hovland, Harvey, \& Sherif, 1957). For example, if the objective performance of the product fails to meet the consumer's expectations, the consumer will evaluate the product less favourably. This causes consumers to exaggerate or magnify the disparity (Anderson, 1973). Similarly, the generalised negativity theory, introduced by Anderson (1973), holds that any discrepancy between expectation and performance results to receive a more unfavourable rating for that product/service. Even if the performance exceeds the objective expectation, it will be perceived as less satisfying. Thus, the contrast theory and the generalised negativity theory hold an extreme perspective similar to assimilation theory.

Sherif and Hovland's assimilation-contrast theory states that there are zones or latitudes of acceptance and rejection in consumer perceptions (Sherif \& Hovland, 1961). If the disparity between expectation and performance is small and within the tolerable zone, consumer will tend to adjust the difference by rating the product more in line with expectations than its objective performance. If the difference between expectation and performance is large that it falls into the zone of rejection, then a contrast effect takes place and consumers magnify the discrepancy between perceived performance and expectation. These four theories discuss satisfaction in terms of consumers' expectation and perceived performance.

There are a number of satisfaction theories that also contribute to the existing literature from the perspective of relationship and customer value. For example, the equity theory explains relational satisfaction in terms of perceptions of fair/unfair distribution of resources in terms of interpersonal relationships (Adams, 1965). Equity theory states that individuals who perceive themselves as either under-rewarded or over-rewarded may experience distress and may result in dissatisfaction. The implication of this theory is that consumers are satisfied if the ratio between perceived inputs and perceived outcomes are similar or greater than that of their peers. While 
the equity theory underlines the interpersonal comparative perceived ratio of inputs and outputs, the value-percept theory underlines individual values that determine satisfaction. The theory also states that only the unfulfilled values, important to the individual, would be dissatisfying (Locke, 1976). According to Locke's (1976) valuepercept model, satisfaction can be modelled as:

$$
\mathrm{S}=\left(\mathrm{V}_{\mathrm{t}}-\mathrm{P}\right) \mathrm{V}_{\mathrm{i}}
$$

Where $S$ is satisfaction, $V_{t}$ is value content (amount wanted), $\mathrm{P}$ is the perceived amount of the value provided, and $V_{i}$ is the importance of the value to the individual. Overall satisfaction is estimated by total features received, weighted by their importance to the individual (Locke, 1976). Thus, the value-percept theory is the weighted discrepancies between expected values and perceived values. One of the particular strengths of this model is that it highlights the role of individual differences in values and outcomes. However, one potential limitation with the value-percept theory is that what one desires $\left(V_{t}\right)$ and what one considers important $\left(V_{i}\right)$ are likely to be highly correlated. In addition, the use of weighting may be inappropriate unless weighting variables are measured with very high reliability. The model also ignores influences from exogenous factors, such as present and past social, economic, or organisational conditions external to the individual (Judge \& Klinger, 2007).

The concept of comparison level theory is that previous experiences and expectations determine the level of satisfaction of an individual with a relationship. Individuals come to their relationships with an awareness of societal norms for relationships and an accumulation of experiences. Being influenced by these backups, the comparison level theory reflects-(a) what individuals feel is deserved and realistically obtainable within relationships, and (b) what individuals feel is important for them to experience within a relationship. When the outcomes derived from a relationship exceed the comparison level (particularly highly valued outcomes or ones that are important to individuals), global assessments of a relationship are likely to be high (Thibaut \& Kelley, 1959). The marketing implication of this theory is that the company must improve customer relationship management compared to its competitors, and that this distinctive relationship must be visualised and valued to the customer groups. 
The above theories, namely, generalised negativity theory, contrast theory, assimilation-contrast theory, dissonance or assimilation theory, comparison level theory, equity theory and value-percept theory, underline two critical issues contributing to satisfaction and building relationships. These are expectation and perceived performance. Oliver's study is the first to integrate expectation and perception issues and develop a satisfaction measure, expectancy-disconfirmation paradigm (EDP) (Oliver, 1980). The EDP holds that satisfaction is a function of expectation and expectancy-disconfirmation (Oliver, 1980). The EDP suggests that customers assess their levels of satisfaction by comparing their actual experiences with their expectations. It states that: (a) a confirmation occurs when the actual performance matches the standard. This leads to a neutral feeling; (b) a positive disconfirmation occurs when the performance is better than the standard, which leads to satisfaction; and (c) a negative disconfirmation occurs when the performance is worse than the standard, which leads to dissatisfaction (Fullard, 2006; Oliver, 1980; Yuksel \& Yuksel, 2001). The core issue of this paradigm is that the expectation level is a standard against present performance by which consumers' satisfaction is judged.

Until now two methods have been developed in investigating the EDP. The first is the inferred or indirect approach or the subtractive approach, and the second is the direct approach or the subjective approach (Meyer \& Westerbarkey, 1996; Prakash \& Loundsbury, 1992; Yuksel \& Yuksel, 2001). The inferred or indirect approach of measuring satisfaction involves the computation of the difference between expectation and performance. The direct approach, however, requires the use of summary judgment scales ranging from better than expectation to worse than expectation to measure confirmation or disconfirmation. As an alternative approach, direct approach represents a distinct psychological construct encompassing a subjective evaluation of the difference between product performance and the comparison standard (Churchill \& Surprenant, 1982; Oliver, 1980; Yuksel \& Yuksel, 2001). The EDP approach to measure satisfaction and service quality has been used widely. The pioneering study of Parasuraman et al.'s (1988) SERVQUAL to measure service quality is conceptualised on the EDP approach following the inferred or 
indirect approach. Despite its acceptance, the current literature has widely criticised the EDP approach, hence applicable to SERVQUAL.

Although the EDP has been extensively used in literature, the validity and reliability may be disputable for a number of reasons. First, the use of expectations might be less meaningful for experiential services (e.g. tourism, higher education, banking etc.) than for tangible consumer goods (e.g. rice, television etc.) that are easy to evaluate prior to purchase (Hill, 1985). Second, the EDP measures expectations after experience. Therefore, the reliability of a positive or negative confirmation or disconfirmation of initially measured expectations is disputable (Yuksel \& Yuksel, 2001). Third, the logic of EDP is that satisfaction/quality will be the same even if expectation and performance vary each time. For example, on a seven-point SERVQUAL scale (where, $1=$ strongly disagree and $7=$ strongly agree), expectation is 3 and performance is 6 at one time, and at other time, expectation is 6 while performance is 7. In both of these cases EDP's satisfaction (or SERVQUAL's quality) are 3 and 1, respectively. The EDP assumes that the level of satisfaction is the same in both of these cases. Fourth, studies demonstrate that the reliability of difference scores between expectation and performance is also disputable. If expectation and performance receive the highest scores, respectively, the EDP finds perceived quality/satisfaction as zero despite a positive disconfirmation (see, for example, Yi, 1990; Yuksel \& Yuksel, 2001). Fifth, the literature shows that respondents interpret expectations in various ways. Thus, it creates confusion among respondents regarding the actual meaning of expectations. For example, one study finds that respondents use expectations as an importance measure, while other respondents use it to predict performance, ideal point concept and minimum tolerable concept (Teas, 1993). Therefore, it causes serious discriminant validity shortcomings. Moreover, respondents' capability to correctly remember prior expectations raises doubts about the validity of the measures (Loundsbury \& Hoopes, 1985). Sixth, the EDP cannot accommodate the dynamic nature of expectations (Yuksel \& Yuksel, 2001), that is the process of how expectation forms and changes overtime. Customers with little/no brand experience constitute a special case in the EDP. This occurs because it is not clear how the EDP may be applied to the evaluation of services for which the 
consumer has little information or experience to generate a meaningful expectation (Halstead, Hartman, \& Schmidt, 1994; McGill \& Iacobucci, 1992; Yuksel \& Yuksel, 2001). Thus,

The expectation component of both service quality and satisfaction investigations might have serious discriminant validity shortcomings, which causes the performance-minus-expectation measurement framework to be a potentially misleading indicator of customer perceptions of services (Yuksel \& Yuksel, 2001, pp. 12-13).

Seventh, it is assumed that the EDP takes place in every consumption situation (Yuksel \& Yuksel, 2001). Depending on the product category and the nature of customers' expectations, the customer assessment of certain services may not even rely on disconfirmation, but instead rely on performance evaluations only (Churchill \& Surprenant, 1982; Halstead, Hartman, \& Schmidt, 1994; Hui, Wan, \& Ho, 2007; Landrum, Prybutok, \& Zhang, 2007). Thus, performance evaluation is the only tangible evidence on which to base consumer service evaluation (Jayanti \& Jackson, 1991). Since performance is the main feature of service that creates the consumption experience (Halstead et al., 1994), consumers' judgment of the service performance alone can be an evaluation of the global quality judgment itself (Llosa, Chandon, \& Orsingher, 1998). Eighth, there are some operational difficulties related to the EDP in addition to the conceptual issues discussed above. The EDP results in an imperfect assessment of satisfaction. For example, some researchers suggest that expectations should be measured before the service experience (Carman, 1990), whereas others argue that expectations should be measured after the service experience (Parasuraman et al., 1988). However, Grönroos argued that

Measuring expectations is not a sound way of proceeding anyway, because experiences are in fact perceptions of reality, and inherent in these perceptions are the prior expectations. Consequently if first, one way or the other, expectations are measured and then experiences are measured, then expectations are measured twice (Grönroos, 1993, p. $56)$. 
Thus, estimates of perceptions already include a perception-minus-expectation mental process (Yuksel \& Yuksel, 2001). Ninth, studies suggest that updated expectations may be more influential in satisfaction judgments than pre-consumption expectations (Zwick, Pieters, \& Baumgartner, 1995). If learning takes place during the service encounter, and expectations are modified as a consequence of this, the use of initially measured expectations in satisfaction assessment is not logical. Satisfaction is most accurately measured at the conclusion of transaction, and thus the expectation relevant to satisfaction would be the one actually used by the consumer in satisfaction formation, not necessarily the one measured before consumption (Oliver, 1997; Yuksel \& Yuksel, 2001). Tenth, the scores of expectation relative to the performance are found to be higher. For example, studies show that scores on expectations are indeed rated consistently higher than the scores on the performance components (Fick \& Ritchie, 1991; Halstead et al., 1994; Parasuraman et al., 1988; Parasuraman, Zeithaml, \& Berry, 1994). Therefore, the recalled expectations are biased toward the experienced performance (Oliver, 1997), and finally, the use of prior expectations in the assessment of customer satisfaction may be redundant when there is a high familiarity with the product or service (Yuksel \& Rimmington, 1998).

In summary, the above discussion demonstrates that Oliver's (1980) EDP approach is one of the important measures of satisfaction. Despite this, it has been widely criticised. The service quality measure, SERVQUAL, based on the EDP approach, has also been criticised for similar reasons. The major distinction between satisfaction and service quality is that while satisfaction is a transaction-specific measure, service quality is a form of attitude and a long-run overall evaluation (Bitner, 1990; Bolton \& Drew, 1991; Cronin \& Taylor, 1992; Douglas et al., 2008; Einasto, 2009; Parasuraman et al., 1988; Wong, Rexha, \& Phau, 2008). Therefore, a number of researchers have placed arguments for perception-only measure to determine satisfaction and quality (Churchill \& Surprenant, 1982; Cronin \& Taylor, 1992, 1994; Grönroos, 1993; Halstead et al., 1994; Jayanti \& Jackson, 1991; Sultan \& Wong, 2010a, 2010b). One of the reasons for this is that the perception-only measure demonstrates more convergent and discriminate validity and explains more variance in the dependent constructs (Jain \& Gupta, 2004; Meng \& Elliott, 2009). The 
following section discusses the current studies relevant to two critical service quality measures, perception-only measure and perception-minus-expectation measure.

\subsection{The service quality measures}

Service quality is defined as "the totality of features and characteristics of a product or service that bears on its ability to satisfy stated or implied needs" (Johnson \& Winchell, 1988, p. 48). Service quality has also been viewed as a critical determinant of competitiveness (Lewis, 1989), as a source of lasting competitive advantage through service differentiation (Moore, 1987), and as a driver of corporate financial and marketing performance (Buttle, 1996). Until now two critical measures are dominating in the service quality literature. These are the SERVQUAL (Parasuraman et al., 1985, 1988) and the SERVPERF (Cronin \& Taylor, 1992, 1994). In fact, these are the flagships in service quality measure. While SERVQUAL is conceptualised on the EDP, the SERVPERF is conceptualised on the perception-only perspective. Thus, the existing literature is divided into two major segments to measure service quality, the EDP approach and the perception-only approach. One school of thoughts supports the view in favour of the EDP (Chebat, Filiatrault, Gelinas-Chebat, \& Vaninsky, 1995; Spreng \& Olshavsky, 1993; Spreng \& Singh, 1993; Zeithaml \& Bitner, 2003). Whereas, the other school of thoughts states that perception-only measure is a better alternative than EDP measure (Babakus \& Boller, 1992; Brady, Cronin, \& Brand, 2002; Brown, Churchill, \& Peter, 1993; Cronin \& Taylor, 1992, 1994; Zhou, 2004). Thus, the purpose of this section is to discuss the key literature in order to conceptualise the service quality measure.

According to the SERVQUAL measure, quality is perception-minus-expectation $(\mathrm{Q}=\mathrm{P}-\mathrm{E})$. It has five dimensions and twenty-two items. These dimensions are reliability, assurance, tangibles, empathy and responsiveness (Parasuraman et al., 1988). Although the SERVQUAL has been empirically examined widely, it has also been criticised for a number of reasons. Research demonstrates serious conceptual and operational flaws in perception-minus-expectation measure, especially with respect to its theoretical justification and interpretation of the framework (Brown et al., 1993; 
Cronin \& Taylor, 1992, 1994; Lee, Lee, \& Yoo, 2000; Teas, 1993, 1994). The SERVQUAL measure, $\mathrm{Q}=\mathrm{P}-\mathrm{E}$, assumes that there will always be a difference between expectation (E) and perception (P). If the resulting score for $\mathrm{Q}$ is zero due to same scores received for each of the $\mathrm{E}$ and $\mathrm{P}$, the quality is absent (or zero). The measure, SERVQUAL, does not explain this critical issue. Moreover, recalling expectation while experiencing a particular service creates repetition of expectation and thus it is biased. The SERVQUAL cannot prioritise which factors (or set of factors/items) need proper attention and/or resource allocation. Despite these limitations, some authors have used the SERVQUAL measure as the basic framework to measure service quality (Parasuraman, Berry, \& Zeithaml, 1993; Parasuraman et al., 1988). In the revised SERVQUAL measure, first, the authors incorporated 'would' perspective instead of 'should' perspective in all of its expectation items to reduce high expectation scores and to make the expectation items more relevant to predictive expectations instead of consumers' normative expectations or ideal standards. Second, they replaced negatively worded items with positive words (Parasuraman, Zeithaml, \& Berry, 1991c). However, in their book, Marketing Services, Berry and Parasuraman, two of the three pioneers of P-E gap concept, stated that

Service quality is the foundation for services marketing because the core product being marketed is a performance. The performance is the product; the performance is what consumers buy (Berry \& Parasuraman, 1991, p. 5).

The subsequent developments in service quality measures have followed the SERVQUAL method. One of such developments is the SERVPERF scale, also known as perception-only scale. The SERVPERF scale is the unweighted perception components of the SERVQUAL scale, which consists of 22 perception items and excludes any consideration of expectations (Cronin \& Taylor, 1992, 1994). The perception-only construct, the SERVPERF, demonstrates its relative superiority over the SERVQUAL scale in terms of its measurements. Although the SERVPERF scale is based on customers' judgments evaluating perceived service performance, such judgments of customers are formulated with reference to some form of expectations. 
Expectations, regardless of whether they are measured explicitly or not, are likely to form an anchor for quality assessment (Devlin et al., 2002).

Empirical studies of service quality in terms of relative superiority between the SERVQUAL scale and the SERVPERF scale have been examined. On the one hand, these studies reveal that the SERVPERF scale is a better alternative than the SERVQUAL scale (Babakus \& Boller, 1992; Brady et al., 2002; Brown et al., 1993; Jain \& Gupta, 2004; Zhou, 2004). On the other hand, SERVQUAL has received much attention as a measure of service quality (Chebat et al., 1995; Furrer, Liu, \& Sudharshan, 2000; Zeithaml \& Bitner, 2003). However, one recent study states that both of these two scales have received more than 46 percent of their total citations in marketing literature, respectively (Carrillat, Jaramillo, \& Mulki, 2007). Thus, these approaches carry similar weights and predict service quality from two different perspectives. One of the commonalities of these two measures is that both of these measures focus on service attributes and their dimensionalities. The present studies mostly concentrate their findings on the dimensionalities of service quality across industries, cultures and firms.

\subsubsection{The dimensional approach of service quality}

Most of the service quality measures in the last few decades have focused on the dimensional approach, and thus the dimensional study of service quality still dominates the current literature. The dimensional approach of service quality provides an understanding of quality dimensions and its relevant attributes. "Identification of service quality dimensions aids an understanding of customer needs and wants" (O’Neill \& Palmer, 2003, p. 188). However, the dimensions of service quality vary by the thoughts of two different schools, Nordic school (Grönroos, 1982, 1984) and American school (Parasuraman et al., 1985, 1988). While the Nordic school defines service quality using overall categorical terms, the American school uses descriptive terms (Brady \& Cronin, 2001). The dimensions of service quality also vary by industries (Lee et al., 2000), by service types (Babakus \& Boller, 1992), by culture 
(Furrer et al., 2000) or even by providers or firms in the same industry (Abdullah, 2005; Sureshchandar, Rajendran, \& Kamalanabhan, 2001; Zeithaml et al., 1993).

There are critical features of the dimensional approach to service quality. Firstly, this approach is a service specific approach, meaning that the direction is from service to consumer. The research instruments are designed considering the specific features and natures of the service, and its delivery. Secondly, the resulting dimensions vary, based on service types, firms or provider, industry and even culture. The major benefit of using the dimensional approach is that it gives an understanding of the service features and their relevant dimensions. However, researchers have failed to replicate the five original dimensions of SERVQUAL or SERVPERF scales, namely, reliability, responsiveness, tangibility, assurance and empathy (Carrillat et al., 2007; White \& Schneider, 2000). Therefore, studies suggest that service quality measures need to be adapted to the study context (Carman, 1990; Carrillat et al., 2007). Another approach to study service quality is the antecedent perspective.

\subsubsection{The antecedent perspective of service quality}

The antecedent approach to study service quality has received little attention in literature. The antecedent framework provides an insight of how consumers view service quality as a whole and how this view contributes predicting their behaviour (Dabholkar et al., 2000). The two particular strengths of Dabholkar et al.'s (2000) study are that it is a longitudinal study and that it uses three measures, namely perception-only measure, measured disconfirmation (where explicit comparisons are made in the instruments after the service received) and computed disconfirmation (expectations before the service experience-minus-perceptions after the service experience). The findings state that a perception-only measure is superior to computed disconfirmation and measured disconfirmation. Literature suggests that the perception-only measure demonstrates more convergent and discriminate validity and explains more variance in the dependent constructs (Jain \& Gupta, 2004; Meng \& Elliott, 2009). Dabholkar et al.'s (2000) study recommends that if the objective of the study is to predict service quality or to gauge its determinants, a perception-only 
measure should be used rather than disconfirmation. The present thesis is based upon the perception-only measure.

The antecedent approach starts from customers. However, customer-specific antecedent to service quality has received only a little attention. The customerspecific antecedent approach helps by explaining the formation of service quality in customers' cognition. Thus, the direction is from customers to service quality. Customer perception of service quality is affected by factors such as communications from salespeople, social referrals, various types of information collected, and the credence consumers develop towards a service organisation (Gounaris et al., 2003; Kangis \& Passa, 1997). Gounaris et al. (2003) examine customer-specific antecedents to service quality in banking services, and found that perceived service quality is affected by customer and company specific antecedents. These antecedents are wordof-mouth, comparison shopping, personal relationships and perceived market orientation. Although this study considers word-of-mouth communication as one of the four antecedents consisting of three indicators, two of the three indicators of word-of-mouth are seriously lacking from content and face validity. These are 'family bank' and 'get information from advertising campaign'.

O'Neill and Palmer (2003) examine SERVQUAL dimensions in terms of 'with experience' and 'without experience' in order to find if experience makes a difference in SERVQUAL dimensions in the context of respondents' theme park visits. As a result of factor analyses of experienced park users, six factors are derived, where two factors (named in their study as D2 and D5) have low coefficient alpha (0.19) values, and factor D4 has a negative coefficient alpha $(-0.47)$ value. In contrast, five factors are derived from the factor analyses of inexperienced park users, where one factor (D3) has a low coefficient alpha value and one factor (D5) has a negative coefficient alpha $(-0.23)$ value. A low coefficient alpha value suggests a low reliability of the scale. The other conceptual flaw of this study is that respondents' evaluation of theme park visits cannot take place unless they experience it. Without experience, it may be the 'pre-experience expectations' that the study has dealt with. Thus, it is essential to understand the role of experience in the formation of service quality perceptions (O’Neill \& Palmer, 2003). 
The 'pre-experience expectation' can be biased (Sultan \& Wong, 2010a). However, one recent conceptual study stresses the importance on 'pre-experience expectation' stage and its effect on experience and service quality (Knutson, Beck, Kim, \& Cha, 2010). While real time experience and service quality evaluation both take place simultaneously, it may be conceptually weak to consider them as two separate constructs. The literature is also in support of considering experience-based service quality construct (Brady et al., 2002; Cronin \& Taylor, 1992, 1994; Parasuraman, Berry, \& Zeithaml, 1991a; Sultan \& Wong, 2010a). The effect of (pre-experience) expectation on service quality as a separate construct has also been criticised in the existing studies (Grönroos, 1993; Yuksel \& Yuksel, 2001). Thus, Knutson et al.'s (2010) study lacks conceptual soundness and also from empirical evidence.

Customer experience has been considered as the sole antecedent of perceived quality, brand awareness, brand association and brand loyalty in the context of four auditing companies in Sweden (Biedenbach \& Marell, 2010). This study conceptualises customers' experience as 'the results of the customers' interpretation of his or her total interaction with the brand and perceived value of this encounter" (Biedenbach \& Marell, 2010, p. 450). The perceived quality has been viewed as overall customers' evaluation of quality of auditing services provided by the Swedish companies. However, a close examination of the items used to measure customer experience construct reveals that three of the five items are double-barrelled that violate the principles of a good questionnaire.

In summary, the current literature in service quality uses two approaches to measure quality of services. These are perception-minus-expectation and perception-only measures. The literature demonstrates that the perception-only measure is an effective measure. While the focus of dimensional approach is on finding critical service attributes and their categorisation, the antecedent perspective focuses on what affects (forms) service quality, how consumers view service quality as a whole, and how this view contributes evaluating service quality and predicting their behaviour. Therefore, both antecedent and dimensional perspectives to study service quality can better explain service quality phenomena. 


\subsection{Consequences of service quality}

A number of studies have used perception-only perspective to study the consequences of service quality (Cassel \& Eklöf, 2001; Fornell, 1992; Fornell, Johnson, Anderson, Cha, \& Bryant, 1996). Showing satisfaction, value and loyalty are the major consequences of service quality, these studies develop satisfaction index models that have been implemented to determine consumers' level of satisfaction in several country specific contexts.

\subsubsection{The satisfaction index models}

The concept of consumer satisfaction occupies a central position in marketing thought and practice. Satisfaction is a psychological state of happiness received in a transaction. Satisfaction is idiosyncratic. It emerges from the interaction of perceptual interpretations (Ueltschy et al., 2007). As a result, consumers express varying levels of satisfaction for the same experience that they encounter. In a nut shell, satisfaction (or dissatisfaction) is not inherent in the product or service instead it is the consumer's perceptions of the attributes of the product or service (Boshoff \& Gray, 2004). Satisfaction has been viewed from transaction-specific perspective in the literature (Cronin \& Taylor, 1992, 1994). Satisfaction has also been viewed as having both affective (emotional) and cognitive dimensions (Oliver, 1996). Satisfaction is a major outcome of marketing activity that links purchase and consumption with postpurchase phenomena such as attitude change, repeat purchase and brand loyalty (Churchill \& Surprenant, 1982).

A number of satisfaction index models, evolved in marketing literatures, are based on perception-only perspective. For example, Fornell's (1992) study is one of the first studies to establish a national economic indicator, the Swedish Customer Satisfaction Barometer (SCSB), reflecting customer satisfaction. The two key determinants of satisfaction in this model are customer expectations and product/service performance. In this study, product/service performance has been viewed as perceived value. As for the consequences of satisfaction, the model considers decreased customer complaints 
and increased customer loyalty. The results show that performance has a greater effect on satisfaction compared to expectations and this is consistent in all the industries included in this survey.

In a subsequent study, Fornell et al. (1996) develop the American Customer Satisfaction Index model, commonly known as the ACSI model. The key difference between SCSB and ACSI model is that the ACSI model considers perceived value and perceived quality as two separate concepts. The studies show that perceived quality and perceived value are two key and distinct constructs (Alves \& Raposo, 2007; Cronin, Brady, \& Hult, 2000; Patterson \& Spreng, 1997; Whittaker, Ledden, \& Kalafatis, 2007). Although the ACSI model advances the literature to a degree, it has some limitations. First, in a multi-dimensional multi-attribute model, the latent variable-customer complaint has one item only. Studies suggest that multi-item measure is typically much better than a single item measure (Churchill, 1979; Churchill \& Surprenant, 1982; Nunnally, 1978). Second, two of the items of perceived value, quality with regard to price and price with regard to quality, are measuring the same issues. Third, customer's ideal point for each of the items of product's performance, expectation and satisfaction are basically their expectation. Thus, these constructs repeatedly use expectation items. Research states that experiences are in fact perceptions of reality and that includes prior expectations (Grönroos, 1993).

One of the most widely implemented models to measure the level of customer satisfaction is the European Customer Satisfaction Index (ECSI) model. Following the ACSI model, Cassel and Eklöf (2001) develop the ECSI model. There are two major distinctions between the ACSI and the ECSI models. First, the ECSI model does not consider 'customer complaints' as the consequences of satisfaction, rather this model considers loyalty as a sole consequence of satisfaction. Second, the ECSI model incorporates '(Corporate) Image', and shows that (corporate) image affects expectation, value, satisfaction and loyalty. There are six latent variables in the ECSI model, namely image, expectation, perceived quality, perceived value, satisfaction and loyalty. 
Image (corporate image) is identified as an important factor in the overall evaluation of the service and the company. Grönroos (1984) argues that corporate image is built mainly by technical quality, meaning that what the customer gets from the service experience, and functional quality, meaning that the way it is delivered. Another study defines corporate image as the accumulation of purchasing/consumption experience over time (Andreassen \& Lindestad, 1998). Thus, corporate image has been modelled as the consequence of perceived value, perceived quality (Nguyen \& LeBlanc, 1998) and satisfaction (Johnson, Gustafsson, Andreassen, Lervik, \& Cha, 2001). The effect of customer satisfaction on corporate image reflects both the degree to which consumption experience enhances corporate image and the consistency of customers' experiences over time. Thus, Johnson et al. (2001) develop the Norwegian Customer Satisfaction Barometer (NCSB) where corporate image was modelled as a consequence of satisfaction. The NCSB model has several features. These include: (a) perceived quality is based on the gap concept, perception-minus-expectation, (b) removes the expectation construct, (c) replaces value construct with price index, (d) corporate image is considered as an outcome of satisfaction, (e) includes affective commitment and cumulative commitment constructs, and (f) includes complaint handling construct.

The key attention of satisfaction index models, namely SCSB, ACSI, ECSI and $\mathrm{NCSB}$, is to determine the extent of customer satisfaction across national level industries. Overall, these models play a significant role in determining customer satisfaction, particularly the ECSI model. In the context of higher education, only the ECSI model has been empirically examined in a few studies (Alves \& Raposo, 2007; Brown \& Mazzarol, 2009). The findings of these studies show that the interrelationships among a number of constructs of the ECSI model in the context of higher education appear statistically insignificant and negative. This is because the ECSI model was developed for the commercial service sector. The ECSI's application in the higher education domain requires a separate attention. In this respect, Sultan and Wong state that

...universities and commercial enterprises are two different streams; literature puts an effort to develop a model, borrowed from 
commercial settings, in the context of higher education (Sultan \& Wong, 2010b, p. 260).

Therefore, there is a need to further examine the ECSI model in the context of higher education.

While the ECSI model is based on the perception-only concept, the NCSB model is based on perception-minus-expectation concept. As the ECSI model is based on the perception-only concept, the ECSI model is an appropriate model as the point of departure for this thesis. Section 2.5 discusses the literatures that considered the ECSI model in the context of higher education in detail.

In the higher education domain, students develop cumulative effects of trust in their cognitive structure with their academic and administrative staff during the period of study. Students' trust is the foundation in the higher education services marketing where they have to go through a longitudinal process with their enthusiasm in order to get an outcome at a cost. Thus, achieving students' trust during their course of study has tremendous role in managerial decision making. While implementing the ECSI model in the higher education sector, none of the studies (Alves \& Raposo, 2007; Brown \& Mazzarol, 2009; Chitty \& Soutar, 2004; Martensen et al., 2000) examine the role of students' trust in the model. In addition, the ECSI model itself does not measure trust's effect in the model.

\subsubsection{The role of trust}

The concept of trust is relevant to building relationships. The current literature labelled trust as the central issue of any long-term relationship (Delgado-Ballester \& Munuera-Aleman, 2001; Morgan \& Hunt, 1994). It is valuable, especially, in any social interactions where a more enduring relationship is desired. Trust has been defined as “one party's belief that its needs will be fulfilled in the future by actions undertaken by the other party" (Anderson \& Weitz, 1989, p. 312). Trust has been viewed as having two dimensions, namely perceived credibility and perceived benevolence of the provider (Doney, Barry, \& Abratt, 2007). Trust in a partner's 
credibility is viewed as a belief that one's partner stands by its word, fulfils promised role obligations, and is sincere. Trust in a partner's benevolence is viewed as beliefs that one's partner is interested in the firm's welfare and will not take unexpected actions that would have a negative impact on the firm (Doney et al., 2007; Doney \& Cannon, 1997). Achieving customers' trust in transactions implies that the seller maintains the welfare and interests of the customers, that the seller neither lies nor exaggerates relevant to the offer, that the seller keeps promises, and that the seller does not take advantage of customers' vulnerability (Delgado-Ballester \& MunueraAleman, 2001).

Trust plays an important part in developing customers' loyalty commitment (DelgadoBallester \& Munuera-Aleman, 2001; Doney et al., 2007). It is also an important force of customer retention (Doney et al., 2007). Thus, the management of customers' trust is especially important in the marketing of services (Berry \& Parasuraman, 1991). In the context of higher education, students' trust can be defined as students' confidence in the university's integrity and reliable service performance. The students' trust mainly depends on students' experiences with the academic and administrative staffs, and their satisfaction with service performance. The lack of building trust in students may affect the institution achieving long-term goals. Thus, students' trust is important for a university in order to build a long-run relationship with students with an aim to sustainable future development.

\subsubsection{Service quality and trust}

Although trust is essentially a social construct, achieving customers' trust in service organisations is a key concern to managers. In the extant literature, trust has been playing a major role concomitant to relationship building. Service quality and trust have been viewed as the centre of relationship marketing (Berry, 2002). Trust is considered as customers' confidence in a service seller's reliability and integrity (Morgan \& Hunt, 1994). The process by which an individual characterises trust is based on one's experience with the service use. As an experience attribute, it is influenced by customers' evaluation of any direct (e.g. trial, usage, satisfaction) and 
indirect contact (e.g. advertising) with the provider. Among all of these different contacts, the consumption experience gains more relevance and importance as a source of trust (Delgado-Ballester \& Munuera-Aleman, 2001). Customers' favourable perception of service quality gives more confidence that in turn increases their trust in service provider (Chiou, Droge, \& Hanvanich, 2002; Eisingerich \& Bell, 2008). This occurs because the experience of service encounter generates associations and feelings that are more self-relevant and held with more certainty (Dwyer, Schurr, \& Sejo, 1987; Krishnan, 1996).

The current research has underscored the importance of trust and its implications for driving profitable and long-lasting customer relationships (Eisingerich \& Bell, 2008; Garbarino \& Johnson, 1999; Morgan \& Hunt, 1999). Trust has economic implications (Venetis \& Ghauri, 2004) in that customers' trust leads to positive behavioural intention that in turn generates a steady cash flow to the organisation. Surprisingly, the relationships among service quality, trust and satisfaction receive only a little attention in the context of higher education. Trust can have a significant impact in the higher education domain as students build cumulative effects of trust over the years with their teachers, staff, institution, and with the brand itself.

\subsubsection{Satisfaction and trust}

Trust of a brand or provider, in customers' cognition, develops through consumption experience and their subsequent satisfaction. Overall satisfaction generates trust because it indicates seller's consistency and ability in fulfilling promise and that the seller keeps buyer's welfare, security and interest (Delgado-Ballester \& MunueraAleman, 2001; Ganesan, 1994; Selnes, 1998). The existing studies demonstrate that satisfaction affects trusts (Delgado-Ballester \& Munuera-Aleman, 2001; Horppu, Kuivalainen, Tarkiainen, \& Ellonen, 2008; Lau \& Lee, 2000; Zboja \& Voorkees, 2006). However, research also demonstrates that trust proceeds to satisfaction in that pre-exchange trust has a direct influence on the postpurchase satisfaction (Chiou et al., 2002). Therefore, the literature is inconclusive about the direction between satisfaction and trust. Pre-exchange trust is weak compared to post-exchange trust 
because the later provides deep consumers' belief and understanding. Thus, it is heavily appropriate to conceptualise that consumption satisfaction affects consumers' trust. In the context of higher education, one study finds that satisfaction has a positive and significant effect on trust (Rojas-Me'ndez et al., 2009). However, this study is based on such a ground where one variable affects the next variable on straight line relationships. For example, service quality affects satisfaction; satisfaction affects trust; trust affects commitment; and commitment affects loyalty. Rojas-Me'ndez et al. (2009) ignore the role of service quality and satisfaction on trust in the context of higher education.

Trust resembles one's emotional norm derived from service experience and subsequent satisfaction. It is more enduring than satisfaction, and builds a long-term relationship between supplier and customer. The current literature does not provide a clear understanding about the relationships between trust and satisfaction. On the one hand, the literature states that trust affects satisfaction (Chiou et al., 2002). On the other hand, studies show that satisfaction affects trusts (Delgado-Ballester \& Munuera-Aleman, 2001; Horppu et al., 2008; Lau \& Lee, 2000; Zboja \& Voorkees, 2006). While satisfaction is a transactional outcome (Cronin \& Taylor, 1992), trust is a belief of consumer that the subsequent service performance and satisfaction will be identical in any future transaction. Thus, trust is an effect of service performance and subsequent satisfaction.

In summary, there is inadequate research that aims at examining the role of students' trust in the context of higher education. The role of trust is absent both in the ECSI model and subsequent empirical studies in the context of higher education that are based on the ECSI model. This thesis examines the role of students' trust as one of the important consequences of service quality and satisfaction.

Students' satisfaction and their trust can have an impact on the UniBrand (i.e. the name of university as a brand) in that these lead to increased image and reputation in the market. The following section discusses the extant literature relevant to brand performance. 


\subsubsection{The role of brand performance}

Brand is everywhere. In a competitive world, companies invest more on getting acceptability of their brands. In fact, they appear in the global brands' performance war. The contribution of branding research has been well documented in the academic literature (Alexandris, Douka, Papadopoulos, \& Kaltsatou, 2008; Wong \& Merrilees, 2008). Wong and Merrilees stated that

The branding literature has developed considerably over the past decade or two, with considerable understanding of the nature of branding and in the formulation of effective branding strategies (Wong \& Merrilees, 2008, p. 372).

In academic literature, brand performance has been viewed as the success of a brand within the market. It has been measured through a four item construct, and they are related to brand awareness, brand reputation, brand loyalty and brand satisfaction (Wong \& Merrilees, 2007a) from managerial perspectives. However, another group of literature measures brand performance with respect to brand size (market share and percent buying), loyalty related measures (purchases per buyer annually) and annual switching (Ehrenberg, Uncles, \& Goodhard, 2004). The extant literature also viewed 'brand performance outcomes' as greater market share and a premium price relative to the leading competitor (Chaudhuri \& Holbrook, 2001). These studies conceptualise brand performance measures from managerial and brand outcome perspectives. Nevertheless, the current literature review reveal that no study has conceptualised the brand performance from customers' attitudinal perspectives.

One of the key topics in branding research is the measurement and development of brand equity. Brand equity is defined as the marketing effects distinctively attributable to the brand (Keller, 1993). These effects are related to the outcomes derived as a result of the unique characteristics of a brand in comparison to its competitors. In the current literature, two models are proposed to conceptualise brand equity. The first model states that brand equity is a two dimensional construct, consisting of brand awareness and brand image. Brand awareness has been defined as 
whether a brand comes to customers' minds when customers think about purchasing a particular product category (Wong \& Merrilees, 2007a). They also stated that

Brand awareness is a basic dimension of brand performance, as a brand is unlikely to perform well unless the customer is at least aware of the brand (Wong \& Merrilees, 2007a, p. 392).

Brand image is described as the overall impression made on the minds of customers (Dichter, 1985). Therefore, brand image is a distinct image about a product/service/organisation that consumer cognitively associate with what they are being exposed to through marketing communication. However, some authors argue that the development of brand image is based on brand associations held in consumers' memory (Alexandris et al., 2008; Keller, 1993). Brand associations are defined as thoughts and ideas held by individuals in their memory related to a specific service or a product (Aaker, 1991, 1996; Alexandris et al., 2008; Keller, 1993). It has also been argued that brand image is closely tied to brand reputation in that it affects customer expectation with regard to the quality of service (Yoon, Guffey, \& Kijewski, 1993). Brand reputation (or goodwill) is defined as the consistency of an organisation's actions over time (Herbig, Milewicz, \& Golden, 1994). Brand reputation is also described as an extrinsic cue or an attribute related to the product/service (Guolla, 1999). The literature also labels brand reputation as a close representation of brand performance measure (Harris \& de Chernatony, 2001), and that it is a collective measure of trustworthiness (Jøsang, Ismail, \& Boyd, 2007). Whilst brand image reflects the current perception of the brand and that is changing, brand reputation/performance is relatively stable and represents the distillation of multiple images over time (Fombrun \& van Riel, 1997). Thus, brand reputation/performance is conceptualised as the guarantee of reliable service, credible actions of management and of course providing value for money to customers.

The second model, however, states that brand equity is a four dimensional construct, consisting of brand awareness, brand associations, perceived quality and brand loyalty (Aaker \& McLoughlin, 2007; Alexandris et al., 2008). Whilst the current studies (Alves \& Raposo, 2007; Cassel \& Eklöf, 2001; Cronin et al., 2000; Eklöf, 2000; 
Fornell, 1992; Fornell et al., 1996; Johnson et al., 2001; Patterson \& Spreng, 1997; Whittaker et al., 2007) show that perceived quality is the antecedent of value, satisfaction, image and loyalty; the evidence of perceived quality as a dimension of brand equity is not clearly evident in literature. The marketing literature uses brand loyalty as one of the instruments to measure brand performance in a way that the customer will only buy a specific brand and will delay purchasing if the brand is not available (see, for example, Chaudhuri \& Holbrook, 2001; Reid, 2002). Following these discussions, brand performance can be conceptualised as the brand's relative success in the market as perceived by consumers.

\subsubsection{Satisfaction and brand performance}

O'Neill et al.'s (2006) study conceptualises brand performance in the context of tourism industry as higher average daily rates for hotel rooms, higher occupancy and higher increases in the total number of guests. O'Neill et al. (2006) examine the relationships between satisfaction and brand performance in the context of hotel industry. The brand performance measure as conceptualised by O'Neill et al. (2006) is relevant to profitability or outcome perspective, which is similar to the study of Chaudhuri \& Holbrook (2001). Chaudhuri and Holbrook's (2001) study conceptualises brand performance as an outcome measure, for example, greater market share and a premium price relative to the leading competitor. However, the present study conceptualises brand performance as an attitude measure.

Attitudes of consumers toward a brand play a critical role with regard to future purchase and brand positioning. Attitude is an important issue because it can help towards a better understanding of consumer choices (Keller, 1993). Brand attitudes are defined as "consumers' overall evaluation about the brand" (Keller, 1993, p. 4). More specifically, Grace and O'Cass (2004) define brand attitude in terms of its goodness, liking, attractiveness, niceness and desirableness. The relationship between satisfaction and brand performance, in the context of higher education, is still unknown. 


\subsubsection{Trust and brand performance}

Trust evolves from past experience and prior interaction (Garbarino \& Johnson, 1999). In terms of a brand, it summarises consumers' knowledge and experiences with the brand. Brand trust is defined as the confidence of brand's reliability and intentions in situations entailing risk to the consumer (Delgado-Ballester, 2004). This definition reflects two distinct issues. First, consumers' confidence that the brand is reliable in terms of its performance. Second, brand's intentions to minimise consumption risks relative to other brands.

The marketing literature (for example, Wong \& Merrilees, 2007a, 2008) examines the relationships of innovation, brand orientation, marketing strategy and brand performance. Chaudhuri and Holbrook (2001) examine relationships among brand trust, loyalty and brand performance, where loyalty is a mediating variable between brand trust and brand performance. Chaudhuri and Holbrook's (2001) brand performance measure is relevant to outcome measure. However, a direct relationship between trust and brand performance (as an outcome measure) has been examined in the context of the Taipei's health food industry (Hu, Chang, Hsieh, \& Chen, 2010). There are several flaws in this study. First, Hu et al.'s (2010) study shows that trust affects brand performance in the research framework; however, the final model shows a reverse relationship with a new construct, where brand performance affects customer's confidence. Second, the study defines trust and customers' confidence, separately, and incorporates trust construct in the research framework and confidence construct in the final model, respectively.

Although a number of studies in brand performance are conducted from service providers' perspective (Chaudhuri \& Holbrook, 2001; Ehrenberg et al., 2004; Harris \& de Chernatony, 2001; Wong \& Merrilees, 2007a, 2008); there is further scope for reassessing the findings from consumer specific perspectives. The consumers are only one of the major forces that determine the performance of a brand relative to other brands. 
The above discussion summarises that perceived brand performance is customers' evaluation of a brand's success in relation to other competing brands in the market in terms of brand awareness, brand image, brand attitude, brand reputation, brand satisfaction, brand trust and brand loyalty. It has been found in the current literature that there is no study in the context of higher education where students' perceptions of brand performance (or brand reputation) with regard to their university is assessed, and modelled in terms of the consequences of service quality. Another important consequence of service quality found in the current literature is behavioural intention. The following section discusses relevant studies in behavioural intention, the final and indirect consequence of service quality.

\subsubsection{Behavioural intention}

Behavioural intention is consumers' readiness to behave. Once consumers are satisfied, their behavioural intention is assumed to be positive. The behavioural intention includes re-buy, more buy and positive word-of-mouth. One study defined behavioural intention as the indicators that signal whether customers will remain with or defect from the company (Zeithaml et al., 1996). Behavioural intention can be favourable or unfavourable to the company. In contrast, loyalty is consumers' preference for a company over others, by continuing to purchase from it, or by increasing business with it in the future (Zeithaml et al., 1996). Thus, loyalty refers to a positive outcome favourable to the company. While behavioural intention is relevant to predicting consumers' post-purchase intentions, loyalty is relevant to commitment of consumers to be with the company in future. Therefore, favourable behavioural intention of customers is associated with their favourable word-of-mouth, recommendations made to prospective customers, a commitment to repurchasing from the company, a commitment to spending more with the company and a commitment to pay price premiums (Cronin et al., 2000; Zeithaml et al., 1996). These discussions imply that customers' trust is one of the major antecedents of behavioural intention. This is because consumers' trust on service provider leads them to repurchase, more purchase and say positive words to prospective customers. 
The extant literature finds that service quality affects behavioural intention (Cronin et al., 2000; Zeithaml et al., 1996); and satisfaction and repeat purchase are dependent on perceived service quality (Selnes, 1993). Unless customers are satisfied with the service performance or they trust the brand, consumers are unwilling to show favourable intentions and be loyal to the company. Therefore, satisfaction is one of the important issues for getting favourable behavioural intention of the customers. The following paragraphs discuss the relationship between satisfaction and behavioural intention, and brand performance and behavioural intention.

\subsubsection{Satisfaction and behavioural intention}

The relationship between satisfaction and behavioural intention has been examined in the present literature (Cronin et al., 2000; Gounaris, Dimitriadis, \& Stathakopoulos, 2010; Patterson \& Spreng, 1997; Zeng, Hu, Chen, \& Yang, 2009). The relationship between satisfaction and loyalty has also been empirically examined in the current literature (Alves \& Raposo, 2007; Cassel \& Eklöf, 2001; Fornell, 1992; Fornell et al., 1996; Johnson et al., 2001). These studies demonstrate strong and positive relationships exist between satisfaction, and loyalty or behavioural intention, and that satisfaction affects loyalty or behavioural intention. Despite this evidence, there are a number of studies showing opposite findings that satisfaction does not affect loyalty (Hellier, Geursen, Carr, \& Rickard, 2003; Skogland \& Siguaw, 2004).

Although there are studies (see, for example, Taylor \& Baker, 1994; Cronin et al., 2000) in marketing literature measuring customer satisfaction and behavioural intention, only a few studies relevant to student satisfaction and loyalty contribute in the marketing literature in the context of higher education. In the current competitive university environment, which includes a reduction of the potential number of students, the need to guarantee the survival of university institutions justifies the importance of analysing the concepts of satisfaction and loyalty in this context (Navarro, Iglesias, \& Torres, 2005). Navarro et al. (2005) find that satisfaction is an antecedent to loyalty. Their study takes 369 student samples from a Spanish university who attended courses in 2003. In a multi-attribute structural equation 
model, Navarro et al. (2005) measure the key construct, satisfaction, with a single item. Although Navarro et al. (2005) find that satisfaction is an antecedent to loyalty, one recent study finds that perceived service quality and student satisfaction do not translate directly into loyalty, but, rather indirectly through the mediation of trust in the context of higher education (Rojas-Me'ndez et al., 2009). Thus, the literature does not provide a clear understanding about the direction of causal relationships between satisfaction and loyalty. The review of literature also revealed that there is no study showing relationship between satisfaction and behavioural intention in the context of higher education.

\subsubsection{Brand performance and behavioural intention}

The extant literature viewed 'brand performance outcomes' as greater market share and a premium price relative to the leading competitor (Chaudhuri \& Holbrook, 2001). Chaudhuri and Holbrook's (2001) study examines the relationships among brand trust, brand affect and brand outcomes. The findings of Chaudhuri and Holbrook's (2001) study show that there is a positive and significant relationship between loyalty (purchase loyalty and attitudinal loyalty) and brand outcomes (market share and relative price).

Selnes (1993) finds a positive relationship between brand reputation and loyalty in the context of commercial and non-commercial service sectors. A close examination reveals that one of the two items of brand reputation is double-barrelled. The item is as follows: "what reputation has $\mathrm{xx}$ among your colleagues/friends and family?" (Selnes, 1993, p. 26). In this item 'and' joins two different issues. For example, while one's colleagues might hold a good reputation about brand $\mathrm{xx}$, family might not hold a good reputation for the same brand, and vice-versa. The present literature suggests to avoid double-barrelled questions in a questionnaire (Baker, 2003; Linda \& Wikke, 1987). It is surprising that the literature is lacking any further evidence showing the interrelationship between brand performance and behavioural intention. Nevertheless, the relationship between brand performance and behavioural intention in the context of higher education is still untapped. 
In summary of section 2.4 , the major consequences of service quality reported in the current literatures are satisfaction and behavioural intention. The other important issues derived from the review of the extant literature are trust and brand performance. With regard to trust, it appears that there is no study that determines the role of trust between service quality and brand performance. Trust is an important issue that creates loyal customer groups and generates steady cash flows. It is particularly significant in the context of higher education as students build cumulative effects of trust over the years with their teachers, staff, institution, and with the brand itself. It helps to retain the students and attract new students. Another issue is brand performance. Because consumers hold the sole authority to evaluate a brand, it appears from the review of current marketing literature that there is no study that measures brand performance from students' (consumer) perspective and in the context of higher education. The current marketing literature does not answer whether students' satisfaction and trust affect brand performance, and whether brand performance affects behavioural intention in the context of higher education. Thus, these pose research gaps. In addition, the literature does not provide a clear understanding about the direction of causal relationships between satisfaction and loyalty in the context of higher education. Therefore, there is a need to empirically examine these issues, and develop an integrated model in the context of higher education. The following section discusses service quality research in the context of higher education.

\subsection{Service quality research in higher education}

Although there are debates in relation to the measures of service quality, the perception-only measure of service quality has been termed as an effective measure for the purpose of explaining variance in dependent constructs (Cronin et al., 2000; Parasuraman et al., 1994; Zeithaml et al., 1996). After a thorough analysis of the performance-minus-expectation and perception-only measures in the context of higher education, only one study reported that the perception-only approach is a superior measure to the Gap approach in explaining and predicting the overall degree of students' satisfaction (Li \& Kaye, 1998). Therefore, the perception-only measure is 
more appropriate to use in developing an integrated model and explaining causal relationships. This section confines discussion and review of the current literature that uses perception-only paradigm of service quality in the context of higher education. The section is organised in the following way. First, the performance-based service quality measures relevant to higher education are discussed with relevant critiques. Second, the service quality models evolved in higher education domain are discussed. The relevant critiques are also wrapped-up in this section.

\subsubsection{Service quality measures in higher education}

The service quality literature, based on perception-only measure, develops service quality measures for higher education, the Higher Education Perception-only (HEdPERF) measure (see, for example, Abdullah, 2005, 2006a, 2006b, 2006c). The HEdPERF is a performance-based measuring scale that attempts to capture the aspects of perceived service quality within Malaysian higher education sector. The HEdPERF is a 41-item scale, consisting of 13 items adapted from SERVPERF, and 28 items generated from literature review and various qualitative research inputs, namely focus groups, pilot test and expert validation. The HEdPERF has five dimensions, namely non-academic aspects, academic aspects, reputation, access and program issues. The Cronbach Alpha for these dimensions are 0.92, 0.89, 0.85, 0.88 and 0.81 , respectively. The regression analyses results show that the standardised Beta coefficients for non-academic aspects and academic aspects are (-) 0.11 and (-) 0.02, respectively, where global assessment of service quality is a dependent variable (Abdullah, 2005, 2006a, 2006b). While academic and non-academic aspects are two core issues to evaluate educational service quality in the context of higher education, the findings of those studies show that standardised regression coefficients are negative. The negative coefficients may be due to the unsatisfactory validities. There are some limitations in these studies. First, Abdullah (2005, 2006a, 2006b, 2006c) states that the questionnaire was pretested with 30 students and three experts, and the feedback received from them had been incorporated. However, I find that the content and the face validity of many of the items in the questionnaire are weak. Some major issues include double-barrelled questions, poorly worded questions, including items 
that are not consistent with factor naming, asking questions about what other people think, asking questions that students could not possibly know the answer, asking questions what students think about a particular issue rather than what the students have experienced, in particular, are some of the limitations in those studies. Second, the results of the factor analysis have many cross loadings and low loadings (even below 0.3 ). Cross loadings are not apparently cleared.

The Performance-based Higher Education (PHEd) measure addresses some of the limitations of the HEdPERF instruments, and develops 67-item instruments for service quality measure (Sultan \& Wong, 2010a). This study has eight dimensions. These are dependability, effectiveness, capability, efficiency, competencies, assurance, unusual situation management, and semester-syllabus. The Cronbach Alpha for these dimensions is between 0.78 and 0.91 . The factor loadings are between 0.93 and 0.36 . The PHEd measure is empirically examined among the international students studying at 11 Japanese universities. However, the scope of this study was confined to international students and thus generalisation was not possible. There are further avenues to determine the predictive ability of the PHEd model in terms of overall satisfaction, and its relative strength compared to the HEdPERF measure.

LeBlanc and Nguyen (1997) examine the dimensions of service quality and their relative importance to service quality as perceived by business students. This study develops 38-item instruments and seven factors. These factors are contact personnel/faculty, contact personnel/administration, responsiveness, reputation, curriculum, physical evidence and access to facilities. Despite the contribution of this study to finding dimensions, the major limitation of this study is that it considers only a small business school of a university and its student population (LeBlanc \& Nguyen, 1997). Another study, during the same period, find seven factors for perceived service quality in the context New Zealand's business students. These factors are program issues, academic reputation, physical aspects, career opportunities, location, time and other (Joseph \& Joseph, 1997). Thus, the service quality dimensions developed in various country perspectives varied widely. Table 1 shows the service quality dimensions developed in the existing literature across countries. 
Table 1: Service quality dimensions in higher education

\begin{tabular}{|c|c|c|c|}
\hline Author, Date & Items & Dimensions & Country/University \\
\hline $\begin{array}{l}\text { (Sultan \& Wong, } \\
\text { 2010a) }\end{array}$ & 67 Items & $\begin{array}{l}\text { Dependability, effectiveness, } \\
\text { capability, efficiency, } \\
\text { competencies, assurance, } \\
\text { unusual situation management } \\
\text { and semester-syllabus }\end{array}$ & Japan \\
\hline $\begin{array}{l}\text { (Rojas-Me'ndez et } \\
\text { al., 2009) }\end{array}$ & 18 Items & $\begin{array}{l}\text { Instructors, program director, } \\
\text { secretaries, service attitude and } \\
\text { competence development. }\end{array}$ & Chilean University \\
\hline $\begin{array}{l}\text { (Stodnick \& } \\
\text { Rogers, 2008) }\end{array}$ & 18 Items & $\begin{array}{l}\text { Reliability, Assurance, } \\
\text { Tangibles, Empathy and } \\
\text { Responsiveness }\end{array}$ & $\begin{array}{l}\text { One course, } \\
\text { Southwestern } \\
\text { University, USA }\end{array}$ \\
\hline $\begin{array}{l}\text { (Angell et al., } \\
\text { 2008) }\end{array}$ & 18 Items & $\begin{array}{l}\text { Academic, leisure, industry links } \\
\text { and cost }\end{array}$ & One university, UK \\
\hline $\begin{array}{l}\text { (Smith, Smith, \& } \\
\text { Clarke, 2007) }\end{array}$ & 22 Items & $\begin{array}{l}\text { Reliability, Assurance, } \\
\text { Tangibles, Empathy and } \\
\text { Responsiveness }\end{array}$ & $\begin{array}{l}\text { IT Department, one } \\
\text { university, UK }\end{array}$ \\
\hline (Abdullah, 2006c) & 41 Items & $\begin{array}{l}\text { Non-academic, academic, } \\
\text { reputation, access, program and } \\
\text { understanding }\end{array}$ & Malaysia \\
\hline $\begin{array}{l}\text { (Abdullah, 2005, } \\
\text { 2006a, 2006b) }\end{array}$ & 35 Items & $\begin{array}{l}\text { Non-academic, academic, } \\
\text { reliability and empathy }\end{array}$ & Malaysia \\
\hline $\begin{array}{l}\text { (Gatfield, Barker, } \\
\text { \& Graham, 1999) }\end{array}$ & 26 Items & $\begin{array}{l}\text { Academic instruction, campus } \\
\text { life, guidance, recognition }\end{array}$ & $\begin{array}{l}\text { One Australian } \\
\text { University }\end{array}$ \\
\hline $\begin{array}{l}\text { (Kwan \& Ng, } \\
\text { 1999) }\end{array}$ & 31 Items & $\begin{array}{l}\text { Course content, concern for } \\
\text { students, facilities, assessment, } \\
\text { medium of instruction, social } \\
\text { activities and people. }\end{array}$ & $\begin{array}{l}\text { China and } \\
\text { Hong Kong }\end{array}$ \\
\hline (Li \& Kaye, 1998) & 27 Items & $\begin{array}{l}\text { Reliability, Assurance, } \\
\text { Tangibles, Empathy and } \\
\text { Responsiveness }\end{array}$ & One university, UK \\
\hline $\begin{array}{l}\text { (Joseph \& Joseph, } \\
\text { 1997) }\end{array}$ & - & $\begin{array}{l}\text { Program, academic reputation, } \\
\text { physical aspects, career } \\
\text { opportunities, location, time and } \\
\text { other }\end{array}$ & New Zealand \\
\hline $\begin{array}{l}\text { (LeBlanc \& } \\
\text { Nguyen, 1997) }\end{array}$ & 38 Items & $\begin{array}{l}\text { Contact personnel/faculty, } \\
\text { contact personnel/ } \\
\text { administration, responsiveness, } \\
\text { reputation, curriculum, physical } \\
\text { evidence and access to facilities }\end{array}$ & $\begin{array}{l}\text { Business School, one } \\
\text { university, Canada }\end{array}$ \\
\hline
\end{tabular}


The findings of these studies suggest that the dimensions or factors of perceived service quality vary widely in the context of culture, university and even school or department. In the context of Australian higher education, the present study finds one journal article (Brown \& Mazzarol, 2009) and one conference paper (Chitty \& Soutar, 2004) that replicated and examined the ECSI model in the context of higher education. In these studies (Brown \& Mazzarol, 2009; Chitty \& Soutar, 2004), service quality has been conceptualised as humanware quality and hardware quality. While Brown and Mazzarol's (2009) study find statistically insignificant paths between humanware quality and perceived value, and hardware quality and perceived value, the Chitty and Soutar's (2004) study find positive and significant relationship between hardware quality and perceived value. These imply that the findings may differ even if the ECSI model is implemented in different institutional contexts in a country. The following section discusses integrated models in the context of higher education, in detail, where service quality plays a major role.

\subsubsection{Integrated models in higher education}

Students' satisfaction has been the centre of all integrated service quality models in the context of higher education. While service quality is a form of attitude and a longrun overall evaluation, satisfaction is a transaction specific measure (Bitner, 1990; Bolton \& Drew, 1991; Cronin et al., 2000; Cronin \& Taylor, 1992). One study viewed perceived service quality and satisfaction as an attitude, and stated that satisfaction is short-term and results from an evaluation of a specific consumption experience (Athiyaman, 1997). While perceived service quality and satisfaction may be attitudes, the marketing literature stated that these are two distinct constructs (Cronin \& Taylor, 1992; Parasuraman et al., 1988), and perceived service quality is the determinant of satisfaction (Carlson \& O'Cass, 2010; Gounaris et al., 2010). In the context of higher education, satisfaction is the result of perception of service quality.

Higher education institutions are service organisations (Hennig-Thurau, Langer, \& Hansen, 2001; Joseph \& Joseph, 1997; Sultan \& Wong, 2010a). The concept of relationship marketing is of high importance in services marketing, especially, the 
services that require high-contact and long-term contact to get an outcome. In this context, maintaining relationships with tertiary students in a higher education environment can produce long-term benefit to the university. A relational approach to higher education context has been examined in the context of higher education (Hennig-Thurau et al., 2001; Newbold, Mehta, \& Forbus, 2010). In their study, Hennig-Thurau et al. (2001) develop a student loyalty model and empirically examines the model with 1,162 former German university students. It shows that perceived quality, trust and a number of various types of commitments affect student loyalty directly.

Navarro et al. (2005) consider enrolled students' perception of the elements that determined their satisfaction and analysed the extent of relationships between student satisfaction and loyalty. This study has several limitations. First, the core construct, satisfaction, consists of one item only. The existing literature argues that multi-item measures are typically much better than single item measure (Churchill, 1979; Churchill \& Surprenant, 1982; Nunnally, 1978). Second, the exogenous variable, infrastructure, consists of one item only. Third, the model establishes a spurious relationship and shows that one of the dimensions of course organisation and development, 'course administration', affects one of the two items of loyalty: 'I will return to participate in the course'. Navarro et al.'s (2005) study, then, all of a sudden makes a path relation between a dimension and an item without explaining any theoretical background about the relationship. Therefore, these limitations demand for further empirical evidences.

As student loyalty has become an important strategic theme for universities (Helgesen \& Nesset, 2007; Hennig-Thurau et al., 2001; Navarro et al., 2005) to determine their future strategies, the marketing literature is currently examining students' loyalty in various aspects. For example, Helgesen and Nesset's (2007) study addresses some of the limitations of Navarro et al.'s (2005) study. Helgesen and Nesset (2007) state that satisfaction and reputation are affected by a number of determinants, namely service quality, information, social aspects, facilities and commitment; and that satisfaction and reputation affect students' loyalty. Helgesen and Nesset's (2007) study empirically examines the conceptual model taking undergraduate students of a 
Norwegian university as sample units. The findings suggest that none of these determinants affect reputation. The findings also show that social aspects and commitment are not statistically significant when affecting satisfaction; and satisfaction and reputation affect student loyalty and these are statistically significant. However, there are some limitations of this study. First, the exogenous variable, commitment, is a single item construct. Second, the Cronbach Alpha coefficients for a number of constructs are low, for example, information (0.67), Social (0.57), facilities (0.67), commitment (n/a), reputation (0.61). Despite these limitations, the study contributes in that it shows the role of institutional reputation between students' satisfaction and students' loyalty.

Another recent study (Rojas-Me'ndez et al., 2009) examines the determinants of student loyalty in higher education from the perspective of relationship approach in the context of a Latin American university. Particularly, this study attempts to explain long-term student loyalty by examining key factors and shows the straight line process of student loyalty. The straight line process of student loyalty shows that service quality affects satisfaction; satisfaction affects trust; trust affects commitment; and commitment affects loyalty. Thus, the important critique of this study is that it conceptualises service quality as people-based and includes service quality indicators or instruments that require human interaction. There are a number of physical facilities that play a major role in measuring service quality of a university; for example, library facilities, access to internet, classroom facilities and the like. This study ignores the physical facilities as measures of service quality of a university. The other important critique of this study is that loyalty may not only take place in a straight line form, and this is evident in a number of studies. Consumers' loyalty or behavioural intention may stream directly from their cognition. For example, the current literature finds that satisfaction affects loyalty (Cassel \& Eklöf, 2001; Fornell, 1992; Fornell et al., 1996) and service quality also affects behavioural intention (Cronin et al., 2000).

Studies examining the ECSI model in the context of higher education domain do not find statistically significant causal relationships among some of the latent variables of the ECSI model (see, for example, Brown \& Mazzarol, 2009; Chitty \& Soutar, 2004; 
Martensen et al., 2000). For example, the ECSI model has been empirically examined in the context of an Australian university where undergraduate students of two marketing classes are surveyed. This paper finds that soft side of service quality (people-based and process-based) has statistically insignificant impact on value and that satisfaction does not impact significantly on loyalty (Chitty \& Soutar, 2004). However, Chitty and Soutar's (2004) study finds that the image of the university plays a greater role on perceived value, satisfaction and loyalty. Therefore, one study suggests that tertiary education is different from other commercial services as the prior studies in commercial service sectors find significant relationships among the latent variables of the ECSI model (Chitty \& Soutar, 2004). This, in turn, implies that higher education services marketing needs an alternative model.

The present literature has replicated and examined the ECSI model to assess student satisfaction and loyalty. For example, Alves and Raposo (2007) examine the ECSI model in the context of Portuguese state universities. Like Martensen et al. (2000), Alves and Raposo (2007) also find that expectation has negative impact on satisfaction. Studies find that past experience helps in forming service expectations (see, for example, Devlin et al., 2002; Zeithaml et al., 1993). However, inexperience of service encounter or unrealistic expectations may results to fuzzy prediction of service quality standards, and hence may affect satisfaction.

The ECSI model has a loyalty construct, which may be appropriate for commercial services. However, this may not be appropriate for higher education sector. While the extant literatures conceptualise word-of-mouth as part of customer loyalty (for example, Zeithaml et al., 1996), Alves and Raposo (2007) conceptualised word-ofmouth and loyalty as separate constructs and show that loyalty affects word-ofmouth. While the extant literatures show that perceived value (benefit versus cost) plays a major role for commercial services (Cronin et al., 2000) and in the ECSI model (Cassel \& Eklöf, 2001), some studies do not find perceived value as an important part in the context of higher education especially in terms of relationship between service quality and value (Brown \& Mazzarol, 2009; Chitty \& Soutar, 2004). 
While the ECSI model assesses the level of customer satisfaction of industrial and commercial service sectors at the national level, implementing ECSI model in the context of higher education needs proper attention. This occurs because students' satisfaction and trust are developed over the years of university-student relationships that affect their behavioural intention. This may have an effect on increased enrolment. However, none of aforesaid studies, including the ECSI model itself, is able to explain what factors have prima facie merit to form service quality; and how service quality helps achieving students' trust, improving brand's performance and getting favourable behavioural intention.

In summary, the dimensional aspects of service quality measure in the context of higher education vary by type of institutions, schools/departments, cultures and countries. It has also been evident that the findings of the ECSI model in the context of higher education also varied widely, and that the current studies (Chitty \& Soutar, 2004; Gallifa \& Batalle, 2010; Sultan \& Wong, 2010a, 2010b) suggested a need of a separate model in the context of higher education. Thus, there is a research thrust to further explore the nature and perspective of service quality, and its consequences in the context of higher education. The following section specifically addresses the research gaps.

\subsection{The research gap}

The students are unaware about the specialised service aspects of higher education mainly due to their absence of experience with regard to a particular university. It is essential to know what affects their quality evaluation prior to get enrolled in a program/course and how they form service quality. In the context of higher education, no prior study has focused on antecedents, dimensions and consequences of service quality. This possesses a major research gap in higher education service quality research.

The role of trust in the context of higher education possesses another important research gap. Trust is an important issue, especially, in the context of higher education 
as it is a precursor of having favourable behavioural intention. Trust helps to retain current students and attract new students. It is an important issue that generates steady cash flows. Trust in a brand increases its potential in the market. Thus, it affects brand's performance. It is particularly significant in the context of higher education as students build cumulative effects of trust over the years with their teachers, staff, institution, and with the brand itself. The role of trust in marketing literature is confounding in that whether trust is an antecedent or consequence of satisfaction (see, for example, Chiou et al., 2002; Delgado-Ballester \& Munuera-Aleman, 2001; Horppu et al., 2008; Lau \& Lee, 2000; Zboja \& Voorkees, 2006). In the context of higher education, the role of trust between service quality, satisfaction and brand performance is still unexplored.

Finally, it has also emerged from the review of the current literature that there is no study in the context of higher education where students' perceptions of brand performance with regard to their university is assessed, and modelled in terms of the consequences of service quality, and as a direct effect of satisfaction and trust. Because consumers hold the sole authority to evaluate a brand, it appears from the review of literature that there is no study that measure brand performance from the perspective of consumers. The extant literatures do not answer whether students' satisfaction and trust affect brand performance, and whether brand performance affects behavioural intention in the context of higher education. Thus, these pose research gaps, as well.

In conclusion, there is a need to empirically examine these issues, and develop an integrated model in the context of higher education. This study is designed to contribute to filling these research gaps (see Figure 1), first, by exploring the new constructs and their respective measuring instruments as the antecedents of service quality. Second, by exploring and developing service attributes, and categorising these as the dimensions of service quality. Third, by exploring and identifying the major consequences of service quality in a higher education context. In these three steps, this study depends on focus group discussions and conceptualisation from the review of the services quality literature. Finally, the proposed conceptual model will be tested and reported. 
Figure 1: The research gaps

\section{Perspective: Higher Education}

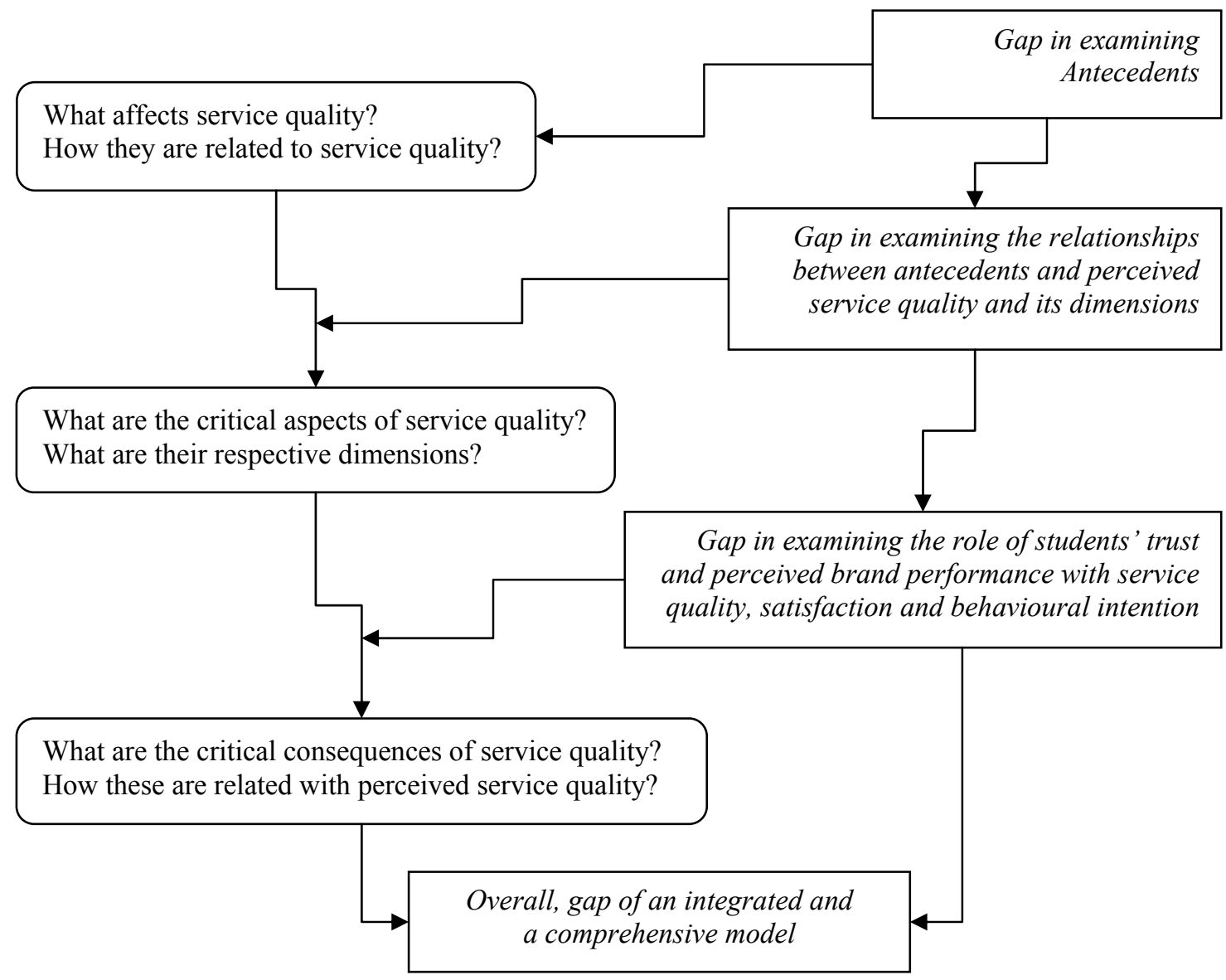




\subsection{Chapter summary}

This chapter has covered five major areas related to the existing literature on service quality. First, this chapter has discussed the theoretical evolution of satisfaction, the development of satisfaction paradigm and relevant measures of service quality derived from satisfaction paradigm. Oliver's (1980) expectation-disconfirmation paradigm has been found to be one of the important paradigmatic developments of satisfaction. However, it has been criticised widely. The service quality measure, SERVQUAL, conceptualised based on the EDP approach, has also been criticised for similar reasons. The extant literatures show the major distinction between satisfaction and service quality and state that while satisfaction is a transaction-specific measure, service quality is a form of attitude and a long-run overall evaluation (Bitner, 1990; Bolton \& Drew, 1991; Cronin \& Taylor, 1992; Parasuraman et al., 1988). A number of researchers have also placed arguments for perception-only measure to determine satisfaction and perceived quality (Churchill \& Surprenant, 1982; Cronin \& Taylor, 1992, 1994; Grönroos, 1993; Halstead et al., 1994; Jayanti \& Jackson, 1991) as it explains more of the variances compared to expectation-minus-performance measure in dependent constructs (Cronin et al., 2000; Parasuraman et al., 1994; Zeithaml et al., 1996).

Second, this chapter addresses the approaches to study service quality, dimensional approach and antecedent approach. Relevant literature and critique of these studies are discussed in this section. While the dimensional approach focuses on the critical service attributes and their categorisation, the antecedent approach focuses on what affects service quality, how consumers view service quality as a whole and how this view contributes to evaluate service quality and predict their behaviour.

Third, this chapter discusses the literature that is relevant to the development of an integrated model, where service quality has been a major part. This section of the chapter identifies relevant issues and constructs, and their interrelationships. The critiques of the literature are also discussed in this section. 
Fourth, this section of the chapter discusses the empirical studies on service quality and its modelling in the context of higher education. Although there are some empirical evidence that the ECSI model has been empirically examined in the context of higher education, the review of the current literature reveal that none of those studies examining the ECSI model found positive and significant relationships among all of the constructs. In addition, none of those studies including the ECSI model itself consider trust, perceived brand performance and behavioural intention in their respective studies.

Fifth, following the literature review, this chapter then identifies and discusses the research gaps and produces a diagram for a better understanding. The research thrusts are related to exploring the nature and perspective of service quality, and its consequences in the context of higher education. In the next chapter, theoretical model and construct development process are discussed, where the gaps are tied with relevant hypotheses. 


\section{Chapter 3: The Research Model}

\subsection{Introduction}

This chapter discusses the research model including the discussion of focus group findings, the latent variables and the measurement variables. Followed by introduction, section 3.2 of this chapter discusses an overview of the research model. Section 3.3 defines each of the constructs (latent variables), namely, information (In), past experience (PE), service quality (SQ), satisfaction (S), trust $(\mathrm{T})$, brand performance (BP) and behavioural intention (BI). This chapter, then, discusses the measurement variables relevant to respective constructs. Section 3.4 discusses the research model in detail and includes the focus group findings, and shows the hypothesised relationships among the constructs. This section also includes the theoretical underpinnings of the research to justify the hypothesised relationships to be tested. Section 3.5 discusses the key features of the research model. Finally, section 3.6 discusses chapter summary.

\subsection{The research model: an overview}

This research investigates the antecedents and consequences of service quality in a higher education context. Research shows that expectation is an antecedent to perceived performance, where perception of performance and perception of service quality are considered as two separate constructs (Spreng \& Mackoy, 1996). The extant literatures argue that perception itself carries expectation (Grönroos, 1993), and that repeating an expectation measure is misleading and creates serious discriminant validity shortcomings (Yuksel \& Yuksel, 2001). Expectation as an antecedent to service quality and as a measure of service quality has been seriously criticised by the current studies (Brady \& Cronin, 2001; Brady et al., 2002; Cronin \& Taylor, 1992, 1994; Dabholkar et al., 2000; Grönroos, 1993; Yuksel \& Yuksel, 2001). The other antecedents of service quality reported in the extant studies (Dabholkar et al., 2000; Gounaris et al., 2003) are based on commercial service sectors. Section 2.3.2 discussed some of the limitations of these studies. 
The present studies have also investigated service quality and its effects on a number of latent variables including value, satisfaction, trust, commitment and loyalty in the context of higher education. Some of these studies (for example, Alves \& Raposo, 2007; Brown \& Mazzarol, 2009) are based on the ECSI model. While other studies (for example, Helgesen \& Nesset, 2007; Hennig-Thurau et al., 2001; Navarro et al., 2005; Rojas-Me'ndez et al., 2009) have empirically examined the relationships among a number of constructs from relationship marketing perspectives. Section 2.4 discussed these along with their critiques.

These discussions suggest that there is no comprehensive model explaining the antecedents and dimensional perspectives of service quality, and its effects on longterm consequences, especially, in the context of higher education. The antecedent perspective of studying service quality is important as it helps to gain insights about the issues that affect and form customers' perception of service quality. As this thesis is based on a performance-only concept, the ECSI model is an appropriate model in this context as the point of departure. Although the ECSI model has been empirically examined in the context of higher education, the review of the extant studies (discussed in chapter 2) demonstrates that the relationships among a number of constructs possess limitations, which call for a further examination.

To begin empirical phase pertaining to antecedents and consequences of service quality for this research, it starts with focus group discussions. The focus groups are important to generate relevant themes concerning antecedents and consequences of service quality and its key attributes. As commercial enterprises and the higher education sector are two different service sectors, students' focus group discussions were deemed appropriate to generate relevant themes, their interrelationships and to advance the ECSI model in the context of a higher education. Qualitative research (in this case, the focus group discussions) in marketing is of high importance as the theory generation is more often the outcome of a conceptual and qualitative process, whereas theory testing is more relevant to quantitative process (for example, hypothesis testing) (Gummesson, 2005). 
The findings of focus group discussions reveal that service quality has two antecedents, information and past experience, and that the antecedents are quite different to service quality aspects. Service quality aspects are relevant to quality attributes of the university. With regard to the long-term consequences of service quality, the focus group findings show several key themes. There are satisfaction, trust, brand performance and behavioural intention.

Information is particularly important as an antecedent to perceive service quality as students get information about quality aspects from a number of marketing communication sources. They tend to consider these during service encounter. Embedded in information are explicit and implicit promises. Students are very serious, and evaluate these promised issues cognitively when they encounter the specific service attributes.

The findings also reveal that past experience is also a vital issue to form and evaluate service quality. Customers' past experience encountering same service, similar service or some service provide a basis for evaluating a potential service. In the context of higher education, past experience of high school and/or attending a different university provides a basis for evaluating service quality of a potential university. Students' recent experience with staff of the university may also provide a basis for forming service quality perception of a potential university.

Student satisfaction with their courses is an important issue both for academic and administrative purposes. As universities are contending for an increased number of paid students and improved quality programs, students' satisfaction is a critical issue to measure the extent of their satisfaction with regard to academic programs and administrative supports. Thus, students' satisfaction mediates between service quality, and trust, brand performance and behavioural intention in this thesis. Students' satisfaction directly affects students' trust with regard to future performance of educational services. Students' satisfaction also directly affects the brand of the University in terms of its performance, and behavioural intention in terms of increased enrolments and retention of existing students. Therefore, students' satisfaction has been considered as one of the core issues in the research model. 
The inclusion of student's trust and their perception of brand performance in terms of their university are also particularly relevant for a University. Students build cumulative effects of trust over the years with their teachers, staff, institution, and with the brand itself. The trust of students depends on students' experiences with the academic and administrative staffs, and their satisfaction with service performance. The existing literature labelled trust as the central issue of any long-term relationship (Delgado-Ballester \& Munuera-Aleman, 2001; Morgan \& Hunt, 1994). Therefore, the lack of building trust in students may affect the institution achieving long-term goals.

While the concept of trust is relevant to building relationships between students and the university, the concept of brand performance is relevant to the relational outcome of students' satisfaction and students' trust. Students are the key stakeholder in the higher education domain. Thus, their favourable evaluation of the UniBrand, as measured by brand performance, affects their behavioural intention favourable to the university. Figure 2 shows the conceptual model.

Figure 2: The conceptual model

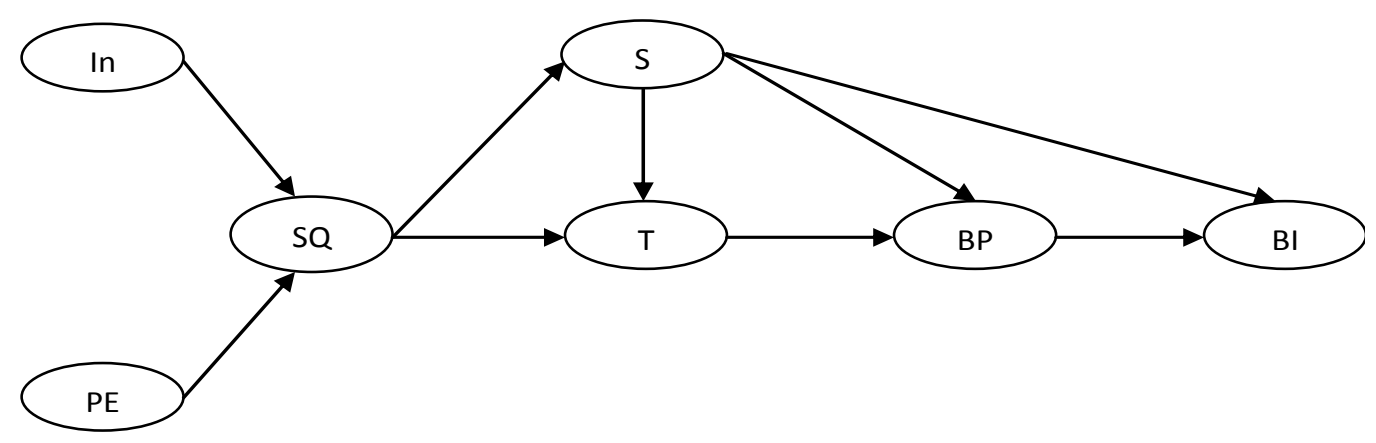

In=Information, $\mathrm{PE}=$ Past Experience, $\mathrm{SQ}=$ Perceived Service Quality, $\mathrm{S}=$ Satisfaction, $\mathrm{T}=$ Trust, $\mathrm{BP}=\mathrm{Brand}$ Performance, $\mathrm{BI}=$ Behavioural Intention. 


\subsection{Construct development}

This section discusses the definitions of constructs (latent variables). The development of measurement variables for each of the constructs are also discussed in this section.

\subsubsection{Information}

Information is defined as explicit and implicit messages that students receive directly and indirectly from the Central Queensland University (CQUniversity) before enrolment. As there is no study showing the effects of information on service quality, this study develops instruments based on focus group findings. The focus group findings reveal that students consider information as a prime source of forming service quality about a university prior to enrolment. Information plays a critical role to inform students about the key attributes of the University. In turn, this may help students selecting a particular university. The focus group findings (discussed in section 3.4.1) also reveal that students consider promise and information communicated through marketing tools and its genuineness, when forming and evaluating service quality in the context of a higher education. Thus, the construct and its measurement variables are as follows:

Table 2: Latent variable - information

\begin{tabular}{ll}
\hline Measurement variables & Adapted from \\
\hline Information provided by this University makes promises about their quality & $\begin{array}{l}\text { Focus Group } \\
\text { Discussion }\end{array}$ \\
\hline Word-of-mouth information strengthens my understanding of this University & $\begin{array}{l}\text { Focus Group } \\
\text { Discussion }\end{array}$ \\
\hline I used word-of-mouth information prior to enrolment & $\begin{array}{l}\text { Focus Group } \\
\text { Discussion }\end{array}$ \\
\hline Advertisements about this University are a good source of information & $\begin{array}{l}\text { Focus Group } \\
\text { Discussion }\end{array}$ \\
\hline Overall, information provided by this University helps me find service attributes & $\begin{array}{l}\text { Focus Group } \\
\text { Discussion }\end{array}$ \\
\hline
\end{tabular}




\subsubsection{Past experience}

In the extant literature, past experience was defined as customers' experience with the service organisation and service personnel (Devlin et al., 2002), and previous exposure to the firm, to similar firms in the same industry or to any service firms (Zeithaml et al., 1993). While Zeithaml et al.'s (1993) study is a conceptual study and provides no indication of instruments to measure past experience, Devlin et al.'s (2002) study shows four instruments to measure past experience in terms of banking services. Of these, three instruments are particularly relevant to banking services, and thus only one item is adapted for measuring past experience for this study. In the context of CQUniversity, the focus group findings (discussed in section 3.4.2) reveal that past experience refers to students' previous educational experience before enrolment, previous experience of service encounter, their interaction and relationships with staff and/or the university prior to enrolment, and subsequent treatment provided by the CQUniversity. Therefore, five research instruments are developed based on focus group findings, and one instrument is adapted from Devlin et al.'s (2002) study. The construct and its measurement variables are as follows:

Table 3: Latent variable - past experience

\begin{tabular}{ll}
\hline Measurement variables & Adapted from \\
\hline Overall, my experience with this University is good & $\begin{array}{l}\text { (Devlin et al., } \\
\text { 2002) }\end{array}$ \\
\hline $\begin{array}{l}\text { My previous study background helps me to predict the service quality of this } \\
\text { University }\end{array}$ & $\begin{array}{l}\text { Focus Group } \\
\text { Discussion }\end{array}$ \\
\hline $\begin{array}{l}\text { Before enrolling, I had a good relationship with this University } \\
\text { This University has maintained a good relationship with me }\end{array}$ & $\begin{array}{l}\text { Focus Group } \\
\text { Discussion }\end{array}$ \\
\hline $\begin{array}{l}\text { Before enrolment, I was impressed when I interacted with staff of this } \\
\text { University }\end{array}$ & $\begin{array}{l}\text { Focus Group } \\
\text { Discussion }\end{array}$ \\
\hline $\begin{array}{l}\text { Overall, my past educational experience helps to assess performance of this } \\
\text { University }\end{array}$ & $\begin{array}{l}\text { Focus Group } \\
\text { Discussion }\end{array}$ \\
\hline
\end{tabular}




\subsubsection{Service quality}

It has been accepted in the current literature that the perception-only measure of service quality is an effective measure for the purpose of explaining variance in dependent constructs (Cronin et al., 2000; Parasuraman et al., 1994; Zeithaml et al., 1996). Thus, service quality is defined as the performance evaluation of the service attributes of the CQUniversity from students' perspectives during service encounter. Service quality assessment is students' judgments of service attributes. The following quotes of focus group discussions are relevant to service quality assessment.

"...quality relates to certain attributes of a product which exceeds certain perceived standards or set standard. If it exceeds set standards, it's of quality and if it's below set standards, it's below quality" (R16).

"I consider my recent experience and present performance to assess quality" (R7).

"I think we add-up the issues like recent experience, present performance and our interests in a subconscious manner..." (R12)

"Quality is a relative performance and it is result oriented to me" (R15).

"When it comes to quality of service it's obviously a bit difficult if not impossible for anyone who assesses service actually before he experiences. Therefore, three issues that would play, firstly, what is it that I want and what promises the services provider has put forward. Secondly, of course whether the service is able to actually meet the promises that are made before customers. Thirdly, the consumption experience, which is itself an important one. I think these three issues would be the core of evaluating service quality" (R17). 
These quotations suggest that service quality assessment is the students' judgments of service attributes during service encounter. It is a cognitive process, meaning that service quality assessment is a psychological result of perception, learning, reasoning and understanding of the service attributes. Further, the focus groups were asked to discuss the critical quality aspects of services of their university in order to fully comprehend the nature of service quality. The following are the quotes of focus group discussions.

"I think the most important is the quality of lecturers and how entertaining they are. The lecture should not be boring. After lecture availability is also important" (R2).

"To me the delivery of lecture should be good and lecturers to be interactive, so that at the end I can understand that I have learnt something" (R4).

"...they should have research expertise and intellectual capacity to conduct research and supervise the research students" (R14).

“...they should be specialised in research of a particular area" (R18).

"Sometimes staff takes time to reply to our query, and send us the common web links to search instead of addressing the queries. They should know what they are doing" (R1).

“...student recruitment procedures, overall people and process of delivery are also vital as quality aspects" (R17).

"...of course the critical aspects are library facilities and then is career counselling” (R9).

"I face specific problem with transport services" (R4).

"We do not have a good dining facility here" (R5).

"The other important issues are whether the university holds workshops and invites renowned people to deliver speeches" (R2). “...accessibilities to entertainment centres and resources" (R6). 
The above quotes identify several critical attributes of service quality in terms of a higher education institute. These includes quality and intellectual capability of lecturers, interactive lecture, entertaining lecture, after lecture availability, research expertise of the lecturer, supervision capacity of the lecturer, academic workshops, lectures/seminars of renowned persons, prompt reply to query, admission procedures, library facilities, career counselling, transport services, dining facilities, entertainment centres and access to resources.

A number of service quality attributes are developed in the context of higher education. Of these the HEdPERF (Abdullah, 2005, 2006a, 2006b, 2006c) and the PHEd (Sultan \& Wong, 2010a) are comprehensive as these measures have 41 items and 67 items, respectively. It is found that both HEdPERF and PHEd models capture the core and specific issues of measuring service quality in the context of higher education of Malaysia and Japan, respectively. The review of literature has also found seven generic items in each of the scales that carry high loadings. Thus, the service quality measure of this study adapts these items.

Four items are adapted from Fornell et al.'s (1996) study. These items focus on overall evaluation of some broad aspects in the context of higher education. Since up-to-date equipment, for example, internet and computer, are a major factor in evaluating service quality, one item is adopted from Cronin and Taylor (1992). Finally, focus group findings of this study produced eleven items. The focus group items are found to represent the measure of service quality. These new items are specifically emphasised by the focus group members. The following table shows the adapted measurement variables for service quality and their sources of adaptation.

Table 4: Latent variable—service quality

\begin{tabular}{ll}
\hline Measurement variables & Adapted from \\
\hline I find that academics at this University are knowledgeable & (Abdullah, 2006c) \\
\hline Lecturers show sincere interest in solving my academic problems & (Abdullah, 2006c) \\
\hline Lecturers provide feedback about my progress & (Abdullah, 2006c) \\
\hline I receive adequate time for consultation with lecturers & (Abdullah, 2006c) \\
\hline
\end{tabular}




\begin{tabular}{|c|c|}
\hline Measurement variables & Adapted from \\
\hline I find that the administrative staff is prompt to provide service & (Abdullah, 2006c) \\
\hline The location of the University is ideal & (Abdullah, 2006c) \\
\hline I find that the classroom facilities are adequate & (Abdullah, 2006c) \\
\hline $\begin{array}{l}\text { My overall evaluation of quality with regard to study } \\
\text { programs/courses of this University is good }\end{array}$ & (Fornell et al., 1996) \\
\hline $\begin{array}{l}\text { My overall evaluation of quality with regard to support functions } \\
\text { of this University is good }\end{array}$ & (Fornell et al., 1996) \\
\hline $\begin{array}{l}\text { My overall evaluation of the service quality provided by the } \\
\text { teaching staff of this University is good }\end{array}$ & (Fornell et al., 1996) \\
\hline $\begin{array}{l}\text { My overall evaluation of the service quality provided by the } \\
\text { administrative staff of this University is good }\end{array}$ & (Fornell et al., 1996) \\
\hline I find that this University has up-to-date equipment & (Cronin \& Taylor, 1992) \\
\hline My academic performance is recorded correctly & (Sultan \& Wong, 2010a) \\
\hline The course designed by the academic staff is effective & (Sultan \& Wong, 2010a) \\
\hline I find that the administrative staff is courteous & (Sultan \& Wong, 2010a) \\
\hline I find that the administrative staff keeps accurate records & (Sultan \& Wong, 2010a) \\
\hline The overall environment of this University is friendly & (Sultan \& Wong, 2010a) \\
\hline I find that this University has good infrastructure & (Sultan \& Wong, 2010a) \\
\hline I find that the scenic beauty of this University is excellent & (Sultan \& Wong, 2010a) \\
\hline The provided study programs/course meet my requirements & Focus Group Discussion \\
\hline The teaching staff meet my requirements & Focus Group Discussion \\
\hline The administrative staff meet my requirements & Focus Group Discussion \\
\hline I find that lecturers are skilled in teaching & Focus Group Discussion \\
\hline The academic backgrounds of the lecturers are excellent & Focus Group Discussion \\
\hline The admission department of this University is very helpful & Focus Group Discussion \\
\hline I find that the University's career counselling service is very helpful & Focus Group Discussion \\
\hline I find that the administrative staff is skilled & Focus Group Discussion \\
\hline I find that classroom learning is very practical & Focus Group Discussion \\
\hline I find that the recreational facilities of this University are adequate & Focus Group Discussion \\
\hline I find that the library facilities are adequate & Focus Group Discussion \\
\hline
\end{tabular}




\subsubsection{Satisfaction}

Satisfaction is defined as a psychological state of happiness of the students as a result of performance evaluation of service attributes. Thus, evaluative instruments are developed to measure the satisfaction scale. The item, "it has been a good decision to select this University", measuring satisfaction has been used as an evaluative item in service quality studies (Cronin et al., 2000; Patterson \& Spreng, 1997). Thus, this item has been adapted.

The item, "the University fulfils my needs" has been adapted from Cronin et al.'s (2000) study. The other five evaluative items are generated from focus group findings. These evaluative items measure satisfaction in terms of: overall ability to fulfil needs, comparing an alternate institution, quality and price, overall service performance and overall goodness of the University. These items are incorporated. The construct and its measurement variables are as follows:

Table 5: Latent variable — satisfaction

\begin{tabular}{ll}
\hline Measurement variables & Adapted from \\
\hline It has been a good decision to select this University & $\begin{array}{l}\text { (Cronin et al., 2000; } \\
\text { Patterson \& Spreng, 1997) }\end{array}$ \\
\hline Overall, this University fulfils my needs & (Cronin et al., 2000) \\
\hline Overall, I am satisfied with this University & Focus Group Discussion \\
\hline $\begin{array}{l}\text { Overall, this University provides satisfaction compared to an alternate } \\
\text { higher education institution }\end{array}$ & Focus Group Discussion \\
\hline Overall, I am satisfied with the quality relative to price & Focus Group Discussion \\
\hline Overall, I am satisfied with the service performance & Focus Group Discussion \\
\hline Overall, it is a good University & Focus Group Discussion \\
\hline
\end{tabular}




\subsubsection{Trust}

Trust is a belief and confidence that the service performance and subsequent satisfaction will be identical in future. In the context of higher education, students' trust refers to students' confidence in the university's integrity and reliable service performance (Rojas-Me'ndez et al., 2009). The review of the extant literature suggested mixed results in terms of operationalisation of the trust construct. For example, Chaudhuri \& Holbrook (2001) operationalise brand trust using four items. Of these, three items are found to have relevant to measure trust construct in the context of higher education. These items receive attention in the current studies, as well. For example, the item, I trust the brand ' $\mathrm{x}$ ', has been used in the study of Zboja and Voorkees (2006); the item, I can rely on brand ' $\mathrm{x}$ ', has been used in the studies of Horppu et al. (2008) and Lau and Lee (2000); and the item, brand ' $\mathrm{x}$ ' is honest with me, has been used in the studies of Delgado-Ballester and Munuera-Aleman (2005) and Horppu et al. (2008). These three items are adapted for this study. In their study, Delgado-Ballester and Munuera-Aleman (2005) introduce a trust item, brand ' $\mathrm{x}$ ' guarantees satisfaction, which has also been used in Horppu et al. (2008). This study adapts this item.

A review of Zboja and Voorkees's (2006) study reveals that three of the trust's items are negatively worded, while other three items are positively worded. Of these positively worded items two are incorporated and one is found irrelevant in the context of trust of students in terms of higher education institute. Although Sultan and Wong's (2010a) study develops a number of items to measure service quality, a close examination of these items reveal that two items are closely related to trust. These are 'feeling security' and 'getting help on request'. The item, 'feeling security' has also been used as an item of trust in Lau and Lee's (2000) study. These two items are incorporated. Another item, keeping promises, has been incorporated from RojasMe'ndez et al.'s (2009) study. The other two items, despite their high loadings in Rojas-Me'ndez et al.'s (2009) study, were deemed inappropriate because of the complex nature of the items' wordings. Finally, four items are derived from focus group findings. The following table shows the measurement variables for the construct, trust. 
Table 6: Latent variable_-trust

\begin{tabular}{ll}
\hline Measurement variables & Adapted from \\
\hline I trust this University & $\begin{array}{l}\text { (Chaudhuri \& Holbrook, 2001; Zboja \& } \\
\text { Voorkees, 2006) }\end{array}$ \\
\hline This University provides reliable quality of services & $\begin{array}{l}\text { (Chaudhuri \& Holbrook, 2001; Horppu et } \\
\text { al., 2008; Lau \& Lee, 2000) }\end{array}$ \\
\hline Overall, this University is honest with me & $\begin{array}{l}\text { (Chaudhuri \& Holbrook, 2001; Delgado- } \\
\text { Ballester \& Munuera-Aleman, 2005; }\end{array}$ \\
\hline This University guarantees satisfaction & $\begin{array}{l}\text { (Delgado-Ballester \& Munuera-Aleman, } \\
\text { 2005; Horppu et al., 2008) }\end{array}$ \\
\hline I feel secure at this University & (Lau \& Lee, 2000; Sultan \& Wong, 2010a) \\
\hline I find that this University keeps promises & (Rojas-Me'ndez et al., 2009) \\
\hline I always get help from staff, if I ask for it & (Sultan \& Wong, 2010a) \\
\hline I can depend on this University & (Zboja \& Voorkees, 2006) \\
\hline The University staff are trustworthy & Focus Group Discussion \\
\hline This University guarantees best value & Focus Group Discussion \\
\hline I am confident that I will get a good job after graduation & Focus Group Discussion \\
\hline My emotional relationship with this University is strong & Focus Group Discussion \\
\hline
\end{tabular}

\subsubsection{Brand performance}

Brand performance refers to the performance of the CQUniversity as a brand (UniBrand) in terms of students' perception with regard to their association, understanding and evaluation of the UniBrand in the market. Harris and de Chernatony's (2001) study, perhaps, one of the pioneering studies that advocate consumer-based brand performance measure. However, Harris and de Chernatony's (2001) conceptual study does not state the items for measuring consumer-based brand performance scale. While developing brand performance measure from managers' perception, Wong and Merrilees (2007a) develop four items construct based on several studies (Chaudhuri, 2002; Chaudhuri \& Holbrook, 2001; Reid, 2002). These 
items are relevant to brand awareness, brand reputation, satisfaction in terms of brand marketing and brand loyalty.

Brand awareness has been viewed as whether a brand comes to customer minds when customers think about purchasing a particular product category (Wong \& Merrilees, 2007a). Since the present study attempts to develop students' perception of brand performance scale in terms of their university and that these students have already purchased (i.e. enrolled in a study program) this particular type of service, the present study avoids an 'awareness' item. The present study also avoids the satisfaction and loyalty items to develop a brand performance measure. This is because the conceptual model of the present thesis has a satisfaction construct and a behavioural intention construct. Placing satisfaction and loyalty items in brand performance construct may create tautology. The other reason to avoid including brand loyalty item is that the focus group findings state that students may not be loyal to a university. Thus, the brand performance construct of this study adapts one item from Wong and Merrilees's (2007a) study, and develops seven items from focus group findings.

The focus groups' participants were asked what they understand about the UniBrand. The following are the quotes of focus group discussions.

“...the University's standing in terms of popularity and by its employment rates" (R4).

'Employers' choice of the graduates, students' perception of the degree that the degree is valuable, employers' understanding that the university provide solid foundations, determining how successful the uni is in providing its students with job facilities" (R9).

“...students' employment rates; noble prize; previous students of the university contributing to society as a political leader, government officer or highly recognized person; whether students are proud to be a student of the university and salary range of the graduates" (R11). 
These responses are useful to conceptualise brand performance measure in the context of a university. The focus group findings state that students perceive brand performance (of a university) as their success in employment rates and their perceived salary range (after graduation) as received from the employer, employers' preference of them, students' pride, worthiness of the degree in the market, reputation of the university and the university's international standing in terms of its reliable performance. Thus, the construct and its measurement variables are as follows:

Table 7: Latent variable_-brand performance

\begin{tabular}{ll}
\hline Measurement variables & Adapted from \\
\hline I found that this University has a good reputation & (Wong \& Merrilees, 2007a) \\
\hline I am proud to be a student of this University & Focus Group Discussion \\
\hline A degree from this University is worthy & Focus Group Discussion \\
\hline This university performs well & Focus Group Discussion \\
\hline CQUniversity as a brand is reliable & Focus Group Discussion \\
\hline The graduates of this University receive a good salary & Focus Group Discussion \\
\hline A degree from this University enhances employability & Focus Group Discussion \\
\hline Employers prefer graduates from this University & Focus Group Discussion
\end{tabular}

\subsubsection{Behavioural intention}

In this study, behavioural intention is defined as the students' readiness to behave favourably towards the University. The item, recommending friends/others, is found to be an effective item measuring behavioural intention in the existing studies (Cronin et al., 2000; Hennig-Thurau et al., 2001; Zeithaml et al., 1996). The behavioural intention scale of the present study examines this item. Another item, paying more, is found in the Zeithaml et al.'s (1996) study and has been incorporated. The next three items of the following table have been used in the extant studies (Hennig-Thurau et al., 2001; Martensen et al., 2000) and these are incorporated to develop behavioural 
intention scale. Finally, the last two items of the following table are derived from focus group findings. The following table shows the measurement variables for the construct, behavioural intention.

Table 8: Latent variable-behavioural intention

\begin{tabular}{|c|c|}
\hline Measurement variables & Adapted from \\
\hline I will recommend others to study at this University & $\begin{array}{l}\text { (Cronin et al., 2000; Hennig-Thurau } \\
\text { et al., 2001; Zeithaml et al., 1996) }\end{array}$ \\
\hline I would pay more to get a degree from this university & (Zeithaml et al., 1996) \\
\hline If I had to choose today, I would select this University & $\begin{array}{l}\text { (Hennig-Thurau et al., 2001; } \\
\text { Martensen et al., 2000) }\end{array}$ \\
\hline $\begin{array}{l}\text { I will recommend the study programs of this University to } \\
\text { others }\end{array}$ & $\begin{array}{l}\text { (Hennig-Thurau et al., 2001; } \\
\text { Martensen et al., 2000) }\end{array}$ \\
\hline $\begin{array}{l}\text { If I had to choose today, I would select the study } \\
\text { programs of this University }\end{array}$ & $\begin{array}{l}\text { (Hennig-Thurau et al., 2001; } \\
\text { Martensen et al., 2000) }\end{array}$ \\
\hline $\begin{array}{l}\text { I will definitely consider this University as my future } \\
\text { study destination }\end{array}$ & Focus Group Discussion \\
\hline $\begin{array}{l}\text { I will recommend this University in preference to other } \\
\text { options }\end{array}$ & Focus Group Discussion \\
\hline
\end{tabular}

In summary, this section contains the definitions of seven constructs (or latent variables) along with their measurement variables. This study has developed three new constructs along with their measurement variables, namely, information, past experience and brand performance (except one item) in the context of higher education and for empirical investigation. In addition, a number of indicators for each of the constructs in the model have been developed using the findings of focus group discussions. These constructs are service quality, satisfaction, trust and behavioural intention. The following section discusses the constructs and their interrelationships with an aim to develop hypotheses in the research model. 


\subsection{The constructs and hypotheses}

In this section, each of the constructs used in the research model is discussed. The discussion also includes relevant studies and focus group findings (demographics of the participants are in Appendix E). Then each of the discussions develops a relevant hypothesis.

\subsubsection{The relationship between information and service quality}

Information pertaining to service quality is important as it provides a basis for evaluating service quality attributes during service encounter. Studies described that formal communications from various sources, including advertisements, leaflets, and related articles in magazines and newspapers, affect the way customers interpret ambiguous evidence concerning quality (Deighton, 1984; Devlin et al., 2002; Mathews, 1994). Adequate information accelerates consumers' learning in terms of attributes of the product or service. Information alone cannot provide a complete view of the world around us. To get a complete view about a particular phenomenon, one needs to integrate his/her imagination and experience along with information (Blythe, 1997; O’Neill \& Palmer, 2003). Information helps finding critical service attributes that the organisation offers. It is also a basis of forming quality standards as it often provides evidence of past performance. Together with past evidence, information may play a vital role in forming quality perception. However, exaggerated information with gimmick promises may adversely affect quality perception during customers' service encounter.

The focus groups were asked to discuss the factors that affect quality of services in terms of their university prior to enrolment. Respondents stated that information affects the level of quality judgment. They also underlined that the information provided by the institution has to be true, want satisfying and reliable. The following are the quotes of focus groups' participants.

"If the product is new and there is no set standard, in that case, the level of quality in terms of my needs would be very much influenced 
by whatever product related promotional materials are being discharged by the supplier" (R17).

"The underlying factors affecting quality are adequate information and its genuineness" (R15).

"...delivered promise must be equal to the delivered service" (R5).

"Quality is affected, among other things, by the promise that would have been provided by the supplier" (R14).

"Quality evaluation starts from promise and information provided by the supplier" (R16).

“...I consider how the delivered service attributes are important to me.

That is the most basic is what is that I want from the service" (R6).

These findings state that information affects quality evaluation in that students evaluate stated or implied promise and provided information during or after service encounter. These findings suggest that the role of providing adequate and reliable information to the students, prior to their enrolment, can have a tremendous impact in forming the perception of service quality of a university. In short, quality is affected by reliable information. Therefore, the first hypothesis is:

H1: There is a positive relationship between information received by the students and their perception of service quality.

\subsubsection{The relationship between past experience and service quality}

Past experience of the service encounter helps customers to determine the standards of any future service performance, especially, if the service is same or similar. It provides a brief cognitive standard and helps in evaluating the standard of service quality of present and/or future service encounter. 
Trial of a product may be seen as an important part of individual's learning since it provides evidence (through experience) that affects the evaluation of product performance (Biedenbach \& Marell, 2010). When customers accumulate negative experience, they evaluate perceived quality negatively (Hoch \& Deighton, 1989). In other words, consumers' perception of service quality is influenced by the degree of prior experience (O’Neill \& Palmer, 2003). Studies demonstrate that service experience affects perceived quality (Biedenbach \& Marell, 2010), and satisfaction, feeling and brand attitude (Grace \& O'Cass, 2004) in the commercial service sectors. This occurs because experience, perceived quality and satisfaction are experiential and attitude-based norms. Since service quality is an attitude measure (Sultan \& Wong, 2010a), it is likely that customers' past experience affects perceived service quality.

In the context of higher education, students' previous educational experience, including, high school experience of the undergraduate students, students' previous experience with the course from the same or different institution(s), and their previous interactions both physical and electronic with the staff and friends affect service quality. For example, a student might have received good service quality from his/her high school in terms of academic, administrative and support services. The same student when entering in a university environment might use his/her past experience, as a standard, to evaluate service quality of the university he/she is currently attending. Students' high school experience is the foundational experience that may help them to evaluate service experience in a university environment. This happens because their past experience affects the way they standardise their quality evaluation.

The focus group findings state that students' past experience forms and affects service quality assessment. Students' recent experience of meeting or interacting with staff of a university also affects service quality judgment. Their past educational experiences with high schools and universities/institutions are major sources to determine quality standards for any present or future higher educational institutions. As a result, past experience is a determinant to form and evaluate service quality. The following are the quotes relevant to past experience and its relationship with perception of service quality. 
"... among the other factors that play a key role to form quality is past experience" (R14).

“...before coming to this university, I had only high school experience. From that point, it is hard to say. But at least it tells that we would learn some advanced stuff at the university" (R5).

"I'd say like if I had experience of attending other university, I was gonna learn quite advanced stuffs" (R4).

"I will compare my past experience, for example, the experience with my previous university and present university" (R6).

“...definitely past experience has a role to play and evaluate quality of university services" (R17).

"As a student of this university, I can't compare the services of other universities. To me it has no bad experience and it fulfils what I want" (R5).

"I've attended three different universities in Australia. Many people would agree that out of these three,... University is the prestigious. But why I didn't go back to that university? So, considering location, proximity and recent experience with staff, I'm keep going with the Central Queensland University" (R13).

These findings suggest that past experience is one of the key issues that play a vital role to form the perception of quality. Past experience is vital to form perceived quality as customers recall and compare their past experience of receiving the same service with the present one during the service encounter. They tend to compare similar types of service attributes received from various providers. This leads to positive or negative assessment of service quality attributes during service encounter. Thus, 
H2: There is a positive relationship between past experience of the students and perception of service quality.

\subsubsection{Service quality and its consequences}

A favourable perception of service quality is most desirable to any organisation. This is because it not only reflects their efficiencies and effectiveness but also it helps to retain and attract new customers. Customer satisfaction is the centre of all marketing activities, and the most powerful base that retains and attracts customers. Perhaps, customer satisfaction is the single most powerful consequence of perceived service quality. The present studies (see, for example, Alves \& Raposo, 2007; Brown \& Mazzarol, 2009; Chitty \& Soutar, 2004; Martensen et al., 2000) examining the ECSI model in the context of higher education have found a number of consequences of perceived service quality, including value, satisfaction and loyalty. Based on the findings of these studies it is hard to draw any conclusion with regard to the consequences of service quality in the context of higher education as some of these relationships are found to be negative and insignificant. To gain insights in this issue, the focus groups were asked to discuss the consequences of service quality evaluation in the context of their university in the long run. The following are the quotes of focus groups.

"...if the university provides quality services the obvious outcome is our satisfaction and the next is our understanding that the University can satisfy us in future" (R2).

"Satisfaction and brand plays a pivotal role. The employers never see whether you have HD or D. What they see is which university you have attended. So, satisfaction and brand play pivotal roles" (R11).

"If the students have very good experience they will recommend others to come and they themselves can come again for higher studies, as well” (R10). 
"I think loyalty is more related to commodity marketing but not relevant to a university. I don't actually believe that I am loyal to a university" (R8).

"...it is not necessary to be loyal to a university. For example, I may not come to do $\mathrm{PhD}$ here even if I am satisfied. Rather, if I find that lecturers moved from this university to another, I may consider that university for my future study destination. It's all about my belief of lecturers" (R13).

The focus group data uncovers several facets. First, student satisfaction is found as an important consequence of service quality. In fact, satisfaction has been found as one of the core issues relevant to the consequences of service quality. Second, 'trust of students' that the academic and administrative performances will be satisfactory in future has been found as another important consequence of service quality and satisfaction. Third, the position of the University as a Brand (UniBrand) in the market, brand performance, has been found as another consequence of service quality. Fourth, the focus group findings suggest that loyalty may not be an appropriate issue in the context of higher education; instead, behavioural intention may play a vital role. While loyalty, as perceived by the students, is related to studying further at the same university; behavioural intention, in contrast, is perceived as recommending other to come at the university and in general, their intention to come again at the university. Thus, behavioural intention is the final consequence of service quality. Therefore, the critical consequences of service quality in a higher education context are satisfaction, trust, brand performance and behavioural intention.

\subsubsection{The relationship between service quality and satisfaction}

The concept of satisfaction occupies a central position in marketing thought and practice. Satisfaction (or dissatisfaction) is not inherent in the product or service instead it is the consumer's perceptions of the attributes of the product or service (Boshoff \& Gray, 2004). The relationship between service quality and satisfaction is well documented in academic literature in the context of commercial sectors. These 
studies suggest that the critical determinant of perceived satisfaction is perceived quality (see, for example, Cronin et al., 2000; Eskildsen, Kristensen, Juhl, \& Østergaard, 2004; Fornell et al., 1996). This is because both perceived quality and satisfaction are attitude driven. While perceived quality is a long run, overall evaluation, satisfaction is the outcome of this overall evaluation.

In the context of higher education, several studies attempted to examine these relationships using the ECSI model, and find that service quality directly affects satisfaction (Alves \& Raposo, 2007) and that it also affects satisfaction through perceived value (Brown \& Mazzarol, 2009). The following are the quotes of the focus group discussions.

"If someone is not satisfied with the performance of the university, he has to finish his degree. He can't just be in the middle of no way and do nothing" (R7).

"I think for us satisfaction of a particular incidence of any aspects of this University depends on the performance of several factors, for example, quality of lecturers, counselling, staff's behaviour and the like" (R12).

"Everyone says .... and .... are big and better universities in .... comparative to this University. I have no experience with them...But to me this university fulfils my need. I have never found anything lacking. I have access to the resources that I need" (R2).

The focus group findings suggest that the students are satisfied if service attributes perform well. The existing literatures in the context of both commercial and higher education sectors also confirm that satisfaction is one of the major and direct consequences of perceived service quality. Therefore,

H3: Perception of service quality positively affects students' satisfaction in a higher education context. 


\subsubsection{The relationship between service quality and trust}

Service quality and trust have been viewed as the centre of relationship marketing (Berry, 2002). While perceived service quality is similar to the notion of perceived experience and attitudes of consumers (Sultan \& Wong, 2010a), consumers' trust is viewed as the driver of customer retention (Doney et al., 2007). Consumers' positive attitudes towards a brand lead him/her to believe that the brand is capable of providing satisfaction. Thus, trust is a belief and confidence that the service performance and subsequent satisfaction will be identical in future.

Students' trust, in the context of higher education, is found as one of the major consequences of perceived quality in the context of graduated and dropout students of four German universities (Hennig-Thurau et al., 2001). This is because perception of service performance often provides a deep understanding (belief and confidence) among students about the outcome of any future service encounter. Students may positively generalise their trust on the UniBrand based on any of the aspects of service performance that they have evaluated positively. In this respect, Delgado-Ballester and Munuera-Aleman (2001, p. 1243) states that "the process by which an individual attributes a trust image to the brand is based on his/her experience with that brand". Thus, university's integrity and reliable service performance builds students' belief and confidence which in turn determines students' trust.

The focus group findings of the present study reveal that the students' trust is one of the critical consequences of service quality evaluation. While evaluation of service quality is an experiential norm, the students' trust is an emotional norm. The students' trust determines the relationship strength between students and university staff. It is enduring relative to satisfaction. While higher education institutes are trying to increase student numbers each year, trust of enrolled students and past students may play a vital role to increase the marketability of the university's programs and the brand itself. The focus group findings support this notion. The focus groups were asked to contextualise their trust on CQUniversity. The specific quotes are as follows. 
"...if the university provides quality services the obvious outcome is our satisfaction and the next is our understanding that the University can satisfy us in future" (R3).

"...trust is whether the university keeps promises or not. Promise is of two types, implicit, for example, the pictures displayed on the website of the university, and explicit, for example, the commitment made through papers or verbal communication" (R16).

"How far they can solve any problem without difficulty" (R1).

Trust has a significant role in the higher education domain as students build cumulative effects of trust over the years with their teachers, staff and the institution. These findings reveal that students trust is rooted in the performance of the promised issues, commitments and university's overall integrity to solve academic and administrative problems that students face. Therefore,

H4: Perception of service quality affects students' trust positively in a higher education context.

\subsubsection{The relationship between satisfaction and trust}

"Satisfaction is a foundation of trust" (Rojas-Me'ndez et al., 2009, p. 25). In other words, trust is a consequential effect of satisfaction. Unless one experiences a service and satisfied with its performance, it is unlikely that one would develop trust on it. Although trust is an emotional norm, it is influenced by consumers' evaluation of any direct evaluation, for example, trial, usage and satisfaction (Delgado-Ballester \& Munuera-Aleman, 2001). It is evident in the extant studies that satisfaction is the antecedent of trust in commercial service sectors (Delgado-Ballester \& MunueraAleman, 2001; Zboja \& Voorkees, 2006). The reason for this is that the customer's satisfaction in a transaction indicates that the brand protects and takes care of the customer's interests and welfare (Delgado-Ballester \& Munuera-Aleman, 2001). Satisfaction, as a result of consumption experience (evaluation), is transaction specific, 
and it indicates the product's (or brand's) ability and consistency in the fulfilment of commercial promise.

In the context of Latin American higher education, research demonstrates that students' satisfaction affects students' trust (Rojas-Me'ndez et al., 2009). Students' cumulative satisfaction with the service attributes make him/her believe that the service attributes have consistent capacity to satisfy his/her needs in any future service encounter. While satisfaction is transaction specific, trust is a cognitive understanding and a thorough emotional belief of future service performance and subsequent satisfaction. It is more enduring than satisfaction. The following are the specific quotes in the context of CQUniversity, Australia.

"The students have trust of a university if it provides satisfaction in terms of value for money, security and integrity in fulfilling promises" (R10).

"The trust is to provide me something for which I pay the money" (R7).

The focus group findings reveal that students' satisfaction is the basis of their trust. These suggest that students perceive trust as the ability to provide satisfaction in terms of providing secure environment, ability to perform well and providing good value for money. While satisfaction is evaluative, affective and emotional judgment (Oliver \& Swan, 1989), trust is a cognitive understanding and a thorough emotional belief derived from any transactional, evaluative, affective and emotional judgment. Therefore,

H5: Perceived satisfaction affects students' trust positively in a higher education context. 


\subsubsection{The relationship between satisfaction and brand performance}

Satisfaction affects brand outcome (in terms of profitability) in the context of the hotel industry (O’Neill, Mattila, \& Xiao, 2006). This occurs because satisfaction results in achieving more sales and increased price premiums. In the context of higher education, students' perceived satisfaction results from perception of service performance and available evidence (e.g. experiential evidence of comparative satisfaction and/or performance of similar attributes between two or more institutes) affects university's brand performance (i.e. UniBrand). In this context, the UniBrand refers to an attitude measure and an overall evaluation in terms of students' relative attitude towards the brand in the market. The focus group data reveals that UniBrand plays a pivotal role in the market as one of the consequences of service quality and a direct consequence of satisfaction. The following are the specific quotes.

"Satisfaction and brand plays a pivotal role. The employers never see whether you have HD or D. What they see is which university you have attended. So, satisfaction and brand play pivotal roles" (R11).

"I think students' satisfaction play a vital role in building a brand in the market. I am more concerned about how successful the Uni is in terms of providing job opportunities and whether employers prefer the graduates of this Uni”" (R3).

Satisfaction is one of the major sources of a brand's relative performance in the market in that satisfaction results to increased market share, low switching and improved brand perception. In the context of higher education, students' satisfaction results to UniBrand's performance in that this increases, 3Rs, reputation of the brand, retention of the existing students and registration of the new students. Therefore,

H6: Perceived satisfaction affects brand performance positively in a higher education context. 


\subsubsection{The relationship between trust and brand performance}

The relationship between brand trust and brand (as an outcome variable), within commercial settings, was examined in Chaudhuri and Holbrook's (2001) study, where brand loyalty mediated between brand trust and brand performance. Customers' trust in a brand increases brand's reputation (Jøsang et al., 2007), which is a close representation of brand performance (Harris \& de Chernatony, 2001). This implies that customers' trust may have an influence on brand performance. The degree of customer' confidence (trust) in the company leads to achieve superior brand performance (Chaudhuri \& Holbrook, 2001; Hu et al., 2010). For example, the degree of consumers' trust on a brand (e.g. Toyota) compared to other available brands in the market determines the level of Toyota's reputation. While brand performance is an attitude measure, trust is a thorough emotional belief. Trust affects brand performance in the long run in that the belief of consumers, backed by their experience (performance), satisfaction and other available evidence, is extended on the brand both by the consumers and the company.

In the context of higher education, students' trust summarises their knowledge and experiences toward the UniBrand. Students' trust, backed by their experience in regard to service performance and their satisfaction, influences their attitude towards the UniBrand positively. Students develop cumulative effects of trust over the years with their academic and administrative staff and with the institution. This in turn affects their attitudes to their university (UniBrand). The following are the specific quotations:

"Everyone says .... and .... are big and better universities in .... comparative to this University....But to me this university fulfils my need. I have never found anything lacking. I have access to the resources that I need" (R2).

"...the University claims that the graduates of this University receive high pay in Australia. As a student, I believe it is true" (R5). 
Students' trust is a belief that the university keeps its promises, performs well and provides satisfaction in any future transactions. Students' perception of brand performance is important as it summarises students' insights of the standing of the UniBrand in a market. Students' trust determines the value of the programs or degree in the market. They feel proud of having an association with the UniBrand, which lead them to uphold the brand in market. Thus,

H7: Perceived trust affects brand performance positively in a higher education context.

\subsubsection{The relationship between brand performance and behavioural intention}

Behavioural intention indicates whether customers will remain with or defect from the company (Zeithaml et al., 1996). It is relevant in predicting consumers' postpurchase intentions. Chaudhuri and Holbrook (2001) find a weak relationship between loyalty (as measured by purchase loyalty and attitudinal loyalty) and brand outcomes (as measured by market share and relative price). In contrast, Selnes (1993) finds a strong relationship between brand reputation and loyalty. However, the question is - does behavioural intention/loyalty affect brand performance or vice versa? To answer this, the following example is worth mentioning. A customer has recently been posted to a remote place. He used to use brand ' $\mathrm{Y}$ ' for his regular banking services. Now, he is looking for a banking service which has ATM machines that are easily accessible throughout the country. Several brands in the banking sector are operating with ATM machines. However, the customer switchover to brand ' $\mathrm{X}$ ' because it provides easy access-plus-no fees with their ATMs located at the shopping centres and service stations throughout the country. He is quite satisfied with the serviceability of Brand X. He also finds that most of his colleagues are satisfied with the Brand X. A few days later, a new colleague joined and he recommended Brand $\mathrm{X}$ to the new colleague. In this example, we find that brand's performance in the market makes favourable behavioural intention. Customers' favourable behavioural intention affects market share and relative market price. A satisfied customer may not necessarily be loyal to a brand. This is because there might be nothing better than this brand. If a relatively 
better brand comes in the market, the customer will adopt the new brand. Therefore, the answer to the question is superior brand performance produces positive behavioural intention. The specific focus group quotations are as follows.

"If the University is good in terms of people and process, as a student I'd tell others to come to this Uni and I may come to study at this Uni" (R8).

"It's not that I have to come again and do my $\mathrm{PhD}$, right. It's something like recommending others to come to take the courses. But having said that like as I am paying money I may not be loyal to them. In fact it depends on the merits of the university" (R4).

The focus groups findings reveal that the students are particular about UniBrand's performance in terms of people and process. It is also revealed from the focus group findings that students refer a good UniBrand as the ability: to provide reliable performance; to get employment for its graduates; to attract good salaries for its graduates; and to ensure overall value in market. The findings also state that students are reluctant to be loyal, and instead they are more acclaimed to show positive behavioural intention in favour of the university. Meaning that student attitudes towards the UniBrand might play an important role to attracting new students and retaining existing students. Therefore:

H8: Perceived brand performance positively affects behavioural intention in a higher education context.

\subsubsection{The relationship between satisfaction and behavioural intention}

A satisfied customer is more willing to show positive behavioural intention, at least, by word-of-mouth recommendations, than a dissatisfied customer. A satisfied customer is highly prone to say positive words to others about the company, product or brand, and may likely to repurchase the brand or product in any future occasion without much concern. In the context of online commercial service sectors, it is 
evident that online customer satisfaction directly affects online customers' behavioural intention (Gounaris et al., 2010; Zeng et al., 2009). This is because satisfied customers generate high patronage frequency (Zeng et al., 2009). Thus, it is likely that a firm would receive favourable customer behavioural intention in the long run if the primary goal of the firm is customer satisfaction (Zeithaml et al., 1996).

In the context of CQUniversity, the focus group data reveals that students are more aligned to show positive behavioural intention instead of being loyal to the CQUniversity if they are satisfied. Once students receive their undergraduate or postgraduate degree from a university, this does not necessitates having a further or a higher qualification from the same university even if they are satisfied. A satisfied student is likely to recommend others and may undertake further study (i.e. show positive behavioural intention) in future. Thus, students' satisfaction may be an important determinant of positive behavioural intention. The following are the specific quotes of the focus group discussions.

"Loyalty is something like friendship, a kind of trust. If you do something better to me, I will do something better for you. In a university they are not giving you anything except education. That's also because we pay. So how can you put that loyalty in a university? I don't know" (R2).

"In a university setting 'loyalty' is not an important issue. I can never be loyal to a university" (R6).

"They are selling the education, aren't they? We are paying money for a service. I see the ads on TV. If I am not satisfied, I go and complain. So, in a sense we customers or clients may be" (R5).

"If the students have very good experience they will recommend others to come and they themselves can come again for higher studies, as well" (R9). 
"...it is not necessary to be loyal to a university. For example, I may not come to do PhD here even if I am satisfied. Rather, if I find that lecturers moved from this university to another, I may consider that university for my future study destination. It's all about my belief of lecturers" (R13).

The focus group findings reveal that a satisfied student shows positive behavioural intention by word-of-mouth or recommending others to study and may return at the same university for future study. However, they also clarified that they might not be loyal to a university. Therefore:

H9: Perceived satisfaction affects behavioural intention positively in a higher education context.

Figure 3 shows the overall research model. There are seven constructs and nine hypothesised positive relationships in this model. The hypotheses are for testing the causal relationships between constructs. This model shows that information and past experience are the antecedents of service quality, and satisfaction and trust are the direct consequences of service quality. The indirect consequences of service quality are brand performance and behavioural intention mediated through satisfaction and trust.

Figure 3: The overall research model

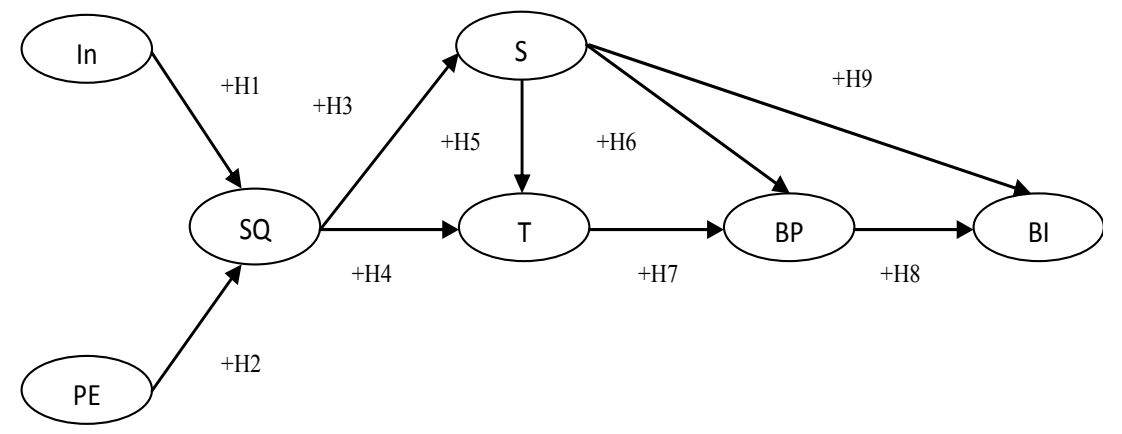




\subsection{The research model: key features}

There are several key features of the research model. First, it develops two constructs along with their measurement variables as antecedents to service quality, namely information and past experience (except one item for measuring past experience). Second, it develops a number of service quality attributes as measurement variables, and shows distinctions between antecedents and dimensional aspects of service quality in the context of a university using focus group findings. Third, it substantially improves one construct, brand performance, from focus group findings and literature review particularly in the context of university services marketing. It also improves trust, satisfaction and behavioural intention constructs in the context of a higher education. Fourth, this model examines the role of information and past experience as antecedents to service quality in the context of a higher education. Fifth, the model examines the effects of service quality and students' satisfaction on students' trust, their perception of brand performance and their readiness to behave (behavioural intention) as consequences of service quality. Sixth, it also examines the role of students' trust among perceived service quality, satisfaction and brand performance. Seventh, the model examines the role of brand performance among satisfaction, trust and behavioural intention.

The above discussions indicate that there are several critical features of this model that are distinctive in terms of theory and practice. For example, although studies (see, for example, Alves \& Raposo, 2007; Brown \& Mazzarol, 2009; Chitty \& Soutar, 2004; Martensen et al., 2000) examined the ECSI model in the higher education domain, these studies along with similar satisfaction index models have not examined the antecedents (i.e. information and past experience) of service quality and the roles of trust and brand performance in the model as consequences of service quality. These studies have not found logical relationships among some of the constructs of the ECSI model when implementing it in the context of higher education. The present model, following the findings of focus group discussions and literature review, incorporates five constructs. These are information, past experience, trust, brand performance and behavioural intention. The proposed model excludes image, 
expectation, value and loyalty constructs. These excluded constructs were found to have contributed in the ECSI model in the context of commercial service sectors. However, these constructs were found to have negative and non-significant relationships in the context of higher education. As a result, the proposed model is an alternative model for higher education services marketing.

Second, this model empirically develops and examines four constructs in the context of higher education. These constructs are information, past experience, brand performance and behavioural intention. The model also improves a number of measures including service quality, satisfaction, trust, brand performance and behavioural intention in the context of higher education. This model is an extension of the ECSI model, particularly, in the context of higher education.

Third, the national student survey is important in the decision making process for students in selecting which university they will attend (Asthana \& Biggs, 2007). Since poor retention rates have adverse funding consequences for institutions (Rowley, 2003), the recruitment and retention of students have been moved to the top of most universities' agendas due to the desire to increase the student population in line with the Government targets. Thus, recruitment, student satisfaction and retention are closely linked and student satisfaction has become an extremely important issue for universities and their management (Douglas et al., 2008). This model shows indices to measure the level/degree of service quality, student satisfaction, students' trust, UniBrand's performance and students' behavioural intention.

Finally, Australia faces a critical challenge in higher education. This challenge keeps Australia behind other countries in performance and investment in higher education (Bradley et al., 2008). The importance of a national student survey has been emphasised as one of the important recommendations in the Bradley Review of Australian Higher Education published in December, 2008. This report also focuses on regional universities of Australia in terms of government's serious concern about increased participation. It also stresses the importance of course experience as perceived by the students (Bradley et al., 2008). In addition, the current studies (Gallifa \& Batalle, 2010; Sultan \& Wong, 2010a, 2010b) also emphasise the need for 
an integrated model in the context of higher education. Addressing these issues, the model studies CQUniversity's students' perception of service quality, and its antecedents, dimensions and consequences with an aim to develop and examine an integrated model.

\subsection{Chapter summary}

This chapter discussed the development of the research model following the framework suggested by Churchill (1979). First, this chapter discussed the domain of the proposed research model. In this context, it is the ECSI model (Cassel \& Eklöf, 2001). It then discussed relevant literature and justification to develop a new model in the context of higher education. Second, the construct development process also followed the current studies and focus group findings. Third, relevant constructs and hypotheses were developed following the extant studies and focus group findings. In a nut shell, the research model attempts to explain that the CQUniversity needs to adopt a marketing perspective due to increased global competition, and that it needs a separate model in order to determine the level of delivered service quality, the level of students' satisfaction, the level of achieved trust amongst students, the level of performance of the UniBrand in the market and the extent of students' behavioural intention. 


\section{Chapter 4: The Research Method}

\subsection{Introduction}

This chapter discusses the research method employed in this research and its justification. The research method used methodological triangulation following a scientific investigation of the phenomena. This approach is discussed in section 4.2. The research process started with qualitative data gathered through focus group discussions. Details about qualitative data collection process including selection of focus group participants, conducting the interview process, data analysis process are discussed in section 4.3. The major findings of qualitative data analysis are discussed in chapter 3 . Followed by qualitative method, an online click-only survey was conducted for quantitative research process. The quantitative aspects of this research including scale development process, survey design, selection of samples, data collection process, non-response bias and data cleaning process, and data analysis process are discussed in section 4.4. Finally, section 4.5 summarises the chapter.

\subsection{The paradigmatic approach to research design}

"A paradigm is a very general conception of the nature of scientific endeavour within which a given enquiry is undertaken" (Mangan, Lalwani, \& Gardner, 2004, p. 566). Selection of an appropriate paradigm is a fundamental issue for any research design. There are two critical research paradigms in theory development. These are deductive theory testing and inductive theory building. The deductive approach is relevant to positivist paradigm and the inductive approach represents the phenomological paradigm (Perry, 1998). While the phenomological paradigm employs a research method such as a case study that is essentially an inductive theory building research (Perry, 1998) through describing a phenomena (Husserl, 1970), the positivist paradigm aims at explaining and predicting a phenomena (Hudson \& Ozanne, 1988) using quantitative research method (Mangan et al., 2004). The quantitative research method is conventionally based on the positivist approach to explore scientific enquiry of the phenomena (Saleh, 2006). Hunt (1991a, p. 33) stated that "the search 
for causal relations or causal explanations figures prominently in positivistic social science". However, there is no agreement about which of the philosophies of social sciences is best suited in marketing research. This is because philosophy can never provide a definitive answer to this question, rather, it shows some guidelines and justifications (Easton, 2002), and scopes and benefits of using a particular philosophy in a research method. In marketing research, there is neither any dominating paradigm nor any dominating philosophical 'ism' (Hunt, 1991a). Therefore, one study concludes that "debates in the philosophy of social science may not seem very relevant to most marketing academics" (Easton, 2002, p. 108). Despite this, a number of studies underscored the importance of selecting an appropriate research approach (Ali \& Birley, 1999; Deshpande, 1983; Mangan et al., 2004; Vignali \& Zundel, 2003).

Positivism is understood as knowledge that is based directly on experience or empirical observations, and that is important, useful and scientifically meaningful (Easton, 2002; Peter \& Olson, 1983). In contrast, the phenomenology is defined as:

The idea that reality is socially constructed and given meaning by people rather than objectively determined. Hence the task of the researcher should not be to gather facts and measure how often certain patterns occur, but to appreciate the different constructions and meanings that people place on their experience (Vignali \& Zundel, 2003, p. 206).

Marketing academia has been criticised for lacking the ability of theory-generation due to the application of positivistic methods. The positivistic approach mainly verifies a theory instead of generating a new theory (Kovacs \& Spens, 2005; Vignali \& Zundel, 2003). Thus, both of these paradigms, positivism and phenomenology, have importance in marketing research.

Instead of taking one of these polarised paradigmatic sides, a marketing researcher should triangulate these procedures (Deshpande, 1983). A number of studies state that the triangulation procedure is an appropriate mix (a middle ground) of both qualitative and quantitative research methods (Deshpande, 1983; Easterby-Smith, Thorpe, \& Lowe, 1991; Mangan et al., 2004). The use of these two paradigms in a single study 
can overcome the potential bias and sterility of a single approach (Hussey \& Husset, 1997; Mangan et al., 2004). As a result, the methodological triangulation has been receiving growing interest in marketing research for its contribution to develop knowledge (see, for example, Dahlstrom, Nygaard, \& Crosno, 2008; Freling \& Forbes, 2005; Stavros \& Westberg, 2009). The major benefit of using both approaches in a research method is that the weaknesses of a set of research methods are compensated for by the strengths of the other set of research methods and vice versa (Deshpande, 1983).

The present study adopts methodological triangulation (Figure 4) approach, meaning that this research undertakes a combination of positivism (i.e. deductive strategy) and phenomological (i.e. inductive strategy) paradigms. Thus, this study uses both qualitative and quantitative triangulation of data where empirical findings show the level of significance of the causal relationships. Adopting the qualitative research method enables the researcher to gain full insights about the perception of service quality, its antecedents and consequences, and in explaining the causal relationships among them. The quantitative research method allows the researcher to demonstrate these causal relationships and their explanation in a social setting with statistical evidence.

Figure 4: The triangulation approach to research design

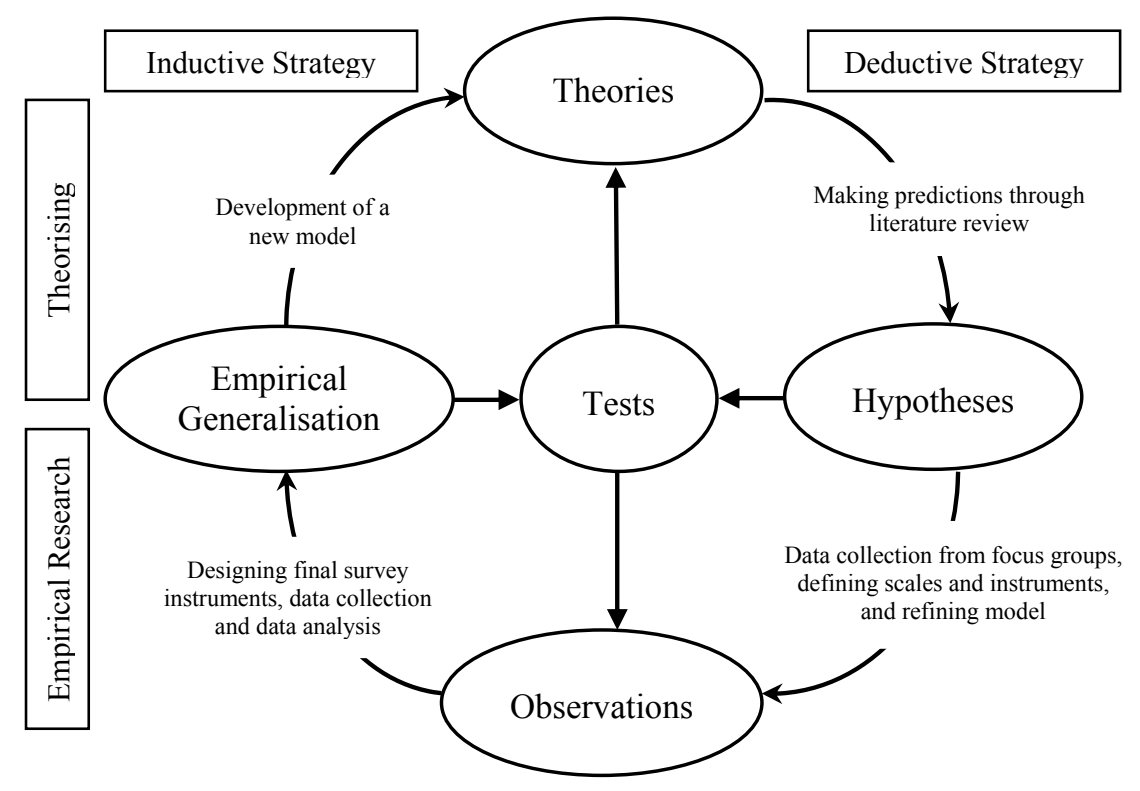

Source: Adapted from Vignali and Zundel (2003) for this study 


\subsection{Qualitative research method}

The approach adopted in this research was an exploratory qualitative method and thus, this research employed the focus group technique. There were several reasons for employing the focus group technique, including, first, to study the perceptions of students with regard to critical antecedents of service quality; second, to study the perceptions of students with regard to critical service attributes and their categorisation; third, to study the perceptions of students with regard to critical consequences of service quality; and fourth, to study the causal relationships among the themes developed and to formulate a research model. There are several advantages of focus groups in a social research context. These include flexibility, time and cost saving, direct interaction, large amount of data, user friendly and easy to understand (Stewart, Shamdasani, \& Rook, 2007). In this research, three focus group discussions were held with nineteen (19) students. The following paragraphs describe this approach.

\subsubsection{Selection of focus group members}

The participants for focus group discussions were students studying at the CQUniversity, Rockhampton, Australia. The participants were divided into distinct segments based on their level of study, for example, undergraduate and postgraduate (master's and doctoral) programs. This was done in order to minimise the dominance of senior student over junior student, and to ensure interactive participation among the group members. Research examining students' choice processes of university course selection used 22 students as focus group members (Brown, Varley, \& Pal, 2009). Although there is no rule of thumb about the number of members in a focus group, one study suggested that "a group consisting of 5-10 respondents is appropriate" (Krueger \& Casey, 2000, p. 10). Literature suggests that several (3-4) groups are convened depending on distinct population segments (see, for example, Morgan, 1988; Stewart et al., 2007). Thus, there were five, eight and six undergraduate, master's and doctoral students, respectively, in three focus group discussions in this study. The members of these groups can be selected using non-probability sampling technique 
(Babbie, 2007). Studies also suggest that convenience sampling technique (Gatfield et al., 1999) and purposive sampling technique (Punch, 2005) are useful for selection of focus group members. Therefore, this study designed three focus group interviews (Appendix E provides the demographics of the participants) at the main campus following the suggestions of these studies, and due to budget constraints and time limitations.

The respondents had more than six months experience at CQUniversity. This is because research shows that novices/beginners are lacking of concrete insights with regard to service attributes (McGill \& Iacobucci, 1992). As stated, the respondents for the focus group discussions were selected using convenience and purposive sampling techniques (Babbie, 2007; Gatfield et al., 1999; Morgan, 1997; Punch, 2005; Stewart \& Shamdasani, 1990). The focus group discussions included the representative members (for example, undergraduate, postgraduate, domestic and international students) of the larger population in order to avoid possible bias. In this regard, one study stated that

The limitations on the generalizability of focus group results have at least the advantage that convenience sampling can be employed. Indeed, convenience sampling is the most common method for selecting participants in focus groups. This type of sampling saves both time and money...the group must consist of representative members of the larger population (Stewart, Shamdasani \& Rook, 2007, p. 54).

Another study suggested that

In selecting participants for a focus group project, it is often more useful to think in terms of minimizing sample bias rather than generalizability. Focus groups are frequently conducted with purposively selected samples in which participants are recruited from a limited number of sources (often only one) (Morgan, 1997, p. $35)$. 
This study ensured representative members of the larger population in each of these groups following the suggestions of several studies (Morgan, 1997; Stewart \& Shamdasani, 1990; Stewart et al., 2007)

\subsubsection{Designing the topic for discussion}

The focus group discussions are exploratory in nature. One of the aims of focus group discussion, for the purpose of this study, is to generate relevant themes and determining their relationships. Using a facilitator or moderator for this type of investigation may bias the findings in that the cues provided by the moderator, knowingly or unknowingly, inform the group what information is desired and can get group consensus on a particular issue (Stewart et al., 2007). In addition, hiring a moderator is time consuming and increases the cost of the research project substantially (Morgan, 1997). Thus, the focus group interviews were conducted by the researcher in a non-directive and unstructured fashion. Broad questions were asked to each of these groups (Zeithaml et al., 1993). First, the respondents were told about the research aims, and the tasks they would perform during focus group discussion. Second, broad and open-ended questions were posed. Those included:

- What factors affect perceived quality evaluation in terms of the CQUniversity prior to enrolment?

- How do they evaluate service quality in terms of their university?

- What are the critical quality aspects of this university?

- What are the outcomes of service quality evaluation in the context of their university in the long-run?

- What do they understand about the 'UniBrand'?

Third, to facilitate the discussion and to keep it compact within the aim of this study, the researcher summarised the discussion when necessary during each of the interviews. This allowed participants to focus on the content of discussions. The discussions were recorded using an electronic device. On an average, each discussion took one hour. 


\subsubsection{Focus group data analysis}

The analysis of focus group data requires a great deal of judgment and care, and this depends on the research question and the purpose of focus group discussion (Morgan, 1988). For the purpose of this study, a thorough content analysis was employed. Krippendorff (2004, p. 3) stated that "content analysis entails a systematic reading of a body of texts, images and symbolic matters, not necessary from an author's or user's perspective". It is used when verbal data is gathered in the form of answers to open ended interview questions and focus group conversation (Krippendorff, 2004).

The content analysis was conducted by manual procedures. The first stage included identifying the recorded information that was important for developing themes and their interrelationships following theoretical and conceptual suggestions (Krippendorff, 2004; Neuendorf, 2005). In this stage of analysis, transcripts were prepared from the recorded focus group discussions. The manuscript was cleaned and edited by eliminating typographical errors and contradictions in the text that were irrelevant to the central issue of the study.

The second stage followed coding and categorising, including, assigning key words suitable for a section of text, giving a particular meaning to or labelling a section of the material (Sarantakos, 1997). Thus, the texts were classified or categorised. The coding process not only involved categorising the chunks of texts but also included memoing the data. Memo is the notes, backgrounds, ideas or thoughts about coding data (Babbie, 2007; Sarantakos, 1997).

The third stage was concept mapping. Concept mapping is the display of concepts and their interrelations to formulate a theory (Babbie, 2007). It also helps strengthening the theoretical model. The purification of the theoretical model and internal validity of the instruments for each of constructs were ensured following two step procedures. First, the researcher independently reviewed the transcripts and developed a list of themes, and formulated the interrelationships among them. A list of items or instruments derived from focus group interviews were also developed under each of the themes, and these were cross examined with the current studies. Second, the 
findings and transcripts were delivered to two marketing academics of the School of Management and Marketing, CQUniversity, for the purpose of validation. They are experts in qualitative and quantitative research in the field of marketing, particularly. The cross validation was ensured by comparing the outcomes. These attempts minimised any anomaly and possible bias, and ensured validity of the instruments. Finally, the research model along with nine hypotheses was developed following the inferences derived from focus group findings and literature review. Chapter 3 discussed the focus group findings and the current literature while developing the research model, hypotheses and research instruments.

\subsection{Quantitative research method}

The quantitative research method starts with a scale development process. This study followed step-by-step procedures for developing better measures. The extant literature provides a well-structured procedure for developing better measures. The procedure suggests eight steps, namely, specify domain of construct, generate sample of items, collect data, purify measure, collect data, assess reliability, assess validity and develop norms (Churchill, 1979). Thus, the overall design and development of measures followed the suggestions of Churchill (1979). This section discusses data analyses procedures and cut-offs in terms of statistical analyses. The results are discussed in chapter 5 .

\subsubsection{Domain of construct}

This has been stated in chapter 2 and chapter 3 that the research model takes performance-only perspective to define and develop the constructs for the proposed research model. This perspective is also aligned with the ECSI model. Section 3.4 of chapter 3 discussed the definition, scope and instruments for each of the constructs included in the research model. The domain of the constructs was derived from both the literature review and focus group findings. 


\subsubsection{Item generation and questionnaire design}

At this stage, a set of items available for each of the scales were designed following the literature review and focus group findings. The set of items for each of the scales can be generated either inductively, due to a lack of available theory, by asking respondents to describe attitudes and feelings, or deductively from previous research (Hinkin, 2005; Hunt, 1991b). The items/instruments for service quality, satisfaction, trust, brand performance and behavioural intention were generated using both inductive and deductive approaches. However, the items of information and past experience followed purely inductive approach due to absence of items in literature. Details about the final items for each of the scales can be found in chapter 3 .

The current literature stated that multi-item measures are typically much better than single item measure (Churchill, 1979; Churchill \& Surprenant, 1982; Nunnally, 1978). Thus, each of the constructs contained multi-attributes or multi-items to better reflect the results and their predictabilities. Particular attention was given to develop the wording of the instruments. For example, negative words, double barrelled words and sentences, the issue that students' possibly unaware of and vague words were avoided. The items used short and simple language to make it meaningful and clear to the respondents (Churchill, 1979; DeVellis, 2003). The research instrument appeared in the questionnaire was designed from the customers' (students') point of view (Yang, 2003). In order to ensure face validity and content validity of the research instruments, these items along with their corresponding constructs were reviewed by an expert panel of the School of Management and Marketing, CQUniversity. The expert panel consisted of two marketing academics having relevant research expertise in the field of qualitative and quantitative research in marketing. The suggestions received from the expert panel were incorporated.

Social exchange is a powerful way for motivating people to respond to surveys. It reduces costs, increase responses and trust (Dillman, Smyth, \& Christian, 2009). The design of the questionnaire followed the suggestion of Dillman et al. (2009) and included information about the survey, requested for completion and suggestions, showed positive regards and group values, social validation, attractive layout, and 
thanking and closure. The questionnaire consisted of three sections. The first section contained the social exchange issues. The second section contained information with regard to demography of the respondents. The third section consisted of the research instruments using seven point Likert type scales where 1 represented strongly disagree, 4 represented neutral and 7 represented strongly agree. A brief and general note about each of the constructs was provided between the items and their corresponding construct.

\subsubsection{Pilot testing}

Pilot testing was conducted to find the appropriateness of the questionnaire. Prior to conducting pilot testing, necessary ethical clearance was obtained from the Human Research Ethics Committee, CQUniversity (Ref. H08/12-082). The draft questionnaire included a total of 75 items including information (five items), past experience (six items), service quality (30 items), satisfaction (seven items), trust (12 items), brand performance (eight items) and behavioural intention (seven items). The researcher distributed the draft questionnaire to the students of CQUniversity, Rockhampton campus using convenience and purposive sampling techniques. The researcher calculated the average time of completing the survey which was 15 minutes (approximate). A total of 106 completed and usable responses were received in first two weeks of September 2009. The questionnaire did not ask any personal particulars and followed the necessary protocols stated in the ethical clearance. The respondents were assured about the confidentiality of their responses. They were also informed about their rights (i.e. their rights to quit during the survey process) in the first section or social exchange page if they so wished.

\subsubsection{Scale purification and finalising the questionnaire}

The data was entered into SPSS version 17 and was subsequently cleaned to remove any entry error. The descriptive statistics were determined in order to have an overview of the data set including an examination of skewness and kurtosis in order to determine the normality of the data set (Hair, Black, Babin, \& Anderson, 2010). The 
data was, then, entered for factor analysis using principal component analysis with varimax rotation method. Principal component analysis was used as it explains common, specific and random error variances (Hair et al., 2010). For the proposed research model, there are seven scales (constructs) and each of the scales contains several items, and these are developed from literature review and focus group findings. Thus, factor analysis was conducted for each of the scales separately.

Primarily, the Eigenvalue of one or greater were extracted as factors for these scales, and in this context, the scree plot was also obtained for further clarification (Ho, 2006; Pallant, 2007). For each of the scales, similar and substantial loadings of items on more than one factor were removed (Hair et al., 2010). One study suggested that a factor loading of 0.32 is acceptable as a rule of thumb (Tabachnick \& Fidell, 1989). Ho (2006) suggested that a factor loading of 0.33 is accepted as it denotes approximately $10 \%$ of the variable's total variance is accounted for by the factor. As a guideline, factor loadings between \pm 0.30 and \pm 0.40 are considered to meet the minimal level for interpretation of structure, loadings of \pm 0.50 or greater are considered practically significant and loadings exceeding \pm 0.70 are considered indicative of well-defined structure and are the goal of any factor analysis (Hair et al., 2010). Thus, the factors loading of the items less than 0.30 are removed from their corresponding scales.

The Cronbach's Alpha for each of the scales was also calculated to ensure scale reliability (Churchill, 1979). Cronbach's Alpha is a measure that determines the scale's internal consistency. It is widely used as a means of assessing the reliability of a scale (Churchill, 1979; Hair et al., 2010; Tabachnick \& Fidell, 1989). As a rule of thumb the Cronbach's Alpha of above 0.70 is considered acceptable and above 0.80 is preferable (Pallant, 2007). The results of reliability test for each of the scales was at least 0.70 .

As a result of factor analyses and reliability tests for all of the scales and their corresponding items, a total of 65 items survived for final survey. The following table provides a summary of the number of items included in pilot testing, the number of items entered for final survey. 
Table 9: Summary of items in terms of inductive and deductive approaches

\begin{tabular}{|c|c|c|c|c|}
\hline Scales & $\begin{array}{l}\text { No. of items } \\
\text { (Pre-testing) } \\
\text { (75 items) }\end{array}$ & $\begin{array}{l}\text { No. of items } \\
\text { (Final Survey) } \\
\text { (65 items) }\end{array}$ & Items deleted & $\begin{array}{l}\text { Reason(s) for } \\
\text { deletion }\end{array}$ \\
\hline Information & 05 & 03 & $\begin{array}{l}\text { Word-of-mouth information strengthens my } \\
\text { understanding of this University } \\
\text { I used word-of-mouth information prior to } \\
\text { enrolment }\end{array}$ & $\begin{array}{l}\text { Cross-loading \& } \\
\text { low-loading } \\
(<0.30)\end{array}$ \\
\hline $\begin{array}{l}\text { Past } \\
\text { Experience }\end{array}$ & 06 & 03 & $\begin{array}{l}\text { This University has maintained a good } \\
\text { relationship with me } \\
\text { Before enrolment, I was impressed when I } \\
\text { interacted with staff of this University } \\
\text { Overall, my experience with this University is } \\
\text { good }\end{array}$ & $\begin{array}{l}\text { Low-loadings } \\
(<0.30)\end{array}$ \\
\hline $\begin{array}{l}\text { Service } \\
\text { Quality }\end{array}$ & 30 & 26 & $\begin{array}{l}\text { I find that the recreational facilities of this } \\
\text { University are adequate } \\
\text { The course designed by the academic staff is } \\
\text { effective } \\
\text { The provided study programs/course meet } \\
\text { my requirements } \\
\text { My overall evaluation of quality with regard to } \\
\text { study programs/courses of this University is } \\
\text { good }\end{array}$ & $\begin{array}{l}\text { Substantially } \\
\text { loaded onto other } \\
\text { components. } \\
\text { Experts' } \\
\text { recommendations }\end{array}$ \\
\hline Satisfaction & 07 & 07 & $\mathrm{~N} / \mathrm{A}$ & N/A \\
\hline Trust & 12 & 12 & $\mathrm{~N} / \mathrm{A}$ & $\mathrm{N} / \mathrm{A}$ \\
\hline $\begin{array}{l}\text { Brand } \\
\text { Performance }\end{array}$ & 08 & 08 & $\mathrm{~N} / \mathrm{A}$ & $\mathrm{N} / \mathrm{A}$ \\
\hline $\begin{array}{l}\text { Behavioural } \\
\text { Intention }\end{array}$ & 07 & 06 & $\begin{array}{l}\text { I would pay more to get a degree from this } \\
\text { university }\end{array}$ & $\begin{array}{l}\text { Low-loadings } \\
(<0.30)\end{array}$ \\
\hline
\end{tabular}

These items were then further examined by the expert panel and deemed appropriate for final survey. A copy of the final survey questionnaire is attached in Appendix A.

\subsubsection{Sampling design decision}

In the context of this study, the population included all the students of the CQUniversity including the students of Sydney, Melbourne, Brisbane, Gold Coast, Mackay, Noosa, Gladstone, Rockhampton, Bundaberg and Emerald campuses having more than six months of study experience with CQUniversity. Literature states that novices/beginners are lacking of concrete insights with regard to service attributes (McGill \& Iacobucci, 1992). Since this study is based on students' experience of higher education service quality, it was deemed appropriate to consider the respondents with more than six months (or one term) of studying experience with the CQUniversity. 
Selecting a single university for the purpose of data collection for the present study also conforms to the present studies (Brown et al., 2009; Douglas et al., 2008; Gatfield et al., 1999; Helgesen \& Nesset, 2007; Navarro et al., 2005; Smith et al., 2007; Stodnick \& Rogers, 2008). Although selecting a single university does not allow one to generalise the findings to other universities (Sawyer \& Thompson, 2003), inclusion of all CQUniversity students, programs, schools and campuses in the context of the present study are a popular alternative to generate important insights about antecedents and consequences of service quality in a higher education context. Using a single university to study students' attitudes generate valuable insights, which can be used as empirical hypotheses for representative follow-up studies (Dolnicar, 2004).

The way, in which quantitative researchers seek to generate a representative sample, is the probability sampling. This procedure largely eliminates bias from the selection of a sample by using a process of random selection. The generalisation of the findings is only applicable to the population from which the sample is taken (Bryman \& Bell, 2007). Therefore, for the purpose of this study a probability technique was adopted.

Various approaches have been suggested for arriving at a sample size decision. For example, Krejcie \& Morgan (1970) suggested an approach of estimating sample size using margin of error. This approach suggests that 547 responses are required for the present study for a population of 14779 students of the CQUniversity with 5\% margin of error at 95\% confidence level. Studies suggest that "a sample size between 50 and 200" (Gorsuch, 1983, p. 129) or a sample size to the number of parameters must be estimated where higher values of the ratio of observations to parameters $(\mathrm{N}: \mathrm{q})$ are preferred (Bentler \& Chou, 1987; Marsh, Balla, \& McDonald, 1988). Although studies have suggested that 200 sample sizes are adequate for analysing a Structural Equation Model (Hoelter, 1983; Loehlin, 1992), the literature also used less than 100 samples to analyse a Structural Equation Model (Whittaker et al., 2007). One study recommended that at least five cases per parameter estimate are required to analyse a Structural Equation Model (Bentler \& Chou, 1987). In this perspective, at least 280 samples are required for the present study as there are 56 parameters in this research. 


\subsubsection{Survey administration}

Online questionnaires are methodologically and financially appealing to those who study and work with student populations. An online survey increases the likelihood of participation and its processing fees are usually lower than those for paper surveys (Sax, Gilmartin, \& Bryant, 2003). It was deemed appropriate to use online survey as student population were studying at distant campuses and as they have access to computer and internet. In addition, this study used an internet survey due to time and budget constraints. Prior to this process, necessary ethical clearance from the office of research, CQUniversity and permission from the student administration division were obtained (Project Number: H08/12-082). The online survey administration consisted of three main steps for the purpose of this study. These were launching the survey, managing the responses and retrieving the responses in usable formats.

The layout design of the online survey questionnaire with 65 items followed the suggestions of Dillman et al. (2009). A simple and understandable layout was produced on 'surveymonkey.com' and 12 web pages were developed on a single link with click-only buttons for each of the items and navigate buttons for going onto next page. A completion scale was placed on each page to guide respondents about their progress. The first page contained demographic information. This survey put two constraints. First, one cannot go onto next item, section or page without completing previous item, section or page, respectively. This constraint ensured completed responses. The literature termed this as 'required completion answer' (Evans \& Mathur, 2005). However, quitting from participation was a choice of the respondents at any time during the process. Second, one can neither incomplete the survey and sit again next time for completing the survey nor one can send multiple responses. Students were required to login to the online survey using their CQUniversity's user name and password, and this login was possible only once.

Once the online click-only survey was ready, the link had been sent to the focus group members for a test-launch. Once it was found effective, the survey link along with social exchange message was sent to all of the students' CQUniversity email accounts through the Information and Technology Divisions of each individual 
campuses of the CQUniversity. The students were guaranteed anonymity in the information sheet of the online questionnaire (please see Appendix A). In order to encourage students to respond and to minimise the impact of non-response bias, an incentive entry to 15 lucky coupons each of 20 dollar from CQUniversity Book Shop were offered. Although lotteries and prize drawings do not increase response rates significantly, the use of incentives to encourage response is recommended by Dillman et al. (2009).

The survey was open between 16 November 2009 and 31 December 2009. There was one reminder email sent to all of the students on 27 November 2009. A total of 1032 responses were received relative to 14779 students [Source: Mr. Michael Neaton, Reporting Analyst (statistics area), Office of Learning and Teaching, CQUniversity, Australia informed (dated 21/04/2010) that the total student population in 2009 was 14779]. Thus, the response rate is seven percent (in terms of CQUniversity's student population), indicating a similar response rate as obtained in the extant literature (Zeng et al., 2009). The number of responses received complies with further statistical analyses. The online system stored the responses as .html format, .xls format and .pdf format. At the end of the survey, all the responses were stored on a compact disk and in hard drive as .pdf format. The system produced a tabulated data sheet (.xls) comprising of all the cases, demographic variables and research instruments. Thus, this data sheet was retrieved in .xls format for further analysis.

\subsubsection{Purifying data}

The tabulated data sheet is extracted in .xls format from the 'surveymonkey' system. Data cleaning is one of the preliminary stages for any structural equation modelling in order to achieve maximum accuracy. Data cleaning was conducted to deal with missing data, potential non-response bias and tests of normality of data (Tabachnick \& Fidell, 2000). 


\subsubsection{Data cleaning and missing data}

The extant literature suggests various approaches to deal with missing data and cleaning the data. The first option is the deletion of the response or variable containing missing data. This can lead to a loss of a substantial amount of data. The other alternative approaches are pairwise deletion, listwise deletion, mean imputation, regression imputation (Hair et al., 2010; Tabachnick \& Fidell, 2000). However, it is argued that there is no single best way to deal with missing values (Hair et al., 2010; Tabachnick \& Fidell, 2000). For the purpose of this study, first, the incomplete responses were deleted. The incomplete responses refer to those respondents who attempted but did not complete the survey. There were 239 incomplete responses that accounted for 23.2 per cent. However, due to 'required completion answer' constraint there was no missing data. Second, the responses (233 responses) having six or less months of study experience with CQUniversity were deleted. Thus, 560 responses were found to be useable for further statistical analyses.

\subsubsection{Assessment of normality and outliers}

Assessing normality of the data set is a primary task for any statistical modelling. One of the primary measures, for this purpose, was to examine the skewness and kurtosis from the descriptive statistics output. If a distribution is normal, the kurtosis and the skewness are zero (Hair et al., 2010; Tabachnick \& Fidell, 2000).

A further attempt was made to detect outliers. Hair et al. (2010) defined outliers as "a unique combination of characteristics identifiable as distinctly different from the other observations" (p. 64). This is important as it may create non-normality of the data set. Using outliers, one can judge an unusual high or low value or a combination of values on a single variable. An outlier case distorts overall statistics (Tabachnick \& Fidell, 2000). Following the descriptive statistics, the skewness and kurtosis for each of the variables were examined. It then entered for identifying outliers. There are three perspectives to identify outliers, univariate, bivariate and multivariate. The univariate perspective looks into the distributions of the cases for each of the variables under examination. If a variable is univariate normal, it is not multivariate normal. However, 
if a variable is multivariate normal, it may be univariate normal (Hair et al., 2010). Thus, this study used both univariate and multivariate perspectives to identify outliers.

Finally, the Kolmogorov-Smirnov (K-S) test for goodness-of-fit was undertaken to examine the normality of the data set. The $\mathrm{K}-\mathrm{S}$ test calculates the level of significance for the differences from a normal distribution, and it is less useful for a small sample size and quite sensitive for a large sample size (Hair et al., 2010). A non-significant result (sig. value $>0.05$ ) indicates normality. If the sig. value is 0.000 , the sample violates the assumption of normality and this is quite common (Pallant, 2007).

\subsubsection{Non-response bias}

Non-response bias refers to the bias that exists when respondents to a survey are different from those who did not respond in terms of demographic or attitudinal variables (Sax et al., 2003). In the present study, the online survey was intended to include anonymous respondents from the student population of the CQUniversity with an aim to collecting data that is representative of CQUniversity's student population with more than six months study experience. It is not usual that all people will participate in the survey or be able to complete the survey (Couper, 2000). Thus, the non-response bias is implicit in the data set unless a survey achieves a one hundred per cent response rate (Chen, 1996). Non-response can take two forms, total nonresponse and unit/item non-response. The first refers to individuals failing to return the survey at all. The later refers to incomplete surveys (Sax et al., 2003). There are three approaches to minimise non-response bias, including, minimise the number of non-response, sample non-response and estimate the effect of non-response (Armstrong \& Overton, 1977).

In order to minimise non-response, the survey offered 15 lucky draws each worth 20 dollar gift coupon following the suggestion of Dillman et al. (2009). Non-price incentives included a gentle reminder email and user friendly format or layout. Due to first constraint (i.e. required completion of answer) there was no section/item nonresponded. Total number of completed survey was 793 (i.e. 76.8 per cent of total survey received) excluding 23.2 per cent respondents who attempted but not 
completed the survey. Taking a sample of non-response and asking them to complete the survey was not possible as this was an anonymous survey, and as there was financial and time constraints. In addition, during survey period a reminder email was sent to all of the students of CQUniversity. Lastly, the estimation of non-response bias has three approaches, comparison with known values, subjective estimation and extrapolation (Armstrong \& Overton, 1977). Of these, the present study adopts the extrapolation method. Armstrong and Overton (1977, p. 397) state that "extrapolation methods are based on the assumption that subjects who respond less readily are more like non-respondents. Less readily has been defined as answering later or as requiring more prodding to answer". Thus, the total responses collected according to dates were divided in two groups, and then independent sample $t$-tests were performed for each of the variables across these groups.

\subsubsection{Data analysis}

At this stage, the data set was subject to a range of statistical analyses in order to establish valid and reliable scales for each of the constructs and to examine their causal relationship in the specified model detailed in chapter 3 . The statistical analyses including descriptive, frequencies, nonparametric chi-square goodness-of-fit test for some key demographic variables, independent sample $t$-test, factor analysis and reliability test were performed using Statistical Package for Social Sciences (SPSS), version 17.

Analysis of Moment Structures (AMOS) version 17 was used to undertake confirmatory factor analyses (CFA) with an aim to test unidimensionality, convergent validity, divergent validity and predictive validity. The CFA tests the relationship that may exist between the observed variables and any underlying factor (Bagozzi, Yi, \& Phillips, 1991; Ding \& Hershberger, 2002). The CFA-based method provides the most comprehensive method for assessing construct validity (O'Leary-Kelly \& Vokurka, 1998). The construct validity represents the correspondence between a construct's conceptual definition and its operational procedure to measure and manipulate that construct (Schwab, 1980). Construct validation is a multifaceted 
process, mainly, involving three major steps. The first step, face and content validity, was ensured before final survey was launched, and through expert validation and the findings derived from pilot survey results. The procedures to ensure face and content validity were discussed in sections between 4.4.2 and 4.4.4. The three major steps of construct validation are as follows (see Figure 5). Followed by this, the quantitative methods are described to purify the variables.

Figure 5: The process of construct validation

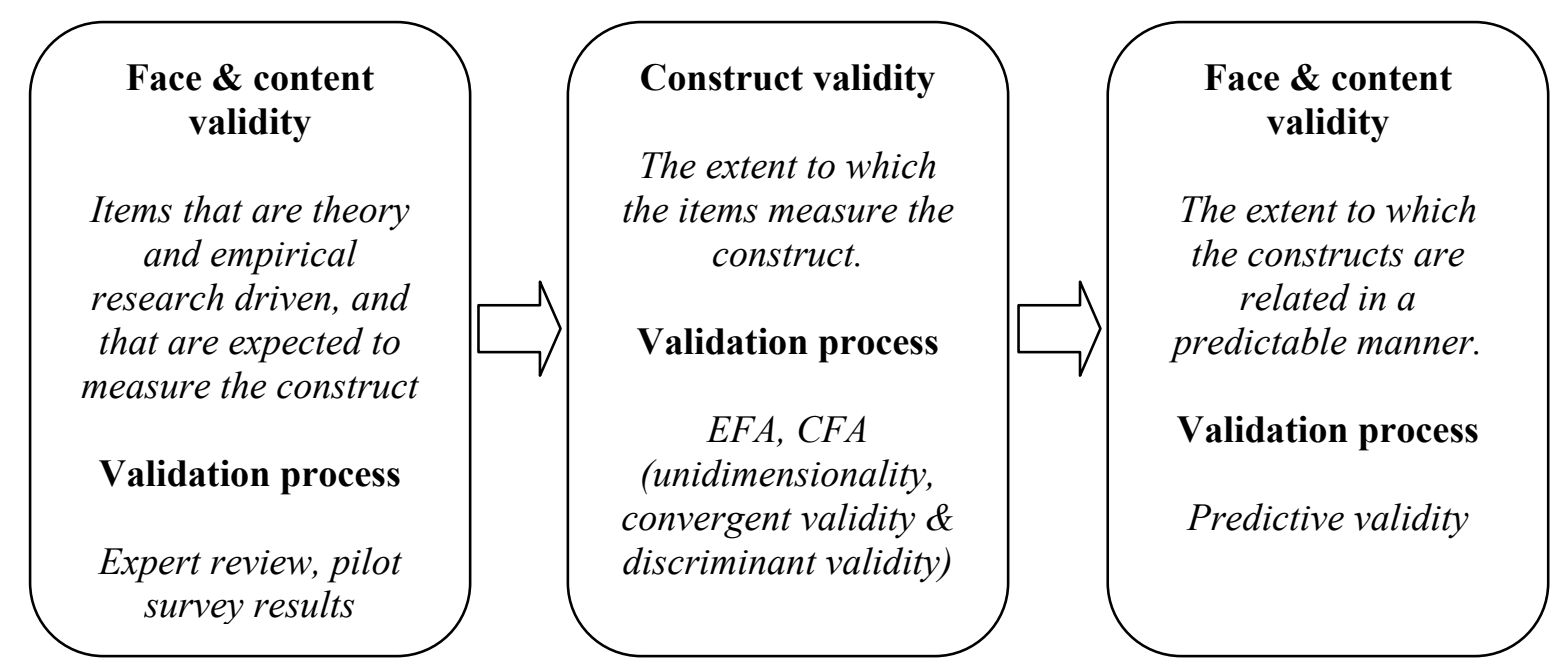

Source: O’Leary-Kelly and Vokurka (1998)

\section{$\underline{\text { 4.4.8.1 Exploratory factor analysis }}$}

The major aim of factor analysis is the orderly simplification of a large number of intercorrelated measures to a few representative constructs or factors. It is based on the assumption that all variables are correlated to some degree (Ho, 2006). The role of factor analysis is to identify the components or factors that derive from a set of variables. In other way, it is used to identify the subset of correlated variables that form a subset that is reasonably uncorrelated with other subsets (Hair et al., 2010; Tabachnick \& Fidell, 2000). 
For the purpose of this study, the exploratory factor analysis or EFA (principal component analysis with varimax rotation method) was undertaken for each of the scales. The items that were loaded onto more than one factor, or showed a factor loading of \pm 0.30 or less were removed (Hair et al., 2010; Ho, 2006). The exploratory principal component analysis (varimax rotation) was used as it incorporates common, specific and error variance. It is appropriate when the objective is to identify minimum number of factors associated with maximum explanation of variance (Hair et al., 2010). Varimax rotation was chosen as it has proved successful as an analytic approach in order to provide clearest separation of factors (Hair et al., 2010; Ho, 2006).

Embedded in factor analysis is the Kaiser-Meyer-Olkin measure of sampling adequacy (KMO) and Bartlett's test of sphericity. The Bartlett's test of sphericity tests the null hypothesis that the items are uncorrelated in the population. As a rule of thumb, a $p$-value of $\leq 0.05$ indicates that the data set is suitable for factor analysis (Pallant, 2007). The KMO test statistic is based on partial correlation and varies between zero and one. The current studies are at variance to determine the level of overall KMO score, for example, one study stated that the overall KOM score should be greater than 0.50 (De Vaus, 2001); another study stated that the KMO value should be 0.6 or greater for factor analysis (Pallant, 2007). This study takes the later perspective. While the EFA determines the set of items corresponds to a factor, the Cronbach's Alpha determines the overall reliability of the items measuring that factor. The following paragraph discusses the method of reliability tests.

\subsubsection{Reliability tests}

The reliability of a scale is the ability of that scale to measure consistently the phenomenon it is designed for to measure. It is a prerequisite for the validity of the test (Ho, 2006). Cronbach's Alpha is the most commonly used statistic to perform reliability test. 
The existing literature emphasised on multi-item measures (Churchill, 1979; Churchill \& Surprenant, 1982; Nunnally, 1978) in order to better reflect the results and their predictabilities. Thus, after pre-testing the questionnaire, the finally selected multi-items for each of the constructs included in the model were operationalised for the Cronbach's Alpha test. The Cronbach's Alpha test was performed for each of the constructs separately. Ideally, the Cronbach's Alpha coefficient of a scale should be above 0.70 (DeVellis, 2003; Pallant, 2007).

\subsubsection{Unidimensionality test}

Measuring unidimensionality is important as it shows that the items are only measuring a single factor. O'Leary-Kelly and Vokurka (1998) stated that a scale must satisfy two conditions to be unidimensional. First, indicators must be significantly associated with an underlying latent variable. Second, the indicators must be associated with one and only one latent variable. There are two methods to achieve unidimensionality, the EFA and the CFA. This study used the EFA method. This method identifies the empirical indicators that are strongly linked to a particular latent variable that in turn indicates that those indicators form a unidimensional factor, and thereby providing the basis for a measure (O’Leary-Kelly \& Vokurka, 1998). In contrast, the CFA method leads to a stricter and more objective interpretation of unidimensionality compared to EFA. Thus, it often produces different conclusions about the unidimensionality of a measure (Anderson \& Gerbing, 1988; O'Leary-Kelly \& Vokurka, 1998). The test of unidimensionality refers to the test of convergent and discriminant validity. The unidimensionality was ensured primarily through EFA.

\subsubsection{Convergent validity}

Convergent validity refers to the degree to which multiple methods of measuring a variable provide the same results. The assumption of convergent validity is that the items explaining a construct should show the same results when different methods are utilized (O'Leary-Kelly \& Vokurka, 1998). There are several ways to find convergent validity. First, the EFA finds convergent validity if the items are loaded together on a 
single construct as hypothesised (Steenkamp, 1991) and that they are statistically significant (Hair et al., 2010). Hair et al. (2010) suggests that a good rule of thumb is that standardised loadings should be minimum 0.5 or higher, and ideally 0.7 or higher. Second, the CFA can analyse convergent validity of the items within the construct using the critical ratio values. The critical ratio (c.r.) value greater than 1.96 with a $p$ value of less than 0.05 suggests strong convergent validity (Wong \& Merrilees, 2007b). Third, the average variance extracted (AVE) within the CFA framework should be 0.5 or higher in order to have adequate convergence. Thus, the AVE measure was computed for each of the latent constructs in a measurement model (Hair et al., 2010). Fourth, a good reliability estimate (i.e. Cronbach's Alpha should be 0.7 or higher) for each of the latent constructs indicates that the items are measuring the same latent construct consistently (Hair et al., 2010). Therefore, these four methods were adopted to determine the convergent validity for each of the latent constructs.

\subsubsection{Discriminant validity}

Discriminant validity measures the distinctiveness of a construct from other constructs. High discriminant validity shows uniqueness of a construct from other constructs (Hair et al., 2010). In order to achieve discriminant validity, three approaches were used in the present study. First, pairwise chi-square $\left(\chi^{2}\right)$ difference tests at a time were performed for discriminant validity checks (Anderson \& Gerbing, 1988). A significant $\chi^{2}$ difference test suggests the existence of discriminant validity between the constructs (Wong \& Merrilees, 2007b). Second, the AVE estimate and the squared correlation estimate were compared. The discriminant validity exists when AVE estimate is greater than the squared correlation estimate between pairs of factors (Fornell \& Larcker, 1981; Hair et al., 2010; Wong \& Merrilees, 2007b). Third, exploratory factor analyses using principal components with varimax rotation were performed for each pair of the constructs. The discriminant validity exists if the findings show that there are two components extracted from each pair of the constructs (Anderson \& Gerbing, 1988; Wong \& Merrilees, 2007b). 


\subsubsection{Measurement model analysis}

The measurement model analysis is a prerequisite before structural model analysis (Anderson \& Gerbing, 1988). Measurement model analysis is an orderly and significant process after convergent and discriminant validity tests. This is a significant step before analysing any structural model. The measurement model within the CFA framework tests all the latent variables (constructs) and their respective indicators at one time. CFA aims to examine how well the hypothesised factor structure accounts for the covariances among the observed variables (Bruin, 2004). While the measurement models test path relationships between the measures or items and the constructs or latent variables that they represent, the structural models specify relationships between the latent variables of interest (Landis, Beal, \& Tesluk, 2000). The measurement model shows how constructs are operationalised by sets of measured variables (Hair et al., 2010).

The use of item parcels or "partial disaggregation model" has become quite common in recent years in analysing measurement model (Bandalos, 2002). This study stated that the item parcelling procedures had been employed in 62 studies among 317 studies that applied SEM or CFA, and that this technique is applied in areas including education, psychology, marketing and organisational research. An item parcel is defined as "an aggregate-level indicator comprised of the sum (or average) of two or more items" (Little, Cunningham, Shahar, \& Widaman, 2002, p. 152). Thus, parcelling involves summing or averaging item scores from two or more items and using these parcel scores in place of the item scores in a SEM analysis (Bandalos, 2002).

The prerequisite for item parcelling is unidimensionality of factor structure (Bandalos, 2002; Hau \& Marsh, 2004). A number of studies recommended that item parcelling should be used only when the items within a scale have a unidimensional structure (Bandalos, 2002; Little et al., 2002). The item parcelling strategy in measurement model should not substantially influence model fit when items are unidimensional (Landis et al., 2000). However, Bandalos (2002) finds that when items within a 
particular scale have a unidimensional structure, the CFA leads to improved model fit and less biased structural parameters.

In a measurement model, the item parcelling technique is used for a number of reasons. Item parcelling is more reliable than individual items. The reason for this includes, first, it has more scale points and is more likely to have linear relations with each other and with factors (Little et al., 2002), second, it provides more normal distribution of data than individual items (Bruin, 2004), third, it provides more stable parameter estimates, reduces idiosyncratic characteristics of items and simplifies model interpretation (Hau \& Marsh, 2004). The use of item parcelling results in the estimation of fewer model parameters and that result in a more optimal variable to sample size ratio and more stable parameter estimates (Bandalos, 2002). The CFA solutions based on item parcels show greater power and smaller mean squared error than those based on individual items (Yuan, Bentler, \& Kano, 1997). Thus, item parcelling provides more satisfactory factor analytical results with improved modeldata fit within a CFA framework, especially when the number of items is many in relation to required sample size.

Although item parcelling is a fairly common practice in analysing a measurement model, there is no single agreed method for forming multi-item composites. Landis et al. (2000) reported six alternative and useful methods for item parcelling. First, the single factor method includes the items with highest and lowest loadings as first composite and continues this process until all the items are included. Second, the correlational approach refers to paring items with highest intercorrelation (within a factor) as first composite and continues this process until all the items are included. Third, the random method refers to assigning items randomly to composites. Fourth, the content approach creates composites based on rational grouping of items. Fifth, the exploratory factor analysis approach depends on the number of components extracted through principal component analysis, and then summing the items that are loaded onto each component. Thus, if EFA produces one component of a latent variable then summing all the items of this variable would produce one composite. Finally, the empirically equivalent approach creates composites with equal means, variances and reliabilities. 
There is no clear understanding in the literature with regard to the number of items required to measure a scale or a latent variable, and how many parcels to be made in order to create improved data fit in the measurement model. For example, one study recommended that each latent factor should have at least three indicators and that item parcels should preferably not be used unless there are sufficient items to construct at least three or four parcels per factor (Hau \& Marsh, 2004). Another dominant study suggested that depending on the number of items of a latent factor, two, three, or possibly four parcels, or groupings of items, could be created (Little et al., 2002). Bentler and Chou (1987) took a different view and stated that the ratio of sample size to estimated parameters should be between 5:1 and 10:1. This study also suggested that it is always important to have as many items of a factor as possible and to have 20 items for a Structural Equation Model at most (and for a measurement model, as well). Landis et al. (2000, p. 189) suggested that "if a two-factor solution fits a given set of items best, it would be preferred. Alternatively, if a three-factor solution provided a better fit, three resulting composites would be used". This study also suggested that the decision to form composites should primarily be driven by the researcher's conceptualisation of the focal construct.

Following the above discussions, the present study adopts single factor method of item parcelling to analyse measurement model instead of item level strategy. As latent constructs with single indicators can be problematic (Hall, Snell, \& Foust, 1999), each latent construct in the present study, followed by unidimensionality and other relevant tests, formed two composites. Specifically, composite one contained highest loading and lowest loading, composite two contained next highest loading and next lowest loading, and this procedure continued until the end item belongs to either composite one or composite two. If there were an odd number of items, the extra item was placed into the composite two. It is worthy to mention here that the number of items to sample size was $56: 528$ or 1:9 (approximate). The underlying purpose of item parcelling or partial disaggregation is to distil the original set of scale items to a reduced number of indicators that are empirically balanced measures of the construct (Landis et al., 2000). 


\subsubsection{Analysis of structural model estimation}

A structural model represents a structural theory. The structural theory is defined as a conceptual representation of the structural relationships between constructs (Hair et al., 2010). The structural model refers to a set of measuring items that corresponds two or more latent variables, and their causal relationships within a theoretical interpretation. Structural equation modelling (SEM) has become one of the most widely applied data analytic techniques in social sciences. One of the primary reasons for this widespread use is the ability of the technique to assess simultaneously the fit of measurement models and structural models (Landis et al., 2000). It analyses data for inferential purposes and provides explicit estimates of the error variance parameters (Byrne, 2006). The SEM is a confirmatory approach where the relationships among latent variables and their measurement variables are set prior to analysis.

A structural model can be complex due to many latent variables and measurement variables, and interrelationships among them. This leads to a poorer fit, increased measurement error, improper solutions, inflated standard error and other relevant computational problems (Bentler \& Chou, 1987). The literature suggests adopting partial disaggregation or item parcelling technique to overcome this problem (Bandalos, 2002; Landis et al., 2000; Little et al., 2002). This technique has been discussed in 4.4.9 section, and also adopted for analysing structural model estimates. In short, all of the composites and their corresponding latent variables were positioned and linked following the research model, and run the simulation using AMOS version 17.

Prior to analysing goodness-of-fit (GOF) measures, it is necessary to assess nomological and predictive validity of the measures. The relationships among the constructs (latent variables) can be determined through nomological and predictive validity. Nomological validity examines whether the correlations between the constructs in the measurement theory make sense. The coefficient of correlation between constructs is useful in this assessment (Hair et al., 2010). The predictive validity, in contrast, examines predictive ability of the measure against some future 
outcome (Greene, 2008). The predictive ability of a measure can be determined by examining the regression weight and its level of significance.

Research suggests a number of GOF measures for assessing measurement model and structural model. "The GOF measures indicate how well the specified model reproduces the observed covariance matrix among the indicator items" (Hair et al., 2010, p. 664). The GOF measures are classified into three broad categories, absolute fit measures, incremental fit measures and parsimonious fit measures.

\subsubsection{Absolute fit measures}

The absolute fit measures are the most basic assessment that determines how well a researcher's theory fits the sample data. In other words, these measures assess how well the model specified by the researcher reproduces the observed data (Hair et al., 2010). Ho (2006) stated that absolute fit measures "determine the degree to which the proposed model predicts the observed covariance matrix" (p. 284). There are three major and commonly used absolute fit measures. These are chi-square test, goodness-of-fit and adjusted goodness-of-fit indices, and root mean square error of approximation.

Chi-square $\left(\chi^{2}\right)$ : It is the difference in the observed and the estimated covariance matrices (Hair et al., 2010). This is a fundamental test measure for overall fit (Ho, 2006). The standard of $\chi^{2}$ measure in SEM is that the $\chi^{2}$ value should be small and not be significant (i.e., $p>0.05$ ). In this way, the researcher does not wish to reject the null hypothesis that there is a significant difference between the observed and the estimated covariance matrices (Ho, 2006). The $\chi^{2}$ test is highly sensitive because of its statistical power. Almost every reasonable model can be rejected in SEM if a researcher only considers $\chi^{2}$ value and its associated probability (Ho, 2006). Thus, researchers complement $\chi^{2}$ statistic with other GOF measures. These include, normed $\chi^{2}\left(\chi^{2} / d f\right)$, standardised root mean square (SRMR) statistic and Hoelter's values at the 0.05 and 0.01 level. 
Goodness of Fit Index (GFI): The GFI measures how much better the model fits compared with no model at all. This nonstatistical measure varies between 0 (poor fit) and 1 (perfect fit) (Ho, 2006). Thus, a GFI value close to 1 resembles a better fit.

Root Mean Square Error of Approximation (RMSEA): The RMSEA has been viewed as "how well a model fits a population, not just a sample used for estimation" (Hair et al., 2010, p. 667). The RMSEA values between 0.05 and 0.08 are deemed acceptable, values ranging from 0.08 to 0.10 indicate an average fit and values greater than 0.10 indicate a poor fit (Ho, 2006). Although a lower RMSEA value (i.e. less than 0.05) indicates a better fit, the RMSEA value of zero would indicate a perfect fit (Byrne, 2006).

\subsubsection{Incremental fit measures}

The incremental fit measures compare the theoretical model to some baseline model, which is referred to as the null model (Ho, 2006). It differs from absolute fit measures. While the absolute fit measure assesses the proposed model's fit in terms of sample data, the incremental fit measure assesses the proposed model's fit to some alternative baseline model (or null model). The null model assumes that all observed variables are uncorrelated. The most common incremental fit indices are Tucker-Lewis index, normed fit index, incremental fit index and comparative fit index (Hair et al., 2010; Ho, 2006).

Tucker-Lewis Index (TLI): The TLI compares the chi-square values for the null model and the specified model. It ranges between 0 and 1 , and a TLI value close to 1 suggests a better fit (Hair et al., 2010).

Normed fit index (NFI): The NFI is one of the original incremental fit indices. This is the proportion in the chi-square value for the fitted model and a null model divided by the chi-square for the null model. It ranges between 0 and 1, and an NFI value close to 1 suggests a better fit (Hair et al., 2010). 
Incremental fit index (IFI): The IFI compares the lack of fit of the proposed model to the lack of fit of the null model. The IFI value estimates the relative improvement of the proposed model in term of per degree of freedom to a null model. It also ranges between 0 and 1, and an IFI value close to 1 suggests a better fit (Ho, 2006).

Comparative fit index (CFI): The CFI is an improved version of the NFI. The CFI value greater than 0.90 is usually associated with a model that fits well (Hair et al., 2010).

\subsubsection{Parsimonious fit measures}

Ho (2006, p. 286) stated that "in scientific research, theories should be as simple, or parsimonious, as possible". This study also stated that the parsimonious fit measures relate the GOF of the proposed model to the number of estimated coefficients required to achieve the level of fit. The common parsimonious fit indices are parsimonious normed fit index and parsimonious comparative fit index.

Parsimonious normed fit index (PNFI): The PNFI considers the number of degrees of freedom used to achieve a level of fit (Ho, 2006). The value of PNFI is used to compare one model to another with the highest PNFI value (Hair et al., 2010). Thus, a higher PNFI value (close to 1 ) is better for comparison of models (Ho, 2006).

Parsimonious comparative fit index (PCFI): The PCFI tests the proposed model's fit is not due to simply a result of greater model complexity. A higher PCFI value (close to 1) is better (Salmon \& Hall, 2001).

Adjusted Goodness of Fit Index (AGFI): The AGFI is an extension of GFI, and adjusted by the ratio of degrees of freedom for the proposed model to the degrees of freedom for the null model (Hair et al., 2010). Similar to GFI, the value of the AGFI closure to 1 indicate a better fit (Hair et al., 2010). 


\subsection{Chapter summary}

This chapter discussed the research method employed in this study. First, this chapter clarified the methodological approach and its justification. This study used methodological triangulation where both qualitative and quantitative approaches of research were implemented. Second, this study, then, discussed the qualitative and quantitative research methods.

Focus group technique with content analysis was employed to develop the research model for this study. For the purpose of quantitative analysis, the scale development process followed the suggestions of Churchill (1979). The methodological issues relevant to scales and indicators, the pilot testing and finalizing the questionnaire were addressed. One of the methodological contributions of this study is that it used online click-only survey following the suggestion of Dillman et al. (2009). Prior to data analysis, the data screening methods including non-response bias and tests of normality were also addressed. Then, the quantitative research method was employed to empirically examine reliability, validity and causal relationships of the model using SPSS and AMOS version 17. Thus, this study used exploratory factor analysis, confirmatory factor analysis and structural equation modelling. The analysis of the measurement model and the structural model followed the partial disaggregation method or the item parcelling technique in this study. Detail about this issue was also discussed. All relevant procedures with regard to data analysis were discussed stepby-step in this chapter. Finally, various fit indices including absolute fit measures, incremental fit measures and parsimonious fit measures and their respective standards were also discussed. 


\section{Chapter 5: Results}

\subsection{Introduction}

This chapter discusses the findings of statistical analyses of the data set collected through online survey. The objective of this chapter is to present a reliable and valid model using statistical measures to explain antecedents, dimensions and consequences of service quality phenomena in terms of a university. Thus, this chapter aims to present the findings of the quantitative research method employed in this study.

Section 5.2 of this chapter presents data cleaning in terms of outliers and normality tests, non-response bias. This section, then, discusses respondents' demographics and a brief descriptive statistics in order to better understand the data set. Section 5.3 discusses the results of data analysis including test of sphericity, measure of sampling adequacy, exploratory factor analysis and test of reliability. Various types of validity tests are discussed in section 5.4. The findings of the measurement model analysis are reported in section 5.5. The findings of the structural model estimation are reported in section 5.6. This chapter then proceeds to address each of the nine hypotheses identified in chapter 3 and discusses their results in determining and predicting the causal relationships in the model in section 5.7. Finally, section 5.8 summarises the chapter.

\subsection{Data cleaning, demographics and descriptive statistics}

This section provides information about the data set that was primarily entered for analysis purposes. First, it discusses the number of responses received from online survey and primary cleaning processes of the data set. Second, it discusses the data cleaning process in terms of outliers and normality tests and reports the results of non-response bias. Third, it then discusses respondents' demographics and brief descriptive statistics in order to better understand the data set. 


\subsubsection{Survey response}

A total of 1032 responses were received using online survey technique (a response rate of seven per cent compared to CQUniversity's student population). Reasons for a low response rate include junk mail, large number of invitations to participate in voluntary survey both online and paper-based, fast-paced culture, increased demand for students' paid hours and less willingness (Sax et al., 2003). In their study, Sax et al. (2003) demonstrated that Web-based survey receives a low response rate compared to paper-based survey.

It was stated earlier that 793 responses were found to have completed and 239 responses were incomplete. These incomplete responses were received from those respondents who attempted but quitted from the survey process. Thus, these incomplete responses were deleted before any primary analysis. A further 233 respondents were found to have six or less months of studying experience with CQUniversity, and these were deleted. There was no missing data due to 'required completion answer' constraint. Thus, a total of 560 responses were entered for normality tests.

\subsubsection{Assessment of normality and outliers}

Following the descriptive statistics, it is found that none of the variables are normally distributed. The skewness and the kurtosis values are ranging \pm 1 . There is no value showing an extreme score that exceeds critical values of \pm 2.58 and \pm 1.96 for skewness and kurtosis, respectively (Hair et al., 2010). However, a further attempt was made to identify the specific responses with extreme values and very different from the other data set. This refers to detecting outliers.

The standardised $z$ scores of \pm 3.29 for assessing univariate outliers and the Mahalanobis distance greater than $\chi^{2}(5)=20.52(\mathrm{p}<.001)$ for multivariate outliers were used for the assessment of normality of the data set (Pallant, 2007; Tabachnick \& Fidell, 2000). These analyses found 32 responses as univariate and multivariate outliers. Most of these responses were found to have taken extreme positions 
constantly in each of the variables. As these might affect overall statistical interpretation, these responses were deleted. Finally, a total of 528 responses entered for further statistical analyses. The response rate was estimated using two methods. First, the CASRO method (Alsnih \& Stopher, 2004) was used for determining the response rate. The formula is as follows:

$R R=\frac{S R}{E+e_{c} * U}$

Where:

$\mathrm{RR}=$ response rate, $\mathrm{SR}=$ completed interviews, $\mathrm{E}=$ eligible sample units, $\mathrm{e}_{\mathrm{c}}=\mathrm{CASRO}$ eligibility rate (eligible units divided by the sum of the eligible and ineligible units) and $U=$ unknown sample units refer to the sample units with unknown eligibility.

The CASRO eligibility rate $\left(\mathrm{e}_{\mathrm{c}}\right)$ is:

$e_{c}=\frac{14779+14779}{14779+14779+(1032-528)}=0.98$ or $98 \%$

$R R=\frac{1032}{14779+(0.98 \times 13747)} \quad=\quad 0.036$ or $3.6 \%$

Thus, the CASRO response rate is 3.6\%. Second, the general method of determining survey response rate was calculated and compared with the CASRO rate. Since this survey was conducted considering the census (i.e. student population) of the CQUniversity, the CASRO response rate was found equal to the general method of determining response rate: valid response received / total number of samples (in this case the population) $=528 / 14779=0.0357$ or $3.6 \%$. Although the response rate (3.6\%) is low, it is big enough (528 responses) to perform SEM analysis (see, for example, Bentler \& Chou, 1987; Gorsuch, 1983; Hair et al., 2010; Hoelter, 1983; Loehlin, 1992). 
The Kolmogorov-Smirnov (K-S) test was performed to examine the normality of the data set following the suggestions of the extant studies (Hair et al., 2010; Pallant, 2007). The results show that the sig. value is 0.000 for all of the variables, indicating that the sample violates the assumption of normality. This is quite common (Pallant, 2007 ) as the $\mathrm{K}-\mathrm{S}$ test is very sensitive to large sample size and not useable for a small sample size (Hair et al., 2010). One of the major reasons for significant $p$-values for all of the variables is that the sample collected for this study was from one university and the respondents belonged to various age groups, level of study and program of study.

\subsubsection{The non-response bias}

The total response entered for analysing non-response bias is 528. Research states that a low response rate alone does not necessarily suggest non-response bias (Sax et al., 2003). If respondents' characteristics are representative of non-respondents, low response rates are not biased (Dillman, 1991). In order to determine non-response bias, finally selected 528 responses were divided into two groups, early response and late response. This study defined early responses as the first $50 \%$ of the returned surveys and late responses as the other $50 \%$ of the returned surveys. Then these two groups were compared using independent sample $t$-tests for each of the variables at 0.05 significant levels. The results are shown in Appendix B. The results state that the $p$-values for each of the variables is greater than 0.05 in Levene's test for equality of variances, meaning that equal variances are assumed for the two groups compared (Ho, 2006; Pallant, 2007). Thus, there is no significant difference between the two groups on any of the variables considered for this study due to non-response.

\subsubsection{Demographics of the respondents}

The online survey collected demographic information from the respondents. The following sections briefly discuss the demographic information. Demographic information is important in social science research as this validates the data collected from respondents. 


\section{$\underline{\text { 5.2.4.1 Gender }}$}

The number of responses entered for analysis is 528. Of these useable responses, there were 389 and 139 responses received from female and male respondents, respectively. The chi-square $\left(\chi^{2}\right)$ test for goodness-of-fit for gender shows that the $\chi^{2}$ value is insignificant, $\chi^{2}(\mathrm{df}=1, \mathrm{n}=528)=0.029, p<0.86$, meaning that there is no significant difference in the proportion of male and female identified in the current sample as compared with the student population of the CQUniversity. One study found that response rates of female to male are consistently higher both in paper-based survey and web-based survey (Sax et al., 2003). The current study also finds that 73.7 per cent of the total response came from females, which is higher than 26.3 per cent response received from males. The total number of enrolled female and male students in 2009 was 7692 and 7087, respectively.

\subsubsection{Nationality}

The respondents identified themselves as the nationals of various countries or areas. It was found that 82.2 per cent of the respondents were Australian, 5.3 per cent was Indian, 1.7 per cent was from the United Kingdom, 1.5 per cent was Chinese and 1.1 per cent was from New Zealand. The remaining 8.2 per cent were from various countries or areas including Aboriginal and South Sea Islander, Bangladesh, Bhutan, Brazil, Canada, Colombia, Czech Republic, Denmark, Egypt, Fiji, Indonesia, Iran, Japan, Kenya, Malaysia, Mauritius, Myanmar, Nepal, Oman, Pakistan, Papua New Guinea, Peru, Poland, Russia, Saudi Arab, Singapore, South Africa, Solomon Islands, Spain, Sri Lanka, Sweden, Taiwan, Turkey, United States of America, United Arab Emirates, Vietnam, Venezuela and Zimbabwe.

\subsubsection{Age distribution}

It was revealed from the frequency analysis that 5.3 per cent of the respondents, yielding 28 responses, belonging to 21 year old age group and this group dominate the survey responses. Followed by this group is 4.9 per cent of the students, yielding 26 
responses, and they are 19 year old age group. The next group of students belong to 39 year old age group, totalling 21 responses or 4.0 per cent of the total response. Then the two groups of students belonging to 26 and 40 year old age groups provide 3.8 per cent of the total responses or 20 responses, respectively. Figure 6 shows number of responses in terms of age distribution.

Figure 6: Number of responses in terms of age distribution

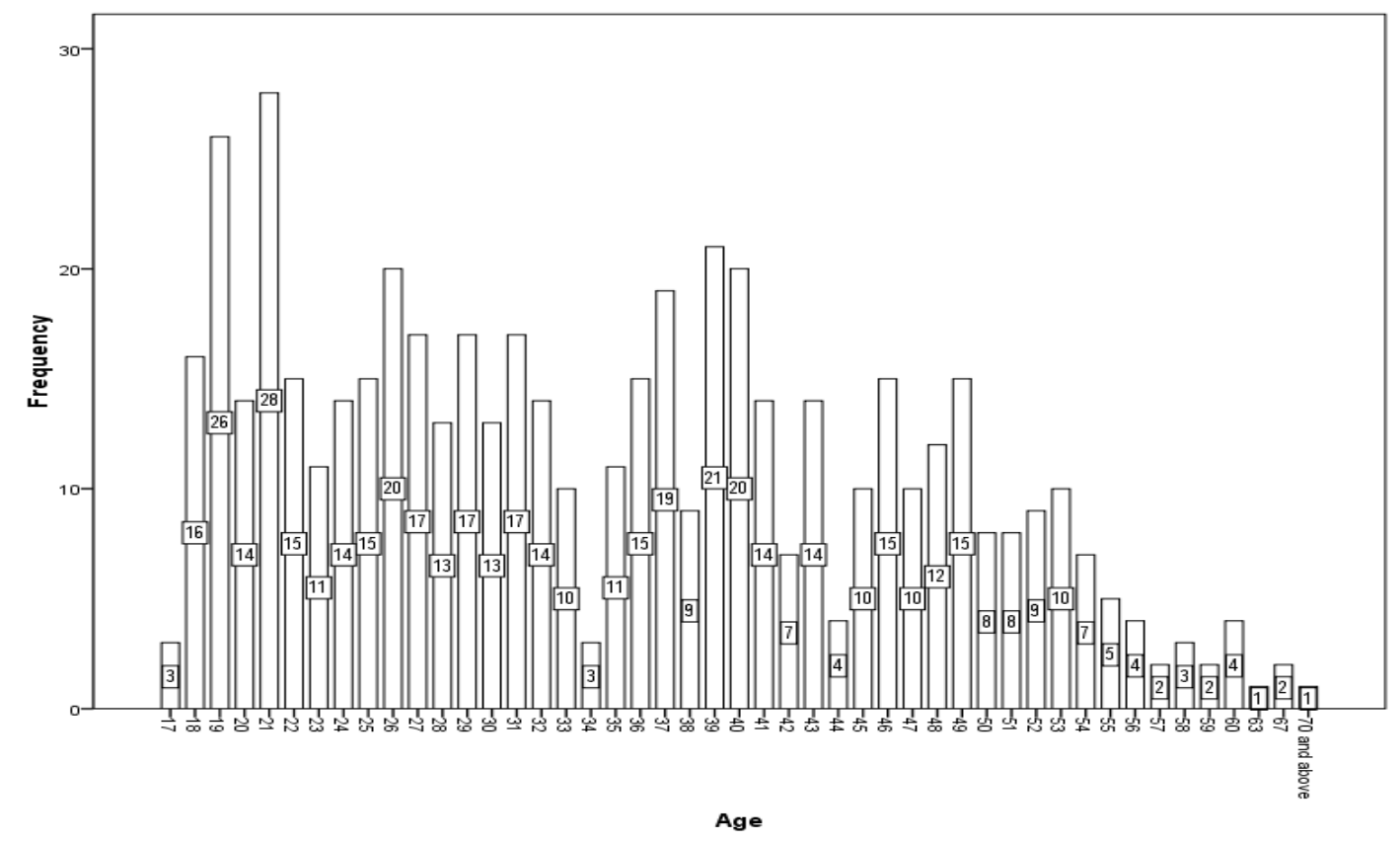

\subsubsection{Current mode and level of study}

The findings show that there were 259 students studying full-time, 223 students studying part-time and 46 students were identified as other category including distance, flex (external) students. Of these respondents, 3.6 per cent were enrolled in short courses, 5.5 per cent were enrolled in diploma programs, 75.2 per cent were enrolled in undergraduate programs, 12.5 per cent were enrolled in masters program and 3.2 per cent were enrolled in doctoral research program. Thus, the survey included representative students from all level of study programs in available study modes. 


\subsubsection{Current program of study}

The survey also tried to incorporate representative student samples across the major programs of study. The findings state that 22 per cent students were from business studies program, 6.6 per cent students were from information technology, 11 per cent students were from engineering and applied sciences, 22.3 percent students were from health sciences, 2.3 per cent students were from pure sciences, 16.5 per cent students were from arts and social sciences, and 19.3 per cent students were from other programs including education, learning management, public administration, environment and design, hospitality and tourism, accounting, social works, property, and music and communication. Thus, the pattern of distribution across current study programs attempted to cover the major programs offered by the CQUniversity. A chisquare $\left(\chi^{2}\right)$ goodness-of-fit test indicates no significant difference in the proportion of students studying in various programs identified in the current sample as compared with the student population of the CQUniversity, $\chi^{2}(\mathrm{df}=6, \mathrm{n}=528)=0.004, p<1.0$.

\subsubsection{Current location of the campus of study}

It was stated earlier that CQUniversity, Australia has four international campuses in Sydney, Melbourne, Brisbane and Gold Coast, and six regional/local campuses in Bundaberg, Emerald, Gladstone, Mackay, Noosa and Rockhampton at Australia. The online survey of the present study included sample students of all of these campuses. Figure 7 shows the number of responses received from the students in terms of these campuses. The other category in this figure refers to distance, flex and external students studying with CQUniversity. The highest responses (160) had been received from Sydney international campus, CQUniversity, Australia. A chi-square $\left(\chi^{2}\right)$ goodness-of-fit test indicates no significant difference in the proportion of students studying at various locations identified in the current sample as compared with the student population of the CQUniversity, $\chi^{2}(\mathrm{df}=10, \mathrm{n}=528)=1.321, p<0.99$. 
Figure 7: Number of responses in terms of CQUniversity campuses

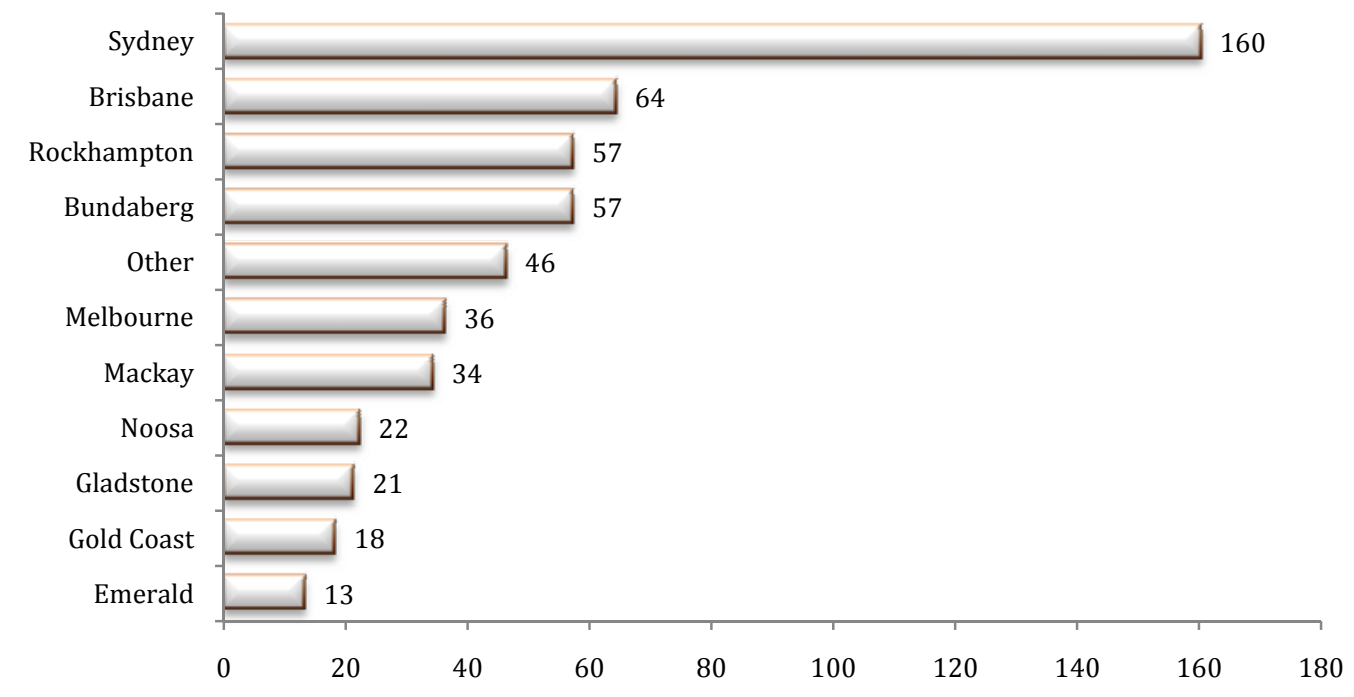

\subsubsection{Current length of study}

The students with seven or more months of experience of attending courses and/or programs at various campuses of CQUniversity, Australia were included for demography analysis. The following table shows respondents' current length of study, where most of the students (282) were found to have two or more years of studying experience with CQUniversity.

Table 10: Current length of study

\begin{tabular}{ccc}
\hline Current length & Number of Students & Percent \\
\hline$\geq 2$ year & 282 & $53.41 \%$ \\
\hline $13-23$ months & 82 & $15.53 \%$ \\
\hline 1 year & 75 & $14.20 \%$ \\
\hline $07-11$ months & 89 & $16.86 \%$ \\
\hline
\end{tabular}




\subsubsection{Average academic performance}

The frequency analyses revealed that 104 students received $85 \%-100 \%, 198$ students received $75 \%-84 \%, 148$ students received $65 \%-74 \%, 47$ students received $50 \%-64 \%$ and three students received $0 \%-49 \%$ marks on average. However, 28 students were found studying in research programs.

\subsubsection{Highest qualification planned for future study}

It was found that three students had planned for short courses, 31 students had planned for diploma programs, 305 students had planned for undergraduate or honours programs, 123 students had planned for masters' level study and 66 students had planned for doctoral level study.

The above summary of demographic variables provides an overview of the characteristics of respondents who provided the data for this research project. These also generalise the student population of the CQUniversity by ensuring the representativeness of the samples. In the following section, an overview of the descriptive statistics for each the measured variables are provided.

\subsubsection{An overview of the descriptive statistics}

The descriptive statistics provide an overview of the data set. The descriptive statistics were calculated before the data cleaning process in order to assess normality and outliers. Following the data cleaning process, the finally selected 528 cases entered for statistical analysis and a further descriptive statistics were calculated. Appendix C provides detailed descriptive statistics for each of the measured variables. In summary, the mean statistic exceeds 4 for each of the items, meaning that respondents exceed 'neutral' position and there is a tendency towards 'agree' zone (i.e. between 5 and 7) for each of the items. The standard deviation varies between 1.003 and 1.324. This is because the data for each of the variables were collected on a seven point Likert type scale and students rated their attitude between 1 (strongly disagree) and 7 (strongly agree). As a result, average dispersion of the data set from the mean values 
was between 1.003 and 1.324. None of the values of the items with regard to skewness and kurtosis are extreme (i.e. greater than \pm 1 ).

\subsection{Exploratory factor analysis and reliability test}

This section discusses the findings of Bartlett's test of sphericity, Kaiser-MayerOlkin (KMO) measure of sampling adequacy, Cronbach's Alpha value to examine reliability and exploratory factor analysis (principal component analysis) with varimax procedure for each of the constructs separately. All of the factors had an Eigenvalue of greater than 1.0.

\subsubsection{Information}

Following the focus group findings and item purification after pilot testing results, three instruments entered to measure the latent variable, 'information'. The EFA results revealed a single factor solution. Table 11 shows that the KMO measure is well above 0.50 as suggested by De Vaus (2001). As the KMO statistic is 0.62 , it is also in line with the suggestion provided by Pallant (2007). The $p$-value of the Bartlett's test of sphericity is also less than 0.05, meaning that it was suitable for factor analysis. The single factor solution of the latent variable, information, shows that the three items were substantially loaded (i.e. greater than \pm 0.30 ) on this latent variable (Hair et al., 2010; Ho, 2006). The Cronbach's Alpha coefficient is 0.71 for the entire scale, suggesting a good reliability (DeVellis, 2003; Pallant, 2007). 
Table 11 Information: exploratory factor analysis and reliability test results

\begin{tabular}{|c|c|c|}
\hline Items & Factor Loading & Cronbach's Alpha \\
\hline $\begin{array}{l}\text { Overall, information provided by this University helps } \\
\text { me find service attributes (In_3) }\end{array}$ & 0.861 & \\
\hline $\begin{array}{l}\text { Advertisements about this University are a good } \\
\text { source of information (In_2) }\end{array}$ & 0.824 & 0.71 \\
\hline $\begin{array}{l}\text { Information provided by this University makes } \\
\text { promises about their quality (In_1) }\end{array}$ & 0.701 & \\
\hline Bartlett's test of sphericity & \multicolumn{2}{|c|}{$\chi^{2}=326.9, \mathrm{df}=3$, sig. $<0.001$} \\
\hline Kaiser-Mayer-Olkin measure of sampling adequacy & \multicolumn{2}{|l|}{0.62} \\
\hline Total variance explained (\%) & \multicolumn{2}{|l|}{62.801} \\
\hline
\end{tabular}

\subsubsection{Past experience}

Three items entered to measure past experience of students following the focus group and item purification after pilot testing results. Table 12 shows that the KMO measure is 0.60 , which is in line with the suggestions provided by the current literature (De Vaus, 2001; Pallant, 2007). The Bartlett's test of sphericity $(p<0.05)$ shows that it was suitable for factor analysis. The single factor solution of the latent variable, past experience, shows that the three items were substantially loaded (i.e. greater than \pm 0.30 ) on this latent variable (Hair et al., 2010; Ho, 2006). The Cronbach's Alpha coefficient is 0.70 for the entire scale, suggesting a good reliability (DeVellis, 2003; Pallant, 2007). 
Table 12 Past experience: exploratory factor analysis and reliability test results

\begin{tabular}{|c|c|c|}
\hline Items & Factor Loading & Cronbach's Alpha \\
\hline $\begin{array}{l}\text { Overall, my past educational experience helps to } \\
\text { assess performance of this University (PE_3) }\end{array}$ & 0.837 & \\
\hline $\begin{array}{l}\text { My previous study background helps me to predict the } \\
\text { service quality of this University (PE_1) }\end{array}$ & 0.831 & 0.70 \\
\hline $\begin{array}{l}\text { Before enrolling, I had a good relationship with this } \\
\text { University (PE_2) }\end{array}$ & 0.622 & \\
\hline Bartlett's test of sphericity & \multicolumn{2}{|c|}{$\chi^{2}=259.4, \mathrm{df}=3$, sig. $<0.001$} \\
\hline Kaiser-Mayer-Olkin measure of sampling adequacy & \multicolumn{2}{|l|}{0.60} \\
\hline Total variance explained (\%) & \multicolumn{2}{|l|}{59.284} \\
\hline
\end{tabular}

\subsubsection{Service quality}

A total of 26 items (derived from the literature review, focus group findings and item purification after pilot testing results) entered for factor analysis. The EFA shows three components, academic service quality (ACSQ), administrative service quality (ADSQ) and facilities service quality (FSQ) (see Table 13). Factor loadings below 0.30 were suppressed following the suggestion of Hair et al. (2010) and Ho (2006). Table 13 shows that the KMO measure is 0.954 , which in line with the suggestions provided by the extant studies (De Vaus, 2001; Pallant, 2007). The Bartlett's test of sphericity $(p<0.05)$ shows that it was suitable for factor analysis. The three factor solution of the latent variable, service quality, shows that the corresponding items were substantially loaded (i.e. greater than \pm 0.30 ) onto three components (or dimensions), ACSQ, ADSQ and FSQ. The Cronbach's Alpha coefficient of ACSQ, ADSQ and FSQ are 0.937, 0.943 and 0.848, respectively, and these suggest good internal consistencies of the dimensions of service quality.

The ACSQ refers to those service attributes that are relevant to teaching quality and ability, course development and teacher-student relationships in order to provide core academic values and/or benefits to the students. Students prefer the lecturer to be 
interactive during class time and after hour consultation, understandable in providing feedback and students' requirements, skilled and knowledgeable in terms of teaching and research, interested to solve students' academic problems, and should have an excellent academic background. Thus, these critical service attributes provide the core benefits/values to the students during their enrolment.

The ADSQ refers to those service attributes that are relevant to skills and abilities of the administrative and supporting staff, and their relationships with students in order to provide smooth functioning of academic activities at a university. The ADSQ has similar importance in overall assessment of service quality in the context of higher education. The administrative staff should be skilful and be able to provide prompt and effective support service to the students, be consultative in terms of career counselling, and be courteous and friendly. These are critical service attributes for providing the support services to smooth running the programs/courses.

The FSQ refers to those service attributes that are required to create a good higher education environment. This refers to good infrastructure, classroom facilities and virtual/practical learning, up-to-date equipment, library facilities, location and environment. Thus, this study finds three categories (or dimensions) of service quality, namely, ACSQ, ADSQ and FSQ, in the context of CQUniversity. These dimensions are related to core attributes of higher educational services that students encounter during their study. 
Table 13 Service quality: exploratory factor analysis and reliability test results

\begin{tabular}{|c|c|c|c|c|}
\hline \multirow{2}{*}{ Items } & \multicolumn{3}{|c|}{ Factor Loading } & \multirow{2}{*}{$\begin{array}{l}\text { Cronbach's } \\
\text { Alpha }\end{array}$} \\
\hline & ACSQ & ADSQ & FSQ & \\
\hline $\begin{array}{l}\text { Lecturers show sincere interest in solving my academic } \\
\text { problems (SQ_2) }\end{array}$ & 0.839 & & & \multirow{9}{*}{0.937} \\
\hline I find that lecturers are skilled in teaching (SQ_6) & 0.800 & & & \\
\hline Lecturers provide feedback about my progress (SQ_4) & 0.774 & & & \\
\hline The teaching staff meet my requirements (SQ_25) & 0.773 & & & \\
\hline $\begin{array}{l}\text { My overall evaluation of the service quality provided by the } \\
\text { teaching staff of this University is good (SQ_23) }\end{array}$ & 0.741 & & & \\
\hline I receive adequate time for consultation with lecturers (SQ_5) & 0.734 & & & \\
\hline I find that academics at this University are knowledgeable (SQ_1) & 0.706 & & & \\
\hline The academic backgrounds of the lecturers are excellent (SQ_7) & 0.658 & & & \\
\hline My academic performance is recorded correctly (SQ_3) & 0.556 & & & \\
\hline $\begin{array}{l}\text { I find that the administrative staff is prompt to provide service } \\
\text { (SQ_9) }\end{array}$ & & 0.859 & & \multirow{10}{*}{0.943} \\
\hline I find that the administrative staff is courteous (SQ_8) & & 0.848 & & \\
\hline The administrative staff meet my requirements (SQ_26) & & 0.823 & & \\
\hline I find that the administrative staff keeps accurate records (SQ_10) & & 0.802 & & \\
\hline I find that the administrative staff is skilled (SQ_13) & & 0.800 & & \\
\hline $\begin{array}{l}\text { My overall evaluation of the service quality provided by the } \\
\text { administrative staff of this University is good (SQ_24) }\end{array}$ & & 0.783 & & \\
\hline $\begin{array}{l}\text { The admission department of this University is very helpful } \\
\text { (SQ_11) }\end{array}$ & & 0.705 & & \\
\hline $\begin{array}{l}\text { My overall evaluation of quality with regard to support } \\
\text { functions of this University is good (SQ_22) }\end{array}$ & & 0.584 & & \\
\hline The overall environment of this University is friendly (SQ_14) & & 0.524 & & \\
\hline $\begin{array}{l}\text { I find that the University's career counselling service is very } \\
\text { helpful (SQ_12) }\end{array}$ & & 0.402 & & \\
\hline I find that this University has good infrastructure (SQ_20) & & & 0.767 & \multirow{7}{*}{0.848} \\
\hline I find that the classroom facilities are adequate (SQ_18) & & & 0.760 & \\
\hline I find that this University has up-to-date equipment (SQ_17) & & & 0.699 & \\
\hline I find that the library facilities are adequate (SQ_19) & & & 0.661 & \\
\hline I find that the scenic beauty of this University is excellent (SQ_21) & & & 0.627 & \\
\hline The location of the University is ideal (SQ_16) & & & 0.507 & \\
\hline I find that classroom learning is very practical (SQ_15) & & & 0.443 & \\
\hline Bartlett's test of sphericity & \multicolumn{4}{|c|}{$\chi^{2}=11188.6, \mathrm{df}=351$, sig. $<0.001$} \\
\hline Kaiser-Mayer-Olkin measure of sampling adequacy & \multicolumn{4}{|c|}{0.954} \\
\hline Total variance explained $(\%)$ & \multicolumn{4}{|l|}{63.473} \\
\hline
\end{tabular}




\subsubsection{Satisfaction}

The seven items were developed to measure satisfaction through the literature review and focus group findings, and subsequent finalization of these instruments was made through pilot testing. Table 14 provides a summary of the findings derived from EFA and reliability test results.

Table 14 Satisfaction: exploratory factor analysis and reliability test results

\begin{tabular}{|c|c|c|}
\hline Items & Factor Loading & Cronbach's Alpha \\
\hline Overall, I am satisfied with this University (S_4) & 0.938 & \multirow{7}{*}{0.942} \\
\hline Overall, it is a good University (S_3) & 0.915 & \\
\hline Overall, this University fulfils my needs (S_5) & 0.907 & \\
\hline It has been a good decision to select this University (S_7) & 0.880 & \\
\hline Overall, I am satisfied with the service performance (S_1) & 0.872 & \\
\hline Overall, I am satisfied with the quality relative to price (S_2) & 0.771 & \\
\hline $\begin{array}{l}\text { Overall, this University provides satisfaction compared } \\
\text { to an alternate higher education institution (S_6) }\end{array}$ & 0.764 & \\
\hline Bartlett's test of sphericity & \multicolumn{2}{|c|}{$\chi^{2}=3506, \mathrm{df}=21$, sig. $<0.001$} \\
\hline Kaiser-Mayer-Olkin measure of sampling adequacy & 0.919 & \\
\hline Total variance explained (\%) & 75.05 & \\
\hline
\end{tabular}

Table 14 shows that the KMO measure is 0.919 , which in line with the suggestions provided by the existing studies (De Vaus, 2001; Pallant, 2007). The Bartlett's test of sphericity $(p<0.05)$ shows that it was suitable for factor analysis. The one factor solution of the latent variable, satisfaction, shows that the corresponding items were substantially loaded (i.e. greater than \pm 0.30 ). The item loadings vary between 0.764 and 0.938. The Cronbach's Alpha coefficient of the entire scale is 0.942 that suggests good internal consistency of the satisfaction scale. 


\subsubsection{Trust}

Following the focus group findings and subsequent purification through pilot survey results, eleven items were developed. One item was derived from the literature review. Table 15 provides a summary of the findings of EFA and reliability test results.

Table 15 Trust: exploratory factor analysis and reliability test results

\begin{tabular}{|c|c|c|}
\hline Items & Factor Loading & Cronbach's Alpha \\
\hline I trust this University (T_4) & 0.913 & \multirow{12}{*}{0.953} \\
\hline I can depend on this University ( $\mathrm{T} \_3$ ) & 0.906 & \\
\hline Overall, this University is honest with me $\left(T_{-} 10\right)$ & 0.865 & \\
\hline I feel secure at this University (T_2) & 0.848 & \\
\hline This University provides reliable quality of services ( $T_{-} 7$ ) & 0.840 & \\
\hline This University guarantees satisfaction ( $\mathrm{T}_{-}$) & 0.838 & \\
\hline This University guarantees best value ( $\mathrm{T}_{-} 6$ ) & 0.819 & \\
\hline The University staff are trustworthy $\left(\mathrm{T}_{-} 1\right)$ & 0.816 & \\
\hline My emotional relationship with this University is strong (T_9) & 0.775 & \\
\hline I find that this University keeps promises $\left(\mathrm{T}_{-} 11\right)$ & 0.755 & \\
\hline I always get help from staff, if I ask for it (T_12) & 0.728 & \\
\hline I am confident that I will get a good job after graduation (T_8) & 0.700 & \\
\hline Bartlett's test of sphericity & \multicolumn{2}{|c|}{$\chi^{2}=5841, \mathrm{df}=66$, sig. $<0.001$} \\
\hline Kaiser-Mayer-Olkin measure of sampling adequacy & 0.940 & \\
\hline Total variance explained (\%) & 66.90 & \\
\hline
\end{tabular}

Table 15 shows that both Bartlett's test of sphericity $(p<0.05)$ and KMO statistic $(0.94)$ are satisfactory. The EFA provided one factor solution of the latent variable, trust. The twelve items are substantially loaded on this latent variable. They are between 0.70 and 0.913. The Cronbach's Alpha coefficient of the entire scale is 0.953, suggesting a good internal consistency of the trust measure. 


\subsubsection{Brand Performance}

Following the focus group findings and subsequent purification through pilot survey results, eight items were developed. Table 16 provides a summary of the findings of EFA and reliability test results.

Table 16 Brand performance: exploratory factor analysis and reliability test results

\begin{tabular}{|c|c|c|}
\hline Items & Factor Loading & Cronbach's Alpha \\
\hline CQUniversity as a brand is reliable (BP_5) & 0.899 & \multirow{8}{*}{0.935} \\
\hline A degree from this University is worthy ( $\mathrm{BP} \_2$ ) & 0.884 & \\
\hline This university performs well (BP_4) & 0.871 & \\
\hline I found that this University has a good reputation (BP_3) & 0.870 & \\
\hline I am proud to be a student of this University (BP_1) & 0.865 & \\
\hline A degree from this University enhances employability (BP_7) & 0.818 & \\
\hline The graduates of this University receive a good salary (BP_6) & 0.727 & \\
\hline Employers prefer graduates from this University (BP_8) & 0.701 & \\
\hline Bartlett's test of sphericity & \multicolumn{2}{|c|}{$\chi^{2}=3650.7, \mathrm{df}=28$, sig. $<0.001$} \\
\hline Kaiser-Mayer-Olkin measure of sampling adequacy & \multicolumn{2}{|l|}{0.915} \\
\hline Total variance explained $(\%)$ & \multicolumn{2}{|l|}{69.24} \\
\hline
\end{tabular}

Table 16 shows that both Bartlett's test of sphericity $(p<0.05)$ and KMO statistic (0.915) are satisfactory. The EFA provided one factor solution of the latent variable, brand performance. The eight items are substantially loaded on this latent variable ranging between 0.701 and 0.899 . The Cronbach's Alpha coefficient of the entire scale is 0.935 , indicating a good reliability of the brand performance scale. 


\subsubsection{Behavioural intention}

The six items were developed to measure behavioural intention through literature review and focus group findings, and subsequent finalization of these instruments was made through pilot testing. Table 17 provides the findings.

Table 17 Behavioural intention: exploratory factor analysis and reliability test results

\begin{tabular}{|c|c|c|}
\hline Items & Factor Loading & Cronbach's Alpha \\
\hline If I had to choose today, I would select this University (BI_4) & 0.898 & \multirow{6}{*}{0.940} \\
\hline $\begin{array}{l}\text { If I had to choose today, I would select the study } \\
\text { programs of this University (BI_6) }\end{array}$ & 0.887 & \\
\hline I will recommend others to study at this University (BI_1) & 0.882 & \\
\hline $\begin{array}{l}\text { I will definitely consider this University as my future } \\
\text { study destination (BI_2) }\end{array}$ & 0.878 & \\
\hline $\begin{array}{l}\text { I will recommend the study programs of this } \\
\text { University to others (BI_5) }\end{array}$ & 0.877 & \\
\hline $\begin{array}{l}\text { I will recommend this University in preference to } \\
\text { other options (BI_3) }\end{array}$ & 0.875 & \\
\hline Bartlett's test of sphericity & \multicolumn{2}{|c|}{$\chi^{2}=3832.33, \mathrm{df}=28$, sig. $<0.001$} \\
\hline Kaiser-Mayer-Olkin measure of sampling adequacy & 0.913 & \\
\hline Total variance explained $(\%)$ & 71.183 & \\
\hline
\end{tabular}

Table 17 shows that both Bartlett's test of sphericity $(p<0.05)$ and KMO statistic (0.913) are satisfactory. The EFA provided one factor solution of the latent variable, behavioural intention. The six items are substantially loaded on this latent variable ranging between 0.875 and 0.898 . The Cronbach's Alpha coefficient of the entire scale is 0.940 , indicates a good reliability of the behavioural intention scale.

The factor loadings of individual construct show that items are substantially loaded onto their corresponding factor and that these items measure only their respective 
construct. Thus, these findings also ensure the unidimensionality of each of the scales (a further discussion is placed below). Overall the exploratory factor analysis, reliability test, KMO measure of sampling adequacy and Bartlett's test of sphericity using SPSS provided satisfactory findings. The following section provides the results of the validity tests.

\subsection{Validity tests}

There are three types of validity tests, convergent validity, discriminant or divergent validity, and nomological or predictive validity. These validity tests were performed using SPSS and AMOS within exploratory and confirmatory factor analyses, respectively. The following paragraphs discuss the findings of the validity tests.

\subsubsection{Convergent validity}

The convergent validity shows that the items uniquely measure their respective construct as hypothesised. There are several ways to find convergent validity. In this study four approaches were undertaken and examined. First, the EFA results show that the factor loadings of 'information' vary between 0.861 and 0.701 ; 'past experience' vary between 0.837 and 0.622 ; 'ACSQ' vary between 0.839 and 0.556 ; 'ADSQ' vary between 0.859 and 0.402 ; 'FSQ' vary between 0.767 and 0.443 ; 'satisfaction' vary between 0.938 and 0.764 ; 'trust' between 0.913 and 0.700 ; 'brand performance' between 0.899 and 0.701 ; and 'behavioural intention' between 0.898 and 0.875. Hair et al. (2010) suggested that a good rule of thumb is that standardised loadings should be minimum 0.5 or higher, and ideally 0.7 or higher. Examining the factor loadings, it was evident that one item of FSQ (SQ_15) and one item of ADSQ (SQ_12) were having 0.443 and 0.402 loadings. These two items were incorporated as these were close to 0.5 and derived from focus group findings.

Second, the CFA can analyse convergent validity of the items within the construct using the critical ratio values. The critical ratio (c.r.) value greater than 1.96 with a $p-$ value of less than 0.05 suggests strong convergent validity (Wong \& Merrilees, 
2007b). The CFA findings for each of the items of their respective constructs show that the critical ratio values were greater than 1.96 and these were significant at the 0.05 level.

Third, the average variance extracted (AVE) was computed for each of the latent constructs using the square root of total variance explained found through EFA. The results showed that in every case the AVE was greater than $50 \%$ (or 0.5 ), suggested a good convergent validity for each of the constructs (Hair et al., 2010).

Fourth, a good reliability estimate (i.e. Cronbach's Alpha should be 0.7 or higher) for each of the latent constructs indicates that the items are measuring the same latent construct consistently (Hair et al., 2010). The Cronbach's Alpha coefficients for the constructs were between 0.70 and 0.953 that suggested that each of the latent constructs were adequately converged. Overall, the four approaches used to measure convergent validity were quite satisfactory.

\subsubsection{Discriminant validity}

The discriminant validity shows that one construct is uniquely different from other constructs in the model. Three approaches were adopted to ensure discriminant validity. First, there were nine constructs that formed 36 pairs. Thus, pairwise chisquare $\left(\chi^{2}\right)$ difference tests at a time were performed for discriminant validity checks using AMOS. Examining AMOS output for each pair, it was found that the $\chi^{2}$ difference for each of the pairs was significant $(p$-value $<0.01)$. Thus, the results suggest the existence of discriminant validity.

Second, the AVE estimate and the squared correlation estimate were compared. Table 18 shows the results. The discriminant validity exists when AVE estimate is greater than the squared correlation estimate between pairs of factors (Fornell \& Larcker, 1981; Hair et al., 2010; Wong \& Merrilees, 2007b). The upper diagonal of Table 18 represents the AVE and the lower diagonal represents the squared correlation estimate. The results show that in every respect the estimated AVE for each pair of construct is 
greater than the squared correlation estimate for that pair. Thus, discriminant validity is established.

Third, the 36 pairs entered (pairwise items) for exploratory factor analyses using principal components with varimax rotation using SPSS in order to examine if the result produce two component extracted for each pair of constructs. The results showed that each time there were always two components with their respective items. Thus, this further ensured discriminant validity.

Table 18: Discriminant validity test using AVE and squared correlation method

\begin{tabular}{llllllllll}
\hline Constructs & IN & PE & ACSQ & ADSQ & FSQ & S & T & BP & BI \\
\hline IN & - & 0.783 & 0.813 & 0.821 & 0.752 & 0.845 & 0.814 & 0.822 & 0.860 \\
\hline PE & 0.16 & - & 0.807 & 0.811 & 0.746 & 0.838 & 0.808 & 0.816 & 0.856 \\
\hline ACSQ & 0.21 & 0.19 & - & 0.825 & 0.785 & 0.843 & 0.823 & 0.826 & 0.852 \\
\hline ADSQ & 0.18 & 0.16 & 0.40 & - & 0.790 & 0.844 & 0.826 & 0.829 & 0.852 \\
\hline FSQ & 0.21 & 0.13 & 0.33 & 0.29 & - & 0.802 & 0.789 & 0.789 & 0.812 \\
\hline S & 0.20 & 0.18 & 0.50 & 0.40 & 0.33 & - & 0.837 & 0.860 & 0.883 \\
\hline T & 0.31 & 0.22 & 0.56 & 0.44 & 0.37 & 0.60 & - & 0.832 & 0.846 \\
\hline BP & 0.34 & 0.16 & 0.39 & 0.33 & 0.27 & 0.54 & 0.58 & - & 0.872 \\
\hline BI & 0.26 & 0.18 & 0.34 & 0.27 & 0.23 & 0.49 & 0.49 & 0.54 & - \\
\hline
\end{tabular}

Overall, the results of convergent validity and discriminant validity tests show that there is a substantial degree of unidimensionality structure within and between the constructs. The following section discusses the results of measurement model analysis, where all the constructs and their respective items entered with the CFA framework simultaneously. 


\subsubsection{Nomological and predictive validity}

Nomological validity has been tested by examining the coefficient of correlation among the constructs. The matrix of constructs' correlation is a useful tool in this assessment (Hair et al., 2010). Among the seven main constructs (namely, information, past experience, service quality, satisfaction, trust, brand performance and behavioural intention), the coefficient of correlations $(0.26 \geq r \geq 0.85)$ are significant at the 0.01 level. This suggests that nomological validity among the constructs exist in the measurement theory.

In order to determine predictive ability of the aforesaid constructs, the regressions weights and their respective significance levels are considered (see Table 19). As, the construct, behavioural intention, does not predict the occurrence of any construct it is excluded. The results of predictive validity tests show that constructs reasonably predicts the occurrence of other constructs. The unstandardised estimates vary between 0.153 and 0.974 . The $p$-values for past experience $\rightarrow$ service quality and satisfaction $\rightarrow$ trust are 0.02 and 0.036 (i.e. $p<0.05$ ), respectively. The $p$-values for other relationships are significant at the 0.01 level (denoted by *** in Table 19). These findings indicate that one construct reasonably predicts the occurrence of the other construct as specified in the research model. Thus, predictive ability is achieved. The standard error estimates vary between 0.046 and 0.093 , and the critical ratios are all above 1.96.

Table 19: Predictive validity of the latent constructs

\begin{tabular}{|c|c|c|c|c|}
\hline Direction of Relationships & Estimate & S.E. & C.R. & $\mathbf{P}$ \\
\hline Service_Quality $\leftarrow$ Past_Experience & 0.216 & 0.093 & 2.333 & .020 \\
\hline Service_Quality $\leftarrow$ Information & 0.792 & 0.078 & 10.154 & $* * *$ \\
\hline Satisfaction $\leftarrow$ Service_Quality & 0.974 & 0.046 & 21.368 & $* * *$ \\
\hline Trust $\leftarrow$ Service_Quality & 0.911 & 0.089 & 10.245 & $* * *$ \\
\hline Trust $\leftarrow$ Satisfaction & 0.153 & 0.073 & 2.096 & .036 \\
\hline Brand_Performance $\leftarrow$ Trust & 0.521 & 0.063 & 8.322 & $* * *$ \\
\hline Brand_Performance $\leftarrow$ Satisfaction & 0.321 & 0.062 & 5.181 & $* * *$ \\
\hline Behavioural_Intention $\leftarrow$ Brand_Performance & 0.763 & 0.071 & 10.697 & $* * *$ \\
\hline Behavioural_Intention $\leftarrow$ Satisfaction & 0.315 & 0.065 & 4.834 & $* * *$ \\
\hline
\end{tabular}




\subsection{Measurement model analysis}

The measurement model within the CFA framework tests all the latent variables (constructs) and their respective indicators at one time. It shows how constructs are operationalised by sets of measured variables (Hair et al., 2010). Following the suggestions of unidimensionality structure of each of the scales in a measurement theory, this study used the partial disaggregation method or the item parcelling method to analyse the measurement model (Bandalos, 2002; Little et al., 2002). The advantages of item parcelling method were discussed in section 4.4.9. Two parcels were formed for each of the nine constructs following the suggestions of the extant studies (Bentler \& Chou, 1987; Landis et al., 2000; Little et al., 2002). The single factor method was used following the suggestion of Landis et al. (2000). Specifically, composite one contained highest loading and lowest loading, composite two contained next highest loading and next lowest loading, and this procedure continued until the end item belongs to either composite one or composite two. If there were an odd number of items, the extra item was placed into the composite two. Appendix D shows the making of composites. In the next stage, the measurement model was tested using maximum likelihood estimation within a CFA framework. The measurement model estimation maximises the likelihood of observing the available data that may represent the parameters in the same population (Wong, 2005). The following figure shows the measurement model. The results of various fit indices along with their accepted norms are reported in Table 20. 
Figure 8: The measurement model

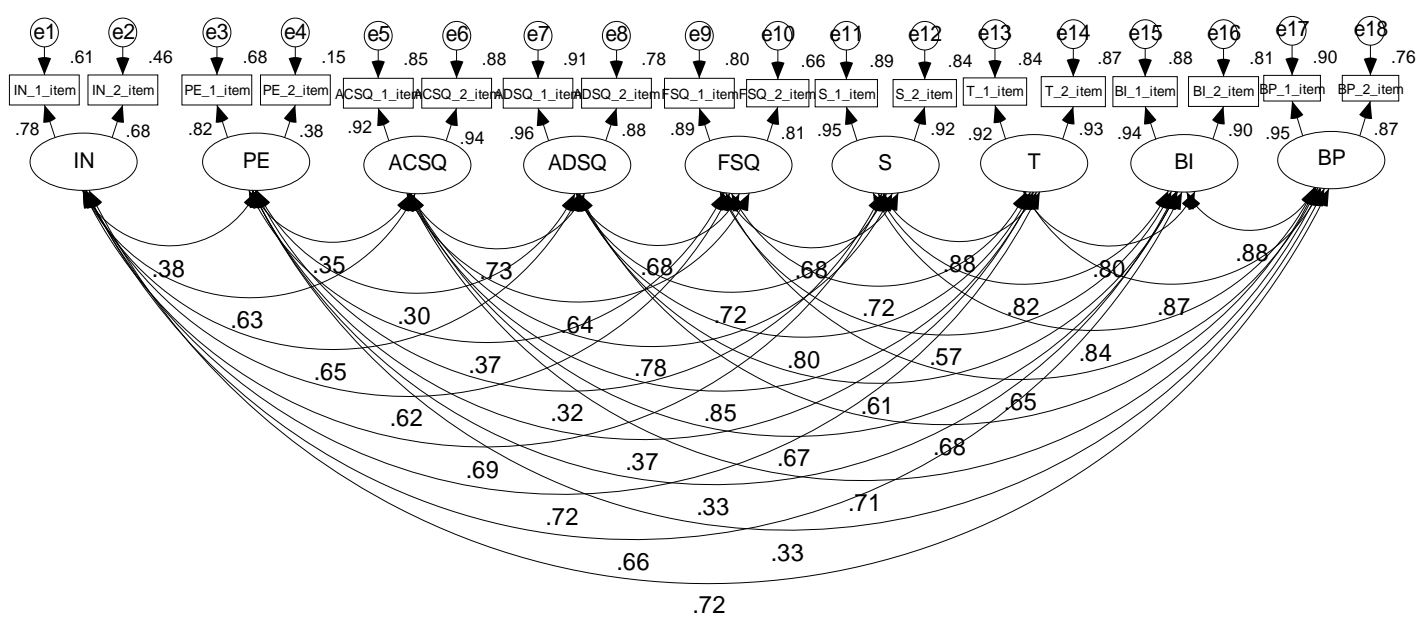

\subsubsection{Absolute fit measures}

The results of absolute fit measures show that GFI, RMSEA and RMR are within the cut-off points of their respective fit indices. The $p$-value of the $\chi^{2}$ is less than 0.01 . The value of $\chi^{2}$ is very sensitive to number of parameters used in the study and the size of the sample. Hair et al. (2010) stated two particular problems that are associated with $\chi^{2}$ estimation. First, increased sample size results in increased $\chi^{2}$ value. Second, the $\chi^{2}$ statistic is also increased when the number of observed variables is increased. As a result, studies show growing concern when using $\chi^{2}$ statistic and its associated $p$ value as a sole fit index (Anderson \& Gerbing, 1988; Hair et al., 2010; Ho, 2006). The associated $p$-value of the $\chi^{2}$ tests become less meaningful if the sample size is large and/or the number of observed variables is large (Anderson \& Gerbing, 1988; Hair et al., 2010; Ho, 2006). There are other three alternative measures, Hoelter's critical N, Standardised Root Mean Residual (SRMR) and Normed $\chi^{2}$, which are used to examine the acceptance of the model with the same $\chi^{2}$ value and degrees of freedom. 
Table 20: The results of measurement model and accepted norms of fit measures

\begin{tabular}{|c|c|c|c|}
\hline Type & Fit Index & Accepted Norms* & The measurement model \\
\hline \multirow{6}{*}{ 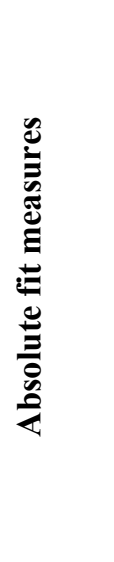 } & $\chi^{2}$ & $\chi^{2}$ value should be less with $p>.05$. & $\chi^{2}(\mathrm{~N}=528, \mathrm{df}=99)=156.8, p<0.01$ \\
\hline & $\chi^{2} / \mathbf{d f}$ & A value 3.0 or less & 1.58 \\
\hline & GFI & A value close to 1.0 is a better fit. & 0.968 \\
\hline & RMSEA & $\begin{array}{l}0.05-0.08 \text { acceptable fit; } 0.08-0.1 \\
\text { average fit; } 0.1 \text { and above poor fit } \\
\text { to a population. }\end{array}$ & 0.033 \\
\hline & RMR & A value close to zero is a better fit. & 0.021 \\
\hline & SRMR & A value less than 0.10 . & 0.0183 \\
\hline \multirow{5}{*}{ 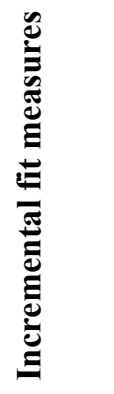 } & TLI & A value close to 1.0 is a better fit. & 0.989 \\
\hline & NFI & A value close to 1.0 is a better fit. & 0.981 \\
\hline & IFI & A value close to 1.0 is a better fit. & 0.993 \\
\hline & RFI & A value close to 1.0 is a better fit. & 0.971 \\
\hline & CFI & A value close to 1.0 is a better fit. & 0.993 \\
\hline \multirow{3}{*}{ 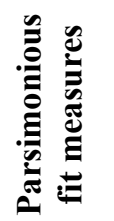 } & AGFI & A value close to 1.0 is a better fit. & 0.944 \\
\hline & PNFI & A higher value is a better fit. & 0.635 \\
\hline & PCFI & A higher value is a better fit. & 0.643 \\
\hline
\end{tabular}

*Developed from Hair et al. (2010) and Ho (2006)

The results of Hoelter's critical $N$ of the present study is 414 at the 0.05 level and 453 at the 0.01 level. In both of these cases, Hoelter values exceeds 200 (Hoelter, 1983), meaning that the model achieves its acceptance at the 0.05 and 0.01 level if the largest samples are 414 and 453, respectively. The Normed $\chi^{2}$ is a ratio between $\chi^{2}$ and degrees of freedom. The accepted norm of $\chi^{2} / \mathrm{df}$ is 3.0 or less (Hair et al., 2010). The Normed $\chi^{2}$ of the measurement model is 1.58 that it indicates a reasonable model fit when considering the sample size effect. The SRMR value of the measurement model is 0.0183 . As a rule of thumb, an SRMR over 0.1 suggests a problem with fit (Hair et al., 2010). These three measures justify that the model is within the acceptable range 
of the fit, and that the estimated $\chi^{2}$ value $(p<0.01)$ may be due to the sample size of this study. Overall, the absolute fit measures are satisfactory for the acceptance of the measurement model.

\subsubsection{Incremental fit measures}

The results of the incremental fit indices including TLI, NFI, IFI, CFI and RFI are satisfactory in that they all show their respective values over 0.90 or close to 1.0 (Hair et al., 2010; Ho, 2006). As a result, the measurement model is acceptable in terms of incremental fit measures.

\subsubsection{Parsimonious fit measures}

The parsimonious fit measures are conceptually similar to the notion of adjusted $R^{2}$. These indices provide information about which model among a set of competing models is best (Hair et al., 2010). Although the parsimonious fit measures compare relative efficacy of the competing model, a number of studies argue that parsimony can be taken into account when evaluating one model (Hair et al., 2010; Ho, 2006). The AGFI is 0.944 , stating a close fit of the model in terms of parsimony. The PNFI and the PCFI are 0.635 and 0.643 respectively that also indicate relatively better fit.

In summary, the results of the fit indices of the measurement model are quite satisfactory in terms of their respective cut-off points. The $p$-value of the $\chi^{2}$ is less than 0.01 , though not desirable. This was, perhaps, due to the size of the samples considered for this study ( $\mathrm{N}=528$, greater than 200). However, alternative fit indices including Hoelter's critical N, Standardised Root Mean Residual (SRMR) and Normed $\chi^{2}$ show that the absolute fit measures are satisfactory. The results of incremental and parsimonious fit measures are also satisfactory in terms of model's acceptability. 


\subsection{The structural model analysis}

The structural model (Figure 9) shows the hypothesised relationships of the latent variables and their corresponding items as designed in a research model. The findings of EFA and reliability tests showed that service quality is a three dimensional construct, and other constructs including information, past experience, satisfaction, trust, brand performance and behavioural intention were a single factor construct only. The reliability tests for each individual construct were satisfactory. The test of unidimensionality including convergent validity and discriminant validity were also satisfactory. The findings of the measurement model using item parcelling technique within the CFA framework were also satisfactory. In this section, the results of the full structural model including the hypothesised relationships of the constructs are discussed.

The results of the structural equation model (SEM) show that the chi-square statistic, $\chi^{2}(\mathrm{~N}=528, \mathrm{df}=122)$ is 202.3 and the associated $p$-value is less than 0.01 . As this result is not desirable, the results of alternative measures show that the Normed $\chi^{2}$ is 1.65 (i.e. $\chi^{2} / d f<3.0$ ), the SRMR is 0.026 (i.e. SRMR $<0.1$ ) and Hoelter's critical $\mathrm{N}$ is 388 and 421 at the 0.05 and 0.01 level, respectively. These alternative measures against $\chi^{2}$ are suggested as the associated $p$-value of the $\chi^{2}$ is less meaningful when the sample size and number of observed variables are large (Hair et al., 2010; Ho, 2006). The results of these alternative fit measures, considering the large sample size, show that the model fits the sample data set. Overall, the results of absolute fit measures, incremental fit measures and parsimonious fit measures are also satisfactory. These values are all within the cut-off points as suggested by several studies (Hair et al., 2010; Ho, 2006). Table 21 shows the results of all the fit measures.

In summary, the SEM fit indices are quite satisfactory in terms of their respective cutoff points. The $p$-value of the $\chi^{2}$ is significant. This was due to the size of the samples considered for this study $(\mathrm{N}=528)$. However, alternative fit indices including Hoelter's critical N, SRMR and Normed $\chi^{2}$ show that the absolute fit measures are satisfactory. The results of incremental fit measures are all close to 1.0 suggesting that 
the model is a better fit compared to null models. The parsimonious fit measures are also satisfactory in terms of model's acceptability.

Table 21: Fit measures of the structural model

\begin{tabular}{|c|c|c|c|c|}
\hline Type & Fit Index & $\begin{array}{l}\text { The results of the } \\
\text { structural model }\end{array}$ & Benchmark & $\begin{array}{c}\text { Accepted } \\
\text { (Yes/No) }\end{array}$ \\
\hline \multirow{6}{*}{ 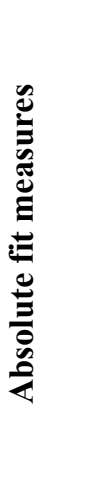 } & $\chi^{2}$ & $\chi^{2}(\mathrm{~N}=528, \mathrm{df}=122)=202.3, p<0.01$ & $P>0.05$ & $\mathrm{~N} / \mathrm{A}^{*}$ \\
\hline & $\chi^{2} / \mathbf{d f}$ & 1.650 & $\chi^{2} / \mathrm{df}<3$ & Yes \\
\hline & GFI & 0.960 & $\mathrm{GFI}>0.90$ & Yes \\
\hline & RMSEA & 0.035 & RMSEA $<0.08$ & Yes \\
\hline & RMR & 0.031 & Close to zero & Yes \\
\hline & SRMR & 0.026 & $\mathrm{SRMR}<0.10$ & Yes \\
\hline \multirow{5}{*}{ 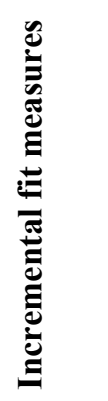 } & TLI & 0.988 & TLI $>0.90$ & Yes \\
\hline & NFI & 0.976 & $\mathrm{NFI}>0.90$ & Yes \\
\hline & IFI & 0.990 & $\mathrm{IFI}>0.90$ & Yes \\
\hline & RFI & 0.970 & $\mathrm{RFI}>0.90$ & Yes \\
\hline & CFI & 0.990 & $\mathrm{CFI}>0.90$ & Yes \\
\hline \multirow{3}{*}{ 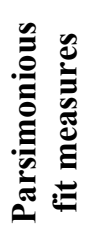 } & AGFI & 0.942 & AGFI $>0.90$ & Yes \\
\hline & PNFI & 0.778 & Close to one & Yes \\
\hline & PCFI & 0.790 & Close to one & Yes \\
\hline
\end{tabular}

* Chi-square is not applicable because of large sample size. The alternative measures to Chi-square are $\chi^{2} / \mathrm{df}$, SRMR and Hoelter's critical N statistic. 
Figure 9: The structural model

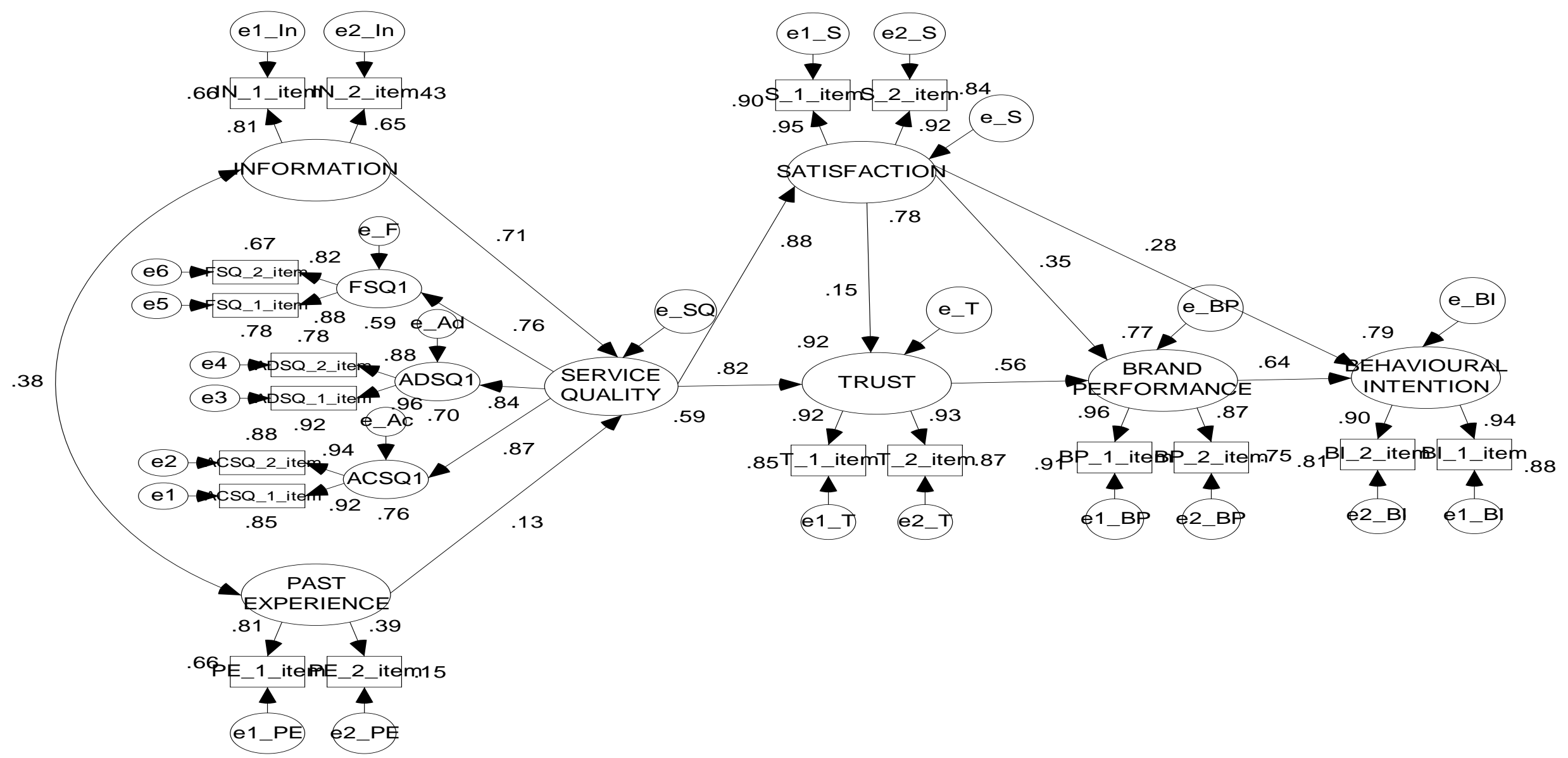




\subsection{Hypotheses testing results}

The hypotheses developed for this study are the causal relationships among the constructs. These causal relationships of the constructs have developed the antecedent and consequence model of service quality. In chapter 3, this study developed the conceptual model along with nine hypotheses. In this section, the causal relationships of constructs are examined. Table 22 shows the results.

Table 22: Results for hypotheses

\begin{tabular}{|c|c|c|c|c|}
\hline No. & Hypotheses & $\begin{array}{l}\text { Standardised } \\
\text { regression weights }\end{array}$ & Significance & $\begin{array}{l}\text { Supported } \\
(\text { Yes/No) }\end{array}$ \\
\hline H1 & $\begin{array}{l}\text { There is a positive relationship between } \\
\text { information received by the students and their } \\
\text { evaluation of service quality }\end{array}$ & 0.71 & $p<0.01$ & Yes \\
\hline $\mathrm{H} 2$ & $\begin{array}{l}\text { There is a positive relationship between past } \\
\text { experience of the students and perception of } \\
\text { service quality }\end{array}$ & 0.13 & $p<0.05$ & Yes \\
\hline H3 & $\begin{array}{l}\text { Performance of service quality positively } \\
\text { affects students' satisfaction in a higher } \\
\text { education context }\end{array}$ & 0.88 & $p<0.01$ & Yes \\
\hline H4 & $\begin{array}{l}\text { Perception of service quality affects trust } \\
\text { positively in a higher education context }\end{array}$ & 0.82 & $p<0.01$ & Yes \\
\hline H5 & $\begin{array}{l}\text { Perceived satisfaction affects trust positively } \\
\text { in a higher education context }\end{array}$ & 0.15 & $p<0.05$ & Yes \\
\hline H6 & $\begin{array}{l}\text { Perceived satisfaction affects brand } \\
\text { performance positively in a higher education } \\
\text { context }\end{array}$ & 0.35 & $p<0.01$ & Yes \\
\hline $\mathrm{H} 7$ & $\begin{array}{l}\text { Perceived trust affects brand performance } \\
\text { positively in a higher education context }\end{array}$ & 0.56 & $p<0.01$ & Yes \\
\hline H8 & $\begin{array}{l}\text { Perceived brand performance affects } \\
\text { behavioural intention positively in a higher } \\
\text { education context }\end{array}$ & 0.64 & $p<0.01$ & Yes \\
\hline H9 & $\begin{array}{l}\text { Perceived satisfaction affects behavioural } \\
\text { intention positively in a higher education } \\
\text { context }\end{array}$ & 0.28 & $p<0.01$ & Yes \\
\hline
\end{tabular}


The hypotheses are examined in terms of their respective standardised regression weights and the associated $p$-value. Overall, all the nine hypotheses have positive coefficients and they all are statistically significant. Thus, this study supports the hypotheses. The results confirm the relationships of antecedent variables to service quality, and consequence variables and their direct and indirect relationships with service quality.

The antecedent and consequence model of service quality has two exogenous variables, information and past experience. There are four consequences of service quality. Of these four consequences of service quality, satisfaction and trust are the direct consequence of service quality, and brand performance and behavioural intention are the indirect consequences of service quality (mediated through satisfaction and trust). The model was experimented in a higher education context.

The results show that the standardised regression weight of information $\rightarrow$ service quality is 0.71 at the 0.01 level, suggesting that information is of high importance to form and evaluate service quality before one experiences it. The literature did not explore this relationship. As discussed in chapter 3, there is another unexplored relationship between students' past experience and its effect on formation and evaluation of service quality. The findings of the present study show that the standardised regression weight of past experience $\rightarrow$ service quality is 0.13 at the 0.05 level, suggesting that students consider their past experience to form and evaluate service quality. Although it appears from the results that information plays a greater role compared to students' past experience, they both are positive and statistically significant.

The hypothesis that service quality affects satisfaction was derived from the literature. While implementing the ECSI model in the context of higher education, one study finds that service quality and satisfaction has positive and significant relationship (Alves \& Raposo, 2007). The present thesis, in contrast, reports that service quality affects satisfaction through value (Brown \& Mazzarol, 2009). As a result, this study re-examines if service quality affects satisfaction directly. The results show that the standardised regression weight of service quality $\rightarrow$ satisfaction is 0.88 at the 0.01 
level, suggesting that this is one of most significant path and that service quality directly affects satisfaction.

The role of trust between service quality and satisfaction is still unexplored in the context of higher education. The results show that the standardised regression weights of service quality $\rightarrow$ trust is 0.82 at the 0.01 level, and satisfaction $\rightarrow$ trust is 0.15 at the 0.05 level, suggesting that service quality and satisfaction directly affect trust, and that service quality also affects trust through satisfaction.

Students' perception of their UniBrand and its relationship with their satisfaction and trust are not examined in the context of higher education. The results confirm that satisfaction $\rightarrow$ brand performance and trust $\rightarrow$ brand performance have positive and significant relationships ( 0.35 and 0.56 , respectively, at the 0.01 level) in the context of a university.

The hypotheses that satisfaction affects loyalty and loyalty affects brand outcomes were existent in the literature. However, this study develops the hypotheses that satisfaction and brand performance affects behavioural intention. The results again confirm that satisfaction $\rightarrow$ behavioural intention and brand performance $\rightarrow$ behavioural intention have positive and significant relationships $(0.28$ and 0.64 , respectively, at the 0.01 level) in the context of CQUniversity.

Finally, the squared multiple correlations are: service quality $=0.59$, satisfaction $=0.78$, trust $=0.92$, brand performance $=0.77$ and behavioural intention $=0.79$. These imply that $59 \%, 78 \%, 92 \%, 77 \%$ and $79 \%$ of the variances of the respective constructs can be explained for by their measurement variables and dependent constructs. Overall, all the hypotheses are supported, and the results of absolute, incremental and parsimonious fit indices have proved the validity of the structural model. 


\subsection{Chapter summary}

This chapter discussed the results of various statistical analyses employed to establish a sound and a valid model. The online survey found 793 completed responses; of these, 233 responses were found to have six or less months of studying experience with CQUniversity. As a result, a total of 560 responses entered for test of normality and outliers. At this stage, 32 responses were identified as univariate and multivariate outliers and these were deleted. Finally, 528 responses entered for $\mathrm{K}-\mathrm{S}$ test and found that the $p$-value was significant. However, this is quite common as the samples were taken from one university and the sample size was large.

To detect non-response bias, 528 responses were formed into two groups, early response and late response, and entered for independent sample $t$-tests. The results showed that there was no significant difference in any of the variables between these two groups. Then the study discussed the descriptive statistics and demographics in terms of gender, nationality, age distribution, mode and level of study, programs of study, location of campus of study, length of study, average academic results and highest qualification planned for future study.

The findings of Bartlett's test of sphericity and KMO measure of sampling adequacy were satisfactory for each of the measures. The test of reliability for each of the measures was determined and found satisfactory. The Cronbach's Alpha statistic varies between 0.70 and 0.953 . The factor loadings of individual items on their respective constructs were between 0.402 and 0.938 . These values exceed the cut-off points, meaning that the results were satisfactory.

The tests of convergent validity in terms of EFA's factor loading, CFA's critical ratio (c.r.), AVE and Cronbach's Alpha were all satisfactory. The discriminant validity test results including pairwise $\chi^{2}$ difference test, comparison of AVE and the squared correlation estimate, pairwise EFA showed satisfactory results.

Then, the analysis of measurement model using partial disaggregation method was calculated. The results of absolute fit measures, incremental fit measures and 
parsimonious fit measures were satisfactory. The results of the nomological and predictive validity were also satisfactory. The structural analysis of the model in terms of various fit indices was also satisfactory. The results of the standardised regression weights (path coefficients) and the associated $p$-value indicated a strong support for each of the hypotheses. Thus, the results support the holistic conceptual model of antecedents and consequences of service quality in the context of a university. 


\section{Chapter 6: Discussion}

\subsection{Introduction}

This chapter is the final part of the thesis, and provides a summary of the chapters, the thesis's contribution to knowledge, practice and methodology, its limitations and future research. This chapter, first, summarises all the previous chapters in section 6.2. It then presents a summary of the research findings in section 6.3. Section 6.4 discusses the contributions of this thesis to knowledge, research method and practice. It then addresses and discusses limitations of the study in section 6.5. Section 6.6 discusses future research, and finally, the concluding comments are placed in section 6.7 .

\subsection{Summary of the chapters}

The first chapter, Introduction, discussed the role and challenges of higher education in Australian economy. It then discussed some recent studies, and brings out the importance of developing a comprehensive model of service quality in the context of higher education. Ensuring quality of services is a major concern in services marketing. This chapter discussed the need for a marketing perspective in higher education. It discussed the research issues briefly, and addressed the research questions and research objectives. The significance of the study and a brief description of research methods were also discussed in this chapter. Finally, it addressed the thesis outlines, delimitations, key definitions and chapter summary.

The second chapter, the literature review, discussed the theoretical developments in terms of customer satisfaction and service quality. It then developed the dimensional and antecedent approaches to study service quality following a review of the current studies. The present literature on satisfaction index models, trust, brand performance and behavioural intention were also reviewed in order to develop an understanding of the relationships among these areas. This chapter, then, attempted to review service quality studies in the context of higher education, and addressed recent developments 
in terms of service quality measures and models. The review of the current literature uncovered some important research gaps in terms of antecedents and consequences of service quality in the context of higher education. Finally, a summary of the literature review was discussed at the end of this chapter.

The third chapter discussed the research model in detail. The research model is based on perception-only measure of service quality, and the ECSI model originally developed by Cassel and Eklöf (2001). This chapter opened up a discussion with antecedents and consequences of service quality in the context of higher education, and the ECSI model. Based on the literature review and focus group findings, an integrated and comprehensive model in a higher education context was presented in this chapter. This chapter also defined and discussed the construct development processes. There were seven constructs and nine hypothesised relationships. The definition and scope of the constructs, and their causal relationships were also explained in this chapter. Finally, this chapter discussed the key features of the research model and its summary.

The fourth chapter discussed the research methods employed to test the research model. First, this chapter clarified the methodological triangulation approach and its importance in marketing research. Second, it discussed the qualitative research method including selection of focus group members and topic of discussion; and focus group data collection, storage, analysis and validation procedures. Third, this chapter then discussed the quantitative research method including the domain of construct, item generation and questionnaire design; pilot testing and purifying the measures; and data collection, assessing reliability and validity processes. The layout design of the online click-only survey followed the suggestions of Dillman et al. (2009). While the construct development processes followed the suggestions of Churchill (1979), the construct validation processes followed the suggestions of O'Leary-Kelly and Vokurka (1998). The data cleaning processes, assessment procedures for normality and outliers, and non-response bias were also discussed in this chapter. The data analysis processes including KMO measure of sampling adequacy and Bartlett's test of sphericity; EFA, Cronbach's Alpha reliability test and test of unidimensionality; convergent validity and discriminant validity; and 
estimations of the measurement model and the structural model were also discussed in this chapter. The item parcelling technique adopted in measurement and structural model analyses was also explained in this chapter. The cut-off criteria for various fit indices as suggested by Hair et al. (2010) and Ho (2006) were described in this chapter. Finally, a summary of the research methods was placed at the end of this chapter.

The fifth chapter presented the findings of the survey data analyses. Items were found reliable and valid for their respective constructs. The whole research model of antecedents and consequences of service quality was tested by using the structural equation modelling technique and found satisfactory in fitting the data set, in both measurement and structural phases. The predictive power of the exogenous variables on endogenous variables was established, and all hypotheses were confirmed.

This chapter discusses a summary of the research findings, and their contributions to knowledge, research method and practice. It also discusses research limitations and future directions of research.

\subsection{Summary of the research findings}

This study has validated an integrated and a comprehensive service quality model in a higher education context. First, the findings suggest that marketing communication plays a vital role in the form of information to shape service quality prior to service encounter. Second, the findings suggest that students' past experience also forms service quality in that these help to build their cognitive structure about anticipated outcomes. Third, the findings suggest that evaluation of service quality is cognitive and that service quality evaluation involves students experience of service attributes. In the context of CQUniversity, service quality has been found as a second order construct having three dimensions, namely, academic service quality, administrative service quality and facilities service quality. Fourth, students' satisfaction and trust have been found to be direct consequences of perceived service quality, and brand performance and behavioural intention are found as indirect consequences. Fifth, the 
findings suggest that while students' satisfaction directly affects the UniBrand (brand performance) and behavioural intention, students' trust directly affects brand performance and indirectly affects behavioural intention (through brand performance). The uniquenesses of this model are: first, the model examines students' perception of information received (marketing communication) and their past experience in forming service quality (as antecedents); and second, the model examines students' perception of trust, brand performance (UniBrand) and behavioural intention in the model as consequences of service quality. Therefore, the findings of this study fill an important research gap, as indicated and identified in several recent studies (Gallifa \& Batalle, 2010; Sultan \& Wong, 2010a, 2010b), relevant to the need for an integrated and a comprehensive service quality model in the context of higher education. Finally, the model may be referred to as the 'continuous effect model' (or CEM) as the model examines two antecedent variables that students consider prior to service experience, service quality evaluation during service experience and post-evaluation consequences of service quality in terms of students' cognitive and attitudinal behaviours. The overall findings of model are statistically valid and reliable.

\subsection{Contributions to knowledge, research method and practice}

The research question of this study was: what are the antecedents and consequences of service quality in a higher education? This research provided important and valuable insights to this question. This study makes several contributions to the academic study, research method and practice. The findings of this study reinforce the extant literature and add new knowledge to it. In terms of practice, this study provides important insights about specific aspects of service quality that need particular attention in a higher education context, communication strategy development and necessary resource deployment. It also provides insights about the consequences of perceived service quality in the long-term, based on which the managers can build their goals in a higher education context. The following paragraphs demonstrate these important and valuable insights, and their contributions to knowledge, research method and practice. 


\subsubsection{Theoretical contributions}

The theoretical/knowledge contributions of this study include a contribution that builds on the current studies but provides a new perspective to the knowledge of higher education services marketing literature and a contribution that strengthen the extant studies through similar findings. Replication of similar findings is important as these examine the extant theories in a similar or new environment and establishes their reliability and validity.

\subsubsection{Contributions providing new perspectives to existing knowledge}

First, this study contributes by developing three new constructs, namely, information, past experience and brand performance. Information was conceptualised, in this study, as explicit and implicit messages that students receive directly and indirectly from the CQUniversity before enrolment. In turn, this may be referred to as marketing communication messages. The items used to measure information, for this study, were developed from focus group findings.

For the purpose of this study, past experience was conceptualised as students' previous educational experience before enrolling at the CQUniversity, previous experience of service encounter, their interaction and relationships with staff and/or the university prior to enrolment, and subsequent treatment provided by the CQUniversity during their past interaction. The conceptualisation of the past experience was based on the extant studies (Devlin et al., 2002; Zeithaml et al., 1993). However, the operationalisation of the past experience measure was based on Devlin et al.'s (2002) study and focus group findings. While Zeithaml et al.'s (1993) study was a conceptual study and provides no indication of instruments to measure past experience; Devlin et al.'s (2002) study was an empirical study. Thus, one item was adapted from Devlin et al.'s (2002) study. However, this item could not be sustained during item purification stage. Therefore, the operationalisation of the past experience measure in the model were based on focus group findings. 
The conceptualisation of the brand performance measure was based on several studies (Harris \& de Chernatony, 2001; Wong \& Merrilees, 2007a) and focus group findings. However, the conceptual study of Harris and de Chernatony (2001) did not state about the items for measuring consumer-based brand performance scale. The present study conceptualised brand performance as the performance of the CQUniversity as a brand (UniBrand) in terms of students' perception with regard to their association, understanding and evaluation of the UniBrand in the market. Since Harris and de Chernatony's (2001) study was a conceptual study, one item was adapted from Wong and Merrilees's (2007a) study. The other seven items to operationalise the brand performance measure were based on focus group findings.

Second, there is a lack of evidence in the literature showing that marketing communication plays a major role to forming perceived service quality. The present study showed that information as a means of marketing communication plays a major role to forming service quality. The results showed that information directly affects service quality (standardised regression weight is 0.71 at the 0.01 level) in a higher education context.

Third, this study validated another exogenous variable, namely, past experience and its relationship with perceived service quality as one of the antecedents. While research shows that customers' present experience affects perceived service quality (Biedenbach \& Marell, 2010), the literature does not explore the relationship between past experience and perceived service quality. The findings of the present study showed that past experience has a direct and significant (standardised regression weight is 0.13 at the 0.05 level) relationship with perceived service quality in a higher education context.

Fourth, service quality measure was operationalised as a first order construct (in the model) in most of the studies in service quality literature (Alves \& Raposo, 2007; Brady et al., 2002; Brown \& Mazzarol, 2009; Helgesen \& Nesset, 2007; Navarro et al., 2005; O’Neill \& Palmer, 2003; Rojas-Me'ndez et al., 2009; Selnes, 1993). The present study operationalised service quality as a second order construct in the model having three dimensions: academic service quality, administrative service quality and 
facilities service quality. Thus, it possessed the comprehensive nature of service quality in the model.

Fifth, Chaudhuri and Holbrook's (2001) study showed that brand trust affects brand outcome through the mediating effects of brand loyalty within commercial settings. However, the present study showed that students' trust has a significant and positive (standardised regression weight is 0.56 at the 0.01 level) impact on brand performance (as an attitude measure). Thus, the study added a new insight to the existing literature.

Sixth, another important aspect of this study was the finding that brand performance influences behavioural intention. Chaudhuri and Holbrook's (2001) study found a positive and significant relationship of brand loyalty affecting brand outcome. In contrast, Selnes's (1993) study found a positive and significant relationship of brand reputation affecting loyalty in the context of commercial and non-commercial service sectors. The findings of the present study suggested that CQUniversity's brand performance plays a significant (standardised regression weight is 0.64 at the 0.01 level) role on students' positive behavioural intention.

Seventh, a number of studies found that student satisfaction has a positive and significant impact on student loyalty in the context of higher education, (Alves \& Raposo, 2007; Brown \& Mazzarol, 2009; Helgesen \& Nesset, 2007; Navarro et al., 2005). However, Rojas-Me'ndez et al.'s (2009) study showed that student satisfaction affects student loyalty through the mediating effects of student trust and their commitment. The focus group findings of the present study showed that students had been anecdotal to be loyal to their University, and instead they had been more accorded to show positive behavioural intention. The results of the hypothesis testing showed that student satisfaction has a direct and significant impact (standardised regression weight is 0.28 at the 0.01 level) on positive behavioural intention. Thus, the study added a new perspective in the higher education services marketing literature.

In summary, this study provided seven new perspectives that contribute to theory advancements in the context of higher education services marketing. These 
perspectives included development of three new constructs; operationalisation of service quality construct as a second order construct in the model; examination of the relationships of information-service quality, past experience-service quality, trustbrand performance, brand performance-behavioural intention and satisfactionbehavioural intention.

\subsubsection{Contributions reinforcing existing knowledge}

First, this study reinforced the existing knowledge by improving four constructs, namely, service quality, satisfaction, trust and behavioural intention. For example, the operationalisation of service quality measure included 17 items that were adapted from the extant studies and nine items were developed from focus group findings. The satisfaction measure included two items adapted from the extant studies and five items developed form the focus group findings. The trust measure included eight items adapted from the extant studies and four items developed from the focus group findings. Finally, the behavioural intention measure included four items adapted from the extant studies and two items developed from the focus group findings.

Second, a review of 14 studies on service quality dimensions in higher education published in the last 14 years (between 1997 and 2010) reveal that there is no agreement about service quality dimensions and that the dimensions vary by country, culture, institution and industry. The findings of this study with regard to service quality dimensions are in line with these findings. For example, Gatfield et al.'s (1999) study finds four service quality dimensions, namely, academic instruction, campus life, guidance and recognition in the context of one Australian university. In contrast, the present study finds that service quality has three dimensions, namely, academic service quality, administrative service quality and facilities service quality in the context of CQUniversity.

Third, the extant literature (Alves \& Raposo, 2007; Rojas-Me'ndez et al., 2009; Helgesen \& Nesset, 2007) suggested that perceived service quality affects students' satisfaction in the context of higher education. The finding of this study also supported that students' perceived service quality affects their satisfaction in a higher 
education context at Australia. The significant $R^{2}$ statistic of satisfaction $(0.78$ at the 0.01 level) and standardised regression weight of service quality affecting satisfaction ( 0.88 at the 0.01 level) suggests that students' satisfaction backed by perceived service quality plays a major role in the model and that this is one of most significant paths in the model, respectively.

Fourth, Rojas-Me'ndez et al.'s (2009) study found that perceived service quality affects trust through the mediating effects of students' satisfaction. However, HennigThurau et al.'s (2001) study found a positive and significant impact of perceived service quality on students' trust in the context of graduated and dropout students of four German universities. With the continuing students, the findings of the present study showed that perceived service quality has a direct and significant impact on students' trust and an indirect impact on students' trust through students' satisfaction. Thus, the study has enriched the existing knowledge.

Fifth, the literature is inconclusive about the relationship between satisfaction and trust, especially in the context of commercial service sectors. On the one hand, the extant studies demonstrated that satisfaction affects trusts (Delgado-Ballester \& Munuera-Aleman, 2001; Horppu et al., 2008; Lau \& Lee, 2000; Zboja \& Voorkees, 2006). On the other hand, research demonstrated that trust proceeds to satisfaction in that pre-exchange trust has a direct influence on the postpurchase satisfaction (Chiou et al., 2002). In the context of higher education, one study found that satisfaction has a positive and significant effect on trust (Rojas-Me'ndez et al., 2009). The present study has found that satisfaction and trust has a positive and significant causal relationship where students' satisfaction build students' trust in the context of CQUniversity.

Sixth, the current studies do not demonstrate the relationship between satisfaction and brand performance in the context of higher education. O'Neill et al.'s (2006) study finds that customer satisfaction affects brand performance in the context of hotel industry. The brand performance measure (as an outcome measure) as conceptualised in O’Neill et al.'s (2006) study refers to higher average daily rates for hotel rooms, higher occupancy and higher increases in the total number of guests. However, the present study conceptualises brand performance as an attitude measure, and finds that 
students' satisfaction has a positive and significant impact (standardised regression weight is 0.35 at the 0.01 level) on brand performance.

In conclusion, this study contributes to reinforcing existing knowledge in six major ways. First, it improves four constructs. Second, it finds that there are three dimensions of perceived service quality in the context of CQUniversity. Third, the study finds that students' perceived service quality has a positive and significant impact on students' satisfaction in the context of CQUniversity, Australia. Fourth, the study finds that perceived service quality affects trust directly, and indirectly through satisfaction. Fifth, the study demonstrates that students' perceived satisfaction has a positive and significant impact on students' perceived trust. Finally, the study finds that students' satisfaction affects brand performance.

\subsubsection{Methodological contribution}

This study has several methodological contributions. First, the research design followed the methodological triangulation approach, where both qualitative and quantitative research methods were employed in order to further advance the theory and to test the theory. This approach is an advancement of the research method compared to many studies that employed quantitative research method only in the context of higher education (Alves \& Raposo, 2007; Helgesen \& Nesset, 2007; Hennig-Thurau et al., 2001; Hill, 1995; Navarro et al., 2005; Paswan \& Ganesh, 2009; Stodnick \& Rogers, 2008; Rojas-Me'ndez et al., 2009; Ueltschy et al., 2007).

Second, the primary data collection used online click-only survey technique, another important aspect that contributed to the advancement of the survey method. Online questionnaire are methodologically and financially appealing for the study that deals with student populations. An online survey increases the likelihood of participation and its processing fees are usually very lower than those for paper surveys (Sax et al., 2003). In particular, the online survey for this study costed 0.06 cents per response. The online click-only survey technique for this study is also conformed to the literature (Angell et al., 2008; Sax et al., 2003; Stodnick \& Rogers, 2008). 
Third, the questionnaire used in the extant service quality research (Biedenbach \& Marell, 2010; Selnes, 1993; Abdullah, 2005, 2006a, 2006b, 2006c) possesses many limitations including double-barrelled questions, poorly worded questions, including items that are not consistent with factor naming, asking questions about what other people think, asking questions about which students could not possibly know the answer, asking questions what students think about a particular issue rather than what the students have experienced, in particular. The questionnaire design of the present study overcomes these limitations, and validates the questionnaire through expert validation and pilot survey processes.

Fourth, several studies, in the context of higher education, used single-item measure (Helgesen \& Nesset, 2007; Navarro et al., 2005). The present study used multi-items to design each of the constructs in the model. The multi-item constructs are designed to better reflect the results and their predictabilities.

Fifth, the nine constructs (including three dimensions of service quality and six constructs, namely, information, past experience, satisfaction, trust, brand performance and behavioural intention) of the model passed through four rigorous convergent validity tests and three discriminant validity tests. The use of these tests were not reported in many studies that attempted to develop a model in the context of higher education (Alves \& Raposo, 2007; Hennig-Thurau et al., 2001; Navarro et al., 2005; Rojas-Me'ndez et al., 2009). Thus, the use of thorough convergent and discriminant validity tests in this study provide a ground for future study.

Sixth, the measurement model of this study used item-parcelling technique as this technique is more reliable, provides more normal distribution data, provides more stable parameter estimates, reduce idiosyncratic characteristics of items and simplifies model interpretation. Thus, it is an advancement of the quantitative research method that successfully implemented the item-parcelling technique in measurement and structural model analyses.

Seventh, this study employed structural equation modelling technique to test hypotheses, thereby, enabling the simultaneous analysis of multiple effects. One of 
the major advantages of using the structural equation modelling technique is that it allows a researcher to evaluate the whole model and propose a network of relationships between variables. It is an advancement of quantitative research method in comparison to many studies that employed multiple regressions (Stodnick \& Rogers, 2008; Paswan \& Ganesh, 2009) and path analysis (Brown \& Mazzarol, 2009).

Therefore, this study has seven methodological contributions, including, application of the methodological triangulation approach in designing the research, online clickonly survey administration, improved and validated questionnaires, application of multi-item measure for each of the constructs, implementation of rigorous convergent and discriminant validity tests, use of the item parcelling technique and use of structural equation modelling technique to test the hypotheses.

\subsubsection{Practical contribution}

There are several managerial implications of this study. First, higher education managers should pay particular attention to develop a concrete information structure for potential students through promise and content of the message. Due to special nature of higher education services, it is imperative to focus on the students' preenrolment information structure that can be strengthened through providing adequate and specific information and ensuring its genuineness, maintaining promises, wordof-mouth from present students and previous alumnae, and above all focusing on what students' desire in terms of educational information. Because quality is affected by reliable information, the marketing communication message should design the information and promises carefully and strengthen students' information structure prior to enrolment. However, managers must remember that exaggerated information with gimmick promises may adversely affect quality perception during students' service encounter.

Second, the University should also develop and maintain good relationships with present and previous students, local and regional school authorities, and other stakeholders. As the high school students might build a fuzzy set of assumptions about higher education services due to absence of concrete experience, the university 
should maintain relationships with local and regional high schools, and invite high school teachers and students to participate in short courses, short visits, fairs, meetings and symposia. This will increase enrolments and impact favourably on quality judgment. The University should continuously improve students' experience with their services, and should focus on maintaining relationships.

Third, the University should continuously upgrade the performance of the service aspects (or dimensions) in order to improve service performance. The present study finds that there are three critical aspects of service quality in the context of CQUniversity. These are academic service quality, administrative service quality and facilities service quality. These categories are related to specific attributes of higher educational services that students encounter during their study. For example, first, the academic service quality includes the quality of lecturers, entertaining and interactive lectures, after lecture availability for consultation, and lastly lecturer's intellectual ability and understanding of the course, students and research. Second, the administrative service quality includes effective reply to students' queries, efficiency and effectiveness during admission procedures and services relevant to overall process of delivering quality education. Third, the facilities service quality includes library facilities, workshops and seminars of resource person, career counselling, transport facilities, dining facilities and entertainment facilities.

Once these aspects and attributes for each of the aspects are identified, it becomes easier for a manager to determine which of the aspects and its attributes require attention and proper resource allocation. Research states that "while service quality has proved to be an essential ingredient to convince customers to choose one service organisation over another, many organisations have realised that maintaining excellence on a consistent basis is imperative..." (Kandampully, 1998, p. 433). This signifies the importance of maintaining favourable service quality as perceived by the customer students. In the context of higher education high performance of service quality attributes can lead to students' satisfaction. Thus, higher education managers, lecturers and staff should ensure high performance of service attributes. 
Fourth, students' satisfaction is, perhaps, the top-most determinant in most of the higher education institutions. As a result, universities are evaluating lecture performance and service performance in order to determine the level of student satisfaction with their course. As universities are contending for full-fee paying students, measuring the level of satisfaction is a must. This study shows a valid students' satisfaction measure that can be implemented in a higher education context.

Fifth, the role of students' trust with perceived service quality, satisfaction and brand performance has not been examined in the extant literature. This study reveals the importance of students' trust in a university context and develops a measure of it. A satisfied student develops trust about the future performance of the service attributes and establishes long-term relationships with the institution. Student trust can be increased if perceived performance and perceived satisfaction are increased. Student trust has an obvious impact on perceived brand performance/reputation and their future behaviour. Therefore, the role of a manager should aim at achieving student trust and monitor the trust measure in terms of academic, administrative and facilities service quality, while ensuring their satisfaction.

Sixth, the UniBrand plays a pivotal role in the market in terms of attracting new students and retaining existing students. This study has developed a UniBrand measure (brand performance measure) and examined its relationships with students' satisfaction, trust and behavioural intention in the model for the first time in comparison to the extant studies. The findings show that students' perception of brand performance, derived directly from students' satisfaction and trust, plays an important role to have positive behavioural intention. Thus, the managerial implications are that the University should try to increase students' trust and satisfaction through their performance. Increased trust and satisfaction will result to increased brand performance, which in turn will increase positive behavioural intention. While brand plays a pivotal role in a globalised market place and to the student-customer, the managers should continuously improve students' trust and their satisfaction. This in turn will be favourable in terms of retaining of the existing students, increasing enrolment of the new students and building reputation of the University. 
Seventh, the focus group findings reveal that students are more compatible to show positive behavioural intention. The results of hypotheses testing also confirm this. The managerial implications have two aspects, here. First, the managers must understand what makes students to show positive behavioural intention. The answers, in the context of CQUniversity, are the direct effects of brand performance and satisfaction and the indirect effects of service performance, satisfaction and trust through brand performance and satisfaction. Second, the managers should also foster the positive behavioural intention through marketing communication messages.

Eighth, using this index model (CEM), managers will be able to examine the level of students' perception in terms of service quality, satisfaction, trust, brand performance and behavioural intention. In this context, the Bradley report states that "satisfaction levels should be at least 66 per cent for one to be confident that the majority of students felt positively about their experience of higher education" (Bradley et al., 2008 , p. 74). Another study stated that $R^{2}$ of customer satisfaction should be at least 0.65 with a $95 \%$ confidence interval and should not be wider that \pm 2 points (ECSI, 1998). In the context of present study, the $R^{2}$ for service quality, satisfaction, trust, brand performance and behavioural intention are 59\%,78\%, $92 \%, 77 \%$ and $79 \%$, respectively. This suggests that the CQUniversity should improve service quality in terms of academic, administrative and facilities service qualities. As service quality is affected by information and past experience. These two antecedents (information as marketing communication messages and past experiences of students) along with the critical aspects of service quality (academic, administrative and facilities) need improvement and proper resource allocation.

\subsection{Limitations of the study}

Although this study makes several contributions in terms of knowledge and practice, its limitations should be noted. First, this study was confined to CQUniversity and its 10 campuses located at various places in Australia to comply with the ethical clearance obtained from the Human Research Ethics Committee, CQUniversity (Ref. H08/12-082). However, a number of existing studies were based on one course and 
one university (Angell et al., 2008; Brown et al., 2009; Douglas et al., 2008; Gatfield et al., 1999; Helgesen \& Nesset, 2007; LeBlanc \& Nguyen, 1997; Li \& Kaye, 1998; Navarro et al., 2005; Smith et al., 2007; Stodnick \& Rogers, 2008). Although selecting a single university does not allow one to extrapolate the findings to other universities (Sawyer \& Thompson, 2003), inclusion of all CQUniversity students, programs, schools and campuses in the context of the present study are popular alternative to generate important insights about antecedents and consequences of service quality in a higher education context. Using a single university to study students' attitudes generate valuable insights, which can be used as empirical hypotheses for representative follow-up studies (Dolnicar, 2004). Thus, the findings of the present study are confined to CQUniversity, only.

Second, this study was based on cross-sectional surveys like most of the academic marketing literature. This limitation can be neutralised by evidence that supports a priory theory-based inferences (Spector, Chen, \& O'Connel, 2000). A number of studies in higher education services marketing were based on the cross-sectional surveys (Angell et al., 2008; Brown et al., 2009; Douglas et al., 2008; Gatfield et al., 1999; Helgesen \& Nesset, 2007; LeBlanc \& Nguyen, 1997; Li \& Kaye, 1998; Navarro et al., 2005; Smith et al., 2007; Stodnick \& Rogers, 2008). Thus, crosssectional surveys may have been unnecessarily criticised (Spector et al., 2000).

Finally, this study used online click-only survey, and the response rate is seven per cent of the CQUniversity's student population. Online surveys, in general, receive a low response rate, and the reasons for low response rate may include junk mail, numerous invitations to participate voluntary survey both online and paper-based, fast-paced culture, increased demand for students' paid hours to work and less willingness to participate in survey (Sax et al., 2003). However, the number of useable responses (or cases) was adequate enough to perform the Structural Equation Modelling and other multivariate analyses. 


\subsection{Future research}

This study identifies a number of opportunities for future research. First, this study develops a number of measures and their respective indicators, and a comprehensive model based on a single university. This implies that there is a scope of further research in broader perspectives including examining the generalizability of the measures and the model in the context of the Australian higher education sector. Second, the validation of the model in the context of higher education industry across various countries should also be contributing to the literature. Third, a longitudinal study may also provide interesting findings. Fourth, future research should use quantitative research method for a Meta analysis of the studies that are summarised in table 1. This may provide important insights about service quality and its dimensions in the higher education sector. Fifth, future research should use multitraitmultimethod (MTMM) technique to further examine construct validity.

\subsection{Concluding comments}

The focus of this thesis was to determine the antecedents and consequences of service quality and their causal relationships in a higher education context. Specifically, the first research objective was relevant to determining the antecedents of service quality in a higher education context. This research finds two antecedents, information and past experience. The findings of this study confirm that marketing communication information and students' past experience play a vital role in forming service quality.

The second objective was relevant to the conceptualisation of perceived service quality in terms of a higher education institute. This study refers perceived service quality as students' cognitive evaluation of performance of the service attributes during service encounter. As it is a cognitive process, perceived service quality assessment is a psychological result of perception, learning, reasoning and understanding of the service attributes. 
The third objective was relevant in assessing impacts of antecedent factors on perceived service quality. This thesis finds that the regression coefficients of information and past experience on service quality are 0.71 and 0.13 , respectively. These are statistically significant at the 0.01 and 0.05 levels, respectively. Meaning that one unit increase in information and past experience will result to 0.71 units and 0.13 units increase in service quality, respectively. These signify the importance of marketing communication (information) and students past experience to form perceived service quality.

The fourth objective was to find the critical consequences of perceived service quality. The focus group findings confirm that there are four critical consequences of perceived service quality in a higher education context. These are students' satisfaction, their trust, perceived brand performance of the university and students' behavioural intention. These are then tested using the Structural Equation Modelling technique and validated.

Finally, the fifth objective was to assess the extent of relationships of these consequences with service quality. This thesis developed hypothesised causal relationships based on the review of the current literature and focus group findings. This thesis then examined these relationships within the Structural Equation Modelling framework. The results show that perceived service quality directly affects students' satisfaction and trust. The standardised regression coefficients are 0.88 and 0.82 . These are statistically significant. Meaning that one unit increase in perceived service quality (in terms of academic, administrative and facilities service quality) results to almost one unit increase in students' satisfaction and trust. The other indirect consequences of perceived service quality (through satisfaction and trust) are brand performance and behavioural intention. Students' satisfaction directly affects students trust, perceived brand performance and behavioural intention. The standardised regression coefficients are positive and significant. The other causal relationships, for example, trust affecting brand performance and brand performance affecting behavioural intention are also found positive and statistically significant. Thus, this research examined and validated an integrated and a comprehensive service quality model comprising of antecedents of service quality, perceived service quality 
and its dimensions, and consequences of service quality in the context of CQUniversity, Australia.

These findings have several theoretical, methodological and practical implications. For example, this study provides seven new perspectives that contribute to theory advancements in the context of higher education services marketing. These perspectives include development of three new constructs; operationalising service quality construct as a second order construct in the model; examining relationships of information-service quality, past experience-service quality, trust-brand performance, brand performance-behavioural intention and satisfaction-behavioural intention.

This study also contributes to reinforcing existing knowledge in six major ways. First, it improves four constructs. Second, it finds that there are three dimensions of perceived service quality in the context of CQUniversity. Third, the study finds that students' perceived service quality has a positive and significant impact on students' satisfaction in the context of CQUniversity, Australia. Fourth, the study finds that perceived service quality affects trust directly and indirectly through satisfaction. Fifth, the study demonstrates that students' perceived satisfaction has a positive and significant impact on students' perceived trust. Finally, the study finds that students' satisfaction affects brand performance.

This study has seven methodological contributions, including, application of the methodological triangulation approach in designing the research, the use of online click-only survey administration, the use of improved and validated questionnaires, the application of multi-item measure for each of the constructs, the implementation of rigorous convergent and discriminant validity tests, the use of the item parcelling technique and the use of the Structural Equation Modelling technique to test the hypotheses.

The practical contributions of this study show the importance of marketing communication messages and students' past experience to build students' perceived service quality and the role that students' trust plays as one of the mediating variables in the model. One of the most important practical contributions is that this study 
shows what affects students' trust and perceived brand performance. This chapter, then, addressed and discussed the limitations and future research.

This study applied rigorous research methods in order to develop a service quality model in a higher education context. It is hoped that the results of this study will stimulate the interests of other academics to expand and strengthen the knowledge in terms of higher education services marketing. 


\section{References}

Aaker, D. (1991). Managing Brand Equity. Ontario: The Free Press.

Aaker, D. (1996). Managing Brand Equity. New York: The Free Press.

Aaker, D., \& McLoughlin, D. (2007). Strategic Market Management. Chichester: John Wiley \& Sons.

Abdullah, F. (2005). HEdPERF versus SERVPERF: The quest for ideal measuring instrument of service quality in higher education sector. Quality Assurance in Education 13(4), 305-328.

Abdullah, F. (2006a). Measuring service quality in higher education: HEdPERF versus SERVPERF. Marketing Intelligence and Planning, 24(1), 31-47.

Abdullah, F. (2006b). Measuring service quality in higher education: three instruments compared. International Journal of Research and Method in Education, 29(1), 71-89.

Abdullah, F. (2006c). The development of HEdPERF: a new measuring instrument of service quality for the higher education sector. International Journal of Consumer Studies, 30(6), 569-581.

Adams, J. S. (1965). Inequity in Social Exchange. In L. Berkowitz (Ed.), Advances in Experimental Social Psychology (Vol. 2). New York: Elsevier.

Alexandris, K., Douka, S., Papadopoulos, P., \& Kaltsatou, A. (2008). Testing the role of service quality on the development of brand associations and brand loyalty. Managing Service Quality, 18(3), 239-254.

Ali, H., \& Birley, S. (1999). Integrating deductive and inductive approaches in a study of new ventures and customer perceived risk. Qualitative Market Research: An International Journal, 2(2), 103-110.

Alsnih, R., \& Stopher, P. (2004). Estimating eligibility rates: a crucial component of the calculation for response rates. Retrieved 9/8/2011, from Institute of Transport Studies, University of Sydney: http:/pubsindex.trb.org/view.aspx?id=741316

Alves, H., \& Raposo, M. (2007). Conceptual model of student satisfaction in higher education. Total Quality Management, 18(5), 571-588.

Anderson, E., \& Weitz, B. (1989). Determinants of Continuity in Conventional Industrial Channel Dyads. Marketing Science, 8(4), 310-323.

Anderson, J., \& Gerbing, D. (1988). Structural equation modeling in practice: a review and recommended two-step approach. Psychological Bulletin, 103(3), 411-423.

Anderson, R. (1973). Consumer dissatisfaction: the effect of disconfirmed expectancy on perceived product performance. Journal of Marketing Research, 10(February), 38-44.

Andreassen, T., \& Lindestad, B. (1998). The impact of corporate image on quality, customer satisfaction and loyalty for customers with varying degrees of service expertise. International Journal of Service Industry Management, 9(1), 7-23. 
Angell, R. J., Heffernan, T. W., \& Megicks, P. (2008). Service quality in postgraduate education. Quality Assurance in Education, 16(3), 236-254.

Armstrong, J. S., \& Overton, T. S. (1977). Estimating nonresponse bias in mail surveys. Journal of Marketing Research, 14(3), 396-402.

Asteriou, D., \& Agiomirgianakis, G. M. (2001). Human capital and economic growth: Time series evidence from Greece. Journal of Policy Modeling, 23(5), 481-489.

Asthana, A., \& Biggs, L. (2007, 11 February). Students pay more but receive less. The Observer.

Athiyaman, A. (1997). Linking student satisfaction and service quality perceptions: The case of university education. European Journal of Marketing, 31(7), 528540 .

Babakus, E., \& Boller, G. W. (1992). An empirical assessment of the SERVQUAL scale. Journal of Business Research, 24 (3), 253-268.

Babbie, E. (2007). The Practice of Social Research. Belmont, USA: Wadsworth.

Bagozzi, R. P., Yi, Y., \& Phillips, L. W. (1991). Assessing construct validity in organizational research. Administrative Science Quarterly, 36(3), 421-458.

Baker, M. J. (2003). Data Collection - Questionnaire Design. Marketing Review, 3(3), 343-370.

Bandalos, D. L. (2002). The Effects of Item Parceling on Goodness-of-Fit and Parameter Estimate Bias in Structural Equation Modeling. Structural Equation Modeling: A Multidisciplinary Journal, 9(1), 78-102.

Bentler, P., \& Chou, C. (1987). Practical Issues in Structural Modeling. Sociological Methods \& Research, 16(1), 78-117.

Berry, L. L. (2002). Relationship marketing of services - Perspectives from 1983 and 2000. Journal of Relationship Marketing, 1(1), 59-77.

Berry, L. L., \& Parasuraman, A. (1991). Marketing Services. New York: The Free Press.

Biedenbach, G., \& Marell, A. (2010). The impact of customer experience on brand equity in a business-to-business services setting. Brand Management, 17(6), 446-458.

Binsardi, A., \& Ekwulugo, F. (2003). International marketing of British education: research on the students' perception and the UK market penetration. Marketing Intelligence \& Planning, 21 (5), 318-327.

Bitner, M. J. (1990). Evaluating Service Encounters: The Effects of Physical Surroundings and Employee Responses. Journal of Marketing, 54(2), 69-82.

Blythe, J. (1997). The Essence of Consumer Behaviour. London: Prentice-Hall.

Bolton, R., \& Drew, J. (1991). A longitudinal analysis of the impact of service changes on customer attitudes. Journal of Marketing 55(1), 1-9. 
Boshoff, C., \& Gray, B. (2004). The relationships between service quality, customer satisfaction and buying intentions in the private hospital industry. South African Journal of Business Management, 35 (4), 27-37.

Bowen, D. E., \& Hallowell, R. (2002). Suppose we took service seriously? An introduction to the special issue. Academy of Management Executive, 16 (4), 6972 .

Bradley, D., Noonan, P., Nugent, H., \& Scales, B. (2008). Review of Australian Higher Education. Canberra: Department of Education, Employment and Workplace Relations.

Brady, M. K., \& Cronin, J. J. (2001). Some new thoughts on conceptualizing perceived service quality: a hierarchical approach. Journal of Marketing, 65(3), 34-49.

Brady, M. K., Cronin, J. J., \& Brand, R. R. (2002). Performance-only measurement of service quality: a replication and extension. Journal of Business Research 55(1), $17-31$.

Brown, C., Varley, P., \& Pal, J. (2009). University course selection and services marketing. Marketing Intelligence \& Planning, 27(3), 310-325.

Brown, R., \& Mazzarol, T. (2009). The importance of institutional image to student satisfaction and loyalty within higher education. Higher Education, 58, 81-95.

Brown, T. J., Churchill, G. A., \& Peter, J. P. (1993). Improving the measurement of service quality. Journal of Retailing, 69(1), 127-139.

Bruin, G. P. (2004). Problems with the factor analysis of items: solutions based on item response theory and item parcelling. Journal of Industrial Psychology, 30(4), 16-26.

Bryman, A., \& Bell, E. (2007). Business Research Methods. Oxford: Oxford University Press.

Buttle, F. (1996). SERVQUAL: review, critique, research agenda. European Journal of Marketing, 30(1), 8-32.

Byrne, B. M. (2006). Structural Equation Modeling with EQS: Basic Concepts, Applications and Programming. London: Routledge.

Carlson, J., \& O'Cass, A. (2010). Exploring the relationships between e-service quality, satisfaction, attitudes and behaviours in content-driven e-service web sites. Journal of Services Marketing, 24(2), 112-127.

Carman, J. M. (1990). Consumer perceptions of service quality: an assessment of the SERVQUAL dimensions. Journal of Retailing, 66 (Spring), 33-55.

Carrillat, F. A., Jaramillo, F., \& Mulki, J. P. (2007). The validity of the SERVQUAL and SERVPERF scales-a meta-analytic view of 17 years of research across five continents. International Journal of Service Industry Management, 18(5), 472490.

Cassel, C., \& Eklöf, J. A. (2001). Modelling consumer satisfaction and loyalty on aggregate levels: experience from the ECSI pilot study. Total Quality Management, 12(7\&8), 834-841. 
Chaudhuri, A. (2002). How brand reputation affects the advertising-brand equity link. Journal of Advertising Research, 42(3), 33-43.

Chaudhuri, A., \& Holbrook, M. B. (2001). The chain of effects from brand trust and brand affect to brand performance: the role of brand loyalty. Journal of Marketing, 65(2), 81-93.

Chebat, J. C., Filiatrault, P., Gelinas-Chebat, C., \& Vaninsky, A. (1995). Impact of waiting attribution and consumer's mood on perceived quality. Journal of Business Research, 34(3), 191-196.

Chen, H. C. K. (1996). Direction, magnitude and implications of non-response bias in mail surveys. Journal of the Market Research Society, 38(3), 267-276.

Chiou, J. S., Droge, C., \& Hanvanich, S. (2002). Does customer knowledge affect how loyalty is formed? Journal of Service Research, 5(2), 113-124.

Chitty, B., \& Soutar, G. N. (2004). Is The European Customer Satisfaction Index Model Applicable to Tertiary Education? Paper presented at the Australian and New Zealand Marketing Academy Conference.

Chowdhury, M. H. K., \& Sultan, M. P. (2005). Determinants of perceived service quality: an empirical study. Journal of Business Administration, 31(1\&2), 179188.

Churchill, G. A. (1979). A paradigm for developing better measures of marketing constructs. Journal of Marketing, 16(2), 64-73.

Churchill, G. A., \& Surprenant, C. (1982). An investigation into the determinants of consumer satisfaction. Journal of Marketing Research, 19(4), 491-504.

Couper, M. P. (2000). Web surveys: A review of issues and approaches. Public Opinion Quarterly, 64, 464-494.

Cronin, J., Brady, M., \& Hult, G. (2000). Assessing the effect of quality, value, and customer satisfaction on consumer behavioral intentions in service environments. Journal of Retailing, 76 (2), 193-218.

Cronin, J., \& Taylor, S. (1992). Measuring service quality: a re-examination and extension. Journal of Marketing, 56(3), 55-68.

Cronin, J., \& Taylor, S. (1994). SERVPERF versus SERVQUAL: reconciling performance-based and perceptions-minus-expectations measurement of service quality. Journal of Marketing, 58(1), 125-131.

Cubillo, J. M., Sanchez, J., \& Cervino, J. (2006). International students'decisionmaking process. International Journal of Educational Management, 20(2), 101115.

Dabholkar, P. A., Shepherd, C. D., \& Thorpe, D. I. (2000). A comprehensive framework for service quality: an investigation of critical conceptual and measurement issues through a longitudinal study. Journal of Retailing, 76(2), 139-173.

Dahlstrom, R., Nygaard, A., \& Crosno, J. (2008). Strategic, metric and methodological trends in marketing research and their implications for future theory and practice. Journal of Marketing Theory and Practice, 16(2), 139-152. 
De Meulemeester, J., \& Rochat, D. (1995). A causality analysis of the link between higher education and economic development. Economics of Education Review, 14(4), 351-361.

De Vaus, D. A. (2001). Research Design in Social Research. London: Sage.

Deighton, J. (1984). The interaction of advertising and evidence. Journal of Consumer Research, 11(3), 763-770.

Delgado-Ballester, E. (2004). Applicability of a brand trust scale across product categories: A multigroup invariance analysis. European Journal of Marketing, 5 (6), 573-592.

Delgado-Ballester, E., \& Munuera-Aleman, J. L. (2001). Brand trust in the context of consumer loyalty. European Journal of Marketing, 35(11\&12), 1238-1258.

Delgado-Ballester, E., \& Munuera-Aleman, J. L. (2005). Does brand trust matter to brand equity? Journal of Product \& Brand Management, 14(2\&3), 187-196.

Deshpande, R. (1983). Paradigms Lost: On Theory and Method in Research in Marketing. Journal of Marketing, 47(Fall), 101-110.

DeVellis, R. F. (2003). Scale Development: Theory and Applications. Thousand Oaks: Sage.

Devlin, J. F., Gwynne, A. L., \& Ennew, C. T. (2002). The antecedents of service expectations. The Service Industries Journal, 22(4), 117-136.

DFAT. (2008). Trade in Services. Canberra: Department of Foreign Affairs and Trade.

Dichter, E. (1985). What's in an image. Journal of Consumer Marketing, 2(1), 75-81.

Dillman, D. A. (1991). The design and administration of mail surveys. Annual Review of Sociology, 17(August), 225-249.

Dillman, D. A., Smyth, J. D., \& Christian, L. M. (2009). Internet, Mail and Mixedmode Surveys: The Tailored Design Method. New Jersey: John Wiley \& Sons Inc.

Ding, C. S., \& Hershberger, S. L. (2002). Assessing content validity and content equivalence using structural equation modeling. Structural Equation Modeling, 9(2), 283-297.

Dolnicar, S. (2004, 29 November-01December). What makes students attend lectures? The shift towards pragmatism in undergraduate lecture attendance. Paper presented at the Conference proceedings of the Australian and New Zealand Marketing Academy, Wellington, New Zealand.

Donaldson, B., \& McNicholas, C. (2004). Understanding the postgraduate education market for UK-based students: a review and empirical study. International Journal of Nonprofit and Voluntary Sector Marketing, 9(4), 346-360.

Doney, P. M., Barry, J. M., \& Abratt, R. (2007). Trust determinants and outcomes in global B2B services. European Journal of Marketing, 41 (9\&10), 1096-1116.

Doney, P. M., \& Cannon, J. P. (1997). An examination of the nature of trust in buyerseller relationships. Journal of Marketing, 61, 35-51. 
Douglas, J., McClelland, R., \& Davies, J. (2008). The development of a conceptual model of student satisfaction with their experience in higher education. Quality Assurance in Education, 16(1), 19-35.

Dwyer, F. R., Schurr, P. H., \& Sejo, O. (1987). Developing buyer-seller relationship. Journal of Marketing, 51(2), 11-27.

Easterby-Smith, M., Thorpe, R., \& Lowe, A. (1991). Management Research: an Introduction. London: Sage.

Easton, G. (2002). Marketing: A critical realist approach. Journal of Business Research, 55, 103-109.

ECSI. (1998). European Customer Satisfaction Index: Foundation and Structure for Harmonized National Pilot Projects Report prepared for the ECSI Technical Committee, October.

Ehrenberg, A. S. C., Uncles, M. D., \& Goodhard, G. J. (2004). Understanding brand performance measures: Using Dirichlet benchmarks. Journal of Business Research, 57(12), 1307-1325.

Einasto, O. (2009). Using service quality monitoring to support library management decisions: A case study from Estonia. The International Information and Library Review, 41(1), 12-20.

Eisingerich, A. B., \& Bell, S. J. (2008). Perceived service quality and customer trust: Does enhancing customers' service knowledge. Journal of Service Research, $10(3), 256-268$.

Eklöf, J. A. (2000). European Customer Satisfaction Index: Pan-European Telecommunication Sector Report - Based on the Pilot Studies 1999. Stockholm, Sweden.

Eskildsen, J., Kristensen, K., Juhl, H. J., \& Østergaard, P. (2004). The Drivers of Customer Satisfaction and Loyalty. The Case of Denmark 2000-2002. Total Quality Management, 15(5\&6), 859-868.

Evans, J. R., \& Mathur, A. (2005). The value of online surveys. Internet Research, 15(2), 195-219.

Festinger, L. (1957). A theory of cognitive dissonance. Evanston: Row Peterson.

Fick, G. R., \& Ritchie, J. R. B. (1991). Measuring service quality in the travel and tourism industry. Journal of Travel Research, 30(2), 2-9.

Fombrun, C., \& van Riel, C. (1997). The reputational landscape. Corporate Reputation Review, 1(1\&2), 5-13.

Fornell, C. (1992). A national customer satisfaction barometer: The Swedish experience. Journal of Marketing, 56(1), 6-21.

Fornell, C., Johnson, M. D., Anderson, E. W., Cha, J., \& Bryant, B. E. (1996). The American customer satisfaction index: nature, purpose and findings. Journal of Marketing, 60(4), 7-18. 
Fornell, C., \& Larcker, D. F. (1981). Evaluating structural equation models with unobservable variables and measurement errors. Journal of Marketing Research, 18(1), 39-50.

Franz, R. S. (1998). Whatever you do, don't treat your students like customers! Journal of Management Education, 22(1), 63-69.

Freling, T. H., \& Forbes, L. (2005). An examination of brand personality through methodological triangulation. Journal of Brand Management, 13(2), 148-162.

Fullard, F. (2006). A model to evaluate the effectiveness of enterprise training programmes. The International Entrepreneurship and Management Journal, 3(3), 263-276.

Furrer, O., Liu, B. S., \& Sudharshan, D. (2000). The relationships between culture and service quality perceptions. Journal of Service Research, 2(4), 355-371.

Gallifa, J., \& Batalle, P. (2010). Student perceptions of service quality in a multicampus higher education system in Spain. Quality Assurance in Education, 18(2), 156-170.

Ganesan, S. (1994). Determinants of long-term orientation in buyer-seller relationships. Journal of Marketing, 58(2), 1-19.

Garbarino, E., \& Johnson, M. (1999). The different roles of satisfaction, trust, and commitment in customer relationships. Journal of Marketing, 63(2), 70-87.

Gatfield, T., Barker, M., \& Graham, P. (1999). Measuring Student Quality Variables and the Implications for Management Practices in Higher Education Institutions: an Australian and international student perspective. Journal of Higher Education Policy and Management, 21(2), 239-252.

Gillard, J. (2010, 5 March 2010). Launch of Australia's workforce futures: A national workforce development strategy. Retrieved 5 September 2010, from http://www.deewr.gov.au/Ministers/Gillard/Media/Speeches/Pages/Article_1003 05_121458.aspx

Gorsuch, R. L. (1983). Factor Analysis. California: Lawrence Erlbaum Associates.

Gounaris, S., Dimitriadis, S., \& Stathakopoulos, V. (2010). An examination of the effects of service quality and satisfaction on customers' behavioural intentions in e-shopping. Journal of Services Marketing, 24(2), 142-156.

Gounaris, S., Stathakopoulos, V., \& Athanassopoulos, A. D. (2003). Antecedents to perceived service quality: an exploratory study in the banking industry. International Journal of Bank Marketing, 21(4), 168-190.

Grace, D., \& O'Cass, A. (2004). Examining service experiences and postconsumption evaluations. Journal of Services Marketing, 18(6), 450-461.

Greene, J. G. (2008). Constructing a standard climacteric scale. Maturitas, 61(1-2), 78-84.

Grönroos, C. (1978). A service-oriented approach to marketing of services. European Journal of Marketing, 12(8), 588-601. 
Grönroos, C. (1982). An applied service marketing theory. European Journal of Marketing, 16(7), 30-41.

Grönroos, C. (1984). A service quality model and its marketing implications European Journal of Marketing, 18(4), 36-44.

Grönroos, C. (1988). Service quality: the six criteria of good perceived service quality. Review of Business, 9(3), 10-13.

Grönroos, C. (1993). Toward a Third Phase in Service Quality Research: Challenges and Future Directions. In T. A. Swartz, D. E. Bowen \& S. W. Brown (Eds.), Advances in Services Marketing and Management (Vol. 2, pp. 49-64). Greenwich, CT: JAI Press.

Gummesson, E. (2005). Qualitative research in marketing. European Journal of Marketing, 39(3-4), 309-327.

Guolla, M. (1999). Assessing the teaching quality to student satisfaction relationship: applied customer satisfaction research in the classroom. Journal of Marketing Theory and Practice, 7 (3), 87-97.

Hair, J. F., Black, W. C., Babin, B. J., \& Anderson, R. E. (2010). Multivariate Data Analysis: A Global Perspective. New York: Pearson Prentice Hall.

Hall, R. J., Snell, A. F., \& Foust, M. S. (1999). Item Parceling Strategies in SEM: Investigating the Subtle Effects of Unmodeled Secondary Constructs. Organizational Research Methods, 2(3), 233-256.

Halstead, D., Hartman, D., \& Schmidt, L. S. (1994). Multi source effects on the satisfaction formation process. Journal of the Academy of Marketing Science, 22(2), 114-129.

Harris, F., \& de Chernatony, L. (2001). Corporate branding and corporate brand performance. European Journal of Marketing, 35(3\&4), 441-456.

Hau, K., \& Marsh, H. W. (2004). The use of item parcels in structural equation modelling: Non-normal data and small sample size. British Journal of Mathematical Statistical Psychology, 57(2), 327-351.

Helgesen, Ø., \& Nesset, E. (2007). What accounts for students' loyalty? Some field study evidence. International Journal of Educational Management Decision, 21(2), 126-143.

Hellier, P. K., Geursen, G. M., Carr, R. A., \& Rickard, J. A. (2003). Customer repurchase intention: A general structure equation model. European Journal of Marketing, 37(11/12), 1762-1800.

Hennig-Thurau, T., Langer, M. F., \& Hansen, U. (2001). Modeling and managing student loyalty: An approach based on the concept of relationship quality. Journal of Service Research, 3(4), 331-344.

Herbig, P., Milewicz, J., \& Golden, J. (1994). A model of reputation building and destruction. Journal of Business Research, 31, 23-31.

Hill, D. J. (1985). Satisfaction and consumer services. Advances in Consumer Satisfaction, 13, 311-315. 
Hinkin, T. R. (2005). Scale Development: Principles and Practices. San Francisco: Berrett-Koehler.

Ho, R. (2006). Handbook of Univariate and Multivariate Data Analysis and Interpretation with SPSS. New York: Taylor \& Francis.

Hoch, S., J, \& Deighton, J. (1989). Managing what consumers learn from experience. Journal of Marketing, 53(2), 1-20.

Hoelter, J. W. (1983). The analysis of covariance structures: Goodness-of-fit indices. Sociological Methods and Research, 11, 325-344.

Hong, S., \& Goo, Y. J. J. (2004). A causal model of customer loyalty in professional service firms: An empirical study. International Journal of Management, 21(4), 531-540.

Horppu, M., Kuivalainen, O., Tarkiainen, A., \& Ellonen, H. (2008). Online satisfaction, trust and loyalty, and the impact of the offline parent brand. Journal of Product \& Brand Management, 17(6), 403-413.

Hovland, C., Harvey, O., \& Sherif, M. (1957). Assimilation and contrast effects in reaction to communication and attitude change. Journal of Abnormal and Social Psychology, 55(7), 244-252.

Hu, T., Chang, C. Y., Hsieh, W., \& Chen, K. (2010). An integrated relationship on brand strategy, brand equity, customer trust and brand performance - An empirical investigation of the health food industry. International Journal of Organizational Innovation, 2(3), 89-106.

Hudson, L. A., \& Ozanne, J. L. (1988). Alternative Ways of Seeking Knowledge in Consumer Research. Journal of Consumer Research, 14(March), 508-521.

Hui, T. K., Wan, D., \& Ho, A. (2007). Tourists' satisfaction, recommendation and revisiting Singapore. Tourism Management, 28, 965-975.

Hunt, S. D. (1991a). Positivism and Paradigm Dominance in Consumer Research: Toward Critical Pluralism and Reapproachment. Journal of Consumer Research, 18(June), 32-44.

Hunt, S. D. (1991b). Modern marketing theory. Cincinnati: South-Western.

Husserl, E. (1970). Logical investigations. New York: Humanities Press.

Hussey, J., \& Husset, R. (1997). Business Research: A Practical Guide for Undergraduate and Postgraduate Students. London: Macmillan Press.

Ivy, J. (2001). Higher education institution image: a correspondence analysis approach. The International Journal of Educational Management, 15(6\&7), 276-282.

Jain, S. K., \& Gupta, G. (2004). Measuring service quality: SERVQUAL vs. SERVPERF scales. Vikalpa, 29(2), 25-37.

Jayanti, R., \& Jackson, A. (1991). Service satisfaction: An exploratory investigation of three models. Advances in Consumer Research, 18, 603-610. 
Jiang, P., \& Rosenbloom, B. (2005). Customer intention to return online: price perception, attribute-level performance, and satisfaction unfolding over time. European Journal of Marketing, 39(1\&2), 150-174.

Johnson, M., Gustafsson, A., Andreassen, T., Lervik, L., \& Cha, J. (2001). The evolution and future of national customer satisfaction index models. Journal of Economic Psychology, 22(2), 217-245.

Johnson, R., \& Winchell, W. (1988). Educating for quality. Quality Progress, 2(1), 48-50.

Jøsang, A., Ismail, R., \& Boyd, C. (2007). A survey of trust and reputation systems for online service provision. Decision Support Systems, 43(2), 618-644.

Joseph, M., \& Joseph, B. (1997). Service quality in education: a student perspective. Quality Assurance in Education, 5(1), 15-19.

Judge, T. A., \& Klinger, R. (2007). Job Satisfaction: Subjective Well-Being at Work. In M. Eid \& R. J. Larsen (Eds.), The Science of Subjective Well-Being (pp. 393412). London: The Guilford Press.

Kandampully, J. (1998). Service quality to service loyalty: A relationship which goes beyond customer services. Total Quality Management, 9(6), 431-443.

Kangis, P., \& Passa, V. (1997). Awareness of service charges and its influence on customer expectations and perceptions of quality in banking. Journal of Services Marketing, 11(2), 105-117.

Keller, K. L. (1993). Conceptualizing, measuring, and managing customer-based brand equity. Journal of Marketing, 57(1), 1-22.

Knutson, B. J., Beck, J. A., Kim, S., \& Cha, J. (2010). Service quality as a component of the hospitality experience: Proposal of a conceptual model and framework for research. Journal of Foodservice Business Research, 13(1), 15-23.

Kovacs, G., \& Spens, K. M. (2005). Abductive reasoning in logistics research. International Journal of Physical Distribution \& Logistics Management, 35(2), 132-144.

Krejcie, R. V., \& Morgan, D. W. (1970). Determining Sample Size for Research Activities. Educational and Psychological Measurement, 30(3), 607-10.

Krippendorff, K. (2004). Content analysis: an introduction to its methodology. London: Sage.

Krishnan, H. S. (1996). Characteristics of memory associations: a consumer-based brand equity perspective. International Journal of Research in Marketing, 13(4), 389-405.

Krueger, R. A. A., \& Casey, M. A. A. (2000). Focus Groups: A Practical Guide for Applied Research: SAGE.

Kwan, P. Y. K., \& Ng, P. W. K. (1999). Quality indicators in higher education: Comparing Hong Kong and China's students. Managerial Auditing Journal, 14, 20-27. 
Landis, R. S., Beal, D. J., \& Tesluk, P. E. (2000). A Comparison of Approaches to Forming Composite Measures in Structural Equation Models. Organizational Research Methods, 3(2), 186-207.

Landrum, H., Prybutok, V. R., \& Zhang, X. (2007). A comparison of Magal's service quality instrument with SERVPERF. Information and Management, 44, 104113.

Lau, G. T., \& Lee, S. H. (2000). Consumer's trust in a brand and the link to brand loyalty. Journal of Market Focused Management, 4(4), 341-370.

LeBlanc, G., \& Nguyen, N. (1997). Searching for excellence in business education: An exploratory study of customer impressions of service quality. International Journal of Educational Management, 11(2), 72-79.

Lee, H., Lee, Y., \& Yoo, D. (2000). The determinants of perceived service quality and its relationship with satisfaction. Journal of Services Marketing, 14(3), 217-231.

Lewis, B. R. (1989). Quality in the service sector-a review. International Journal of Bank Marketing, 7(5), 4-12.

Li, R. Y., \& Kaye, M. (1998). A case study for comparing two service quality measurement approaches in the context of teaching in higher education. Quality in Higher Education, 4(2), 103-113.

Linda, D. G., \& Wikke, W. (1987). Questionnaire development: 1. Formulation. Canadian Medical Association Journal, 136(6), 583-585.

Little, T. D., Cunningham, W. A., Shahar, G., \& Widaman, K. F. (2002). To Parcel or Not to Parcel: Exploring the Question, Weighing the Merits. Structural Equation Modeling: A Multidisciplinary Journal, 9(2), 151-173.

Llosa, S., Chandon, J., \& Orsingher, C. (1998). An empirical study of SERVQUAL's dimensionality. The Service Industries Journal, 18(2), 16-44.

Locke, E. A. (1976). The nature and causes of job satisfaction. In M. D. Dunnette (Ed.), Handbook of Industrial and Organizational Psychology (pp. 1297-1349). Chicago, IL: Rand McNally.

Loehlin, J. C. (1992). Latent variable models: An introduction of factor, path and structural analysis (2nd ed.). Hillsdale, N.J.: Lawrence Drlbaum.

Loundsbury, W. L., \& Hoopes, L. L. (1985). An investigation of factors associated with vacation satisfaction. Journal of Leisure Research, 17(1), 1-13.

Lovelock, C. (Ed.). (1981). Why marketing management needs to be different for services. Chicago: American Marketing Association.

Mangan, J., Lalwani, C., \& Gardner, B. (2004). Combining quantitative and qualitative methodologies in logistics research. International Journal of Physical Distribution \& Logistics Management, 34(7), 565-578.

Marginson, S. (1997). Competition and contestability in Australian higher education, 1987-1997. Australian Universities' Review, 1(1), 5-14. 
Marsh, H. W., Balla, J. R., \& McDonald, R. P. (1988). Goodness-of-fit indexes in confirmatory factor analysis: the effect of sample size. Psychological Bulletin, 103(3), 391-410.

Martensen, A., Grønholdt, L., Eskildsen, J. K., \& Kristensen, K. (2000). Measuring student oriented quality in higher education: Application of the ECSI methodology. Paper presented at the Higher Education Institutions and the Issue of Total Quality. from http://www.blweb.it/esoe/tqmhe2/29.PDF

Martilla, J. A., \& James, J. C. (1977). Importance-performance analysis. Journal of Marketing, 41(1), 77-79.

Mathews, B. P. (1994). Modelling the antecedents of service expectations. Paper presented at the MEG Annual Conference Proceedings, University of Ulster.

McGill, A. L., \& Iacobucci, D. (1992). The role of post-experience comparison standards in the evaluation of unfamiliar services. In J. Sherry \& B. Sternthal (Eds.), Advances in Consumer Research (Vol. 19, pp. 570-578). Provo UT: Association of Consumer Research.

Meng, J., \& Elliott, K. M. (2009). Investigating Structural Relationships between Service Quality, Switching Costs, and Customer Satisfaction. The Journal of Applied Business and Economics, 9(2), 54-66.

Meyer, A., \& Westerbarkey, P. (1996). Measuring and managing hotel guest satisfaction. In D. M. Olsen, R. Teare \& E. Gummesson (Eds.), Service quality in Hospitality Organisations (pp. 185-204). New York: Cassell.

Moore, C. D. (1987). Outclass the competition with service distinction. Mortgage Banking, 47(11), 24-32.

Morgan, D. L. (1988). Focus groups as qualitative research. London: Sage.

Morgan, D. L. (1997). Focus groups as qualitative research. London: Sage.

Morgan, R. M., \& Hunt, S. D. (1994). The commitment-trust theory of relationship marketing. Journal of Marketing, 58(3), 20-38.

Morgan, R. M., \& Hunt, S. D. (1999). Relationship-based competitive advantage: The role of relationship marketing in marketing strategy. Journal of Business Research, 46(3), 281-290.

Navarro, M. M., Iglesias, M. P., \& Torres, P. R. (2005). A new management element for universities: satisfaction with the offered courses. The International Journal of Educational Management, 19(6\&7), 505-526.

Neuendorf, K. A. (2005). The Content Analysis Guidebook. London: Sage.

Newbold, J. J., Mehta, S., \& Forbus, P. (2010). Examining Student Commitment to the Alumni Organization at a 4-Year Commuter Campus. Contemporary Issues in Education Research, 3(3), 47-54.

Nguyen, N., \& LeBlanc, G. (1998). The mediating role of corporate image on customers' retention decisions: an investigation in financial services. International Journal of Bank Marketing, 16(2), 52-65. 
Nicholls, J., Harris, J., Morgan, E., Clarke, K., \& Sims, D. (1995). Marketing higher education: the MBA experience. The International Journal of Educational Management, 9(2), 31-38.

Nunnally, J. C. (1978). Psychometric Theory. New York: McGraw-Hill.

O'Leary-Kelly, S. W., \& Vokurka, R. J. (1998). The empirical assessment of construct validity. Journal of Operations Management, 16(4), 387-405.

O’Neill, J. W., Mattila, A. S., \& Xiao, Q. (2006). Hotel guest satisfaction and brand performance: The effect of franchising strategy. Journal of Quality Assurance in Hospitality and Tourism, 7(3), 25-39.

O’Neill, M., \& Palmer, A. (2003). An exploratory study of the effects of experience on consumer perceptions of the service quality construct. Managing Service Quality, 13(3), 187-196.

OECD. (2009). Education at a Glance. Retrieved 5 September 2010, from http://www.oecd.org/document/24/0,3343,en_2649_39263238_43586328_1_1_ 1_37455,00.html

Oliver, R. L. (1980). A cognitive model of the antecedents and consequences of satisfaction decisions. Journal of Marketing Research, 17(4), 460-469.

Oliver, R. L. (1996). Satisfaction: a behavioural perspective on the consumer. Boston, MA: Irwin- McGraw-Hill.

Oliver, R. L. (1997). Satisfaction: A behavioural perspective on the consumer. New York: McGraw-Hill.

Oliver, R. L., \& Swan, J. E. (1989). Equity and Disconfirmation Perceptions as Influences on Merchant and Product Satisfaction. Journal of Consumer Research, 16(3), 372-383.

Olson, J., \& Dover, P. (1979). Disconfirmation of consumer expectations through product trial. Journal of Applied Psychology, 64(1), 179-189.

Pallant, J. (2007). SPSS: Survival Manual. Sydney: Allen \& Unwin.

Parasuraman, A., Berry, L. L., \& Zeithaml, V. A. (1991a). Perceived service quality as a customer-based performance measure: an empirical examination of organizational barriers using an extended service quality model. Human Resource Management, 30(3), 335-364.

Parasuraman, A., Berry, L. L., \& Zeithaml, V. A. (1993). More on improving service quality measurement. Journal of Retailing, 69(1), 140-147.

Parasuraman, A., Zeithaml, V. A., \& Berry, L. L. (1985). A conceptual model of service quality and its implications for future research. Journal of Marketing, 49(4), 41-50.

Parasuraman, A., Zeithaml, V. A., \& Berry, L. L. (1988). SERVQUAL: a multipleitem scale for measuring consumer perceptions of service quality. Journal of Retailing, 64(1), 12-40.

Parasuraman, A., Zeithaml, V. A., \& Berry, L. L. (1991c). Refinement and reassessment of the SERVQUAL scale. Journal of Retailing, 67(4), 420-450. 
Parasuraman, A., Zeithaml, V. A., \& Berry, L. L. (1994). Reassessment of expectations as a comparison standard in measuring service quality implications for further research. Journal of Marketing, 58(1), 111-124.

Patterson, P. G., \& Spreng, R. A. (1997). Modelling the relationship between perceived value, satisfaction and repurchase intentions in a business-to-business services context: an empirical examination. International Journal of Service Industry Management, 8(5), 414-434.

Perry, C. (1998). Process of a case study methodology for postgraduate research in marketing. European Journal of Marketing, 32(9/10), 785-802.

Peter, J. P., \& Olson, J. C. (1983). Is science marketing. Journal of Marketing, 47, 111-125.

Prakash, V., \& Loundsbury, W. J. (1992). A reliability problem in the measurement of disconfirmation of expectations. In P. R. Bagozzi \& M. A. Tybout (Eds.), Advances in Consumer Research (Vol. 10, pp. 244-249).

Punch, K. F. (2005). Introduction to Social Research: Quantitative and Qualitative Approaches. London: Sage.

Reid, M. (2002). Building strong brands through the management of integrated marketing communications. International Journal of Wine Marketing, 14(3), 3752.

Rojas-Me'ndez, J. I., Vasquez-Parraga, A. Z., Kara, A., \& Cerda-Urrutia, A. (2009). Determinants of student loyalty in higher education: A tested relationship approach in Latin America. Latin American Business Review, 10, 21-39.

Rowley, C. (2003). National labour relations in internationalized markets: a comparative study of institutions, change and performance. International Journal of Human Resource Management, 14(2), 355-358.

Saleh, A. (2006). Antecedents of Commitments to an Import Supplier. Queensland University of Technology, Brisbane.

Salmon, P., \& Hall, G. M. (2001). Postoperative fatigue is a component of the emotional response to surgery: Results of multivariate analysis Journal of Psychosomatic Research, 50(6), 325-335.

Sarantakos, S. (1997). Social Research. Melbourne: Macmillan Education Australia Pty Ltd.

Sawyer, R. G., \& Thompson, E. (2003). Knowledge and attitudes about emergency contraception in university students. College Student Journal, 37(4), 523-529.

Sax, L. J., Gilmartin, S. K., \& Bryant, A. N. (2003). Assessing response rates and nonresponse bias in web and paper surveys. Research in Higher Education, 44(4), 409-432.

Schwab, D. P. (1980). Construct validity in organizational behavior In L. L. Cummings \& B.M.Staw (Eds.), Research in organizational behavior (Vol. 2, pp. 3-43). Greenwich: CT: JAI Press. 
Selnes, F. (1993). An examination of the effect of product performance on brand reputation, satisfaction and loyalty. European Journal of Marketing, 27(9), 1935 .

Selnes, F. (1998). Antecedents and consequences of trust and satisfaction in buyerseller relationships. European Journal of Marketing, 32(3/4), 305-322.

Sherif, M., \& Hovland, C. (1961). Social judgment: Assimilation and contrast effects in communication and attitude change. New Haven: Yale University Press.

Sines, R. G. J., \& Duckworth, E. A. (1994). Customers service in higher education. Journal of Marketing for Higher Education, 5(2), 1-15.

Skogland, I., \& Siguaw, J. A. (2004). Are your satisfied customers loyal? Cornell Hotel and Restaurant Administration Quarterly, 45(3), 221-235.

Smith, G., Smith, A., \& Clarke, A. (2007). Evaluating service quality in universities: a service department perspective. Quality Assurance in Education, 15(3), 334-351.

Soutar, G. N., \& Turner, J. P. (2002). Students' preferences for university: a conjoint analysis. International Journal of Educational Management, 16(1), 40-45.

Spector, P. E., Chen, P. Y., \& O'Connel, B. J. (2000). A longitudinal study of relations between job stressors and job strains while controlling for prior negative affectivity and strains. Journal of Applied Psychology, 85(2), 211-218.

Spreng, R. A., \& Mackoy, R. D. (1996). An empirical examination of a model of perceived service quality and satisfaction. Journal of Retailing, 72(2), 201-214.

Spreng, R. A., \& Olshavsky, R. W. (1993). A desires congruency model of consumer satisfaction. Journal of the Academy of Marketing Science, 21(3), 169-177.

Spreng, R. A., \& Singh, A. K. (1993). An empirical assessment of the SERVQUAL scale and the relationship between service quality and satisfaction. In D. W. Cravens \& P. Dickson (Eds.), AMA Educators' Proceedings (pp. 1-6). Chicago ILL AMA.

Stavros, C., \& Westberg, K. (2009). Using triangulation and multiple case studies to advance relationship marketing theory. Qualitative market research: an international journal, 12(3), 307-320.

Steenkamp, J. E. (1991). The use of LISREL in validating marketing constructs. International Journals of Research in Marketing, 8(4), 283-299.

Stewart, D. W., \& Shamdasani, P. N. (1990). Focus groups: Theory and practice. London: Sage.

Stewart, D. W., Shamdasani, P. N., \& Rook, D. W. (2007). Focus groups: Theory and practice. London: Sage.

Stodnick, M., \& Rogers, P. (2008). Using SERVQUAL to measure the quality of the classroom experience. Decision Sciences Journal of Innovative Education, 6(1), 115-133.

Sultan, P., \& Tarafder, T. (2007). Critical factors in service quality measurement for private universities: The case of Bangladesh. Ritsumeikan Journal of Asia Pacific Studies, 22(1), 75-98. 
Sultan, P., \& Wong, H. Y. (2010a). Performance-based service quality model: an empirical study on Japanese universities Quality Assurance in Education, 18(2), 126-143.

Sultan, P., \& Wong, H. Y. (2010b). Service Quality in Higher Education - A Review and Research Agenda. International Journal of Quality and Service Sciences, 2(2), 259-272.

Sureshchandar, G. S., Rajendran, C., \& Kamalanabhan, T. J. (2001). Customer perceptions of service quality: A critique. Total Quality Management, 12(1), 111-124.

Tabachnick, B. G., \& Fidell, L. S. (1989). Using Multivariate Statistics. New York: HarperCollins.

Tabachnick, B. G., \& Fidell, L. S. (2000). Using Multivariate Statistics. New York: HarperCollins.

Taylor, S. A., \& Baker, T. L. (1994). An assessment of the relationship between service quality and customer satisfaction. Journal of Retailing, 70(2), 163-178.

Teas, R. (1993). Expectations, performance evaluation, and consumers' perceptions of quality. Journal of Marketing, 57(4), 18-34.

Teas, R. (1994). Expectations as a comparison standard in measuring service quality: an assessment of a reassessment. Journal of Marketing, 58(1), 132-139.

Thibaut, J. W., \& Kelley, H. H. (1959). The Social Psychology of Groups. New York: John Wiley \& Sons.

The Australian Higher Education Quality Assurance Framework. (2000). Canberra ACT: Department of Education, Training and Youth Affairs.

Ueltschy, L. C., Laroche, M., Eggert, A., \& Bindl, U. (2007). Service quality and satisfaction: an international comparison of professional services perceptions. Journal of Services Marketing, 21(6), 410-423.

Välimaa, J. (2004). Nationalisation, localisation and globalisation in Finnish higher education. Higher Education, 48 (1).

Venetis, K. A., \& Ghauri, P. N. (2004). Service quality and customer retention: Building long-term relationships. European Journal of Marketing, 38(11/12), 1577-1598.

Vignali, C., \& Zundel, M. (2003). The marketing management process and heuristic devices: an action research investigation. Marketing Intelligence \& Planning, 21(4), 205-219.

White, S. S., \& Schneider, B. (2000). Climbing the commitment ladder: the role of expectations disconfirmation on customers' behavioral intentions. Journal of Service Research, 2(3), 240-253.

Whittaker, G., Ledden, L., \& Kalafatis, S. P. (2007). A re-examination of the relationship between value, satisfaction and intention in business services. Journal of Services Marketing, 21(5), 345-357. 
Winsted, K. F., \& Patterson, P. G. (1998). Internationalization of services: the service exporting decision. The Journal of Services Marketing, 12(4), 294-311.

Wong, D. H., Rexha, N., \& Phau, I. (2008). Re-examining traditional service quality in an e-banking era. International Journal of Bank Marketing, 26(7), 526-545.

Wong, H. Y. (2005). The Strategic Role of Branding in International Marketing. Griffith University.

Wong, H. Y., \& Merrilees, B. (2007a). Closing the marketing strategy to performance gap: the role of brand orientation. Journal of Strategic Marketing, 15(5), 387402.

Wong, H. Y., \& Merrilees, B. (2007b). Multiple roles for branding in international marketing. International Marketing Review, 24(4), 384-408.

Wong, H. Y., \& Merrilees, B. (2008). The performance benefits of being brandoriented. Journal of Product and Brand Management, 17(6), 372-383.

Yang, C. C. (2003). Improvement actions based on the customers' satisfaction survey. Total Quality Management and Business Excellence, 14(8), 919-930.

Yi, Y. (1990). A critical review of consumer satisfaction. In V. A. Zeithaml (Ed.), Review of Marketing 1990 (pp. 68-123). Chicago: American Marketing Association.

Yoon, E., Guffey, H. G., \& Kijewski, V. (1993). The effects of information and company reputation on intentions to buy a business service. Journal of Business Research, 27, 215-228.

Yorke, M. (1999). Leaving early: undergraduate non-completion in higher education. London: Falmer Press.

Yuan, K., Bentler, P., \& Kano, Y. (1997). On averaging variables in a CFA model. Behaviormetrika, 24(1), 71-83.

Yuksel, A., \& Rimmington, M. (1998). Customer-Satisfaction measurement. Cornell Hotel and Restaurant Administration Quarterly, 39(6), 60-70.

Yuksel, A., \& Yuksel, F. (2001). The expectancy-disconfirmation paradigm: a critique. Journal of Hospitality and Tourism Research, 25(2), 107-131.

Zboja, J. J., \& Voorkees, C. M. (2006). The impact of brand trust and satisfaction on retailer purchase intentions. Journal of Services Marketing, 20(6), 381-390.

Zeithaml, V. A. (Ed.). (1981). How consumer evaluation processes differ between goods and services. Chicago: American Marketing Association.

Zeithaml, V. A., Berry, L. L., \& Parasuraman, A. (1993). The nature and determinants of customer expectations of service. Journal of the Academy of Marketing Science, 21(1), 1-12.

Zeithaml, V. A., Berry, L. L., \& Parasuraman, A. (1996). The bahavioral consequences of service quality. Journal of Marketing, 60(2), 31-46.

Zeithaml, V. A., \& Bitner, M. J. (2003). Services Marketing: Integrating Customer Focus across the Firm (3rd ed.). Boston, MA: Irwin McGraw-Hill. 
Zeng, F., Hu, Z., Chen, R., \& Yang, Z. (2009). Determinants of online service satisfaction and their impacts on behavioural intentions. Total Quality Management, 20(9), 953-969.

Zhou, L. (2004). A dimension-specific analysis of performance-only measurement of service quality and satisfaction in china's retail banking. The Journal of Services Marketing, 18(6\&7), 534-546.

Zwick, R., Pieters, R., \& Baumgartner, H. (1995). On the practical significance of hindsight bias, the case of Expectancy Disconfirmation Model of customer satisfaction. Organisational Behaviour and Human Decision Process, 64(1), 103-117. 


\section{Appendices}

\section{Appendix A: The survey questionnaire}

\section{Information Sheet}

\section{What is this research about?}

The aim of this doctoral research project is to study CQUniversity's students' experience of higher education services. This research project, number H08/12-082, has received full ethical clearance from the Human Research Ethics Committee, Central Queensland University.

Who can participate?

Students having at least a fair experience of receiving higher education services from the University are eligible to participate. All you have to do is to complete this online questionnaire. This should not take more than 15 minutes. This survey will remain open until 31 December 2009. Please CLICK on the link below to participate in the survey process.

http://www.surveymonkey.com/s.aspx?sm=bUYN7c2XoVTUnT807WZzwQ 3d 3d

What will you do with the completed questionnaire?

Once you complete the questionnaire, please click on the 'done' button located at the end of the questionnaire.

\section{What are your rights?}

You are invited to become involved in this project voluntarily. You are free to withdraw yourself from participating in this survey at any time. During the participation process, any participant experiencing distress arising from this survey is encouraged to withdraw from participation. However, completion of the survey will be taken as consent to participate. Note that you will only get access to this survey link once.

How does this research maintain respondents' confidentiality/anonymity?

Since this questionnaire does not ask your name and other personal identifications, your identity is completely remaining unknown.

Who to contact for more information?

If you have any query about this research project, please contact:

Parves Sultan

CQUniversity Australia

Faculty of Arts, Business, Informatics and Education

Rockhampton, Qld. 4702, Australia.

E-mail: p.sultan@cqu.edu.au 


\section{$\underline{\text { Section A }}$}

Please provide the following demographic information. This information is necessary for validation of the questionnaire. Please select one option from the dropdown list for each of the following demographic issues. Please click on the "NEXT" button to go to the next page.

Gender

Age

Nationality

Current level of study

Mode of study

Current program of study

Location of your campus

How long have you been studying at the CQUniversity?

What are your average marks at this University?

Highest qualification for which you are planning to study 


\section{$\underline{\text { Section B }}$}

There are no right or wrong answers in this section. However, it is important that you provide a response to a statement that is relevant to your experience with this University.

\section{INFORMATION about CQUniversity}

Information that you receive from various sources may affect your perception of service quality. The following are some statements relevant to information provision. Please evaluate each of the following statements and CLICK on the circle that best describes your opinion.

\begin{tabular}{|c|c|c|c|c|c|c|c|}
\hline & $\begin{array}{l}\text { Strongly } \\
\text { Disagree }\end{array}$ & $\begin{array}{c}\text { Fairly } \\
\text { Disagree }\end{array}$ & Disagree & Neutral & Agree & $\begin{array}{c}\text { Fairl } \\
\text { y } \\
\text { Agre } \\
\text { e } \\
\end{array}$ & $\begin{array}{l}\text { Strongl } \\
\text { y Agree }\end{array}$ \\
\hline $\begin{array}{l}\text { Information provided by this University } \\
\text { makes promises about their quality }\end{array}$ & 0 & 0 & 0 & 0 & $\bigcirc$ & 0 & $\bigcirc$ \\
\hline $\begin{array}{l}\text { Advertisements about this University } \\
\text { are a good source of information. }\end{array}$ & 0 & 0 & 0 & 0 & 0 & 0 & 0 \\
\hline $\begin{array}{l}\text { Overall, information provided by this } \\
\text { University helps me find service } \\
\text { attributes }\end{array}$ & 0 & 0 & 0 & 0 & 0 & 0 & 0 \\
\hline
\end{tabular}

\section{PAST EXPERIENCE of Educational Services}

Past experiences influence evaluation of service related attributes. The following are some statements relevant to past experiences. Please evaluate each of the following statements and CLICK on the circle that best describes your opinion.

\begin{tabular}{|c|c|c|c|c|c|c|c|}
\hline & \multirow[b]{2}{*}{$\begin{array}{l}\text { Strongly } \\
\text { Disagree }\end{array}$} & \multirow[b]{2}{*}{$\begin{array}{c}\text { Fairly } \\
\text { Disagree }\end{array}$} & \multirow[b]{2}{*}{ Disagree } & \multirow[b]{2}{*}{ Neutral } & \multicolumn{3}{|c|}{ Fairl } \\
\hline & & & & & Agree & $\begin{array}{c}\text { y } \\
\text { Agre } \\
\text { e }\end{array}$ & $\begin{array}{l}\text { Strongl } \\
\text { y Agree }\end{array}$ \\
\hline $\begin{array}{l}\text { My previous study background helps } \\
\text { me to predict the service quality of this } \\
\text { University }\end{array}$ & 0 & $\bigcirc$ & 0 & 0 & $\bigcirc$ & 0 & 0 \\
\hline $\begin{array}{l}\text { Before enrolling, I had a good } \\
\text { relationship with this University }\end{array}$ & 0 & 0 & 0 & 0 & 0 & 0 & 0 \\
\hline $\begin{array}{l}\text { Overall, my past educational } \\
\text { experience helps to assess performance } \\
\text { of this University }\end{array}$ & 0 & 0 & 0 & 0 & 0 & 0 & 0 \\
\hline
\end{tabular}


SERVICE QUALITY Attributes of the University

The following are some statements relevant to quality aspects of the CQUniversity. Please evaluate each of the following statements and CLICK on the circle that best describes your opinion.

\begin{tabular}{|c|c|c|c|c|c|c|c|}
\hline & $\begin{array}{l}\text { Strongly } \\
\text { Disagree }\end{array}$ & $\begin{array}{c}\text { Fairly } \\
\text { Disagree }\end{array}$ & Disagree & Neutral & Agree & $\begin{array}{l}\text { Fairly } \\
\text { Agree }\end{array}$ & $\begin{array}{c}\text { Strongly } \\
\text { Agree }\end{array}$ \\
\hline $\begin{array}{l}\text { I find that academics at this University } \\
\text { are knowledgeable }\end{array}$ & O & $\mathrm{O}$ & O & O & O & $\mathrm{O}$ & $\mathrm{O}$ \\
\hline $\begin{array}{l}\text { Lecturers show sincere interest in solving } \\
\text { my academic problems }\end{array}$ & O & $\mathrm{O}$ & O & O & O & O & $\mathrm{O}$ \\
\hline $\begin{array}{l}\text { Lecturers provide feedback about my } \\
\text { progress }\end{array}$ & O & $\mathrm{O}$ & $\mathrm{O}$ & O & $\mathrm{O}$ & O & $\mathrm{O}$ \\
\hline $\begin{array}{l}\text { I receive adequate time for consultation } \\
\text { with lecturers }\end{array}$ & O & $\mathrm{O}$ & $\mathrm{O}$ & O & O & $\mathrm{O}$ & O \\
\hline $\begin{array}{l}\text { I find that the administrative staff is } \\
\text { prompt to provide service }\end{array}$ & O & O & $\mathrm{O}$ & O & O & O & O \\
\hline The location of the University is ideal & $\mathrm{O}$ & $\mathrm{O}$ & $\mathrm{O}$ & $\mathrm{O}$ & $\mathrm{O}$ & $\mathrm{O}$ & $\mathrm{O}$ \\
\hline $\begin{array}{l}\text { I find that the classroom facilities are } \\
\text { adequate }\end{array}$ & O & O & $\mathrm{O}$ & O & $\mathrm{O}$ & $\mathrm{O}$ & O \\
\hline $\begin{array}{l}\text { I find that this University has up-to-date } \\
\text { equipment }\end{array}$ & $\mathrm{O}$ & O & $\mathrm{O}$ & O & $\mathrm{O}$ & $\mathrm{O}$ & O \\
\hline $\begin{array}{l}\text { My overall evaluation of quality with } \\
\text { regard to support functions of this } \\
\text { University is good }\end{array}$ & O & O & $\mathrm{O}$ & O & O & $\mathrm{O}$ & O \\
\hline $\begin{array}{l}\text { My overall evaluation of the service } \\
\text { quality provided by the teaching staff of } \\
\text { this University is good }\end{array}$ & O & O & $\mathrm{O}$ & O & O & $\mathrm{O}$ & O \\
\hline $\begin{array}{l}\text { My overall evaluation of the service } \\
\text { quality provided by the administrative } \\
\text { staff of this University is good }\end{array}$ & O & O & O & O & $\mathrm{O}$ & $\mathrm{O}$ & O \\
\hline The teaching staff meet my requirements & $\mathrm{O}$ & $\mathrm{O}$ & $\mathrm{O}$ & $\mathrm{O}$ & $\mathrm{O}$ & $\mathrm{O}$ & $\mathrm{O}$ \\
\hline $\begin{array}{l}\text { The administrative staff meet my } \\
\text { requirements }\end{array}$ & O & $\mathrm{O}$ & $\mathrm{O}$ & O & O & $\mathrm{O}$ & $\mathrm{O}$ \\
\hline $\begin{array}{l}\text { My academic performance is recorded } \\
\text { correctly }\end{array}$ & O & $\mathrm{O}$ & O & O & O & O & O \\
\hline $\begin{array}{l}\text { I find that the administrative staff is } \\
\text { courteous }\end{array}$ & O & $\mathrm{O}$ & O & O & O & $\mathrm{O}$ & O \\
\hline $\begin{array}{l}\text { I find that the administrative staff keeps } \\
\text { accurate records }\end{array}$ & O & $\mathrm{O}$ & O & O & O & O & O \\
\hline $\begin{array}{l}\text { The overall environment of this } \\
\text { University is friendly }\end{array}$ & O & $\mathrm{O}$ & O & O & O & O & O \\
\hline $\begin{array}{l}\text { I find that this University has good } \\
\text { infrastructure }\end{array}$ & O & $\mathrm{O}$ & O & O & O & O & O \\
\hline $\begin{array}{l}\text { I find that the scenic beauty of this } \\
\text { University is excellent }\end{array}$ & O & $\mathrm{O}$ & O & O & O & O & O \\
\hline I find that lecturers are skilled in teaching & $\mathrm{O}$ & $\mathrm{O}$ & $\mathrm{O}$ & $\mathrm{O}$ & $\mathrm{O}$ & $\mathrm{O}$ & $\mathrm{O}$ \\
\hline $\begin{array}{l}\text { The academic backgrounds of the } \\
\text { lecturers are excellent }\end{array}$ & O & $\mathrm{O}$ & O & O & O & O & O \\
\hline
\end{tabular}




\begin{tabular}{|c|c|c|c|c|c|c|c|}
\hline & $\begin{array}{l}\text { Strongly } \\
\text { Disagree }\end{array}$ & $\begin{array}{c}\text { Fairly } \\
\text { Disagree }\end{array}$ & Disagree & Neutral & Agree & $\begin{array}{l}\text { Fairly } \\
\text { Agree }\end{array}$ & $\begin{array}{r}\text { Strongly } \\
\text { Agree }\end{array}$ \\
\hline $\begin{array}{l}\text { The admission department of this } \\
\text { University is very helpful }\end{array}$ & 0 & 0 & 0 & 0 & 0 & 0 & 0 \\
\hline $\begin{array}{l}\text { I find that the University's career } \\
\text { counselling service is very helpful }\end{array}$ & 0 & 0 & 0 & 0 & 0 & 0 & 0 \\
\hline $\begin{array}{l}\text { I find that the administrative staff is } \\
\text { skilled }\end{array}$ & 0 & 0 & 0 & 0 & 0 & 0 & 0 \\
\hline $\begin{array}{l}\text { I find that classroom learning is very } \\
\text { practical }\end{array}$ & 0 & 0 & 0 & 0 & 0 & 0 & 0 \\
\hline $\begin{array}{l}\text { I find that the library facilities are } \\
\text { adequate }\end{array}$ & 0 & 0 & 0 & 0 & 0 & 0 & 0 \\
\hline
\end{tabular}

\section{Overall SATISFACTION}

The following are some statements relevant to your satisfaction of the performance of the University. Please evaluate each of the following statements and CLICK on the circle that best describes your opinion.

\begin{tabular}{|c|c|c|c|c|c|c|c|}
\hline & $\begin{array}{l}\text { Strongly } \\
\text { Disagree } \\
\end{array}$ & $\begin{array}{c}\text { Fairly } \\
\text { Disagree }\end{array}$ & Disagree & Neutral & Agree & $\begin{array}{l}\text { Fairly } \\
\text { Agree }\end{array}$ & $\begin{array}{c}\text { Strongly } \\
\text { Agree } \\
\end{array}$ \\
\hline $\begin{array}{l}\text { It has been a good decision to select } \\
\text { this University }\end{array}$ & O & O & O & O & $\mathrm{O}$ & O & O \\
\hline $\begin{array}{l}\text { Overall, I am satisfied with this } \\
\text { University }\end{array}$ & O & O & O & O & O & O & O \\
\hline $\begin{array}{l}\text { Overall, this University fulfils my } \\
\text { needs }\end{array}$ & O & O & O & O & O & O & O \\
\hline $\begin{array}{l}\text { Overall, this University provides } \\
\text { satisfaction compared to an alternate } \\
\text { higher education institution }\end{array}$ & O & O & O & $\mathrm{O}$ & O & O & O \\
\hline $\begin{array}{l}\text { Overall, I am satisfied with the quality } \\
\text { relative to price }\end{array}$ & O & 0 & O & O & $\mathrm{O}$ & O & O \\
\hline $\begin{array}{l}\text { Overall, I am satisfied with the service } \\
\text { performance }\end{array}$ & O & O & O & O & O & O & O \\
\hline Overall, it is a good University & O & $\mathrm{O}$ & O & O & O & O & O \\
\hline
\end{tabular}

\section{TRUST on University}

The following statements are related to trust in relation to various aspects of the University. Please evaluate each of the following statements and CLICK on the circle that best describes your opinion. 


\begin{tabular}{|c|c|c|c|c|c|c|c|}
\hline & $\begin{array}{l}\text { Strongly } \\
\text { Disagree }\end{array}$ & $\begin{array}{c}\text { Fairly } \\
\text { Disagree }\end{array}$ & Disagree & Neutral & Agree & $\begin{array}{l}\text { Fairly } \\
\text { Agree }\end{array}$ & $\begin{array}{r}\text { Strongly } \\
\text { Agree }\end{array}$ \\
\hline I trust this University & O & O & O & O & O & O & O \\
\hline $\begin{array}{l}\text { This University provides reliable quality of } \\
\text { services }\end{array}$ & O & O & O & O & O & $\mathrm{O}$ & $\mathrm{O}$ \\
\hline Overall, this University is honest with me & O & $\mathrm{O}$ & $\mathrm{O}$ & $\mathrm{O}$ & $\mathrm{O}$ & $\mathrm{O}$ & $\mathrm{O}$ \\
\hline This University guarantees satisfaction & $\mathrm{O}$ & $\mathrm{O}$ & $\mathrm{O}$ & $\mathrm{O}$ & O & $\mathrm{O}$ & $\mathrm{O}$ \\
\hline I feel secure at this University & $\mathrm{O}$ & $\mathrm{O}$ & $\mathrm{O}$ & $\mathrm{O}$ & $\mathrm{O}$ & $\mathrm{O}$ & $\mathrm{O}$ \\
\hline I find that this University keeps promises & $\mathrm{O}$ & $\mathrm{O}$ & $\mathrm{O}$ & $\mathrm{O}$ & $\mathrm{O}$ & $\mathrm{O}$ & $\mathrm{O}$ \\
\hline I always get help from staff, if I ask for it & $\mathrm{O}$ & $\mathrm{O}$ & $\mathrm{O}$ & $\mathrm{O}$ & $\mathrm{O}$ & $\mathrm{O}$ & $\mathrm{O}$ \\
\hline I can depend on this University & $\mathrm{O}$ & $\mathrm{O}$ & $\mathrm{O}$ & $\mathrm{O}$ & $\mathrm{O}$ & $\mathrm{O}$ & $\mathrm{O}$ \\
\hline The University staff are trustworthy & $\mathrm{O}$ & $\mathrm{O}$ & $\mathrm{O}$ & $\mathrm{O}$ & $\mathrm{O}$ & $\mathrm{O}$ & $\mathrm{O}$ \\
\hline This University guarantees best value & $\mathrm{O}$ & $\mathrm{O}$ & $\mathrm{O}$ & $\mathrm{O}$ & $\mathrm{O}$ & $\mathrm{O}$ & $\mathrm{O}$ \\
\hline $\begin{array}{l}\text { I am confident that I will get a good job } \\
\text { after graduation }\end{array}$ & O & O & O & O & O & O & O \\
\hline $\begin{array}{l}\text { My emotional relationship with this } \\
\text { University is strong }\end{array}$ & O & O & O & O & O & O & 0 \\
\hline
\end{tabular}

\section{BRAND PERFORMANCE}

The following are some statements relevant to the brand performance of the CQUniversity. Please evaluate each of the following statements and CLICK on the circle that best describes your opinion.

\begin{tabular}{|c|c|c|c|c|c|c|c|}
\hline & $\begin{array}{l}\text { Strongly } \\
\text { Disagree }\end{array}$ & $\begin{array}{c}\text { Fairly } \\
\text { Disagree }\end{array}$ & Disagree & Neutral & Agree & $\begin{array}{l}\text { Fairly } \\
\text { Agree }\end{array}$ & $\begin{array}{c}\text { Strongly } \\
\text { Agree } \\
\end{array}$ \\
\hline $\begin{array}{l}\text { I found that this University has a good } \\
\text { reputation }\end{array}$ & O & O & O & $\bigcirc$ & O & ○ & O \\
\hline $\begin{array}{l}\text { I am proud to be a student of this } \\
\text { University }\end{array}$ & O & O & O & O & O & O & O \\
\hline A degree from this University is worthy & $\mathrm{O}$ & $\mathrm{O}$ & $\mathrm{O}$ & $\mathrm{O}$ & $\mathrm{O}$ & $\mathrm{O}$ & $\mathrm{O}$ \\
\hline This university performs well & $\mathrm{O}$ & O & $\mathrm{O}$ & O & $\mathrm{O}$ & O & O \\
\hline CQUniversity as a brand is reliable & $\mathrm{O}$ & $\mathrm{O}$ & $\mathrm{O}$ & $\mathrm{O}$ & $\mathrm{O}$ & $\mathrm{O}$ & $\mathrm{O}$ \\
\hline $\begin{array}{l}\text { The graduates of this University receive a good } \\
\text { salary }\end{array}$ & O & O & O & O & O & O & O \\
\hline $\begin{array}{l}\text { A degree from this University enhances } \\
\text { employability }\end{array}$ & O & O & O & O & O & O & O \\
\hline $\begin{array}{l}\text { Employers prefer graduates from this } \\
\text { University }\end{array}$ & O & O & 0 & 0 & 0 & 0 & 0 \\
\hline
\end{tabular}




\section{BEHAVIOURAL INTENTION}

The following are some statements relevant to your intentions during or after graduation. Please evaluate each of the following statements and CLICK on the circle that best describes your opinion.

\begin{tabular}{lccccccc}
\hline & $\begin{array}{c}\text { Strongly } \\
\text { Disagree }\end{array}$ & $\begin{array}{c}\text { Fairly } \\
\text { Disagree }\end{array}$ & Disagree & Neutral & Agree & $\begin{array}{c}\text { Fairly } \\
\text { Agree }\end{array}$ & $\begin{array}{c}\text { Strongly } \\
\text { Agree }\end{array}$ \\
\hline $\begin{array}{l}\text { I will recommend others to study at this } \\
\text { University }\end{array}$ & 0 & 0 & 0 & 0 & 0 & 0 & 0 \\
\hline $\begin{array}{l}\text { If I had to choose today, I would select this } \\
\text { University }\end{array}$ & 0 & 0 & 0 & 0 & 0 & 0 & 0 \\
\hline $\begin{array}{l}\text { I will recommend the study programs of } \\
\text { this University to others }\end{array}$ & 0 & 0 & 0 & 0 & 0 & 0 & 0 \\
\hline $\begin{array}{l}\text { If I had to choose today, I would select } \\
\text { the study programs of this University }\end{array}$ & 0 & 0 & 0 & 0 & 0 & 0 & 0 \\
\hline $\begin{array}{l}\text { I will definitely consider this University } \\
\text { as my future study destination }\end{array}$ & 0 & 0 & 0 & 0 & 0 & 0 & 0 \\
\hline $\begin{array}{l}\text { I will recommend this University in } \\
\text { preference to other options }\end{array}$ & 0 & 0 & 0 & 0 & 0 & 0 & 0 \\
\hline
\end{tabular}

Thank you for your participation. Please press the DONE button. 
Appendix B: Non-response bias (independent sample t-test)

\begin{tabular}{|c|c|c|c|c|c|}
\hline \multirow[t]{2}{*}{ Variables } & \multicolumn{2}{|c|}{$\begin{array}{l}\text { Levene's Test for Equality } \\
\text { of Variances }\end{array}$} & \multirow[t]{2}{*}{$\mathbf{t}$} & \multirow[t]{2}{*}{ df } & \multirow{2}{*}{$\begin{array}{l}\text { Sig. } \\
\text { (2-tailed) }\end{array}$} \\
\hline & $\mathbf{F}$ & Sig. & & & \\
\hline Information provided by this University makes promises about their quality & 1.791 & .181 & .339 & 526 & .734 \\
\hline Advertisements about this University are a good source of information & .043 & .836 & .102 & 526 & .919 \\
\hline $\begin{array}{l}\text { Overall, information provided by this University helps me find service } \\
\text { attributes }\end{array}$ & .000 & .995 & -.274 & 526 & .784 \\
\hline $\begin{array}{l}\text { My previous study background helps me to predict the service quality of this } \\
\text { University }\end{array}$ & .081 & .776 & .067 & 526 & .947 \\
\hline Before enrolling, I had a good relationship with this University & .191 & .663 & -.533 & 526 & .594 \\
\hline $\begin{array}{l}\text { Overall, my past educational experience helps to assess performance of this } \\
\text { University }\end{array}$ & 1.719 & .190 & .000 & 526 & 1.000 \\
\hline I find that academics at this University are knowledgeable & .504 & .478 & -.898 & 526 & .369 \\
\hline Lecturers show sincere interest in solving my academic problems & .852 & .356 & -1.843 & 526 & .066 \\
\hline My academic performance is recorded correctly & .001 & .980 & .647 & 526 & .518 \\
\hline Lecturers provide feedback about my progress & .030 & .862 & -2.173 & 526 & .030 \\
\hline I receive adequate time for consultation with lecturers & .170 & .680 & -2.246 & 526 & .025 \\
\hline I find that lecturers are skilled in teaching & 1.724 & .190 & -.178 & 526 & .859 \\
\hline The academic backgrounds of the lecturers are excellent & 2.411 & .121 & -1.044 & 526 & .297 \\
\hline I find that the administrative staff is courteous & .027 & .870 & -.730 & 526 & .466 \\
\hline I find that the administrative staff is prompt to provide service & .067 & .796 & -.152 & 526 & .879 \\
\hline I find that the administrative staff keeps accurate records & .297 & .586 & -.620 & 526 & .536 \\
\hline The admission department of this University is very helpful & 2.068 & .151 & -.720 & 526 & .472 \\
\hline I find that the University's career counselling service is very helpful & .000 & .992 & -2.255 & 526 & .025 \\
\hline I find that the administrative staff is skilled & .443 & .506 & -.859 & 526 & .391 \\
\hline The overall environment of this University is friendly & .534 & .465 & -1.129 & 526 & .260 \\
\hline I find that classroom learning is very practical & .164 & .686 & -2.025 & 526 & .043 \\
\hline The location of the University is ideal & .091 & .763 & -.566 & 526 & .572 \\
\hline I find that this University has up-to-date equipment & .483 & .488 & -.125 & 526 & .900 \\
\hline I find that the classroom facilities are adequate & 2.326 & .128 & -.348 & 526 & .728 \\
\hline I find that the library facilities are adequate & .000 & .992 & -1.568 & 526 & .117 \\
\hline I find that this University has good infrastructure & .394 & .530 & -1.167 & 526 & .244 \\
\hline I find that the scenic beauty of this University is excellent & 3.816 & .051 & -.860 & 526 & .390 \\
\hline $\begin{array}{l}\text { My overall evaluation of quality with regard to support functions of this } \\
\text { University is good }\end{array}$ & 3.535 & .061 & -1.697 & 526 & .090 \\
\hline $\begin{array}{l}\text { My overall evaluation of the service quality provided by the teaching staff of } \\
\text { this University is good }\end{array}$ & .507 & .477 & -1.261 & 526 & .208 \\
\hline $\begin{array}{l}\text { My overall evaluation of the service quality provided by the administrative staff } \\
\text { of this University is good }\end{array}$ & .845 & .358 & -2.291 & 526 & .022 \\
\hline The teaching staff meet my requirements & .840 & .360 & -2.485 & 526 & .013 \\
\hline The administrative staff meet my requirements & .826 & .364 & -2.022 & 526 & .044 \\
\hline Overall, I am satisfied with the service performance & 1.549 & .214 & -.518 & 526 & .605 \\
\hline Overall, I am satisfied with the quality relative to price & .120 & .729 & -.992 & 526 & .322 \\
\hline Overall, it is a good University & .057 & .812 & -.725 & 526 & .469 \\
\hline Overall, I am satisfied with this University & .124 & .725 & -1.252 & 526 & .211 \\
\hline Overall, this University fulfils my needs & .002 & .966 & -.864 & 526 & .388 \\
\hline $\begin{array}{l}\text { Overall, this University provides satisfaction compared to an alternate higher } \\
\text { education institution }\end{array}$ & .017 & .898 & -1.420 & 526 & .156 \\
\hline It has been a good decision to select this University & .241 & .623 & -1.200 & 526 & .231 \\
\hline The University staff are trustworthy & .024 & .878 & -2.231 & 526 & .026 \\
\hline I feel secure at this University & .994 & .319 & -2.142 & 526 & .033 \\
\hline I can depend on this University & .571 & .450 & -2.191 & 526 & .029 \\
\hline I trust this University & .413 & .521 & -2.183 & 526 & .029 \\
\hline
\end{tabular}




\begin{tabular}{|c|c|c|c|c|c|}
\hline \multirow[t]{2}{*}{ Variables } & \multicolumn{2}{|c|}{$\begin{array}{c}\text { Levene's Test for Equality } \\
\text { of Variances }\end{array}$} & \multirow[t]{2}{*}{$\mathrm{t}$} & \multirow[t]{2}{*}{ df } & \multirow{2}{*}{$\begin{array}{c}\text { Sig. } \\
\text { (2-tailed }\end{array}$} \\
\hline & $F$ & Sig. & & & \\
\hline This University guarantees satisfaction & 1.306 & .254 & -1.017 & 526 & .309 \\
\hline This University guarantees best value & 1.100 & .295 & -1.860 & 526 & .063 \\
\hline This University provides reliable quality of services & .116 & .733 & -1.244 & 526 & .214 \\
\hline I am confident that I will get a good job after graduation & .065 & .799 & .404 & 526 & .686 \\
\hline My emotional relationship with this University is strong & 2.051 & .153 & -1.126 & 526 & .261 \\
\hline Overall, this University is honest with me & .057 & .812 & -1.052 & 526 & .293 \\
\hline I find that this University keeps promises & .054 & .816 & -.512 & 526 & .609 \\
\hline I always get help from staff, if I ask for it & .142 & .707 & -1.816 & 526 & .070 \\
\hline I will recommend others to study at this University & .302 & .583 & -.959 & 526 & .338 \\
\hline I will definitely consider this University as my future study destination & .060 & .806 & -.307 & 526 & .759 \\
\hline I will recommend this University in preference to other options & .984 & .322 & -.708 & 526 & .479 \\
\hline If I had to choose today, I would select this University & .933 & .335 & -.263 & 526 & .793 \\
\hline I will recommend the study programs of this University to others & .573 & .449 & .998 & 526 & .319 \\
\hline If I had to choose today, I would select the study programs of this University & .205 & .651 & .172 & 526 & .863 \\
\hline I am proud to be a student of this University & 1.944 & .164 & -1.599 & 526 & .110 \\
\hline A degree from this University is worthy & .833 & .362 & -.797 & 526 & .426 \\
\hline I found that this University has a good reputation & .374 & .541 & -.561 & 526 & .575 \\
\hline This university performs well & 2.280 & .132 & -.040 & 526 & .968 \\
\hline CQUniversity as a brand is reliable & 4.093 & .044 & -.965 & 526 & .335 \\
\hline The graduates of this University receive a good salary & .326 & .568 & -.489 & 526 & .625 \\
\hline A degree from this University enhances employability & 2.677 & .102 & 1.212 & 526 & .226 \\
\hline Employers prefer graduates from this University & .939 & .333 & 1.265 & 526 & .206 \\
\hline
\end{tabular}

\section{Appendix C: Descriptive statistics}

\begin{tabular}{|c|c|c|c|c|c|c|c|c|}
\hline \multirow[t]{2}{*}{ Items $(\mathrm{N}=528)$} & \multirow{2}{*}{$\begin{array}{l}\text { Min } \\
\text { Statistic } \\
\end{array}$} & \multirow{2}{*}{$\begin{array}{l}\text { Max } \\
\text { Statistic }\end{array}$} & \multirow{2}{*}{$\begin{array}{l}\text { Mean } \\
\text { Statistic }\end{array}$} & \multirow{2}{*}{$\begin{array}{l}\text { SD } \\
\text { Statistic }\end{array}$} & \multicolumn{2}{|l|}{ Skewness } & \multicolumn{2}{|l|}{ Kurtosis } \\
\hline & & & & & Statistic & Std. Error & Statistic & Std. Error \\
\hline $\begin{array}{l}\text { Information provided by this University makes promises about } \\
\text { their quality }\end{array}$ & 2 & 7 & 5.13 & 1.025 & .215 & .106 & -.442 & .212 \\
\hline $\begin{array}{l}\text { Advertisements about this University are a good source of } \\
\text { information }\end{array}$ & 1 & 7 & 4.79 & 1.280 & -.385 & 106 & .410 & .212 \\
\hline $\begin{array}{l}\text { Overall, information provided by this University helps me find } \\
\text { service attributes }\end{array}$ & 1 & 7 & 5.02 & 1.110 & -.326 & 106 & .532 & .212 \\
\hline $\begin{array}{l}\text { My previous study background helps me to predict the service } \\
\text { quality of this University }\end{array}$ & 1 & 7 & 4.49 & 1.305 & -.091 & 106 & .139 & 212 \\
\hline Before enrolling, I had a good relationship with this University & 1 & 7 & 4.07 & 1.306 & -.041 & 106 & .969 & 212 \\
\hline $\begin{array}{l}\text { Overall, my past educational experience helps to assess } \\
\text { performance of this University }\end{array}$ & 1 & 7 & 4.88 & 1.224 & -.289 & .106 & .672 & .212 \\
\hline I find that academics at this University are knowledgeable & 2 & 7 & 5.46 & 1.017 & -.114 & 106 & -.311 & 212 \\
\hline Lecturers show sincere interest in solving my academic problems & 2 & 7 & 5.27 & 1.183 & -.305 & 106 & -.332 & 212 \\
\hline My academic performance is recorded correctly & 1 & 7 & 5.62 & 1.143 & -.548 & .106 & .146 & .212 \\
\hline Lecturers provide feedback about my progress & 1 & 7 & 4.91 & 1.306 & -.380 & 106 & -.071 & .212 \\
\hline I receive adequate time for consultation with lecturers & 1 & 7 & 4.84 & 1.303 & -.159 & 106 & -.294 & 212 \\
\hline I find that lecturers are skilled in teaching & 1 & 7 & 5.12 & 1.220 & -.373 & 106 & .234 & 212 \\
\hline The academic backgrounds of the lecturers are excellent & 2 & 7 & 5.13 & 1.168 & .142 & 106 & -.701 & .212 \\
\hline I find that the administrative staff is courteous & 2 & 7 & 5.65 & 1.072 & -.328 & .106 & -.269 & .212 \\
\hline I find that the administrative staff is prompt to provide service & 2 & 7 & 5.52 & 1.144 & -.319 & .106 & -.453 & .212 \\
\hline I find that the administrative staff keeps accurate records & 2 & 7 & 5.45 & 1.123 & -.132 & 106 & -.763 & .212 \\
\hline The admission department of this University is very helpful & 2 & 7 & 5.38 & 1.148 & -.119 & .106 & -.697 & .212 \\
\hline $\begin{array}{l}\text { I find that the University's career counselling service is very } \\
\text { helpful }\end{array}$ & 1 & 7 & 4.71 & 1.163 & .380 & .106 & .441 & .212 \\
\hline
\end{tabular}




\begin{tabular}{|c|c|c|c|c|c|c|c|c|}
\hline \multirow{2}{*}{ Items $(\mathrm{N}=528)$} & \multirow{2}{*}{$\frac{\text { Min }}{\text { Statistic }}$} & \multirow{2}{*}{$\begin{array}{l}\text { Max } \\
\text { Statistic }\end{array}$} & \multirow{2}{*}{$\begin{array}{l}\text { Mean } \\
\text { Statistic }\end{array}$} & \multirow{2}{*}{$\begin{array}{l}\text { SD } \\
\text { Statistic }\end{array}$} & \multicolumn{2}{|l|}{ Skewness } & \multicolumn{2}{|l|}{ Kurtosis } \\
\hline & & & & & Statistic & Std. Error & Statistic & Std. Error \\
\hline I find that the administrative staff is skilled & 2 & 7 & 5.26 & 1.115 & .015 & .106 & -.577 & 212 \\
\hline The overall environment of this University is friendly & 2 & 7 & 5.50 & 1.003 & -.063 & .106 & -.430 & .212 \\
\hline I find that classroom learning is very practical & 1 & 7 & 4.91 & 1.164 & .294 & .106 & -.477 & .212 \\
\hline The location of the University is ideal & 1 & 7 & 5.10 & 1.307 & -.238 & .106 & -.013 & .212 \\
\hline I find that this University has up-to-date equipment & 1 & 7 & 4.79 & 1.239 & -.270 & .106 & .430 & .212 \\
\hline I find that the classroom facilities are adequate & 1 & 7 & 4.75 & 1.125 & .082 & .106 & .476 & .212 \\
\hline I find that the library facilities are adequate & 1 & 7 & 5.14 & 1.223 & -.500 & .106 & .638 & .212 \\
\hline I find that this University has good infrastructure & 1 & 7 & 4.85 & 1.130 & .080 & .106 & .174 & .212 \\
\hline I find that the scenic beauty of this University is excellent & 1 & 7 & 5.02 & 1.215 & .065 & .106 & -.213 & .212 \\
\hline $\begin{array}{l}\text { My overall evaluation of quality with regard to support functions of } \\
\text { this University is good }\end{array}$ & 2 & 7 & 5.30 & 1.079 & -.180 & .106 & -.135 & .212 \\
\hline $\begin{array}{l}\text { My overall evaluation of the service quality provided by the teaching } \\
\text { staff of this University is good }\end{array}$ & 2 & 7 & 5.27 & 1.142 & -.360 & .106 & .012 & .212 \\
\hline $\begin{array}{l}\text { My overall evaluation of the service quality provided by the } \\
\text { administrative staff of this University is good }\end{array}$ & 2 & 7 & 5.46 & 1.068 & -.149 & .106 & -.382 & .212 \\
\hline The teaching staff meet my requirements & 2 & 7 & 5.24 & 1.197 & -.356 & .106 & -.222 & .212 \\
\hline The administrative staff meet my requirements & 2 & 7 & 5.49 & 1.079 & -.185 & .106 & -.288 & .212 \\
\hline Overall, I am satisfied with the service performance & 2 & 7 & 5.23 & 1.092 & -.184 & .106 & -.051 & .212 \\
\hline Overall, I am satisfied with the quality relative to price & 1 & 7 & 4.92 & 1.185 & -.227 & .106 & .189 & .212 \\
\hline Overall, it is a good University & 2 & 7 & 5.41 & 1.020 & .006 & .106 & -.328 & .212 \\
\hline Overall, I am satisfied with this University & 2 & 7 & 5.39 & 1.043 & -.099 & .106 & -.287 & .212 \\
\hline Overall, this University fulfils my needs & 2 & 7 & 5.26 & 1.158 & -.201 & .106 & -.449 & .212 \\
\hline $\begin{array}{l}\text { Overall, this University provides satisfaction compared to an } \\
\text { alternate higher education institution }\end{array}$ & 1 & 7 & 5.00 & 1.166 & .159 & .106 & -.437 & .212 \\
\hline It has been a good decision to select this University & 2 & 7 & 5.44 & 1.124 & -.006 & .106 & -.925 & .212 \\
\hline The University staff are trustworthy & 2 & 7 & 5.43 & 1.077 & .059 & .106 & -.817 & .212 \\
\hline I feel secure at this University & 3 & 7 & 5.37 & 1.101 & .108 & .106 & -.917 & .212 \\
\hline I can depend on this University & 2 & 7 & 5.20 & 1.116 & .041 & .106 & -.567 & .212 \\
\hline I trust this University & 2 & 7 & 5.28 & 1.100 & .135 & .106 & -.774 & .212 \\
\hline This University guarantees satisfaction & 2 & 7 & 4.94 & 1.155 & .271 & .106 & -.636 & .212 \\
\hline This University guarantees best value & 2 & 7 & 4.80 & 1.173 & .303 & .106 & -.537 & .212 \\
\hline This University provides reliable quality of services & 2 & 7 & 5.15 & 1.085 & -.013 & .106 & -.312 & .212 \\
\hline I am confident that I will get a good job after graduation & 2 & 7 & 5.34 & 1.183 & -.171 & .106 & -.607 & .212 \\
\hline My emotional relationship with this University is strong & 1 & 7 & 4.82 & 1.315 & -.111 & .106 & -.283 & .212 \\
\hline Overall, this University is honest with me & 2 & 7 & 5.32 & 1.075 & .086 & .106 & -.652 & .212 \\
\hline I find that this University keeps promises & 1 & 7 & 4.94 & 1.133 & .154 & .106 & -.113 & .212 \\
\hline I always get help from staff, if I ask for it & 2 & 7 & 5.39 & 1.227 & -.508 & .106 & -.124 & .212 \\
\hline I will recommend others to study at this University & 2 & 7 & 5.34 & 1.225 & -.223 & .106 & -.526 & .212 \\
\hline I will definitely consider this University as my future study destination & 1 & 7 & 5.22 & 1.274 & -.187 & .106 & -.548 & .212 \\
\hline I will recommend this University in preference to other options & 1 & 7 & 4.72 & 1.290 & .037 & .106 & -.145 & .212 \\
\hline If I had to choose today, I would select this University & 1 & 7 & 5.00 & 1.324 & -.113 & .106 & -.245 & .212 \\
\hline I will recommend the study programs of this University to others & 1 & 7 & 5.19 & 1.221 & -.133 & .106 & -.311 & .212 \\
\hline $\begin{array}{l}\text { If I had to choose today, I would select the study programs of this } \\
\text { University }\end{array}$ & 1 & 7 & 5.06 & 1.262 & -.060 & .106 & -.430 & .212 \\
\hline I am proud to be a student of this University & 2 & 7 & 5.28 & 1.172 & .048 & .106 & -.691 & .212 \\
\hline A degree from this University is worthy & 2 & 7 & 5.46 & 1.038 & -.047 & .106 & -.416 & .212 \\
\hline I found that this University has a good reputation & 1 & 7 & 5.07 & 1.319 & -.372 & .106 & .122 & .212 \\
\hline This university performs well & 2 & 7 & 5.26 & 1.076 & .084 & .106 & -.447 & .212 \\
\hline CQUniversity as a brand is reliable & 1 & 7 & 5.15 & 1.127 & .062 & .106 & -.276 & .212 \\
\hline The graduates of this University receive a good salary & 2 & 7 & 4.81 & 1.066 & .732 & .106 & -.288 & .212 \\
\hline A degree from this University enhances employability & 2 & 7 & 5.15 & 1.078 & .280 & .106 & -.631 & .212 \\
\hline Employers prefer graduates from this University & 1 & 7 & 4.56 & 1.067 & .660 & .106 & .657 & .212 \\
\hline
\end{tabular}




\section{Appendix D: Item parcelling method used for analysing measurement model}

\begin{tabular}{|c|c|c|c|}
\hline \multirow{2}{*}{ Factor } & \multirow{2}{*}{ Items' ID_(factor loading) } & \multicolumn{2}{|c|}{ Composites } \\
\hline & & Composite-1 & Composite-2 \\
\hline Information (IN) & $\begin{array}{l}\text { In_3 (0.861), In_2 (0.824), } \\
\text { In_1 (0.701) }\end{array}$ & In_3 $(0.861)$ & $\begin{array}{l}\text { In_2 (0.824), In_1 } \\
(0.701)\end{array}$ \\
\hline $\begin{array}{l}\text { Past Experience } \\
\text { (PE) }\end{array}$ & $\begin{array}{l}\text { PE_3 (0.837), PE_1 (0.831), } \\
\text { PE_2 }(0.622)\end{array}$ & PE_3 (0.837) & $\begin{array}{l}\text { PE_1 (0.831), PE_2 } \\
(0.622)\end{array}$ \\
\hline $\begin{array}{l}\text { Academic } \\
\text { Service Quality } \\
\text { (ACSQ) }\end{array}$ & $\begin{array}{l}\text { SQ_2 (0.839), SQ_6 }(0.800) \text {, } \\
\text { SQ_4 (0.774), SQ_25 }(0.773) \text {, } \\
\text { SQ_23 (0.741), SQ_5 }(0.734) \text {, } \\
\text { SQ_1 }(0.706), \text { SQ_7 }(0.658) \text {, } \\
\text { SQ_3 }(0.556)\end{array}$ & $\begin{array}{l}\text { SQ_2 }(0.839), \text { SQ_3 } \\
(0.556), \text { SQ_1 (0.706), } \\
\text { SQ_23 (0.741) }\end{array}$ & $\begin{array}{l}\text { SQ_6 (0.800), SQ_7 } \\
(0.658), \text { SQ_5 (0.734), } \\
\text { SQ_25 (0.773), SQ_4 } \\
(0.774)\end{array}$ \\
\hline $\begin{array}{l}\text { Administrative } \\
\text { Service Quality } \\
\text { (ADSQ) }\end{array}$ & $\begin{array}{l}\text { SQ_9 (0.859), SQ_8 }(0.848) \text {, } \\
\text { SQ_26 (0.823), SQ_10 (0.802), } \\
\text { SQ_13 (0.800), SQ_24 (0.783), } \\
\text { SQ_11 (0.705), SQ_22 }(0.584), \\
\text { SQ_14 (0.524), SQ_12 }(0.402)\end{array}$ & $\begin{array}{l}\text { SQ_9 (0.859), SQ_12 } \\
(0.402), \text { SQ_22 (0.584), } \\
\text { SQ_24 (0.783), SQ_10 } \\
(0.802)\end{array}$ & $\begin{array}{l}\text { SQ_8 }(0.848), \text { SQ_14 } \\
(0.524), \text { SQ_11 } \\
(0.705), \text { SQ_13 } \\
(0.800), \text { SQ_26 } \\
(0.823)\end{array}$ \\
\hline $\begin{array}{l}\text { Facilities Service } \\
\text { Quality (FSQ) }\end{array}$ & $\begin{array}{l}\text { SQ_20 (0.767), SQ_18 }(0.760), \\
\text { SQ_17 (0.699), SQ_19 }(0.661), \\
\text { SQ_21 (0.627), SQ_16 (0.507), } \\
\text { SQ_15 (0.443) }\end{array}$ & $\begin{array}{l}\text { SQ_20 (0.767), SQ_15 } \\
(0.443), \text { SQ_21 (0.627), }\end{array}$ & $\begin{array}{l}\text { SQ_18 }(0.760), \text { SQ_16 } \\
(0.507), S_{-19} \\
(0.661), S_{-} 17 \\
(0.699)\end{array}$ \\
\hline Satisfaction (S) & $\begin{array}{l}\text { S_4 (0.938), S_3 (0.915), S_5 } \\
(0.907), \text { S_7 }(0.880), \text { S_1 } \\
(0.872), \text { S_2 }(0.771), S_{-} 6 \\
(0.764)\end{array}$ & $\begin{array}{l}\text { S_4 (0.938), S_6 } \\
(0.764), \text { S_1 }(0.872)\end{array}$ & $\begin{array}{l}\text { S_3 }(0.915), S \_2 \\
(0.771), S \_7(0.880), \\
\text { S_5 (0.907) }\end{array}$ \\
\hline Trust (T) & 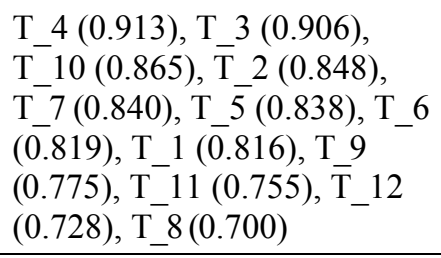 & $\begin{array}{l}\text { T_4 (0.913), T_8 } \\
(0.700), T \_11(0.755), \\
\text { T_1 (0.816), T_5 } \\
(0.838), T \_2(0.848)\end{array}$ & $\begin{array}{l}\text { T_3 (0.906), T_12 } \\
(0.728), T \_9(0.775), \\
\text { T_6 (0.819), T_7 } \\
(0.840), T_{-} 10(0.865)\end{array}$ \\
\hline $\begin{array}{l}\text { Brand } \\
\text { Performance (BP) }\end{array}$ & $\begin{array}{l}\text { BP_5 (0.899), BP_2 }(0.884) \text {, } \\
\text { BP_4 (0.871), BP_3 }(0.870), \\
\text { BP_1 }(0.865), \text { BP_7 }(0.818) \text {, } \\
\text { BP_6 (0.727), BP_8 }(0.701)\end{array}$ & $\begin{array}{l}\text { BP } 5(0.899), \text { BP } \_8 \\
(0.701), \text { BP } 7(0.818), \\
\text { BP_3 }(0.870),\end{array}$ & $\begin{array}{l}\text { BP_2 (0.884), BP } 6 \\
(0.727), \text { BP_1 }(0.865), \\
\text { BP_4 (0.871) }\end{array}$ \\
\hline $\begin{array}{l}\text { Behavioural } \\
\text { Intention (BI) }\end{array}$ & $\begin{array}{l}\text { BI_4 (0.898), BI_6 (0.887), } \\
\text { BI_1 (0.882), BI_2 }(0.878) \text {, } \\
\text { BI_5 (0.877), BI_3 }(0.875)\end{array}$ & $\begin{array}{l}\text { BI_4(0.898), BI_3 } \\
(0.875), \text { BI_2 }(0.878)\end{array}$ & $\begin{array}{l}\text { BI_6 (0.887), BI 5 } \\
(0.877), \text { BI_1 }(0.882)\end{array}$ \\
\hline
\end{tabular}




\section{Appendix E: Demographics of the focus group participants}

\begin{tabular}{ccccccc}
\hline No & Age & Gender & Nationality & Level of Study & Program of Study & $\begin{array}{c}\text { Duration of Study } \\
\text { at the CQU }\end{array}$ \\
\hline R1. & 19 & Female & Japan & Undergraduate & Arts & 07 Months \\
\hline R2. & 20 & Male & Australia & Undergraduate & Information Tech & 10 Months \\
\hline R3. & 20 & Male & Australia & Undergraduate & Business Studies & 09 Months \\
\hline R4. & 21 & Male & Australia & Undergraduate & Business Studies & 09 Months \\
\hline R5. & 21 & Male & Australia & Undergraduate & Information Tech & 10 Months \\
\hline R6. & 26 & Male & Australia & Postgraduate & Business Studies & 07 Months \\
\hline R7. & 26 & Male & China & Postgraduate & Business Studies & 07 Months \\
\hline R8. & 26 & Male & China & Postgraduate & Business Studies & 07 Months \\
\hline R9. & 27 & Male & India & Postgraduate & Business Studies & 07 Months \\
\hline R10. & 27 & Male & India & Postgraduate & Business Studies & 07 Months \\
\hline R11. & 27 & Male & India & Postgraduate & Business Studies & 07 Months \\
\hline R12. & 33 & Female & Singapore & Postgraduate & Business Studies & 07 Months \\
\hline R13. & 34 & Female & Australia & Postgraduate & Business Studies & 07 Months \\
\hline R14. & 33 & Female & Bangladesh & Doctoral & Education & 06 Months \\
\hline R15. & 34 & Male & Bangladesh & Doctoral & Accounting & 07 Months \\
\hline R16. & 34 & Male & Pakistan & Doctoral & Law & 07 Months \\
\hline R17. & 38 & Male & Botswana & Doctoral & Accounting & >03 years \\
\hline R18. & 38 & Female & China & Doctoral & Information Tech & $>01$ year \\
\hline R19. & 38 & Male & Pakistan & Doctoral & Information Tech & >03 years \\
\hline
\end{tabular}

